\title{
Niger: Poverty Reduction Strategy Paper
}

Poverty Reduction Strategy Papers (PRSPs) are prepared by member countries in broad consultation with stakeholders and development partners, including the staffs of the World Bank and the IMF. Updated every three years with annual progress reports, they describe the country's macroeconomic, structural, and social policies in support of growth and poverty reduction, as well as associated external financing needs and major sources of financing. This country document for Niger, dated August 2007, is being made available on the IMF website by agreement with the member country as a service to users of the IMF website.

To assist the IMF in evaluating the publication policy, reader comments are invited and may be sent by e-mail to publicationpolicy@imf.org.

Copies of this report are available to the public from

International Monetary Fund • Publication Services

$70019^{\text {th }}$ Street, N.W. • Washington, D.C. 20431

Telephone: (202) 623-7430 • Telefax: (202) 623-7201

E-mail: publications@imf.org • Internet: http://www.imf.org

Price: $\$ 18.00$ a copy

\section{International Monetary Fund Washington, D.C.}





\section{REPUBLIC OF NIGER}

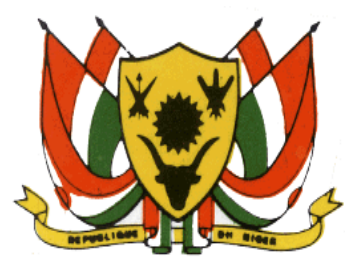

PRIME MINISTER'S OFFICE

PRS PERMANENT SECRETARIAT

Poverty Reduction Strategy, Second Generation

Fraternity, Work, Progress

"Combating Poverty, a Challenge for All"

\section{ACCELERATED \\ DEVELOPMENT AND POVERTY \\ REDUCTION STRATEGY \\ $2008-2012$}

August 2007 


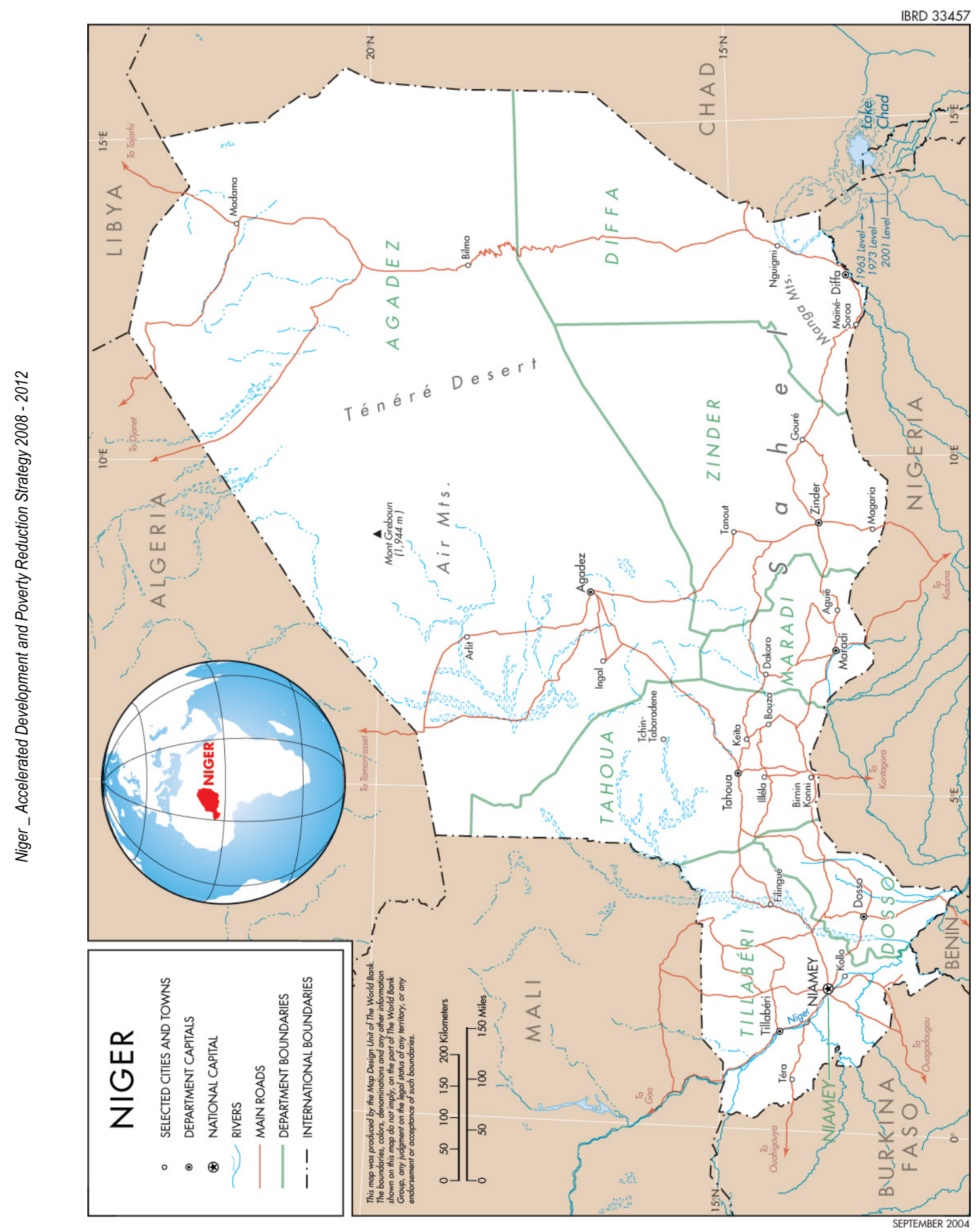




\section{TABLE OF CONTENTS}

FOREWORD

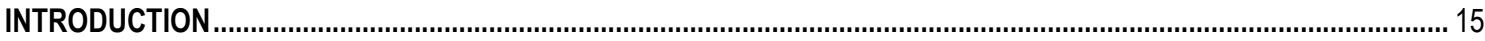

1. PART ONE: STRATEGIC DIAGNOSIS OF POVERTY …….................................................................................. 17

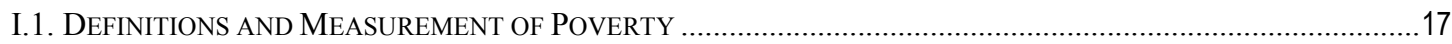

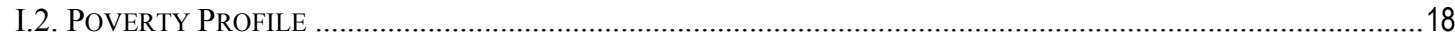

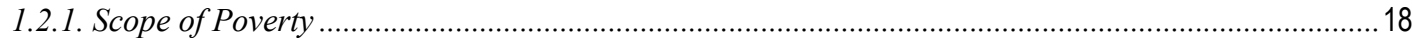

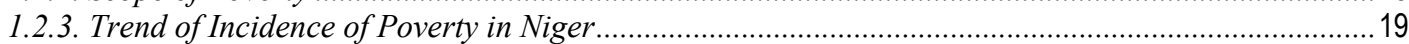

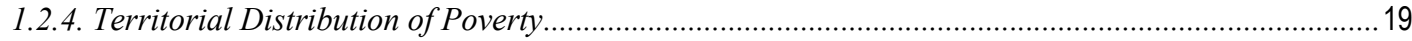

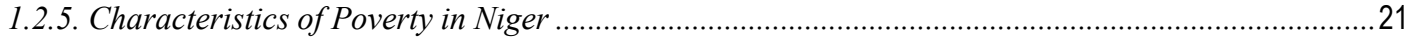

1.2.6.) Perception of Results of PRS Implementation bythe Populations ....................................................2

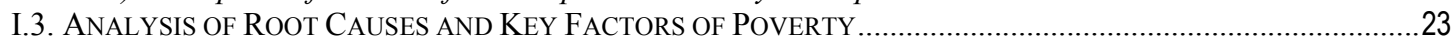

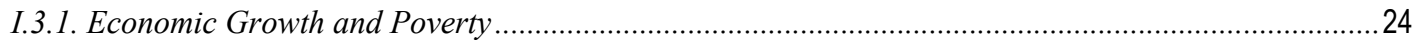

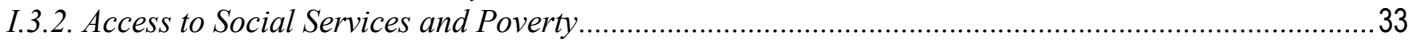

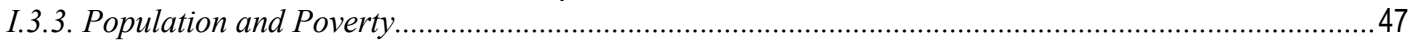

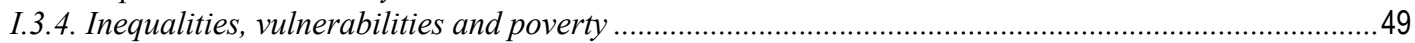

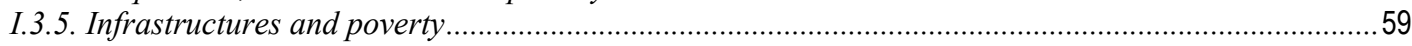

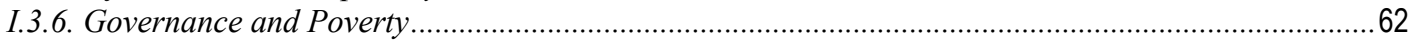

I.3.7. Factors limiting the implementation of the Poverty Reduction Strategy ................................................... 66

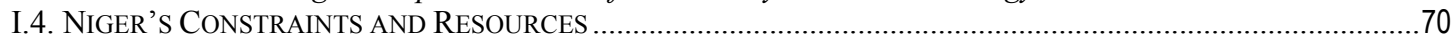

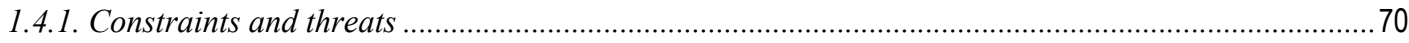

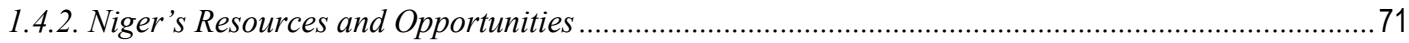

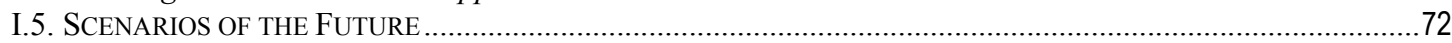

2. PART TWO: VISION, OBJECTIVES AND STRATEGIC ORIENTATIONS …....................................................... 74

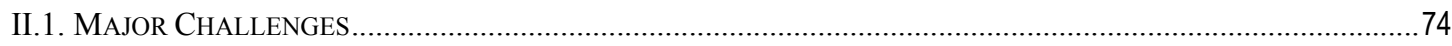

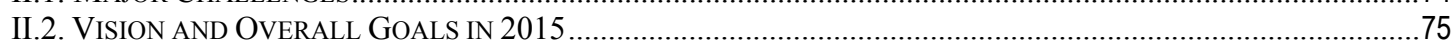

II.3. STRATEGIES FOR POVERTY REDUCTION AND MDG ACHIEVEMENT ……………………………….........79

2.3.1. Search for strong, diversified, sustainable and job-creating growth ............................................... 79

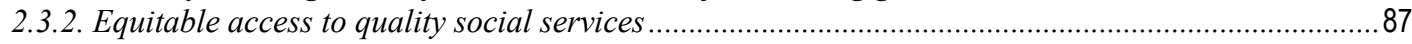

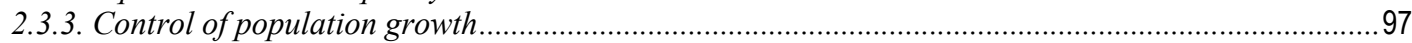

2.3.4. Reduction of inequalities and strengthening of social protection for vulnerable groups.....................98

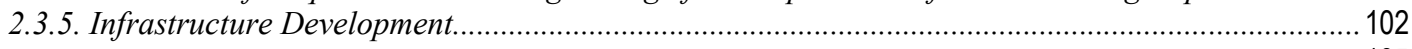

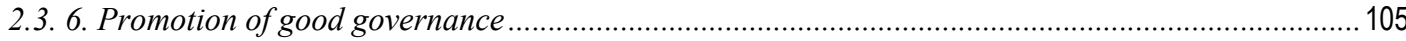

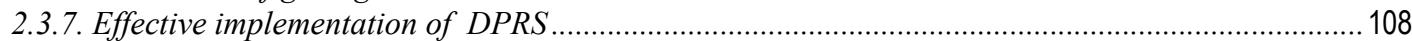

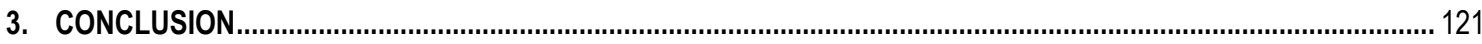

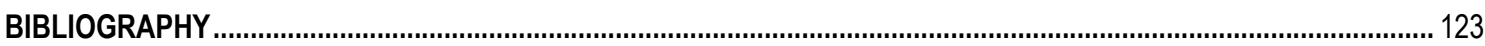

\section{List of Boxes}

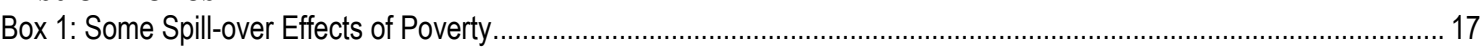

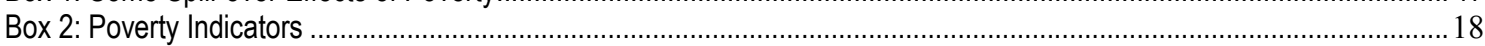

Box 3: Population's Perception of the Special Programme of the President of the Republic (PS/PR) ................................. 23

Box 4: Progress made by Niger in Achievement of some MDGs ....................................................................... 47

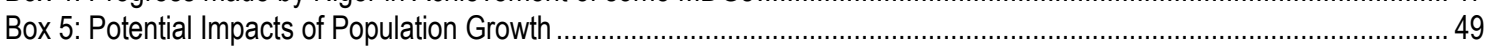

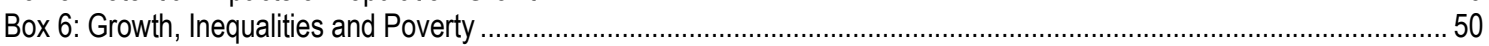

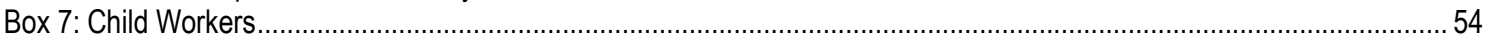

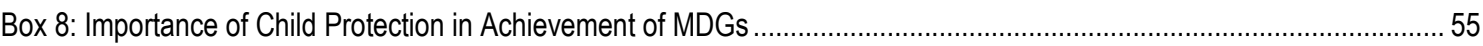

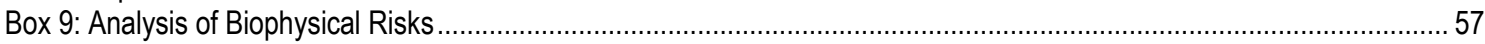

Box 10: The WAEMU Regional Economie Programme ……….............................................................................. 104

Box 11: The importance of the Quality of Service to Poor People .............................................................................. 113

\section{List of Charts}

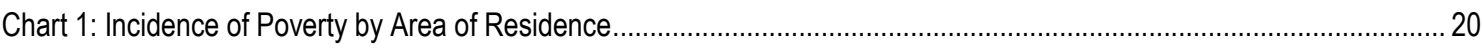

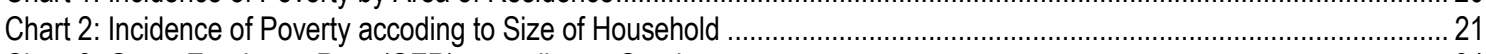

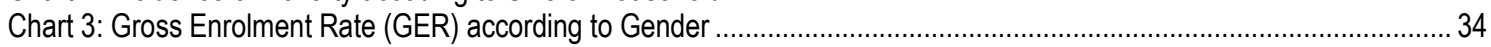

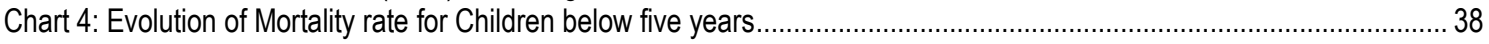

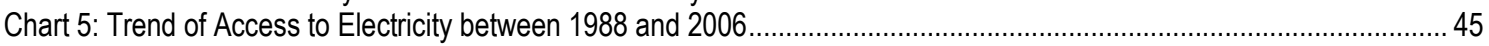


Chart 6: Reduced Amounts under HIPCI and MDRI (in US\$ million).

\section{List of Figures}

Figure 1 : Conceptual Framework for the MDG-based-ADPRS

Figure 2: Overall Structure of the Institutional and Operational Functioning of the ADPRS Monitoring-evaluatioon Mechanism

\section{list of Tables}

Table 1: Summary Status of Key MDG Indicators in Niger .... 14

Table 2: Breakdown of Poverty Status by Geographical Area in 2005.

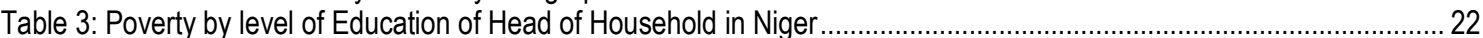

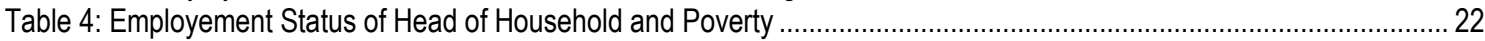

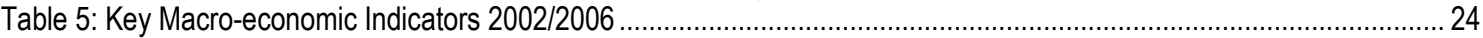

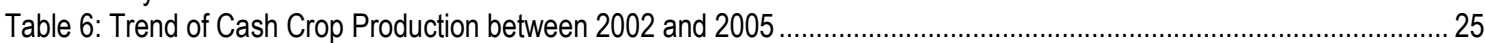

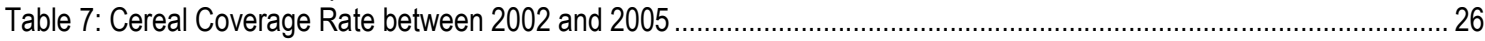

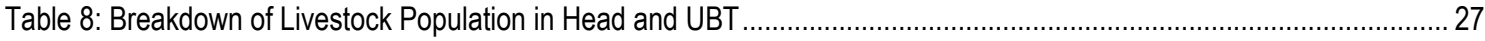

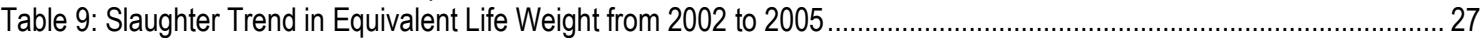

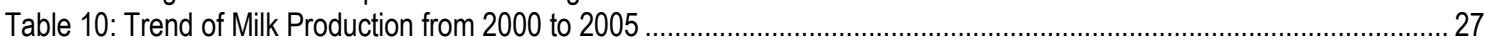

Table 11: Trend of Credit Ratios to the Economy in Niger and soem WAEMU Countries (in \% of GDP............................ 30

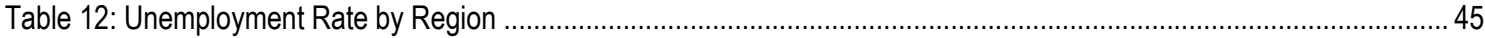

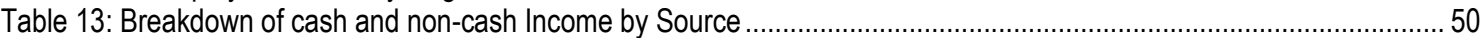

Table 14: Proportion of Consumer Expenditures in the Total Expenditure by Quintile ......................................................5 51

Table 15: Comparison of Gini Index for Consumption per Capita and per Household .........................................................5 51

Table 16: Classification of the Poor according to Vulnerability by Place of Residence .....................................................55

Table 17: Vulnerablility to Poverty for Individuals according to Employer of main job .......................................................56

Table 18: Trend Tax Pressure Rate in Niger and some WAEMU Countries (in \% of GDP) ............................................6

Table 19:Amount of Resource Allocations to Key Sectors over the 20022005 period (in CFAF billion) ..............................67

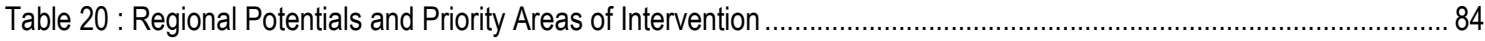

Table 21: Summary of the Different Growth Scenarios - Total cost in millions of CFAF for the period $2008-2012 \ldots \ldots \ldots . . .110$

Table 22: Financing requiriements - Annual amount in billions of CFAF ...................................................................111

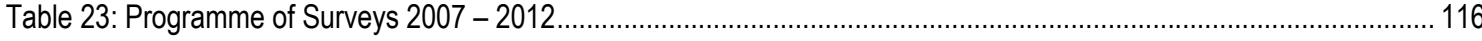

\section{Annexes}

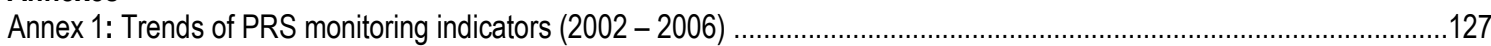

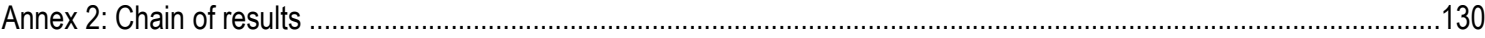

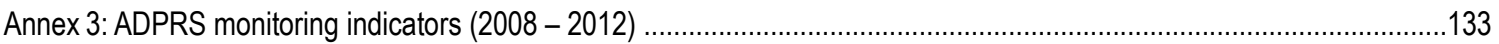

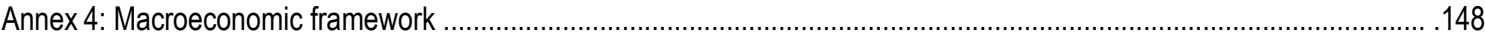

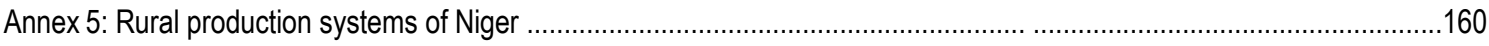

Annex 6: Summary table of the functioning of the ADPRS monitoring and evaluation system........................................161

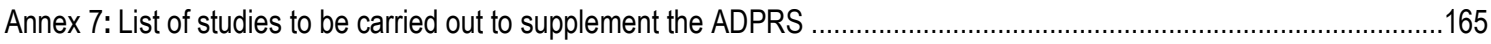

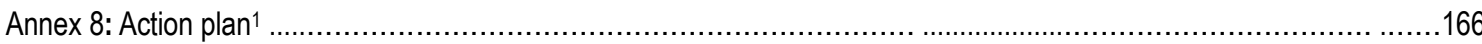

\footnotetext{
${ }^{1}$ This is a Draft Action Plan elaborated in October 2007 and numbers may be inconsistent with those in the main document (page 111) based on an earlier Draft Action Plan. The final PAP would be updated and annexed to the PRSP PR every year.
} 


\section{List of Acronyms}

ACRWC: African Charter on the Rights and Welfare of the Child

ADPRS: Accelerated Development and Poverty Reduction Strategy

AGOA: African Growth and Opportunity Act

AGRHYMET: Regional Centre for Agronomy, Hydrology and Meteorology

ALG: Liptako Gourma Authority

ANIPEX: Export Promotion Agency of Niger

ANIP-MF : Association Nigérienne des Professionnels de la Micro Finance

ANPE: National Employment Promotion Agency

ARI: Acute Respiratory Infection

ARM: Multisectoral Regulation Authority

ARMP: Public Procurement Regulation Agency

ARV: Anti Retro Viral

BCEAO: Central Bank of West African States

BEPC: Brevet d'Etudes du Premier Cycle (First Cycle Education Certificate/GCSE)

BIE: State Investment Budget

BRS : Banque Régionale de Solidarité (Regional Solidarity Bank)

BTP: Public Works and Civil Engineering

CAFER: Autonomous Road Maintenance Financing Fund

CAPED: Development Analysis and Forecasting Unit

CARFO: Autonomous Civil Service Pension Financing Fund

CCAIAN: Chamber of Commerce, Agriculture, Industry and Handicraft of Niger

CCD : Commissariat Chargé due Développement (Commissioner for Development)

CCE: Commissariat Chargé de l'Economie (Commissioner for the Economy)

CCP : Centre de Chèques Postaux (National Girobank)

CEDAV: Anonymous and Voluntary Screening Centre

CEDAW: Convention on the Elimination of all Forms of Discrimination against Women

CEG: General Education College

CENI: National Independent Electoral Commission

CEN-SAD: Community of Sahel-Saharan States

CENTIF: National Financial Information Processing Unit

CES: Secondary Education Complex

CES/DRS : Water and Soil Conservation and Soil Protection and Restoration

CESOC: Economic, Social and Cultural Council

CET: Common External Tariff

CFDC: Community Development Training Centre

CFEPD: Certificat de fin d'Etudes du Premier degree (First School Leaving Certificate)

CILSS: Permanent Inter-State Committee on Drought Control in the Sahel

CM2: Cours moyen 2 ème année

CMCN: Leather Trades Centre of Niger

$\mathrm{CNC/T}$ : National Cartography and Remote Sensing Committee

CNDH/LF: National Human Rights and Basic Freedoms Commission

CNDP: National Political Dialogue Council

CNESLCC: National Commission for Preparation of National Anti-Corruption Strategies

CNIP: National Private Investors Council

CNJ: National Youth Council

CNPG: National Management Development Centre

CNS: National Statistics Council

CNSS: National Social Security Fund

CNT: National Labour Council

CNUT: Public Transport Users Council of Niger

COGES: Schools Management Committee

COMINAK: Compagnie Minière d'Akouta

CPI: Investors Promotion Centre

CRC: Convention on the Rights of the Child

CRENA: Ambulatory Centre for Nutritional Recovery and Education

CRENI: Centre for Intensive Nutritional Recovery and Education

CS: Health Centre

CSC: Higher Communication Council

CSI: Integrated Health Centre

CSO: Civil Society Organization 
CTA: Ambulatory Treatment Centre

CUN: Niamey Urban Community

DDP: Department of Public Debt

DEP: Department of Studies and Programming

DGEPD: General Directorate of Development Programmes

DIEPA: International Drinking Water and Sanitation Decade (1981-1990)

DS: Department of Statistics

DSBE: Survey on Satisfaction of Basic Needs

EAMAC: African Meteorology and Civil Aviation School

EAN: Entreprendre au Niger (Opening a Business in Niger)

ECOWAS: Economic Community of West African States

ECVAM: Survey on the Economic Situation and Food Vulnerability of Households

EDS - MICS: Population/Health and Multiple Indicators Survey

EDS: National Population and Health Survey

EFPT: Vocational and Technical Education and Training

EIB: European Investment Bank

EMIG: School of Mining and Geology

ENAM: National School of Administration and Magistracy

ENBC: National Household Budget and Consumption Survey

ENPLT: National Long-Term Perspectives Study

ENS: Ecole Normale Supérieure (Higher Teacher Training School)

ENSP: National School of Public Health

EPA: Economic Partnership Agreement

EPI: Expanded Programme on Immunization

EPP2: Participatory Evaluation of Poverty_2nd Edition

EPT: Education for All

EU: European Union

FA: Faculty of Agronomy

FLSH: Faculty of Letters and Human Sciences

FS: Faculty of Science

FSEJ: Faculty of Economics and Law

FSS: Faculty of Health Sciences

GER: Gross Enrolment Ratio

GIS: Geographic Information System

GWH: Giga Watt Hour

Ha: Hectare

HCCT: Local Authorities High Council

HCME: High Commission for State Modernization

HCNTIC: High Commission for New Information and Communication technologies

HIMO: Labour Intensive

HIPCl: Heavily Indebted Poor Countries Initiative

HKI: Hellen Keller International (NGO)

IEC: Information, Education and Communication

IES: Secondary Education Inspectorate

IFTIC: Information and Mass Communication Training Institute

IGO: International Governmental Organization

IMCD: Integrated Management of Childhood Diseases

INAARV: Initiative for Access to Anti Retro Virals of Niger

INDRAP: National Pedagogic Documentation and Training Institute

INJS: National Youth and Sports Institute

INRAN: National Agronomic Research Institute

INS: National Statistics Institute

IPN: National Pedagogic Inspectorate

ISP: Public Health Institute

IUT: University Institutes of Technology

LCBC: Lake Chad Basin Commission

LMD: Licence, Masters, Doctorat

LNTP: National Public Works Laboratory

LOSEN: Law on Orientation of the Education System in Niger

MAT/DC: Ministry of Territorial and Community Development

MCA: Millennium Challenge Account

MDG: Millennium Development Goals

MDRI: Multilateral Debt Relief Initiative 
$M E / F:$ Ministry of the Economy and Finance

MEBA: Ministry of Basic Education and Literacy

MESSRT: Ministry of Secondary and Higher Education, Research and Technology

MFI: Micro-Finance Institution

MSP/LCE: Ministry of Public Health and Control of Endemic Diseases

MT/A: Ministry of Tourism and Handicraft

MTEF: Medium Term Expenditure Framework

NBA: Niger Basin Authority

NEPAD: New Partnership for Africa's Development

NGO: Non-Governmental Organization

NGO/DA: Non Governmental Organizations and Development Associations

$\mathrm{NICl}$ : National Information and Communication Technologies Development Plan

NICT: New Information and Communication Technologies

NIGELEC: Société nigérienne d'électricité (Electricity Corporation of Niger)

NIGETECH: National NGO for Vocational and Technical Training

NPV: Net Present Value

OCBN: Benin-Niger Common Organization

OEV: Orphans and Other Vulnerable Children

OHADA: Organization for the Harmonization of Business Law in Africa

ONAFOP: National Vocational Training Authority

ONAPAD: National Poverty and Sustainable Human Development Observatory

ONEP: National Publishing and Press Authority

ONERSOL: National Solar Energy Authority

ONPE: National Postal and Savings Office

PARJ: Judicial Reform Support Programme

PDDE: Ten-Year Education Development Programme

PDS: Health Development Plan

PDSF: Technical Assistance Project for Financial Sector Development

PDSFR: Rural Financial Service Development Programme

PEMFAR: Public Expenditure Management and Financial Accountability Review

PIE: State Investment Programme

PIMAP : Integrated Public Administration Modernization Programme

PLWVIH: Persons Living With HIV

PMA: Minimum Activity Package

PMTCT: Prevention of Mother-To-Child Transmission of HIV

PNAN: National Nutrition Action Plan

PNCD: National Communication Policy for Development

PNDL/C: National Local and Community Development Policy

PNP: National Population Policy

PRGF: Poverty Reduction and Growth Facility

PRODEM: Multisectoral Population Programme

PRSP: Poverty Reduction Strategy Paper

PS/PR: Special Programme of the President of the Republic

QUIBB: Survey on Combined Questionnaire of Basic Welfare Indicators

RAIL/SIDA: Network of Actors in STI/HIVIAIDS Control

RBM: Results-Based Management

RGP/H: General Population and Housing Census

SAP: Early Alert System

SDAU: Urban Development Master Plan

SDR Rural Development Strategy

SIGNER: Geographic Information System of Niger

SIMA : Agricultural Markets Information System

SML: Société des Mines du Liptako

SNCC: Société Nigérienne de Carbonisation du Charbon

SNDS: National Statistics Development Strategy

SNDU: National Urban Development Strategy

SNIS: National Health Information System

SNT: National Transport Strategy

SOMAÏR: Société des Mines de l'Aïr

SONICHAR: Société Nigérienne de Charbon

SONIDEP: Société Nigérienne des Produits Pétroliers

SONITEL: Société Nigérienne des Télécommunications

SP/SRP: PRS Permanent Secretariat 
SSN: National Statistics System

TEP: Tonne Equivalent Petrol

TFR: Total Fertility Rate

UAAP: Advanced Poverty Analysis Unit

UAM: Université Abdou Moumouni

UNESCO: United Nations Educational, Scientific and Cultural Organization

UP: Pedagogic Unit

VAT: Value Added Tax

WAEMU: West African Economic and Monetary Union

WFP: World Food Programme

WHO: World Health Organization

WTO: World Trade Organization 


\section{FOREWORD}

Today, combating poverty and searching for sustainable and sustained economic growth are key imperatives which should mobilize all the people of Niger. To establish genuine development at the country's grassroots in the medium and long term, ambitious measures must be adopted at the domestic level and important initiatives must be undertaken with our Partners.

Driven by this conviction, Niger has embarked on a thorough revision of the Poverty Reduction Strategy (PRS), which was adopted in 2002 as reference framework for the country's development, thus providing appropriate response to the concerns that stakeholders had expressed throughout the pains-taking participatory process.

Like the strategy adopted in January 2002, this strategy is based on the conviction that poverty can be reduced through strong and sustained economic growth that creates wealth and jobs, particularly for the poor and in rural areas. This is why it raises common enthusiasm and legitimate hope for the entire nation.

The Accelerated Development and Poverty Reduction Strategy (ADPRS) is in no way a substitute for the existing sectoral programmes and strategies. Rather, it seeks to adapt them to new national priorities, while ensuring overall coherence between them.

The ADPRS pillars are based on lessons learned from the implementation of development initiatives over the past few years, in particular the Special Programme of the President of the Republic, the deep aspirations of the population, the policies adopted by the Government, requirements for growth that benefits the poor, and taking into account the regional integration efforts made by Niger, as well as the International Development Goals.

We intend to pursue our efforts so as to create conditions for true development at the grassroots through the emergence of a diversified and competitive economy within an integrated sub-regional environment. Our commitment to improving the quality of lives of the people of Niger justifies the decision to guarantee better access by the poor to quality social services, as well as to further reduce vulnerability and make these components the pillars of the Accelerated Development and Poverty Reduction Strategy.

Appropriate action will be taken to ensure a responsible individual and collective response that helps to control population growth and align its rate to the country's economic development.

We are convinced that for poverty reduction efforts to be really efficient and effective, they must be made in an environment that promotes transparency, equity and individual empowerment that enables each person to be the master of their own destiny. Similarly, a Capacity Building Programme will be put in place to enable (i) State employees to better meet to the requirements of their duties, and (ii) the civil society and private sector to understand and to fully play their role in development activities.

These are the objectives of our Accelerated Development and Poverty Reduction Strategy on which wide consensus has been achieved at the national level and for which Niger will, with force and conviction, strive to ensure effective implementation. However, over and above our own efforts, we remain convinced that the achievement of our ambition also requires the commitment of the International Community.

It is on this note of hope that I wish to end my address, as I extend to all, on my behalf and on behalf of the Government and people of Niger, our thanks and gratitude for the constant and continued support that has been given to our country for its economic and social development.

His Excellency Mamadou TANDJA President of the Republic of Niger 


\section{EXECUTIVE SUMMARY}

1. The Republic of Niger covers an area of $1,267,000 \mathrm{~km}^{2}$. Two-thirds of the country are located in the Sahara, and are therefore in the desert. In 2006, the population of the country was estimated at about 13 million inhabitants; with $48.6 \%$ are less than 15 years of age and $83 \%$ of this population live in rural areas. Classified as one of the poorest countries in the world, Niger in 2006 had a per capita Gross Domestic Product of about CFAF 141,800 (equivalent to U\$ 284).

2. After a decade of socio-political instability which led to a deterioration of the country's economic situation, Niger in December 1999 established a new Republic, the Fifth, with democratically elected Authorities. The main challenge of the Government was thus to lay the basis of sustainable and sustained socio-economic development. It is in this light that the country in January 2002 adopted a Poverty Reduction Strategy (PRS) to serve as reference framework for its economic, financial and social policy. After five (5) years of implementation, the PRS stands out as a coordinating instrument for all development actions as it integrates partner operations around priorities defined by the Government.

3. To operationalize the PRS, several sectoral policies and programmes have been prepared and/or implemented; these include in particular: the Special Programme of the President of the Republic (PS/PR), the National Micro-Finance Strategy, the Rural Development Strategy (SDR), the National Infrastructure and Information Technology Plan (NICl), the National Development Communication Policy (PNDC), the Transport Sector Programme (PST), the National Transport Strategy (SNT), the National Strategy and Action Plans on Renewable Energy, the Priority Private Sector Recovery Programme, the National Handicraft Development Policy, the Ten-Year Education Development Programme (PDDE), the Framework Programme for Professional Youth Integration, the Education and Vocational and technical Training Policy, the General Declaration on the National Population Policy (DGPNP), the National Child Protection Policy, the National Integrated Development Policy for Young Children (DIJE), the National Women's Advancement Policy, the Health Development Plan (PDS), the National AIDS Control Strategic Framework, the Water and Sanitation Policy and Strategy, the Urban Environment Management Strategy, the National Youth Policy Declaration and the National Youth Charter, the National Urban Development Strategy, the territorial development policy, the Judicial Reform Support Programme (PARJ), the National Conflict Prevention and Management Strategy, and the National Local and Community Policy.

4. The various annual reports on PRS implementation from 2002 to 2006 , the reports on progress made in MGD achievement, the results of joint reviews in education, health, access to drinking water and desertification control and evaluation reports on the Special programme of the President of the Republic have highlighted the progress made in achieving the poverty reduction goals.

5. Accordingly, over the 2002-2006 period, the average economic growth rate stood at $3.9 \%$, which is almost equivalent to the initial set target of $4 \%$. The initiated reforms, in particular the implementation of two (2) economic and financial programmes supported by the Poverty Reduction and Growth Facility (PRGF), have helped to stabilize the economic framework. Similarly, the application of WAEMU directives and implementation of the Public Finance Management and Financial Accountability Programme (PEMFAR action plan) have contributed to significant progress in public finance management.

6. As regards the implementation of sectoral policies, the priority given to the health, education, rural development and infrastructure sectors, as well as the interventions of the various development partners and implementation of the various components of the Special Programme of the President of the Republic (PS/PR) have provided rural areas with basic socio-economic infrastructures. Similarly, the implementation of sectoral strategies broken down into programmes, action plans and programme budgets, as well as the establishment of management mechanisms have helped to improve management of the sectors concerned (education, health, and rural sector).

7. All in all, the judicious choices made over the period have led to significant improvement of all the economic and social indicators. For example, the infant mortality rate fell sharply from 123 per thousand in 1998 to 81 per thousand in 2006. Similarly, the child mortality rate dropped from 274 per thousand in 1998 to 198 per thousand in 2006. Furthermore, the gross enrolment ratio in primary education increased sharply from $41.7 \%$ in 2002 to $54 \%$ in 2006. Concerning drinking water, the access rate rose from $43 \%$ in 2000 to $68.7 \%$ in 2005 . The 
coverage of rural drinking water requirements stood at $59 \%$ in 2005, as against $55 \%$ in 2001.

8. The installation of Institutions of the Republic and several other organs, in a peaceful socio-political atmosphere, helped to consolidate democracy, promote political good governance, and facilitate dialogue between the different stakeholders. The organs put in place include the National Human Rights and Basic Freedoms Commission (CNDH/LF), the Higher Communication Council (CSC), the National Political Dialogue Council (CNDP), the Economic, Social and Cultural Council (CESOC), the National Commission responsible for preparing national anti-corruption strategies (CNESLCC), the National Labour Council (CNT), the National Private Investors Council (CNIP), and the National Youth Council (CNJ).

9. As regards to local governance, the conduct of council elections, the definition of areas of competence and effective transfer of decision-making power to the new entities, as well as the establishment of the Local Authorities High Council (HCCT) have given content to decentralization and grassroots democracy. The revitalization of the National Territorial Development Policy and preparation of many Council Development Plans (PDC) and related national guide help to strengthen local governance.

10. With respect to administrative governance, institutional, human and technical capacity building for the government and local authorities have been given priority with: (i) the creation of the Development Analysis and Forecasting Unit (CAPED), (ii) the State modernization High Commission, (iii) transformation of the National School of Administration (ENA) into a National School of Administration and Magistracy (ENAM) with the training of magistrates in Niamey, and (iv) the adoption of the Integrated Public Administration Modernization Programme (PIMAP).

11. Furthermore, PRS implementation helped to introduce Results-Based Management (RBM) as the principle for monitoring and evaluating development policies. To that end, emphasis has been placed on updating statistical data so as to better understand the phenomenon of poverty and strengthen the information and monitoring-evaluation system particularly through reform of the national Statistics System which led to the creation of the National Statistics Institute, preparation of a National Statistics Development Strategy (SNDS) and definition of new tools for PRS monitoring.

12. The economic, financial and social performance under the PRGF-supported programme since 2000 enabled Niger to reach the completion point of the Heavily Indebted Poor Countries Initiative (HIPCI) in April 2004, to be admitted into the Multilateral Debt Relief Initiative (MDRI) in 2006, and to be registered in the Threshold Programme of the Millennium Challenge Account (MCA) of the United States off America in November 2006.

13. However, many obstacles and constraints continue to undermine improvement of the well-being of the population. Indeed, the economy is still highly dependent on agriculture that is vulnerable to unstable climatic conditions and based on archaic and inefficient production methods. Similarly, the economic growth rate of $3.9 \%$ per year on average between 2002 and 2006 is not enough to reduce poverty significantly and put Niger on track towards achievement of the Millennium Development Goals by 2015. Poverty was still very broad in scope $(62.1 \%)$ in 2005 . Furthermore, the high population growth rate of $3.3 \%$, which is one of the highest in the world, limits performance, particularly in the basic social sectors, by each day increasing the demand for infrastructures and resources.

14. Accordingly, requirements remain enormous in education, health, access to drinking water, access to energy, as well as in transport and communication infrastructure. Similarly, gender disparities persist, particularly in access to social services and economic opportunities.

15. As a result, today, Niger is no longer on the path to MDG achievement (see Table 1). Generally speaking, this situation is mainly due to inadequate economic growth, the impact of high population growth on activities carried out, the particularly low level of many indicators, inadequate infrastructures and huge financial resources for heavy investments that can stimulate the growth, the inefficiency of some programmes, the limited interaction between the various sectors, as well as the low human capacities of the Administration in the implementation and monitoring-evaluation of development policies. 
16. Over the 2002-2006 period, it also appeared that consultation was generally low between stakeholders in PRS implementation. In particular, there was relative inertia in the institutional mechanism committees at all levels, little contribution by the civil society to PRS monitoring, focus of implementation reports on the national level and their inadequate presentation to the stakeholders.

17. Similarly, the time frame of three years for PRS revision was considered insufficient to carry out major structural changes that will allow for significant improvement in the living conditions of the populations. The country's limited resources require that activities should be within a longer time frame (five years) so as to better articulate long-term objectives with medium-term programmes. This will relax structural constraints and give more sustained impetus, more effectiveness and more impact to the programmes.

18. To meet these different challenges, Niger has embarked on PRS revision so as to initiate a new start and give fresh impetus to its economic and social development policy.

19. Through the Accelerated Development and Poverty Reduction Strategy (ADPRS), which is a new reference framework for the economic, financial and social policy for the next five years, Niger has defined its vision as follows: "To become an emerging country, founded on a dynamic, diversified and sustainable economy, harmoniously distributed on the national territory, a modern, civil, democratic and well-governed republic, a nation rich in its culture and shared values, a society open to the world and attached to knowledge and technological innovation, free from corruption and poverty, a nation that is prosperous, equitable, and respectful of ethics, united, peaceful and committed to African integration."

20. Realizing this vision of the Niger of tomorrow is a long and exacting task. It is necessary for all the people of Niger, at all levels, to stay the course, and lay the bases required for its realization, while avoiding any pause or back tracking in the onward march towards the ultimate goal of integral development.

21. Meanwhile, the vision is not unique because special attention has been given to ADPRS alignment on the Millennium Development Goals (MDG) and on the integration and poverty reduction strategies developed at the continental level (African Union and NEPAD) and at the regional and sub-regional levels (ECOWAS, CENSAD, WAEMU).

22. The activities have been programmed and financial resources allocated on the basis of the MDG targets for 2015 as well as the convergence criteria defined at the sub-regional and regional levels. In so doing, the time frame of five years set for the ADPRS (2008-2012) to achieve a number of indicators at the national level should be considered as an intermediate phase.

23. In the final analysis, on the basis of the vision defined above, Niger is committed to achieving, by 2015, the Millennium Development Goals, and thereby significantly improve, by 2012, all the socio-economic indicators.

24. Based on the vision, Niger seeks, in particular, to attain the following targets by 2012 :

i. an annual economic growth rate of at least $7 \%$;

ii. a poverty rate of $42 \%$ for individuals;

iii. a malnutrition rate (underweight) of $24 \%$;

iv. a gross primary education enrolment rate $94 \%$;

v. an adult literacy rate of $45 \%$ ensuring gender parity;

vi. a child mortality rate of $108 \%$;

vii. a maternal mortality rate of 200 for 100,000 life births;

viii. HIVIAIDS prevalence rate kept below $0.7 \%$

ix. a drinking water access rate of $80 \%$;

$x$. increase the electricity access rate to $3 \%$ in rural areas and $46 \%$ in urban areas;

xi. a $35 \%$ utilization rate of impregnated mosquito nets for children and pregnant women ;

xii. a total fertility rate of 6 children per woman;

xiii. area of protected lands at least equal to $8 \%$ of the national territory;

xiv. at least $110 \%$ coverage of national cereal requirements.

25. To achieve these objectives, the ADPRS will be implemented on the basis of seven pillars: 
- $\quad$ Pillar 1: Search for strong, diversified, sustainable and job-creating growth;

- Pillar 2: Equitable access to quality social services;

- Pillar 3: Control of population growth;

- Pillar 4: Reduction of inequalities and strengthening of social security of the vulnerable groups;

- Pillar 5: Infrastructure development;

- Pillar 6: Promotion of good governance;

- Pillar 7: Effective implementation of the strategy.

26. The macro-economic and budgetary framework estimates the financial requirements for ADPRS implementation over the 2008-2012 period at CFAF 5.556 billion (equivalent to US\$11.112 million ${ }^{1}$ ) which will be financed to the tune of $41.4 \%$ by domestic resources and $58.6 \%$ by external resources. Furthermore, $75.5 \%$ of the final financing will be allocated to the implementation of the related Priority Action Plan.

27. The ADPRS will be implemented and resources allocated through sectoral programmes and medium term expenditure frameworks, which will gradually be extended to all areas of activity. 
Table 1: Summary Status of Key MDG Indicators in Niger

\begin{tabular}{|c|c|c|c|c|c|c|c|}
\hline Objectives & Adopted Targets & Adopted Indicators & $\begin{array}{l}\text { Initial } \\
\text { Level }\end{array}$ & $\begin{array}{l}\text { Current } \\
\text { Level }\end{array}$ & $\begin{array}{l}\text { Projected } \\
\text { Level in } \\
2015 \\
\end{array}$ & $\begin{array}{l}\text { Desired } \\
\text { Level in } \\
2012 \\
\end{array}$ & $\begin{array}{l}\text { MDG } \\
\text { Target in } \\
2015 \\
\end{array}$ \\
\hline \multirow{2}{*}{$\begin{array}{l}\text { 1. Eradicate } \\
\text { extreme poverty } \\
\text { and hunger }\end{array}$} & $\begin{array}{l}\text { 1. Reduce by half the proportion of } \\
\text { people living below the poverty line } \\
\text { by } 2015 \text {. }\end{array}$ & $\begin{array}{l}\text { 1. Proportion of the population } \\
\text { below the poverty line } \\
\text { (in } \% \text { ) }\end{array}$ & $\begin{array}{l}65^{1} .1 \text { in } \\
2001\end{array}$ & $\begin{array}{l}60.7 \text { in } \\
2006\end{array}$ & 50.0 & 42 & 33 \\
\hline & $\begin{array}{l}\text { 2. Reduce by half the proportion of } \\
\text { people suffering from malnutrition by } \\
2015 \text {. }\end{array}$ & $\begin{array}{l}\text { 2. Percentage of children under } 3 \\
\text { years of age who are under weight }\end{array}$ & $\begin{array}{l}50 \% \text { in } \\
1998\end{array}$ & $\begin{array}{l}43 \% \text { in } \\
2006\end{array}$ & 29.7 & 24 & 18 \\
\hline \multirow{2}{*}{$\begin{array}{l}\text { 2. Achieve } \\
\text { universal primary } \\
\text { education }\end{array}$} & \multirow{2}{*}{$\begin{array}{l}\text { 3. Provide primary education to all } \\
\text { children of school age by } 2015\end{array}$} & $\begin{array}{l}\text { 3. Gross enrolment rate in primary } \\
\text { education (in \%) }\end{array}$ & $\begin{array}{l}42 \% \text { in } \\
2001- \\
2002 \\
\end{array}$ & $\begin{array}{l}54 \% \\
2006\end{array}$ & 79.4 & 94 & 105 \\
\hline & & $\begin{array}{l}\text { 4. Completion rate in primary } \\
\text { school (in \%) }\end{array}$ & $\begin{array}{l}26 \% \text { in } \\
2001- \\
2002 \\
\end{array}$ & $\begin{array}{l}40 \% \\
2006\end{array}$ & 96 & 92 & 100 \\
\hline \multirow{6}{*}{$\begin{array}{l}\text { 3. Promote gender } \\
\text { equality and } \\
\text { empower women }\end{array}$} & \multirow{6}{*}{$\begin{array}{l}\text { 4. Eliminate gender disparities in } \\
\text { primary education by } 2005 \text {, and in all } \\
\text { levels of education by } 2015\end{array}$} & $\begin{array}{l}\text { 5. Girls/boys ratio in primary and } \\
\text { secondary education (in \%) }\end{array}$ & 55,7 & 69 & 87 & 95 & 100 \\
\hline & & $\begin{array}{l}\text { 6. Literacy rate among persons of } \\
15 \text { and above (in \%) }\end{array}$ & $\begin{array}{l}19.9 \text { in } \\
2000\end{array}$ & $\begin{array}{l}28.7 \text { in } \\
2005 \\
\end{array}$ & 46.3 & 45 & 52 \\
\hline & & $\begin{array}{l}\text { 7. \% of women employed in the } \\
\text { Public Service }\end{array}$ & 24.4 & 24.5 & - & - & - \\
\hline & & $\begin{array}{l}\text { 8. Proportion of women in } \\
\text { Parliament (in \%) }\end{array}$ & $\begin{array}{l}1.2 \text { in } \\
1998\end{array}$ & $\begin{array}{l}12.4 \text { in } \\
2006\end{array}$ & 23 & 20 & 25 \\
\hline & & $\begin{array}{l}\text { 9. Proportion of women in } \\
\text { Government (in \%) }\end{array}$ & 17.9 & $\begin{array}{l}20 \% \text { in } \\
2006 \\
\end{array}$ & & 25 & 25 \\
\hline & & $\begin{array}{l}\text { 11. Proportion of women in local } \\
\text { authorities (\%) }\end{array}$ & - & 17.6 & - & 25 & 25 \\
\hline \multirow{3}{*}{$\begin{array}{l}\text { 4. Reduce } \\
\text { mortality of } \\
\text { children under } 5\end{array}$} & \multirow{3}{*}{$\begin{array}{l}\text { 5. Reduce by } 2 / 3 \text { the under-five } \\
\text { mortality rate between } 1990 \text { and } \\
2015\end{array}$} & $\begin{array}{l}\text { 12. Mortality rate of children under } \\
5 \text { (per thousand) }\end{array}$ & $\begin{array}{l}274 \text { in } \\
1998\end{array}$ & $\begin{array}{l}198 \text { in } \\
2006\end{array}$ & 115.7 & 112 & 108.7 \\
\hline & & $\begin{array}{l}\text { 13. Infant mortality rate (per } \\
\text { thousand) }\end{array}$ & $\begin{array}{l}123 \text { in } \\
1998 \\
\end{array}$ & $\begin{array}{l}81 \text { in } \\
2006\end{array}$ & 33.8 & 35 & 41.0 \\
\hline & & $\begin{array}{l}\text { 14. } \% \text { of } 1 \text { year old children } \\
\text { vaccinated against measles }\end{array}$ & 35 in 1998 & $\begin{array}{l}47 \text { in } \\
2006 \\
\end{array}$ & 60.5 & - & - \\
\hline \multirow{2}{*}{$\begin{array}{l}\text { 5. Improve } \\
\text { maternal health }\end{array}$} & \multirow{2}{*}{$\begin{array}{l}\text { 6. Reduce by } 3 / 4 \text {, the maternal } \\
\text { mortality rate between } 1990 \text { and } \\
2015\end{array}$} & $\begin{array}{l}\text { 15. Maternal mortality rate (per } \\
1000 \text { births) }\end{array}$ & $\begin{array}{l}6.52 \text { in } \\
1992\end{array}$ & $\begin{array}{l}6.48 \text { in } \\
2006\end{array}$ & 6.45 & 2 & 1.75 \\
\hline & & $\begin{array}{l}\text { 16. Proportion of births assisted } \\
\text { by qualified health staff (in \%) }\end{array}$ & $\begin{array}{l}14.6 \text { in } \\
1998\end{array}$ & $\begin{array}{l}17.2 \text { in } \\
2006\end{array}$ & 20 & - & $50 \%$ \\
\hline \multirow{2}{*}{$\begin{array}{l}\text { 6. Combat } \\
\text { HIVIAIDS, malaria } \\
\text { and other diseases }\end{array}$} & $\begin{array}{l}\text { 7. Halt the spread of HIVIAIDS and } \\
\text { reverse the current trend by } 2015\end{array}$ & $\begin{array}{l}\text { 17. HIVIAIDS prevalence rate } \\
\text { among persons } 15-49 \text { years of } \\
\text { age }\end{array}$ & $\begin{array}{l}0.87 \text { in } \\
2002\end{array}$ & $\begin{array}{l}0.7 \text { in } \\
2005\end{array}$ & - & $<0.7$ & $<0.7$ \\
\hline & $\begin{array}{l}\text { 8. Control malaria and inverse the } \\
\text { trend }\end{array}$ & $\begin{array}{l}\text { 18. Dead rate due to malaria (in } \\
\% \text { ) }\end{array}$ & 1.6 & $\begin{array}{l}2.7 \text { in } \\
2006\end{array}$ & - & - & - \\
\hline \multirow{4}{*}{$\begin{array}{l}\text { 7. Ensure } \\
\text { environmental } \\
\text { sustainability }\end{array}$} & $\begin{array}{l}\text { 9. Integrate the principles of } \\
\text { sustainable development into country } \\
\text { policies, and reverse the current } \\
\text { trend of loss of environmental } \\
\text { resources }\end{array}$ & $\begin{array}{l}\text { 19. Surface area of protected } \\
\text { lands for biodiversity (as } \% \text { of the } \\
\text { national territory) }\end{array}$ & 6.6 & & - & $8 \%$ & $10 \%$ \\
\hline & $\begin{array}{l}\text { 10. Reduce by half the percentage of } \\
\text { population without access to drinking } \\
\text { water by } 2015\end{array}$ & $\begin{array}{l}\text { 20. Proportion of the population } \\
\text { with access to drinking water (in } \\
\% \text { ) }\end{array}$ & 43 in 2000 & $\begin{array}{l}68.7 \% \text { in } \\
2005\end{array}$ & - & 80 & 85 \\
\hline & \multirow{2}{*}{$\begin{array}{l}\text { 11. Facilitate access to decent and } \\
\text { safe housing }\end{array}$} & $\begin{array}{l}\text { 21. \% of urban households with } \\
\text { adequate sanitation facilities }\end{array}$ & 67.5 & 70.3 & - & - & - \\
\hline & & $\begin{array}{l}\text { 22. \% of urban households who } \\
\text { own their lodging }\end{array}$ & 52.2 & 63.9 & - & - & - \\
\hline \multirow{2}{*}{$\begin{array}{l}\text { 8. Develop a } \\
\text { global partnership } \\
\text { for development }\end{array}$} & \multirow{2}{*}{$\begin{array}{l}\text { 12. Address the special needs of the } \\
\text { least developed countries }\end{array}$} & $\begin{array}{l}\text { 23. Official development } \\
\text { assistance in } \% \text { of GDP }\end{array}$ & 16 & 8.3 & - & - & - \\
\hline & & 24. Debt service in $\%$ of exports & 19 & 7 & - & - & - \\
\hline
\end{tabular}

\footnotetext{
${ }^{1}$ This level was estimated on the basis of 2005 data
} 


\section{INTRODUCTION}

28. The Government of the Republic of Niger has, since January 2002, been implementing a Poverty Reduction Strategy (PRS), a reference framework for the country's economic, financial and social development. The strategy, which is the outcome of repeated broad consultation of the stakeholders (government, civil society, private sector, development partners, etc.), was developed within a context marked, at the national level, by the country's return to constitutional normality, and at the international level, by an agenda dominated by the launching of initiatives in favour of poverty reduction and debt cancellation, the achievement of the Millennium Development Goals (MDG), the creation of the African Union (AU) and the advent of the New Partnership for Africa's Development (NEPAD).

29. After five years of implementation, the Government has embarked on a revision of the Poverty Reduction Strategy (PRS). The PRS revision process was officially launched on 1 December 2005, during a meeting of the National Management Committee chaired by His Excellency the Prime Minister and Head of Government.

30. The revision stems from the desire of the Authorities to take into account all the major changes during the implementation phase, as well as the new concerns expressed by stakeholders, in accordance with the commitment made by Niger at the adoption of the Poverty Reduction Strategy Paper in January 2002.

31. The PRS Permanent Secretariat (SP/SRP) subsequently defined a working methodology for the process. To that end, the activities carried out focused on : (i) revitalization of the implementation institutional mechanism organs, (ii) formation and installation of fifteen (15) thematic groups, (iii) capacity building for the thematic groups and Regional Committees, (iv) diagnosis of poverty, (v) preparation of a summary report of the contributions, and (vi) organization of a national validation workshop.

\section{Specifically, the following actions were carried out:}

Revitalization of the implementation institutional mechanism organs, particularly through meetings of: (i) the Consultation and Dialogue Committee, under the supervision of the Minister of Territorial and Community Development, to gather the views of stakeholders of the civil society and Non-Governmental Organizations and Development Associations (NGO/DA) on their participation; (ii) the Regional Steering Committees in the eight (8) chief towns of the regions, to ensure full participation of the decentralized authorities and field senior staff in the preparation of regional reports;

Consultation with the technical ministries, civil society organizations and development partners for the formation and installation of fifteen (15) thematic groups at the national level; the various thematic groups were subdivided into as many sub-groups as necessary to consider the aspects not taken into account in the initial PRSP. In order to ensure consistency in the thematic work and regional contributions, a methodology guide was prepared to facilitate analysis of the reports;

Organization of several capacity building workshops for the thematic groups and Regional Committees on: (i) Results-Based Management; (ii) gender and gender budgeting; (iii) assessment and planning of the requirements for achievement of the MDGs; (iv) mainstreaming of human rights; (v) inclusion of demographic variables in development policies/ programmes;

Organization of a workshop on the diagnosis of poverty, mainly to consider the provisional results of the survey on Combined Questionnaire of Basic Welfare Indicators (QUIBB) that would bee used in updating the poverty profile, as well as the results of the participatory diagnosis of poverty (population's perception of poverty) and some sectoral studies (development, water and electricity) ;

Preparation of regional reports and thematic reports with the support of SP/SRP. These reports have been summarized and used in preparing the initial version of the revised document. The document was made available to the stakeholders to allow for fruitful discussions (sectoral meetings, regional internalization workshops, and consultation with Civil Society Organizations and technical and financial partners) ; 
Organization of a national validation workshop in April 2007 which brought together the representatives of (i) the Institutions of the Republic, (ii) the Administration, (iii) the civil society, (iv) the private sector, (v) the regions, as well as ( vi) the technical and financial partners.

33. The process of revising the PRS provided a new opportunity to strengthen dialogue between the administration (central and decentralized), the civil society, and development partners on sectoral policies being implemented.

34. It was also a unique opportunity for reviewing most of the sectoral policies, studying the causes and consequences of poverty, as well as obstacles to its reduction. Similarly, Niger's potential to ensure strong and sustainable growth, as well as the population's priorities, were identified.

35. Furthermore, the formulation of the PRS used quantitative and qualitative data from recent surveys on thee living conditions of households. The exercise therefore provided Niger with better knowledge of poverty in all its dimensions as well as the constraints that need to be lifted to accelerate the country's development and the well-being of the population.

36. All in all, this new Strategy is the outcome of Consensus between the stakeholders, and demonstrates the strong political will of the Authorities of the $5^{\text {th }}$ Republic to make efforts towards achievement of the Millennium Development Goals by 2015.

37. This document, which is the outcome of concerted analysis, comprises two (2) parts:

- The first part outlines the diagnosis and key factors of poverty;

- The second part presents the major challenges, vision, overall goals, and strategic pillars.

38. The macro-economic and budgetary framework, the priority action plans, and the list of indicators are presented in the Annex. 


\section{PART ONE: STRATEGIC DIAGNOSIS OF POVERTY}

\section{I.1. DEFINITIONS AND MEASUREMENT OF POVERTY}

39. There is no single and universal definition of poverty. However, all analysts recognize that poverty could be defined as "a state of individual or collective destitution which places man in a situation of shortage or lack of essential needs". This operational definition of poverty was used by the Poverty Reduction Strategy Paper adopted in 2002.

40. It reflects, in particular, the lack of adequate income to satisfy basic needs in feeding, health, education, drinking water, decent housing and results in lack of opportunities to participate in social and economic life, an in greater vulnerability of the populations concerned to shocks of various types.

41. The various dimensions of poverty strengthen each other in individuals and prevent them from getting out of poverty themselves. They may even remain in the "trap of poverty" in the absence of exogenous support, particularly from the public authorities, partners or non-governmental organizations. For example, sick or hungry people cannot work under normal circumstances and their incomes are low. Consequently, poor people left to themselves cannot satisfy their essential needs in feeding, health and education. Furthermore, their low levels of education do not allow them access to gainful employment because of lack of appropriate qualifications. In addition, their participation in the decision-making process is marginal.

42. In a nutshell, poverty stems from a process that begins with economic factors (lack of resources, capital, and capacity), assumes a social dimension (dwindling of the social fabric, isolation, exclusion) and leads to political and psychological aspects (despair, deprivation).

\section{Box 1: Some Spill-over Effects of Poverty}

Poverty generates multifaceted effects at the individual and collective levels. Indeed, the views gathered during the participatory survey on poverty show that:

- poverty exacerbates inequalities of access to opportunities and outputs of operations. Indeed, because of their state of destitution, poor people do not have the minimum requirements for access to certain services that could enable them to get out of poverty (education, health, financial services, drinking water, etc.);

- poverty destroys the integrity of famililies, households or communities and lead to deviancy. The poverty of the head of the household leads to loss of authority over the other members;

- poverty brings about psychological stress: it breeds not only humiliation and loss of self-pride, but also some scepticism, despair and passivity.

Source: EPP2, CNSS_BOZARI_2005

43. To measure the level of poverty, several quality or quantity-related approaches are used. The qualityrelated information concerns mainly the definition and causes of poverty, subjective classification of households according to level of poverty, and assessment of poverty reduction operations. The quantity-related data provide information on the living conditions of households (level of expenditure, access to social services, nutrition, housing, etc.). A combination of these various complementary approaches provides a better understanding of the phenomenon of poverty.

44. Among the methodologies used, the monetary approach, which focuses on the monetary measurement of poverty, is the most frequent. In this approach, a poor person is one whose resources are below a given poverty line.

45. The living conditions approach is also used in measuring the level of poverty; it defines poverty in terms of hardships. It seeks to identify a number of difficulties, lack or deprivation in various aspects of the living conditions of households, of an existential nature (e.g. feeding, housing, health) or social nature (relations, employment, recreational activities, etc.). 
46. On the other hand, the subjective approach to poverty consists, not in referring to a minimum level of resources defined conventionally or objective living conditions, but in directly interrogating households on their perception of their situation (living conditions, perceptions, etc.).

47. All these approaches to poverty assessment have been used in Niger over the past few years in the following surveys:

- $\quad$ the Survey on Combined Questionnaire of Basic Welfare Indicators (QUIBB) in 2005 for application of the monetary approach supplemented by the perception of households;

- $\quad$ the Survey on Satisfaction of Basic Needs (DSBE) in 2004 to measure the level of poverty on the basis of living conditions;

- $\quad$ the second participatory survey on poverty (EPP2) in 2005 to assess the perception of poverty in the communities, the causes of poverty and strategies used by the poor to get out of poverty.

\section{Box 2: Poverty Indicators}

\section{Several types of indicators are used in measuring poverty:}

- the incidence of poverty measures the percentage of individuals or households whose consumer spending is below the monetary poverty line. The poverty line corresponds to a minimum annual consumer spending for an individual or household. It should be noted that the subjective incidence of poverty (perception of poverty) is generally higher than the objective incidence of poverty.

- the depth of poverty measures the average gap in percentage between the level of well-being of the poor households and the poverty line. It is used in theoretically calculating the minimum amount of additional resources to be transferred to poor households to place them on the monetary poverty line.

- the severity of poverty measures the average gap between consumption by the poor and the poverty line. It gives relative proportion of the poorer people in a given group.

\section{I.2. POVERTY PROFILE}

48. The poverty profile gives information on the scope, trend and structure of poverty. It helps to determine the main characteristics of the poor and carry out a differential analysis of poverty according to the different subgroups of the population. The analysis is mainly based on results obtained from the monetary approach to poverty, because of the numerous indicators and solid conclusions it provides.

\subsubsection{Scope of Poverty}

49. All methods of measuring poverty show that the incidence poverty is still high in Niger. In fact, the monetary evaluation method for measuring poverty shows, on the basis of data from the QUIBB survey, that a high proportion of the people in Niger are poor. Accordingly, based on poverty thresholds corresponding to an annual minimum income of CFAF 144750 (equivalent to about US\$290) in urban areas and CFAF 105827 (equivalent to about US\$212) in rural areas, it is estimated that $62.1 \%$ of the people of Niger were poor ${ }^{1}$ in 2005 (compared to the target of 59\%).

50. In households, the incidence of poverty is estimated at $53 \%$. However, measuring poverty in households tends to underestimate the incidence of poverty, since poor households are on average larger than non-poor households. That is why priority will be given to the incidence of poverty among individuals in the poverty profile.

\footnotetext{
${ }^{1}$ According to the QUIBB survey, the depth of poverty is estimated at $24.14 \%$, while acute poverty stands at $12.28 \%$,
} 
51. The subjective approach, based on the perception of poverty, shows that nearly $66 \%$ of households consider themselves averagely poor, while $20 \%$ of them consider themselves to be extremely poor. These proportions are similar in rural and urban areas.

52. This wide scale of poverty is also confirmed by the living conditions approach. Indeed, according to the results of the DSBE survey of $2004,70 \%$ of the households in Niger fall far short of meeting their basic needs; they are therefore considered as poor. The identified needs concern mainly food, financial means, employment, farm equipment and land, livestock, education of children and adult literacy, health and drinking water.

\subsubsection{Trend of Incidence of Poverty in Niger}

53. The only available quantitative data in Niger for direct evaluation of the poverty trends are those relating to the QUIBB survey conducted in 2005, which estimates the proportion of poor people at $62.1 \%$, and the results of the 1992 household budget and consumption survey which put the incidence of poverty at $63 \%$.

54. It should be noted that during preparation of the first Poverty Reduction Strategy Paper in 2002, no new data was available; consequently, the 1992 estimates were adopted as the base situation for 2002. Furthermore, it is difficult to objectively assess the poverty trend in Niger in 2002. In addition to this major difficulty, the methodological differences in calculating the poverty rate in the two surveys allow for comparison bias between 1992 and 2005.

55. In a growing economy, a decline in absolute poverty automatically depends on two factors: on the one hand, an increase in the average income of the population, with unchanged relative income distribution, reduced poverty; on the other hand, when the average income remains unchanged, any redistribution of income to the poor produces the same effect. This method is based mainly on the elasticity of poverty in comparison to the per capita real growth rate, which reflects the change in percentage points of the incidence of poverty by point of per capita real income growth based on the country's national accounts.

56. In the absence of intermediate data for a direct analysis of the poverty situation, an indirect method of evaluating the poverty trend, based on back-projection of consumer spending, was used. With this method, assuming that the inequalities remain the same, the incidence of poverty remained constant between 1992 and 2005; the improvement in economic growth between 2002 and 2005 made up for the poor performance in the 1990s. However, with an increase in per capita GDP between 2002 and $2005(0.4 \%$ annual average over the four years), this should reduce poverty slightly in Niger. In this respect, based on the assumption of elasticity of poverty ${ }^{1}$ in comparison to per capita income of -0.93 (average level determined by the WAEMU PER) and that income inequalities remain the same, it is possible to estimate the decline in poverty between 2002 and 2005 at 1.5 percentage points. The incidence of poverty in 2002 was therefore $63.6 \%$.

57. However, the results of the QUIBB survey show that nearly $66 \%$ of households feel that their living conditions have improved relatively over the past five years (from 2000 to 2005). At the national level, the main factors of change, in diminishing order of importance, are: increase in the number of activities in the households $(28 \%)$, the availability of a job (16\%), creation of a business or new activity $(15 \%)$, and migration (15\%).

\subsubsection{Territorial Distribution of Poverty}

58. The levels of poverty in Niger are quite different from area to area. Indeed, according to the QUIBB survey, the incidence of poverty is higher in rural areas (65.7\%) than in urban areas - excluding Niamey (55.5\%). In Maradi region, nearly eight out of every ten persons $(79.5 \%)$ live below the poverty line, while in Niamey Urban Community the incidence of poverty is only $27.1 \%$. Poverty is therefore present in towns, even though the incomes there are generally higher than those in rural areas because of the opportunities to increase them through trade of services and employment. However, these incomes scarcely provide enough money to meet the expenses required for the family beyond the minimum compulsory expenses (feeding, clothing, transport, and housing).

\footnotetext{
${ }^{1}$ The elasticity of poverty measures the impact of the per capita GDP trend on the poverty rate.
} 
Chart 1: Incidence of Poverty by Area of Residence

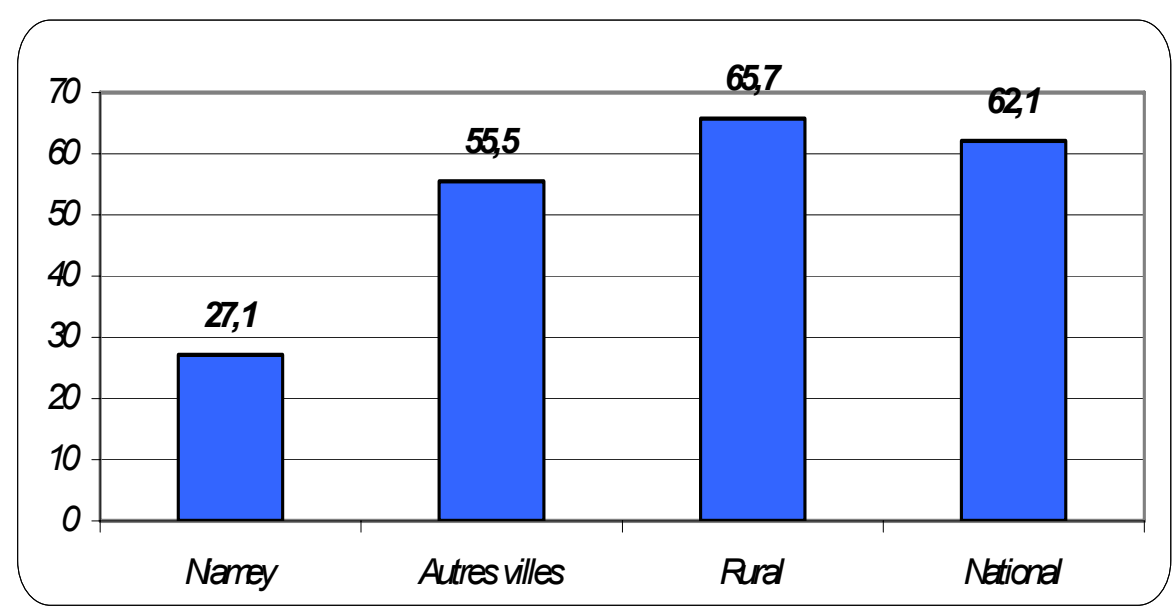

Source: ME/F/INS/QUIBB_2005

59. The proportions of the poor with consumer spending far from the poverty line (depth) are higher in Maradi (35.1\%), Dosso (28.8\%) and Tillabéri (26.8\%) regions. However, even though the incidence of poverty is the same in Agadez and Tahoua (45.9\%), the depth of poverty is more in Agadez (16.1\%) than in Tahoua $(14.5 \%)$.

Table 2: Breakdown of Poverty Status by Geographical Area in 2005

\begin{tabular}{|l|c|c|c|}
\hline \multirow{2}{*}{} & \multicolumn{3}{|c|}{ Poverty Indices } \\
\cline { 2 - 4 } & Incidence & Depth & Severity \\
\hline Agadez & 45.9 & 16.1 & 8.8 \\
\hline Dosso & 67.3 & 28.8 & 15.3 \\
\hline Maradi & 79.7 & 35.1 & 19 \\
\hline Tahoua & 45.9 & 14.5 & 6.2 \\
\hline Tillabéri & 68.9 & 26.8 & 13.9 \\
\hline Zinder - Diffa & 63.1 & 23 & 23 \\
\hline Niamey & 27.1 & 7.2 & 7.2 \\
\hline Ensemble Niger & 62.1 & 24.14 & 12.28 \\
\hline
\end{tabular}

Source: ME/F/INS/QUIBB_2005

60. In rural areas, the poor are not located on specific sites. In urban areas, the poor are mainly located in suburban quarters and old built-up areas. To a lesser extent, they are dispersed in residential quarters on undeveloped plots or parcels of land.

61. Similarly, the poor are increasingly putting up on the public highways. Some transformations of the urban fabric into town centres displace part of the urban population from the centre to the suburban quarters.

62. The costs and constant increases in rents are also factors that cause great mobility of the poor. The concentration of poor people in the suburbs is due mainly to the inflow of people from rural areas, the possibility of access to undeveloped or uninhabited spaces and the urban development policy which, as a result of decamping, push these people to far-off temporary areas where they develop shanty towns.

63. Unlawful occupancy, as a result of decamping, migrations and increase in poverty, has become a common reality in towns, and more particularly Niamey. The living and housing conditions in these suburban quarters are precarious because of inadequate basic infrastructure and facilities. 
64. Furthermore, the low professional qualification of periurban populations reduces their opportunities of access to decent jobs. They work mainly in the informal sector, are not paid well or occupy volatile jobs. Similarly, there is a high propensity for children roaming, begging, juvenile delinquency and the risk of the development of violence spots.

\subsubsection{Characteristics of Poverty in Niger}

65. Poverty can be characterized by carrying out an analysis of the incidence of poverty in terms of the size of the household in which the poor live, the level of education, the gender of the head of household, and the economic status of the head of household.

66. Indeed, the QUIBB survey shows that the larger the household, the greater the increase in the proportion of poor people, particularly in urban areas. The percentage of poor people in households of more than thirteen (13) persons is four times higher than in households with less than three (3) persons.

\section{Chart 2: Incidence of Poverty accoding to Size of Household}

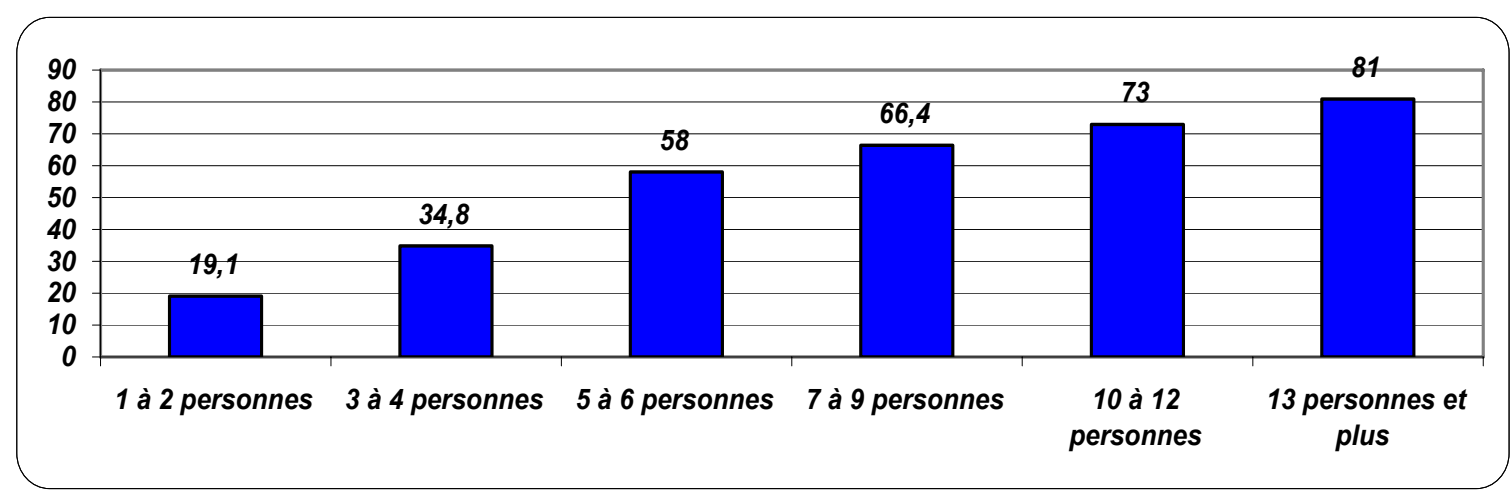

Source: ME/F/INS/QUIBB_2005

67. Furthermore, households with a higher number of children, have higher probability of being poor because each additional child reduces consumption by an amount ranging from $18 \%$ to $28 \%$. The phenomenon is more marked in Niamey Urban Community and other towns where the impact is greater.

68. Similarly, analyses show that all things being equal, a household headed by a woman runs greater risk of having a lower standard of living than one headed by a man.

69. Furthermore, in general, a differential analysis of the incidence of poverty, depending on the level of education, shows a significant impact of education. Indeed, the level of poverty is between $63 \%$ and $65.2 \%$ when the head of household has not completed primary education. It falls to $59.7 \%$ when the head of household is of primary education level, and reduces to less than one-third in households headed by a person of secondary education level or higher. In other words, the more one is educated, the less one is poor.

70. There is also disparity in the depth of poverty depending on the level of education of the head of household. Indeed, this rate is lower for households headed by persons of level of education higher than the primary. This same trend is observed with the level of severity of poverty which shows greater persistence of poverty in households headed by persons of basic education level. 
Table 3: Poverty by level of Education of Head of Household in Niger

\begin{tabular}{|l|c|c|c|}
\hline $\begin{array}{l}\text { Level of Education of Head of } \\
\text { Household }\end{array}$ & Incidence & Depth & Severity \\
\hline None & $65.1 \%$ & $25.3 \%$ & $12.9 \%$ \\
\hline Coranic education & $65.2 \%$ & $26.6 \%$ & $13.8 \%$ \\
\hline Literacy education & $63.4 \%$ & $25.7 \%$ & $14.0 \%$ \\
\hline Primary education & $59.7 \%$ & $21.1 \%$ & $10.0 \%$ \\
\hline Secondary education & $31.8 \%$ & $10.2 \%$ & $4.6 \%$ \\
\hline Vocational and technical training & $12.6 \%$ & $3.0 \%$ & $1.0 \%$ \\
\hline Higher education & $7.7 \%$ & $0.5 \%$ & $0.1 \%$ \\
\hline National & $\mathbf{6 2 . 1 \%}$ & $\mathbf{2 4 . 1 \%}$ & $\mathbf{1 2 . 3 \%}$ \\
\hline
\end{tabular}

Source: ME/F/INS/QUIBB_2005

71. The main source of income for the household has a major impact on per capita consumption and the probability of being poor. The results of the QUIBB survey show that poverty affects much more the people whose head of household is self-employed (with $65 \%$ of the cases), followed by those headed by unpaid apprentices $(61.3 \%)$, by domestic servants $(54.3 \%)$ and, to a lesser extent, by employers $(45.9 \%)$ and wageearners $(23 \%)$.

72. Households, whose main source of income is a formal public sector salary, have a higher standard of living or equivalent to that of the others, since the job and income are more stable in the public service. Households whose income come mainly from the formal private sector, mixed incomes (rents, profits, etc.) and the informal sector, have greater probability of being poor, with per capita consumption levels a little higher than $40 \%$ below those of households living mainly on public sector salaries. The poor condition of those belonging to the private formal sector is due to the fact that it is essentially unskilled labour. This shows the importance to be attached to education and vocational training.

73. In rural areas, the low income, resulting from low yields in agriculture and stockbreeding, raises the issue of supervision in rural areas so as to increase productivity. In urban areas, persons employed in houses or exercising small trades in the informal sector such as (small craftsmen, etc.) also have relatively low income because they are not well educated and have no means and capacities.

Table 4: Employement Status of Head of Household and Poverty

\begin{tabular}{|l|c|c|c|}
\hline \multirow{2}{*}{} & \multicolumn{3}{|c|}{ Poverty Status } \\
\cline { 2 - 4 } & Poor & Not Poor & Total \\
\hline Employer & 45.9 & 54.1 & 100 \\
\hline Self employment & 65.0 & 35.0 & 100 \\
\hline Wage earner & 23.0 & 77.0 & 100 \\
\hline Domestic servant & 54.3 & 45.7 & 100 \\
\hline Unpaid apprentice & 61.3 & 38.7 & 100 \\
\hline Others & 51.6 & 48.4 & 100 \\
\hline Total & 62.2 & 37.8 & 100 \\
\hline
\end{tabular}

Source: ME/F/INS/QUIBB_2005

74. These results are confirmed by the poverty analysis according to the main branch of activity of the head of household. Indeed, poverty affects more the people whose head of household works in agriculture $(68.8 \%)$, building construction (64.0\%), mines and quarries (56.2\%), trade/sales $(53.9 \%)$, production and processing $(51.0 \%)$ and, to a lesser extent, services $(49.52 \%)$. On the other hand, living conditions seem to be relatively better in households headed by a person who works in the transport sector $(32.3 \%$ poor), education and health sectors $(22.7 \%$ poor $)$ and administration (22.4\% poor). 


\subsection{6.) Perception of Results of PRS Implementation bythe Populations}

75. According to the QUIBB survey data, the population's perception of the programmes is as follows:

- $\quad 47 \%$ of households think that access to education has improved over the past five years, while $19 \%$ think it has deteriorated;

- $62 \%$ of households perceive an improvement in access to health services over the past five years, while $19 \%$ perceive a deterioration and $17 \%$ perceive no change;

- $\quad 44 \%$ of households feel that access to water has improved, while $29 \%$ think it has deteriorated, and $25 \%$ think there has been no change;

- the vast majority of households perceive no change in access to electricity, as against $14 \%$ who perceive an improvement, and $5 \%$ a deterioration. (Perceptions on access to electricity are better in urban areas than rural areas);

- for households that have sought legal remedy at national level, the majority $(59 \%)$ are satisfied, while $29 \%$ are unsatisfied, and $12 \%$ are indifferent with respect to the services. (The level of satisfaction seems higher in urban areas than in rural areas);

- $\quad 53 \%$ of households feel that taking into account the population's opinion in Government decisions is better now, as opposed to $19 \%$ who think that the situation has worsened, and $28 \%$ who think that there has been no change. (Rural areas perceive greater improvement (56\%) than urban areas (38\%));

- $58 \%$ of households think that it is less difficult to start an activity in their village/area, while $25 \%$ think that it is more difficult now, and $17 \%$ feel that there has been no change.

Box 3: Population's Perception of the Special Programme of the President of the Republic (PS/PR)

The PS/PR, which was initiated in 2001 under the HIPC Initiative, seeks to contribute to poverty reduction, particularly in rural areas, by providing socio-economic infrastructures as well as financial assets. The second participatory survey (EPP2) also helped to gather the views of the population on the PS/PR.

According to the results of EPP2, the majority of respondents $(90 \%)$ recognize the initiative of the President of the Republic as an investment recovery programme for the rural areas. About $62 \%$ of the respondents appreciate the Programme's approach which focuses on meeting the priority needs of the communities, particularly basic infrastructures (health centre, classes, water supply structures, pharmaceutical depots, veterinary health centres, manuring, etc.). The small drinking water supply structures provide water for the population and cattle $(68 \%)$, reduction of the recurrence of some water-borne diseases $(12 \%)$, reduction of difficulty in fetching water and therefore saving of time, and soil fertilization around water points (25\%). Similarly, in education, $60 \%$ of the people interviewed affirm that literacy classes and schools have contributed to meeting the needs of the communities. Micro-credit operations have helped to develop income-generation activities for the recipient women.

Furthermore, according the results of the QUIBB survey, nearly $40 \%$ of the respondents feel that the programme benefited the population, as against $31 \%$ of respondents who feel it affected the town-dwellers more.

Sources: EPP2, CNESS Bozari, 2005; QUIBB_2005

\section{I.3. ANALYSIS OF ROOT CAUSES AND KEY FACTORS OF POVERTY}

76. The key factors of poverty slow down income growth and affect the quality of life of the population. These various factors, which combine and reinforce each other, account for the poverty situation and trends in Niger. They are linked to the assets of the poor (human, physical, natural, financial and social assets), their yield and volatility of these yields. 
77. Consequently, physical resources, climatic conditions, population trends, qualifications, good health, infrastructure, land, access to credit, and social networks account for the level of poverty. Indeed, from the foregoing, it appears that education, employment and the number of persons in the household is key factors in differentiating the incidence of poverty in Niger.

78. Furthermore, economic growth is indispensable for income to be available to the populations. Similarly, inequalities, particularly gender inequalities, or between the areas of residence in access to services or economic opportunities, sometimes slow down the achievement of poverty reduction objectives.

\section{I.3.1. Economic Growth and Poverty}

\section{(a) Low and structurally unadapted economic growth}

79. Analyses show that, in order to significantly reduce the rate of poverty, an economic growth rate of at least $7 \%$ is required on a long term. However, Niger's economic growth rate has, for a long time, been below the population growth rate $(3.3 \%)$, and only slightly exceeded it over the past five years $(3.9 \%$ on average annually, compared to the initial target of $4 \%$ ) and within a context of low inflation (1.8\% on average) (see Table 5$)$.

80. Between 1993 and 2006, the real per capita GDP virtually remained stagnant. Although a significant improvement was noted over the 2002-2006 period, in reality it only made up for the enormous degradation recorded over the previous period, thereby accounting for the slight reduction of the poverty rate over the period.

Table 5: Key Macro-economic Indicators 2002/2006

\begin{tabular}{|l|r|r|r|r|r|r|}
\hline \multicolumn{1}{|c|}{ Key Indicators } & $\mathbf{2 0 0 2}$ & $\mathbf{2 0 0 3}$ & $\mathbf{2 0 0 4}$ & $\mathbf{2 0 0 5}$ & $\mathbf{2 0 0 6}$ & $\begin{array}{c}\text { Average } \\
\text { Period }\end{array}$ \\
\hline Nominal per capita GDP (in CFAF million) & 130.8 & 129.6 & 125.2 & 139 & 142.8 & 133.3 \\
\hline Real GDP growth rate (in \%) & 5.2 & 3.2 & -0.8 & 7.2 & 4.8 & 3.9 \\
\hline Real per capital GDP growth rate & 1.9 & -0.1 & -4.1 & 3.9 & 1.5 & 0.6 \\
\hline Proportion of informal sector in nominal GDP (in \%) & 72.2 & 72.5 & 70.4 & 70.5 & 70.8 & 71.3 \\
\hline Investment rate (in \%) & 16.1 & 16.3 & 14.6 & 23.1 & 21.8 & 18.4 \\
\hline Domestic savings rate (in \%) & 8.2 & 7.6 & 3.7 & 10.2 & 10.4 & 8.0 \\
\hline Final Consumption (variation in \%) & 6.1 & 4.2 & 3.1 & -0.2 & 3.7 & 3.4 \\
\hline Rate of inflation (in \%) & 2.6 & -1.6 & 0.2 & 7.8 & 0.1 & 1.8 \\
\hline Public debt (NPV as \% of exports) & 221.7 & 217.6 & 428 & 134.6 & 46 & 209.6 \\
\hline
\end{tabular}

Sources: INS/MEF; DGEP/MEF

81. The country's indebtedness ratio fell from $76.6 \%$ of GDP in 2002 to $62.3 \%$ of GDP in 2005 as a result of the various debt reliefs obtained during the period. Accordingly, on the eve of the HIPC Initiative, the public debt amounted to CFAF 1321.3 billion, comprising CFAF 912.40 billion as external debt and CFAF 295.55 billion as domestic debt. The external debt stock as at 31 December 2005 was estimated at CFAF 965.95 billion, while the debt service stood at CFAF 39.39 billion. An analysis of debt sustainability conducted in December 2006 shows that Niger's debt indicators improved significantly following the country's eligibility for the MDRI. Consequently, the debt NPV/exports ratio fell from $134.6 \%$ in 2005 to $46 \%$ in 2006. Niger's debt is very sensitive to external shocks and poor performance of its economy.

82. At the end of 2006, the outstanding domestic debt stood at CFAF 162.8 billion, representing CFAF 132.8 billion reduction in comparison to the outstanding debt of CFAF 295.6 billion at the end of 1999. This absorption of CFAF 132.8 billion of domestic arrears benefited mainly commercial creditors (43.2\%), households (40\%) and the financial sector $(16.8 \%)$.

83. At the macro-economic level, the signing of an economic and financial programme 2000-2003 supported by the IMF Poverty Reduction and Growth Facility (PRGF) and the support of several other multilateral and bilateral partners marked Niger's initiation of a vast programme of economic and structural reforms.

84. The satisfactory implementation of this programme, particularly in the management of public finance, helped the country to make progress in the PRS implementation, reach the completion point of the HIPC Initiative 
in April 2004, benefit from external debt reliefs and conclude a new programme with the IMF for the 2005-2007 period. The various reviews of the programmes highlighted a relative improvement of the macro-economic performance in comparison to the previous decade.

\section{Despite these reforms, Niger's economy remains characterized by:}

- the primary sector's contribution to GDP increased from 39.1\% of GDP over the $1995-2001$ period to $42.8 \%$ over the 2002-2006 period;

- the secondary sector's contribution has declined steadily despite increased activity in the mining sector; it fell from $13.7 \%$ to $13.2 \%$ over the $2002-2006$ period;

- the tertiary sector's contribution to GDP, despite its decline, is still predominant; it was $44 \%$ of GDP over the period as against $47.2 \%$ of GDP over the 1995-2001 period;

- the informal sector's contribution to GDP remains very high (above 70\%), and its evolution shows resistance of these activities to integrate into a modern framework in the short term.

85. The predominance of the primary sector in the economy (agriculture, in particular) and its dependence on climatic factors leads to volatile and erratic economic growth, thereby affecting its sustainability and making the Poverty Reduction Policy rather fragile. Abundant rainfall can trigger double digit growth rates (as in 1998), while rainfall shortages generally coincide with economic recession (as in 2004).

86. Generally, evaluations of the rural development policies show poor performance of the sector due mainly to:

- $\quad$ its management conditions (fragmentation and instability of the institutional framework, precariousness of supervisory services for producers, etc.) and poor organization of stakeholders;

- $\quad$ limited access of the rural stakeholders to financial services to buy inputs and production equipment;

- $\quad$ inadequate conservation and storage infrastructure and equipment;

- $\quad$ poor circulation of information on markets;

- $\quad$ inadequate weather information to warn of risks.

87. Crop production mainly comprises traditional food crops (millet, sorghum, rice, fonio, maize), most of which is for self-consumption, and other cash crops (groundnuts, sesame, sorrel, onion, sweet sedge, cotton, cowpea, souchet) (see Table 6).

Table 6: Trend of Cash Crop Production between 2002 and 2005

\begin{tabular}{|l|r|r|r|r|r|r|r|}
\hline \multirow{2}{*}{ Year } & \multicolumn{7}{|c|}{ Production in tones } \\
\cline { 2 - 8 } & \multicolumn{1}{|c|}{ Cow pea } & Groundnuts & \multicolumn{1}{c|}{ Sesame } & \multicolumn{1}{c|}{ Sedge } & \multicolumn{1}{c|}{ Souchet } & \multicolumn{1}{c|}{ Cotton } & \multicolumn{1}{c|}{ Onion } \\
\hline 2002 & 654232 & 153729 & 9864 & 19441 & 14956 & 8260 & 5074 \\
\hline 2003 & 549035 & 209369 & 5709 & 26312 & 5457 & 4700 & 1575 \\
\hline 2004 & 364757 & 168225 & 28649 & 23214 & Not Available & 27108 & 291780 \\
\hline 2005 & 586078 & 139035 & 42199 & 8095 & 10177 & 28000 & Not Available \\
\hline
\end{tabular}

88. The various crop yields are low and fluctuating mainly because of the following factors:

- low level of fertilization ( $5 \%$ of the areas in 2006 with half under rainfed crops) ;

- reduction of fallows and extension of farmlands by clearing marginal lands which promote water and wind erosion and undermine sustainability of exploitation natural resources; 
- the low technological level of current production systems; farmers continue to use mainly traditional, manual and low intensification and mechanization farming methods;

- the low level of irrigation (only $1.4 \%$ of cultivated lands, whereas the FAO recommends an irrigation rate of $30 \%$ ), despite efforts made over the past few years (irrigation schemes, out-of-season crop areas, private irrigation, runoff water drainage, small dams, etc.). Furthermore, the reduced flow of the Niger river has led to reduction of the land for irrigation;

- problems in the collective management of water and maintenance of structures on the irrigated areas ;

- $\quad$ the small size of the parcels (between 0.25 and 0.5 hectare per family) which does not allow for economically profitable farming;

- the value of post-harvest losses is also high because of limited conservation capacity.

89. Cereal availability remains inadequate in comparison to requirements; it covered only $96.21 \%$ of the average requirements over the 2002-2005 period (see Table 7).

Table 7: Cereal Coverage Rate between 2002 and 2005

\begin{tabular}{|c|c|c|c|}
\hline Year & $\begin{array}{c}\text { Availability } \\
\text { (in tonnes) }\end{array}$ & $\begin{array}{c}\text { Requirements } \\
\text { (in tones) }\end{array}$ & $\begin{array}{c}\text { Coverage Rate (in } \\
\% \text { ) }\end{array}$ \\
\hline 2003 & 2689200 & 2694600 & 99.8 \\
\hline 2004 & 2781538 & 2786401 & 99.8 \\
\hline 2005 & 2541300 & 2991600 & 84.9 \\
\hline 2006 & 3167700 & 3146600 & 100.7 \\
\hline $\begin{array}{c}\text { Average over } \\
\text { the period }\end{array}$ & 2794935 & 2904800 & 96.21 \\
\hline
\end{tabular}

90. The inadequate coverage of cereal requirements in 2005 (about $85 \%$ ) led to difficulties in meeting the food requirements of Niger, forcing the authorities to trigger large-scale actions through the National Food Crises Prevention and Management Mechanism, created to cope with such situations by coordinating all the operators:

- At the national level, the food crises prevention and management mechanism, which has improved over the years, is trying to better target vulnerable areas and households, as well as fine tune its intervention procedures.

- $\quad$ At the regional and sub-regional levels, the mechanism is managed by the Regional Committees (CR/PGCA) and Sub-regional Committees (CSR/PGCA), comprising all the stakeholders concerned and ensuring the strategic and operational management of the prevention and management of food and nutritional crises on the field.

91. The committees collect, summarize and validate information on the food situation. They produce timely analysis of the situation and propose measures to be taken. The food crises management and prevention mechanism is based mainly on the National Reserve Stock, made up of a national buffer stock of 80,000 tonnes and a Food Security Fund equivalent to 30,000 tonnes. This mechanism responded appropriately to the difficult situation in 2005.

92. The interventions and measures concerned mainly the free distribution of food to the most difficult cases, the establishment of Nutritional Recovery Centres (targeting in priority children), the sale of cereals and zootechnical inputs at moderate prices, the creation of cereal banks, the distribution of contingency and substitution seeds, labourintensive works in cash for work or with food in food for work, the promotion of irrigated farming, the replenishment of livestock population and support for income-generating activities.

93. The contribution of the livestock sub-sector to GDP averaged $13.9 \%$ between 2002 and 2006 . The national livestock population comprises cattle, sheep, goats, camels, donkeys, horses and poultry. This production potential is high in terms of quantity and quality, especially as concerns small ruminants (see Table 8). 
Table 8: Breakdown of Livestock Population in Head and UBT

\begin{tabular}{|l|r|r|}
\hline \multicolumn{1}{|c|}{ Species } & \multicolumn{1}{c|}{ Number } & \multicolumn{1}{c|}{ UBT } \\
\hline Cattle & 7336088 & 5868870 \\
\hline Sheep & 9192729 & 1378909 \\
\hline Goats & 11238269 & 1685740 \\
\hline Donkeys & 1477075 & 738538 \\
\hline Horses & 230176 & 230176 \\
\hline Camels & 1565420 & 1565420 \\
\hline Total & 31039757 & 11467654 \\
\hline \multicolumn{2}{|r}{ Source: RGAC/2004_2005 }
\end{tabular}

94. Livestock feeding and availability of water pose serious problems because of the type of extensive stockbreeding, that is quite vulnerable to climatic shocks and local pasturelands, low linkage and inadequate water points, drainage difficulties in areas where the water catchment is very deep (more than $60 \mathrm{~m}$ ), declining water-table and low maintenance of structures. Animal health also remains a major cause for concern despite initiation of privatization of the veterinary profession.

95. Meat production has increased steadily (55\% between 2002 and 2005) (see Table 9). Nevertheless, the livestock exploitation rate remains relatively low, based on records of authorized slaughter and exports. The low capacity of conservation facilities and modern slaughterhouses has contributed to this situation. Almost all the meat produced in Niger is intended for local consumption; only very little quantities are exported, particularly to Nigeria and Côte d'Ivoire.

Table 9: Slaughter Trend in Equivalent Life Weight from 2002 to 2005

\begin{tabular}{|c|c|c|c|c|}
\hline & 2002 & 2003 & 2004 & 2005 \\
\hline Authorized slaughter in $\mathrm{kg}$ & 27919808 & 26921513 & 30107369 & 36924022 \\
\hline Production of offals in $\mathrm{kg}$ & 7396949 & 7138979 & 7997015 & 9631897 \\
\hline Total & 35318759 & 34062495 & 38106388 & 46557924 \\
\hline Unauthorized slaughter & 24721730 & 34060492 & 38104384 & 46555919 \\
\hline Total slaughter & 60040489 & 68122987 & 76210772 & 93113844 \\
\hline Annual Total in tones & 60040 & 68123 & 76211 & 93114 \\
\hline Monthly average in tones & 5003 & 5677 & 6351 & 7759 \\
\hline Average price per kg of meat (in CFAF) & 1200 & 1200 & 1200 & 1200 \\
\hline Annual meat production value in CFAF billion & 72.05 & 81.75 & 91.45 & 111.74 \\
\hline Monthly value in CFAF billion & 6.00 & 6.81 & 7.62 & 9.31 \\
\hline
\end{tabular}

Source: MRA

96. Milk and byproducts constitute the main food for at least $20 \%$ of the population, and important supplementary food for the remaining $80 \%$. Average production per cow (during milking period) is estimated between 1 and 2 litres/day. National production is far below the increasing domestic demand and Niger has become an importer of dairy products: in 2003, powder milk imports stood at about CFAF 5 billion (according to FAO data). The Table below gives the production trend between 2002 and 2005.

Table 10: Trend of Milk Production from 2000 to 2005

\begin{tabular}{|l|r|r|r|r|}
\hline Species & \multicolumn{1}{c|}{$\mathbf{2 0 0 2}$} & \multicolumn{1}{c|}{$\mathbf{2 0 0 3}$} & \multicolumn{1}{c|}{$\mathbf{2 0 0 4}$} & \multicolumn{1}{c|}{$\mathbf{2 0 0 5}$} \\
\hline Cattle & 175411368 & 178919631 & 182497986 & 186147968 \\
\hline Sheep & 84353040 & 86883636 & 89490144 & 91279944 \\
\hline Goats & 188847855 & 193569054 & 198408273 & 202376433 \\
\hline Camels & 66844206 & 67846896 & 68864621 & 70241886 \\
\hline Total & 515458471 & 527221220 & 539263028 & 550048236 \\
\hline \multicolumn{1}{|c|}{ Average per capita } & $\mathbf{4 6}$ & $\mathbf{4 6}$ & $\mathbf{4 6}$ & $\mathbf{4 4}$ \\
\hline
\end{tabular}

Source: MRA 
97. Hides and skins are important sources of foreign currency for the country, because $95 \%$ of the production is exported, either raw, tanned or as handicraft products. The main export market is Nigeria which absorbs about $80 \%$ of exports. The national hides and skins supply is about 200,000 pieces of cattle skins, 900,000 sheep skins and 1,550,000 goat skins. The production capacity of the country's semi-modern tanneries is about 912,000 skins per year. Despite enormous efforts, there are still problems of quality which reduce the export potential of the hides and skins sub-sector.

98. Forest production mainly consists of natural forests which accounted for about 5 million hectares in 2006 and which provide about $87 \%$ of the national energy requirements, as well as $97 \%$ of household energy consumption. They are also used to meet the additional food or survival needs of the riparian populations of the forests. The fauna and flora, which are exploited using traditional methods, are additional sources of monetary income for the rural populations and play a very important role in human food, particularly during periods of shortage, as additional food. They are also the main source of traditional pharmaceutical products. The Arabic gum sector is developing rapidly, with production estimated at between 2,000 and 4,000 tonnes per year, particularly in private and community plantations.

99. To control desertification and reverse the trend towards depletion of environmental resources, efforts have concentrated mainly on reforestation, land reclamation, development of natural forests and protected areas, as well as development of community forestry and agroforestry. Accordingly, 89,000 hectares have been placed under decentralized management for the production of energy wood. Arabic gum and other non-wood forest products, representing about $13 \%$ of the national forest potential and more than 30,000 hectare of reforested lands. However, pressure on resources and aggressions on the environment continue to be potential threats on the preservation of biodiversity.

100. Fisheries and aquaculture are carried out on many water bodies in the country (totaling more than 400,000 hectares): Niger River and its tributaries, Lake Chad, Komadougou Yobé, natural marshlands and artificial water catchment basins. National fish production is relatively low (50,058 tonnes of fish in 2005) and concerns only nearly ten thousand (10.000) fishermen.

101. The handicraft sector concerns about $23 \%$ of the population. It is developed in urban and rural areas, and is done mainly by women and people of the most vulnerable groups (youths, handicapped persons) in almost all the trades. It supports rural development, particularly in the making and maintenance of equipment, supply of spare parts and processing at competitive costs. The development of the sector encounters several obstacles:

- lack of a general micro and small enterprise promotion strategy;

- low capacities o the operators (technical and management skills);

- lack of production equipment;

- inappropriate financing structures;

- low level of innovation ;

- lack of quality standards.

102. The modern private sector comprises small-scale enterprises, most of which are engaged in service activities and use relatively simple technology. Between 2000 and $2004,79 \%$ of private institutions employ less than 15 persons, and barely $2 \%$ of the enterprises have staff of more than 100 employees.

103. The manufacturing industry contributed $8.57 \%$ of GDP over the $2002-2005$ period. The number of enterprises operating in the sub-sector stands at 69 , which are private small and medium-sized enterprises, mainly concentrated in Niamey ( $80 \%$ of the enterprises). The employment situation in the sector is stagnant (around 1,300 workers in 2005) despite the creation of new industrial plants in the past few years.

104. The constraints and obstacles to the development of the manufacturing industrial sector are many; the most significant are:

- socio-cultural practices: The "trader" spirit (buy - sell) is predominant among Niger businessmen who have enough financial opportunities required for productive investments, particularly industrial investments; 
- poor management of enterprises: most industrial plants are poorly managed, in terms of inputs supply, financial management and human resource management. There is also poor marketing to conquer the market;

- lack of integration of plants which work isolated;

- unfair competition due to fraud;

- high costs of technical production factors (electric power, water, telecommunications, transport and logistics);

- low level of production tool, due to obsolete and outdated technology;

- most production plants very often operate below their capacities, thereby generating committed costs which affect the competitiveness of the products;

- the industrial zone in Niamey, the largest in the country, suffers from serious degradation of spaces and access roads;

- lack of specialized technical centres to support the sector in the training of senior staff and in assistance and high-level technical expertise.

105. The mining sector exploits important mineral substances (uranium, gold, phosphate, cassiterite, gypsum, natron, etc.) on a large or small scale. Furthermore, there are huge deposits of iron, phosphate and salt. Niger adhered to the Extractive Industries Transparency Initiative in March 2005. Following relative stability between 2001 and 2002, uranium exports have been increasing sharply since 2004, because of price resurgence on the international market.

106. The constraints and obstacles to development of the mining potential are of several types, in particular:

- landlocked position of the country and far distance from the sea;

- limited integration of the mining sector into the rest of the national economy;

- inadequate geological coverage of the national territory (a large part of he national territory is not yet covered by appropriate scale mapping) ;

- lack of professionalism and resources of the small-scale mine developers;

- limited diversification of investors.

107. The tourism sector benefits from a rich and varied potential (the Air, the Ténéré, the Kawar, the river valley, the W natural park, the centre of the country and all the country's cultural diversity). A National Tourism Promotion Centre (CNPT) was created in 1999 to promote the sector, provide supervisory services, sensitization, information and professionalization of tourism and hotel trade stakeholders.

108. Despite the enormous tourism assets in Niger, its development is hampered by several constraints, including:

- $\quad$ the lack of a national tourism development policy;

- $\quad$ the landlocked position of the country and its wide expanse, which do not facilitate the movement of tourists;

- $\quad$ the arid climate and short tourism season (the tourism season runs only from October to March, or six months);

- $\quad$ the limited air transport services and very high costs to Niger;

- $\quad$ low professionalism of stakeholders and limited quality of the tourism product;

- $\quad$ limited use of modern means of payment;

- $\quad$ lack of adequate financing for the sector.

\section{(b) Uncompetitive business environment}

109. According to the survey on the investment climate in Niger conducted by the World Bank from November 2005 to February 2006, the business environment is, on the whole, not favourable to the private sector. The key negative points are related to corruption perceived as high, inconsistency of regulations, the slowness, complexity and lack of transparency of administrative and legal procedures, problems of access and cost of loans, and serious infrastructure problems (particularly as concerns electricity).

110. In addition, the productivity of manufacturing firms is very low, even when compared to other WAEMU 
countries, mainly because of the lack of initial and/or continuous training of manpower, slow adoption of new technologies and poor allocation of resources and factors of production. All this accounts for the low foreign direct investments in the country, even though such investments have been increasing significantly (CFAF 12.5 billion in 2006 as against CFAF 2.87 billion in 2002).

111. Furthermore, in the Finance Law for 2007, three (3) key measures were taken in December 2006; they are: (i) the abolition of advance payment of business tax when starting a business, (ii) deduction of 5 points from the registration rate of some deeds of conveyance, and (iii) streamlining of the procedure for issuing tax status attestations.

\section{(c) Poor financing of the economy}

112. The financial and banking system is expanding (twelve banks and financial institutions in 2006). Some banks do not comply with all the WAEMU prudential rules. Loans granted by banks in Niger remain relatively low in comparison to other WAEMU countries. They are mainly short-term (74.32\%) and favour big enterprises to the detriment of small enterprises. Similarly, the interest rate and intermediation margins in Niger are the highest in WAEMU, standing at $17 \%$ and $9.1 \%$ respectively in 2006 .

Table 11: Trend of Credit Ratios to the Economy in Niger and soem WAEMU Countries (in \% of GDP

\begin{tabular}{|c|c|c|c|c|c|c|c|}
\hline & 2000 & 2001 & 2002 & 2003 & 2004 & 2005 & 2006 \\
\hline WAEMU & 14.8 & 14.6 & 14.8 & 15.2 & 15.6 & 16.2 & 14.8 \\
\hline Burkina Faso & 12 & 12.1 & 13.3 & 13.6 & 14.1 & 15.9 & 13.4 \\
\hline Mali & 15 & 15.5 & 18.5 & 19.7 & 19.6 & 17.8 & 17.6 \\
\hline Benin & 11.5 & 10.5 & 11.3 & 14.2 & 14.6 & 16.3 & 13.7 \\
\hline Niger & 5.5 & 4.8 & 5.1 & 5.4 & 6.6 & 6.9 & 6.3 \\
\hline
\end{tabular}

Source: BCEAO

113. Several reforms have been initiated in the financial sector by the Government. They concern the following areas:

(i) strengthening of the legal and regulatory environment of the financial system in order to improve the legal and regulatory environment perceived as an obstacle to the promotion of the financial sector and private sector in general. In addition, reforms in this area should foster better access to financing, by facilitating the issue and performance of guarantees by financial institutions and reducing their costs;

(ii) restructuring of banking aimed at developing financial intermediation, particularly cleaning up of the banking sector and increase in financing for housing and local authorities;

(iii) development of local financial intermediation which is a key factor for the development of rural and periurban areas. Indeed, through the development of micro-finance and postal financial services, local financial intermediation would contribute significantly to poverty reduction by mobilizing small savings, developing payment systems and providing small financing adapted to marketing and production in rural areas.

114. The following results were obtained:

a. the conduct of three (3) studies on aspects relating to: (i) the process of issuing and performance of guarantees; (ii) round table on the judicial system and financial institutions; and (iii) reform of the trade and real estate credit register.

b. pursuance of actions towards privatization of "Crédit du Niger" (CDN);

c. restructuring of the CPCT, which depends on the ongoing decentralization process in Niger and the existence of local authorities that can represent solvent demand for financial services, has not been carried out. 
115. Furthermore, the Government has ratified the uniform law on combating money laundering in WAEMU countries; to that end, a financial information unit, known as the National Financial Information Processing Unit (CENTIF) has been set up.

116. Similarly, capacity building actions have been carried out. They seek to develop the financial sector by: (i) improving the institutional framework of the financial sector, building administrative, financial and technical capacities of supervisory and control ministerial structures; and (ii) capacity building for banks and insurance companies in order to improve their operational, managerial and prudential capacity.

117. Accordingly, officials of the sector received training which helped $t$ improve the performance of employees, particularly the degree of satisfaction of service users.

118. The decentralized financial system: The preliminary results of the exhaustive inventory of 162 decentralized financial services (SFD) in Niger present a rather negative image of the micro-finance sector. Despite the steady and high increase in the loans they grant and deposits they collect, the financial situation of SFDs remains fragile and the quality of their portfolio has deteriorated. Similarly, the micro-finance sector in Niger is one of the least developed in the WAEMU space. The most important SFDs have been trusteeship or in liquidation since 2001, and most of them suffer from low institutional capacity, as well as inadequate management tools and strategic development vision. Many SFDs have negative equity capital and are bound to stop their activities if there is no external assistance and important recovery measures are not taken. None of the prudential and management ratios stipulated by the PARMEC law is respected by all the SFDs. Furthermore, despite the numerous violations of prudential standards, the application of sanctions remains inadequate.

119. Micro-finance in Niger also suffers from: (i) lack of technical capacities for the management of the sector, (ii) inadequate supervision by the supervisory authority, (iii) lack of synergy between the various stakeholders, and (iv) the charging of very high interest rates. Poor governance is a major cause for concern for the development of the sector. Such governance is reflected by: (i) the lack or non-application of internal control and risk management procedures which leads to several financial misappropriations.

120. SFDs in Niger depend on donors, especially for providing lines of credit, rather than laying emphasis on internal resource mobilization, such as savings. Accordingly, nearly $50 \%$ of the resources for lending come from subsidies, and equity capital is made up mainly of investment subsidies and other endowment funds.

121. However, micro-finance development in Niger offers the only way for many people, especially in rural areas, to have access to formal financial services. Indeed, the number of SFD customers, which stood at 112,114 as at 31 December 2005, is higher than that of the banking sector which has only 78,456 accounts. However, the outstanding loans of CFAF 8.5 billion and savings of CFAF 5.4 billion represent only $6.01 \%$ and $3.03 \%$ respectively of the entire financial sector.

122. As part of reforms of the sector, the following activities have been initiated by the Government:

- cleaning up of the micro-finance sector by adopting a decree establishing the Micro-finance Regulation and Surveillance Agency (ARSM) so as to strengthen: (i) the control and supervision capacities of the supervisory authority through training and supply of equipment to the Agency, and (ii) those of micro-finance institutions by conducting financial and technical audits;

- $\quad$ restructuring of the Post Office by: (i) establishing the NIGER-POSTE corporation, responsible for promoting the universal postal service and creating FINA-POSTE, as a subsidiary bank of NIGER-POSTE, enjoying management autonomy, as a result of the merger of the Caisse Nationale d'Epargne (CNE) and CCPs, to offer local financial services; and (ii) building the capacities of Management of NIGER-POSTE and FINAPOSTE through advisory, training and material services.

123. Niger has a common plan for cleaning up and stabilizing the SFDs, which is an adequate framework for the support required for viable development of micro-finance. It focuses on the following actions:

- support for regulations and SFD supervision;

- $\quad$ support for SFD in building their institutional capacities; 
- support for apex and professional organizations.

124. Despite the constraints listed above, there are several development opportunities for the sector, in particular:

- the organization of operators in an association (ANIP-MF) since 2000 ;

- $\quad$ the refinancing of MFIs (more than CFAF 500 million in 2005) by the Regional Solidarity Bank (BRS);

- support for the Rural Financial Service Development Programme (PDSFR) and the technical Assistance Project for Financial Sector Development (PDSF);

- $\quad$ capacity building for the institutional stakeholders, as well as those of MFIs;

- reorganization of the institutional and legal framework;

- operationalization of the Micro-Finance Regulation and Surveillance Agency (ARSM) ;

- the "micro-crédit" component of the Special Programme of the President of the Republic and several other development projects;

- the imminent creation of a bank for loans to women, known as "SARAOUNIA" and an agricultural credit bank.

125. The financial market: Capital markets are the "engine" of the economy, in the sense that they transform savings into investments and that these investments foster economic growth and create jobs. The WAEMU financial market was established to enable the States, local authorities and public and private companies to get out of the conventional financial methods by mobilizing public savings to revitalize the West African private sector. It facilitates mobilization, through bond loan, of the huge financial resources required for investments. In this way, it has enabled several WAEMU countries to finance their large projects, clean up their finance and stabilize the macro-economic balances. This sub-sector should enable economic operators to resort to thee financial market to finance their activities. However, the participation of Niger operators is very low.

126. Indeed, the local financial market faces the following constraints:

- $\quad$ inadequate stock market culture in all the countries;

- $\quad$ low supply of Niger securities (shares and bonds);

- $\quad$ very low demand for securities;

- $\quad$ unharmonized tax system;

- $\quad$ lack of regulatory texts to promote privatization by the stock market.

\section{(d) A split private sector support mechanism with limited resources}

127. A National Private Investors Council (CNIP) was established in 2004. Chaired by the Prime Minister, the Council seeks to foster better synergy between the private sector and the State. The implementation of a national private sector promotion policy has also led to the creation and/or strengthening of several support and supervisory structures ; they are, in particular: the Chamber of Commerce, the Investments Promotion Centre $(\mathrm{CPI})$, the Niger Exports Promotion Agency (ANIPEX), the National Management Development Centre (CNPG), and "Entreprendre au Niger" (EAN).

128. Furthermore, the Government has adopted several measures to support promoters in creating new economic units: (i) creation of a single window for corporate formalities; (ii) establishment of a refinancing fund in banks.

129. Some of these structures sometimes have very similar missions and very often lack appropriate means to perform their assigned tasks.

\section{(e) An economy poorly integrated into the regional and world environment}

130. Niger's foreign trade suffers from a structural deficit as a result of the limited range of exports and enormous imports. The concentration of exports on a few products weakens the economy, making it dependent on price fluctuations on the world markets. The trade balance deficit is steadily increasing. It rose from $4.4 \%$ in 2002 to $7.4 \%$ of GDP in 2006 . This deficit is due to imports which increased at an average of $12.3 \%$ and represented $20.4 \%$ of GDP, whereas exports increased only at an average of $8.3 \%$ and represented $14.2 \%$ of 
GDP over the period.

131. Niger exports a very limited variety of products, consisting mainly of mine products, agricultural products, livestock products and fishery products. Uranium is the leading export with $48 \%$ of the total. Uranium sales depend on the highly volatile world prices, which have since 2003 been very favourable for Niger. Livestock products, mainly life animals, come second with an average of $23.48 \%$ exports. Agricultural products come third $(15.16 \%)$ and mainly consist of raw products (onion, cowpea, sweet sedge, dates, and groundnuts) and ginned cotton. Niger also conducts an average of $14 \%$ of its foreign trade with WAEMU countries, despite the entry into force of the CET since 2000 . Furthermore, the economy's opening rate is only about $20.1 \%$, below the rate generally obtained in rapid growing countries, thereby reflecting the limited integration of the country into the international economy.

132. Niger's exports still face several constraints:

- high dependence of the economic situation on the Nigerian market (nearly $16 \%$ of Niger's exports go to Nigeria, and this figure is certainly under-estimated because of the largely informal trade between the two countries) ;

- low storage, packaging and conservation capacities;

- low added value of the products which are simply exported as raw products, without any processing;

- the inadequate quality of products;

- $\quad$ the lack of a real marketing strategy;

- the transport and transit costs are significantly high for some destinations, including Abidjan, Accra and Cotonou;

- the low negotiating power of the informal trade sector actors on foreign markets where they sell Niger's products.

\section{I.3.2. Access to Social Services and Poverty}

133. In order to find a viable solution to the limited access to social services and social demand increasingly exacerbated by high population growth, Niger has embarked on strengthening its human capital, particularly through implementation of policies in education, health, improved access to drinking water, housing, sanitation and urban development, access to modern energy services, social security and support for employment and income-generating activities.

\section{a) Education and Poverty}

134. Education and vocational training have significant impacts on the different dimensions of poverty. They generally facilitate access to the labour market and enable people to benefit from economic opportunities.

135. Analyses performed in Niger show that a household headed by an educated person has higher probability of enjoying a higher standard of living than a household headed by an uneducated person. The same applies to households in which the head's spouse is educated.

136. In order to achieve the Millennium Development Goal (MDG) of Education For All (EFA), Niger has initiated reforms to improve the results of its education system by allocating about CFAF 55 billion per year to the sector, over the 2002-2006 period.

137. The implementation, as from 2003, of the Ten-Year Education Development Programme (PDDE), through its three (3) components (access, quality and institutional development) stems from this desire. The PDDE comprises two (2) blocks, the first of which covers basic education (preschool education, basic education 1 cycle, base 2 cycle; literacy schools and coranic schools) and the second block, which is being finalized, will focus on middle and higher education, as well as vocational and technical training.

\section{- Basic Education}

\section{$\underline{\text { Preschool Education }}$}


138. Preschool education has a very positive impact on improving the knowledge acquired in the primary education cycle. However, compared to the huge requirements and impact of this cycle of education, the PDDE objectives are very modest (increase the gross preschool enrolment rate from $1 \%$ in 2002 to $5 \%$ in 2012). Despite the increase in the number of preschool institutions (average of $15.66 \%$ per year between 2003 and 2005 on the whole, and about $12 \%$ in rural areas) due to an increase in the number of children for such education, and the opening of community nursery schools in rural areas, the overall gross preschool enrolment rate is barely more than $1.4 \%$.

\section{Basic Education 1 (primary)}

139. Despite the progress made in terms of access, PDDE performance in this area in inadequate compared to the set objectives and the huge financial resources mobilized $(76 \%$ of the financial resources allocated to the sector over the period) and the means provided (construction of an average of 1,500 classes per year, recruitment of 2,500 teachers on contract).

140. The primary education gross enrolment rate increased from $41.7 \%$ in 2002 to $53.5 \%$ in 2006 (as against a target of $57 \%$ ). This rate varies greatly from one region to another; it reached $96.9 \%$ in the Niamey Urban Community in 2006 as against $42.6 \%$ in Zinder. Despite a substantial reduction in the disparity between urban and rural areas (from 19 to 5 points gap between 2001 and 2006), the gross enrolment rate in rural areas (52\%) did not achieve the set target (54\%) in 2006.

141. Gender disparities have increased (from 15 points in 2001 to 19 points in 2006). The net enrolment rate stands at $45.5 \%$ for the entire country, and there are still disparities between the regions, as well as in terms of placed of residence ${ }^{1}$ and gender ${ }^{2}$.

Chart 3: Gross Enrolment Rate (GER) according to Gender

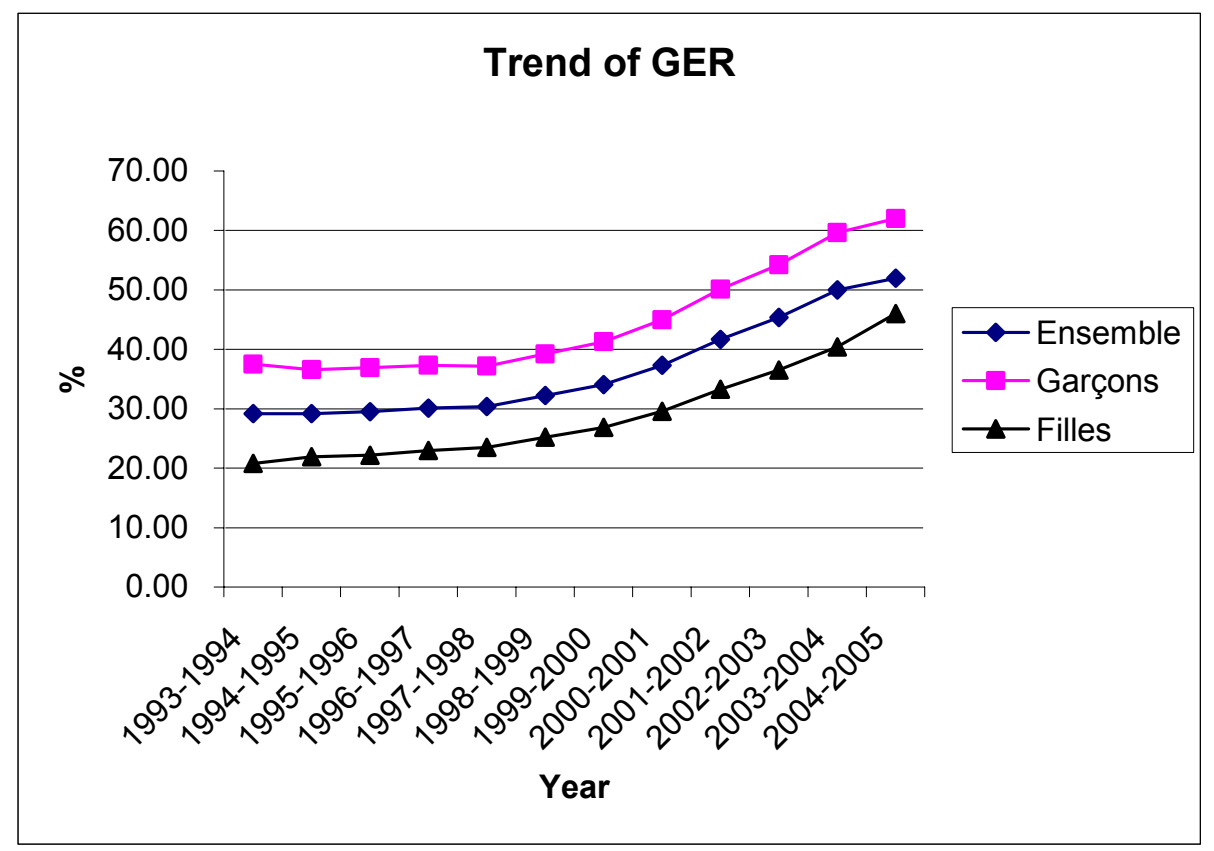

142. Concerning the quality, the completion rate increased from $25.4 \%$ in 2002 to $39.8 \%$ in 2006 (as against an initial target of 46\%); after the repeater rate declined sharply between 2002 and 2005 (from 10\% to 5\%), it rose to $8.9 \%$ in 2006 . The supply of school textbooks and teachers' guides has been increased, while nearly all the teachers receive initial and continuous training in Teacher Training Colleges and Pedagogic Centres.

$152.6 \%$ for urban areas (excluding Niamey) and $45 \%$ in rural areas

$237.8 \%$ for girls and $54.1 \%$ for the boys. 
143. The poor performance which hampers achievement of PDDE objectives and progress towards MDG achievement are due to some factors, in particular : (i) inadequate services (infrastructures, staff, equipment) ; (ii) high population growth; (iii) low incomes; (iv) negative perception of school by the parents, particularly for girls; (v) education development strategy focused mainly on supply (this restrictive approach has shown its limit especially as the implicit assumption that there is high potential demand for enrolment has not been proven); (vi) the delay in the overhauling of curricula; (vii) the shortcomings of the initial and continuous training of teachers; (viii) inefficiency in the management of human resources, leading mainly to disproportionate pupil/teacher ratios and low impact of the massive recruitment contractual teachers on the enrolment ratio; (ix) centralized management of resources; $(x)$ the low level of remuneration of contractual teachers; (xi) the high number of classes in straw huts; (xii) social unrest and demonstrations; (xiii) inadequate actions to stimulate social demand for education (school canteens, far distance to schools and lack of toilet facilities).

\section{$\underline{\text { Informal Education }}$}

144. The "informal education" sub-programme of the PDDE aims at training youths aged 15 and above, particularly 15 to 24 years, who have not been educated in formal education structures. The education is offered through: (i) the activities of adult literacy and training centres, (ii) vocational training in community development training centres (CFDC) and other alternative formulas, and (iii) coranic schools. The general strategy adopted by the State is based on the "do-it-yourself" principle; this is a form of contractual relation between the State, the NGO/DA (as private operators) and the technical and financial partners.

- $\quad$ Adult literacy and education: The adult literacy rate is still very low $(28.7 \%$ in 2005 as against $19.9 \%$ in 2000). This rate conceals wide disparities according to gender; for example, the literacy rate for men increased from $30.4 \%$ in 2000 to $42.9 \%$ in 2005 while that for women stood at $15.1 \%$ in 2005 as against $10.6 \%$ in 2000 . Thus the women/men ratio remained stable (about 0.35 ). The low literacy rate is mainly due to the inadequate opportunities for learning (2,307 functional literacy centres in 2004 as against 1,299 centres in 2000).

- $\quad$ Vocational Training: There are currently eleven (11) Community Development Training Centres under experimentation. An evaluation of these pilot structures which aim at promoting access by drop-outs and uneducated persons to basic vocational training for better integration into the community fabric is underway.

Education in renovated coranic schools: Coranic schools, which are firmly established in the country, admit many children, adolescents and adults seeking for knowledge, and enjoy some prestige among the population. However, these schools face many problems, in particular: (i) the lack of pedagogic supervision, (ii) poor living and working conditions of the instructors, (iii) precarious admission structures, and (iv) lack of appropriate programme. Furthermore, the absence of reliable statistics on coranic schools makes it difficult to evaluate them and include them in the calculation of the enrolment rate. To remedy the situation, the Ministry of National Education, through the PDDE, has embarked on supporting the coranic schools to enable them to contribute to providing basic education and combating poverty by curbing begging; to do this, a sampling of ten (10) coranic schools (one school per region and three for the Niamey Urban Community) have been selected to serve as pilot coranic schools. Today, these ten schools have 5,243 learners, of whom 2,948 are female (representing 56.3\%). These schools provide renovated and harmonious teaching that give basic skills. Reorientation classes will be created for persons who leave these informal system schools to the formal system (médersa classique) and they will be initiated to productive practical activities.

\section{- Post-basic education}

\section{Basic Education 2}

145. In line with PDDE objective of developing opportunities for public basic education 2 (General education colleges, Secondary Education Complexes Cycle 1, French-Arabic Schools) to deal with inflow of pupils from basic education 1, the number of schools increased from 273 in 2002 to 460 in 2006. Most of these schools are built with make-shift materials and have no laboratories, libraries, infirmaries, fences and toilet facilities. Despite the increase in enrolment, there low development of private education with most schools concentrated in urban centres, particularly Niamey. The pupil enrolment in basic education 2 increased from 93,407 in 2002/2003 to 163,360 in 2005/2006. 
146. This increase, generated by an admission rate into college of about $71.4 \%$, has helped to increase the gross enrolment rate which rose from $12.97 \%$ in 2002 to $17.1 \%$ in 2006 . This apparent good performance of access should not conceal the low output of the system and its disparities (the GER for girls in this cycle is only $12.5 \%$ ). indeed, the BEPC success rate was only $11.97 \%$ in 2006 , while the repeater rate stood at $26.8 \%$ in 3ème (Form 4). Furthermore, there is a high drop-out rate among girls.

\section{Middle Education}

147. The enrolment in the middle school cycle increased from 11,712 in 2002/2003 to 24,726 in 2005/2006. The pass rate from "classe de Troisième" (Form 4) to "classe de Seconde" (Form 5) was $67.6 \%$ in 2006 as against $40.85 \%$ in $2001 / 2002$. The gross enrolment rate is $4.1 \%$; the rate for girls is $2.7 \%$ while that for boys is $5.9 \%$. Drop-outs are more frequent among girls, particularly in rural areas. Although this cycle is essentially intended to lead to higher education after the "Baccalauréat", barely $32.5 \%$ of enrolled students pass this examination.

\section{Higher Education}

148. Higher education is dominated by the public sector and concentrated in the capital (Niamey). The education is provided by Université Abdou Moumouni (UAM) which has 5 faculties and one higher teachers' training school (ENS), as well as several higher education institutes and schools. The introduction of the Licence/Master/Doctorat (LMD) system which should facilitate the mobility of students sharing of training programmes between institutions has not yet taken place. Admission rate into the university is low. In 2004, this rate was 73 students for 100,000 inhabitants, which is far below the sub-Saharan average (230 students for 100,000 inhabitants). The failure rates are structurally high in UAM, particularly the first cycle. In 2002, the overall failure rate was $54.6 \%$, with more than $64.47 \%$ in the first cycle.

149. These poor results in all the cycles have a negative impact on the internal efficiency of the system as a result of drop-outs and repeaters, and constitute wastage of resources allocated to the university.

150. Other factors also contribute to this poor internal success rate, in particular: (i) the unbalanced structure of the teaching corps; (ii) inappropriate programmes and teaching methods; (iii) inadequate teaching aids, in terms of quantity and quality; (iv) the inadequate teaching time as a result of university strikes; (v) inadequate lecture rooms and halls, amphitheatres and laboratory equipment in comparison to the growing number of students; (vi) the low number of textbooks in libraries; (vii) inadequate computer equipment and Internet connection.

151. Given this situation, the external output of higher education is low; students face difficulties in integrating into the formal sector of the labour market. University research is rather dormant in UAM and has contributed very little to national development, because of inadequate allocations and career incentives. Research is currently conducted mainly on an individual and isolated basis by lecturers isolated and mobilized by teaching activities.

\section{Vocational and Technical Education and Training (EFPT)}

152. Access to this type of education is limited. In 2005, it was provided in 11 public institutions (one technical high school, one vocational education high school, nine vocational and technical training centres) and 41 private institutions. Similarly, this type of education admitted $2.5 \%$ of secondary school students for a total enrolment of 4,608 students, with more than half (2.534) in private institutions. In the public sector, the number of students has fallen sharply, from 3,995 students in 1999 to 2,074 in 2004-05. Girls are under-represented in EFPT; their enrolment over the same period was estimated at 39\% (with $72 \%$ in private institutions) as against $44 \%$ for boys.

153. Until recently, training in government schools was concentrated in Niamey. However, now, all the eight regions have at least one government vocational and technical training centre. These centres are under-equipped and lack their own facilities. Former government institutions are relatively well equipped with facilities, but they are still not operating at their highest capacity, because of inadequate resources and teachers. In private institutions, the facilities are rather overexploited and inappropriate for education. Training opportunities in the EFPT sub-sector is mainly geared towards the tertiary sector and based on job descriptions which rarely exist in rural areas. Indeed, vocational and technical training for rural workers does not exist on the market. 
154. Lastly, it should be noted that all these types of education suffer from the following inadequacies: (i) inadequate training of teachers and educational support, (ii) teaching programmes not in line with the country's development needs, and (iii) poor performance of the administration.

\section{b) Health and Poverty}

155. It is generally accepted that high morbidity rate is an obstacle to productivity and economic growth. The health status is also an indicator of the quality of life and human development. Consequently, improving the health status and life expectancy of the populations, particularly in rural areas, is a fundamental objective of government policy and MDG achievement.

156. In this light, a Health Development Plan (PDS) (2005-2010) has been put in place to contribute to reducing maternal and child mortality, by Improving the effectiveness and quality of health care. Sustained efforts by the State, private sector and technical and financial partners in implementing various programmes of the health policy have helped to improve the results, even though the indicators remain generally low.

\section{Health and reproduction}

\section{Maternal health}

157. In order to improve maternal health, Niger, in collaboration with its partners, embarked in 2006 on the implementation of a road map to control maternal and neonatal mortality. Indeed, pre-natal consultations and cesarean interventions are now free. Delivery rates in health facilities which are the main factors of maternity with the least risk, is still very low (17.2\% in 2006); with very wide variations according to place of residence and region ( $8 \%$ of births in rural areas take place in health units as against $69.5 \%$ in urban areas). Furthermore, the percentage of births assisted by trained staff declined from $44 \%$ in 1998 to $33 \%$ in 2006. The proportion of women who put to birth with the assistance of medical staff increased from $15 \%$ to $18 \%$. Despite the significant improvement in the rate of prenatal consultations (46\% in 2006 as against $40 \%$ in 1998), maternal mortality remains high (648 per 100,000).

158. Achievement of the millennium development goal for maternal mortality may be undermined by the following constraints: (i) inadequate supply of quality health care and services, particularly in rural areas, (ii) low incomes of households, (iii) low level of education of women, (iv) problems of hygiene and sanitation, (v) high levels of malnutrition, (vi) socio-cultural practices, (vii) poor family planning, and (viii) high population growth.

\section{Family Planning}

159. The rate of use of modern contraception methods among married women increased slightly from $4.6 \%$ in 1998 to $5 \%$ in 2006. This limited performance is due mainly to low access by women to reproductive health services, limited accessibility to contraceptive products, pro-natalist behaviour ( $24.6 \%$ of married women want to have as many children as possible), inadequate information (16.2\%), the weight of stereotypes, socio-cultural and religious considerations. Nevertheless, there is a large proportion of women whose needs in family planning are not satisfied ( $15.8 \%$ for married women). This situation leads to a higher a total fertility rate (average of 7.1 children per woman in 2006 as against 7.5 children in 1998).

\section{Child health}

160. The vaccination coverage of $12-23$ months children has improved; the proportion of children completely vaccinated against the target diseases of the EPI increased from 18\% to 29\% between 1998 and 2006 . However, it varies greatly according to the place of residence with $25 \%$ in rural areas, $41 \%$ for the town of Niamey and $54 \%$ for other urban centres. Depending on the type of antigen, it is estimated by EDSN-2006 for measles at $47 \%$ (as against $35 \%$ in 1998), for BCG at $64 \%$ (as against $47 \%$ in 1998), for DTC at $39 \%$ (as against $25 \%$ in 1998) and for Polio at $55 \%$ (as against $24 \%$ in 1998).

161. However, since EDSN 2006 measures only progress made before 2005, the country made significant efforts between 2005 and 2006 in vaccination, particularly against measles and poliomyelitis; a combination of 
routine EPI and mass campaigns helped to reduce cases of measles drastically, from 63,913 declared cases in 2004 (with more than 420 deaths) to 478 declared cases in 2006 (with 4 deaths throughout the country). Concerning poliomyelitis, Niger was declared in 2005 as having broken the transmission of the aboriginal virus and is no longer one of the endemic countries.

162. Despite the progress, the health conditions are still a cause for concern. According to the EDS-MICS 2006 results, although infant mortality is reducing sharply, it is still high because it still stood at 81 deaths per 1,000 children from 0 to 11 months old in 2006 (as against 123 per 1,000 in 1998). Similarly, child mortality still stands at 198 deaths per 1,000 children from 0 to 59 months (as against 274 per 1,000 in 1998).

163. Among the target diseases of the Integrated Management of Childhood Diseases (IMCD) strategy, malaria is the most lethal disease among $0-5$ years old children with $52 \%$ deaths. Furthermore, the diarrheas that affect about $21 \%$ of children below 5 result in a significant proportion of the cases of deaths (10\%); the deaths are due to dehydration, late consultations and poor quality of care.

164. Achievement of the target of "reduction by $2 / 3$ of the mortality rate of children below five years" is hampered by the following factors: (i) inadequate health care and services, particularly in rural areas, (ii) low incomes of households (iii) low level of education of the mothers, (iv) hygiene and sanitation problems, (v) the high levels of malnutrition.

\section{Chart 4: Evolution of Mortality rate for Children below five years}

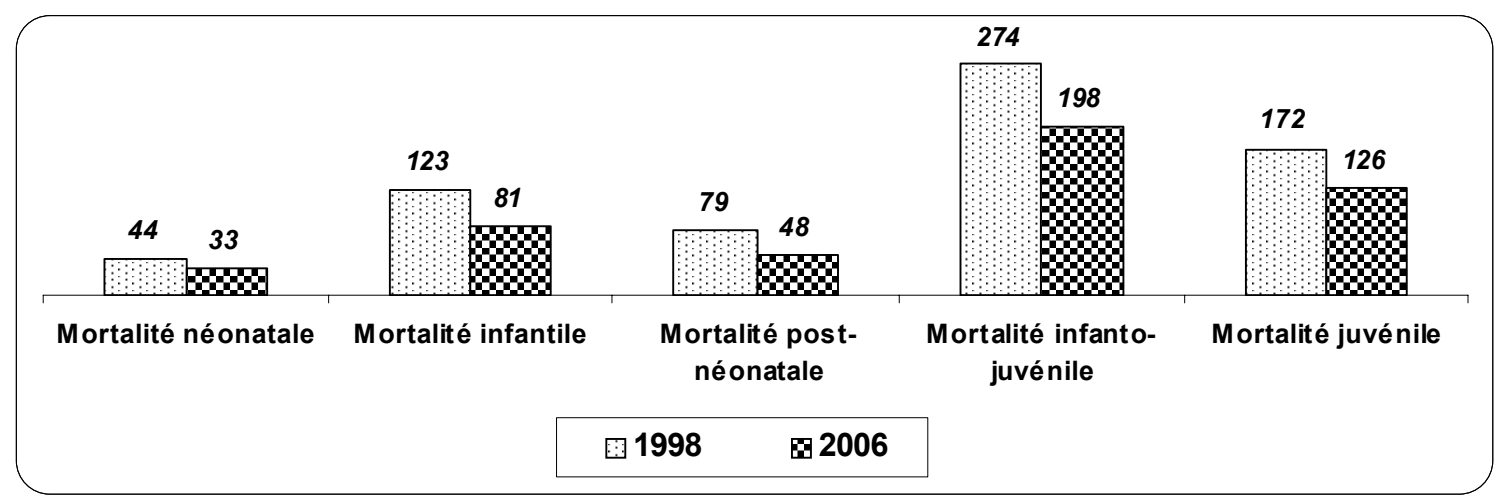

Source: ME/F/INS/EDS98-EDS-MICS2006

\section{Disease control and essential interventions}

\section{Malaria}

165. According to EDS-MICS 2006, malaria remains a major endemic disease (24\% of the consultations) and the primary cause of morbidity and mortality for women and children. It is the cause of about $30 \%$ of deaths for the entire population, of whom $52 \%$ are children below 5 years. The lethality rate due to malaria is 27 per thousand. Malaria cases stand at about 850,000 per year; however, in view of the low medical coverage $(42 \%)$, the incidence of malaria is greatly under-estimated. The use of mosquito nets treated with insecticides remains limited ( $13.3 \%$ for pregnant women, $14 \%$ for children below 5 years); $57 \%$ of household do not have them.

166. Indeed, (i) low medical coverage; (ii) inadequate sanitation infrastructures; (iii) the habits of the population; (iv) low incomes; and (v) limited access to treated mosquito nets are major constraints on the achievement of MDG 6 .

\section{Tuberculosis}

167. As regards tuberculosis, the screening rate has improved significantly, from $33.4 \%$ in 2001 to $43.6 \%$ in 2005 , representing nearly one-third increase. However, this rate is far short of the international target of $70 \%$ set by the WHO. The performance comes as a result of the improvement of laboratories, staff training, and regular supervision by district workers. The increase in the screening and treatment rate $(60 \%)$ remains low when 
compared to the WHO standard of $85 \%$. Constraints on the treatment of the disease concern: (i) the quality of services due to low geographic access; (ii) acceptability; (iii) availability of drugs; (iv) poor IEC; (v) high stigmatization of the disease.

\section{HIV/AIDS Control}

168. STI/HIVIAIDS control is organized under the national HIVIAIDS control strategic framework defined in 2002. Like most developing countries, AIDS control activities have mainly concerned prevention, care and advisory services with access to ARV, and socio-economic support to persons living with HIV (PLWHIV). The various activities have helped to maintain the AIDS prevalence rate at $0.7 \%$.

169. However, AIDS control activities are not adequately integrated into the minimum activity package of health units due to vertical management of the AIDS control programme. Similarly, no data on routing surveillance have been collected. In the other sectors, the situation is moderate, because consideration of AIDS in the sectoral planning process is limited to implementation of specific sensitization or staff training activities, without making efforts to anticipate the possible impacts of the epidemic on the sectors and populations in interrelation with them.

\section{Control of non-transmissible diseases}

170. Despite the creation of a Non-transmissible Diseases Control Division in the Ministry of Health, the strategies that have been developed remain inadequate; the strategies concern the use of iodized salt, micronutriments, treatment of female cancer and metabolic diseases (diabetes, hypertension). These strategies seek to promote access to health care for the most underprivileged groups in the society.

\section{$\underline{\text { Human and material resources }}$}

171. Obviously, much effort has been made over the past few years to improve the availability of human and material resources in health services. However, in view of the magnitude of needs in this sector, there are still many difficulties.

172. Indeed, the accelerated recruitment of doctors in 2005 more than doubled their numbers, increasing their relative number from 1 doctor for 72,781 inhabitants in 2002 to 1 doctor for 35,759 in 2005 (as against the WHO standard of 1 doctor for 10,000 inhabitants). The number of State-registered nurses increased slightly from one (1) nurse for 5,969 inhabitants in 2002 to one (1) nurse for 5,825 inhabitants in 2005, which is closer to the WHO standard of one (1) nurse for 5,000 inhabitants. As concerns midwives, their proportion increased from one (1) midwife for 29,685 women of child-bearing age in 2002 to one (1) midwife for 25,532 women of child-bearing age in 2005 , as against the standard of one (1) midwife for 5,000 women of child-bearing age.

173. However, these data do not take into account the existing geographical disparities; most of the health professionals are in big urban centres, leaving rural areas unserved. Indeed, Niamey has $33 \%$ of the total staff, and nearly $37 \%$ of the senior staff for $6 \%$ of the population; the other seven regional chief towns (less than $25 \%$ of the population) absorb $65 \%$ of the senior staff.

174. Equipment has been increased in health units. However, the equipment is not always distributed in an equitable manner. The lack of national standards for equipment at each level, as well as the lack of an updated inventory of existing equipment at the central and regional levels, makes it difficult to ensure equitable distribution.

175. The availability of drugs in operational services remains low, leading to lack of trust on the part of the users. This inadequacy is mainly due to the inability of the purchasing centre to ensure regular supply of products.

\section{Accessibility and use of health services}

176. Geographic accessibility to health services has been improved significantly over the past five years. The physical health coverage of the integrated health centres (CSI) alone increased from $47.6 \%$ in 2001 to $65 \%$ in 
2005. Furthermore, 2,111 health centres (CS) have been constructed, including 160 that are being transformed into CSI.

177. However, according to the QUIBB results, $39 \%$ of the populations take more than 30 minutes to go to health centres and $24.3 \%$ to clinics and hospitals. Furthermore, there are shortcomings due mainly to: (i) lack of the minimum activity package (PMA) in most of the health centres; (ii) slow services in some health centres due to inadequate staff; and (iii) lack of a national health map.

178. As regards use of health services, the results of the QUIBB survey 2005 show that $68.2 \%$ of sick or injured people turn to health services. The utilization rate of curative consultation (new cases per inhabitant and per year) has remained constant over the past few years; it has even decline, in view of the improved geographic accessibility estimated at $65 \%$. This situation is due mainly to the inadequacy of services offered by the health centres and new CSIs and the relatively high cost of consultation ( $29.4 \%$ of patients give this reason, particularly in urban areas).

179. Furthermore, of all the persons consulted, only $6.2 \%$ said they were satisfied with the services received The inadequate quality of health care is due to inadequacy of human resources in terms of numbers and their distribution according to the administrative levels and health structures, as well as between urban areas, rural areas and the regions. The low quality is also due to: (i) inadequate or very old equipment; (ii) unavailability of drugs ; (iii) inadequate consumables in the health centres; (iv) inadequate funds; (v) non-implementation of the minimum activity package (PMA) by all the districts; (vi) limited use of the standard protocol; and (vii) inadequate supervision of staff.

180. Lastly, the lack of a national training plan and coordination between the national health programmes and initial training of Public health Schools and the University is a major cause of the problems of quality in clinic services.

\section{Health information system}

181. Statistics on the health sector are produced by the National Health Information System (SNIS). The SNIS was established in 1994 to provide policy makers, health officials and partners with reliable quality information for decision-making. Despite the assets of the SNIS, it has, for the past few years, encountered problems in carrying out its mission in the collection, processing, archiving and dissemination of data. Indeed, the following difficulties could be mentioned: (i) too much mobility of staff and low capacities; (ii) inadequate material resources; (iii) high dependence on external resources; (iv) failure to integrate some public data (vertical programmes, hospitals, etc.) ; (v) inadequate facilities for collection of information; and (vi) delays in the transmission of data from field structures.

\section{(c) Nutrition and poverty}

182. The nutrition situation in Niger is marked by the persistence, for the past ten years, of a state of emergency, with acute prevalence of malnutrition higher than the intervention threshold of $10 \%$ and the emergency threshold of $15 \%$ for some years. Malnutrition is systemic by nature; it is frequent in some regions of the country with high rates for the chronic and severe forms. It is mainly the result of social behaviour, poverty and recurrence of food crises. It affects a high proportion of children. Notwithstanding the existence of a National Nutrition Enhancement Plan and a Nutrition Management Protocol, malnutrition causes $59.3 \%$ in child mortality.

183. The proportion of underweight children below 3 years still stood at $43 \%$ in 2006 (as against $50 \%$ in 1998), that of children with stunted growth (chronic malnutrition index) increased from $41 \%$ in 1998 to $45 \%$ in 2006, while tendency toward emaciation (conjunctural malnutrition index) is on the decline (13\% in 2006 as against $21 \%$ in 1998). These rates are higher for boys than for girls, and higher in rural than urban areas. The prevalence of chronic undernutrition is above $40 \%$ in six of the eight regions of the country, and is above $59 \%$ in Maradi and Zinder regions. The highest infant mortality rates are recorded in regions where the infant undernutrition rates are also highest.

184. The proportion of children below 5 years with stunted growth stood at 50\% in 2006 (51.4 \% for boys and $48.5 \%$ for girls). The emaciation level is high for children below five years with $10.3 \%$ ( $11.2 \%$ for boys and $9.4 \%$ for 
girls) while underweight affected $44.4 \%$ of children below five years. One of the major causes of malnutrition among children is the low rate of exclusive breastfeeding of babies up to the age of six months (14\%). It should be noted that parents do not always have a correct perception of the phenomenon since at least one-third of them perceive the phenomenon of malnutrition among their children.

185. Furthermore, a relatively high proportion (19\%) of women suffers from chronic energy deficiency. This could be a risk factor during pregnancy. On the other hand, $13 \%$ of women are classified as overweight, and this could foster the development of certain diseases (diabetes, obesity, hypertension, and cardio-vascular diseases). Furthermore, nearly one woman out of every two is anemic (46\%) as against $24 \%$ for men. The consumption of nutritive supplements is low among pregnant women is low (22\% for the consumption of vitamin A and $45 \%$ for iron).

\section{(d) Access to drinking water and poverty}

186. As part of activities during the International Drinking Water Supply and Sanitation Decade (IDWSSD) (1981-1990), the water and sanitation sector has undergone major changes, with in particular the revision of the Water Resources Development and Management Master Plan in 1998 and adoption of a Water and Sanitation Policy and Strategy Paper in October 2000. The water resources policy, planning and development instruments were supplemented by the adoption of rural and urban water supply policies.

\section{$\underline{\text { Access }}$}

187. At the national level, the access rate of households to drinking water is $68.7 \%$ in 2005 as against $43 \%$ in 2000. In urban areas, this rate is $96.7 \%$ as against $60.3 \%$ in rural areas. The main source of drinking water supply for the entire country is wells. Indeed, $60.8 \%$ of households use this source of supply $(42.8 \%$ use unprotected wells and $18 \%$ use protected wells). In rural areas, the proportion of households that use unprotected wells is high $-50.8 \%$. At the regional level, there are wide disparities in tap water supply. While in Niamey more than 6 households out of $10(65.3 \%)$ use this source, in the other regions of the country less than half of the households use it.

188. Furthermore, nearly $57 \%$ of households take more than 15 minutes to fetch water. The disparities are wide, depending on the place of residence. The current number of modern water points in rural built-up areas and the quality of water service force the population, particularly women, and to a lesser extent, youths, to spend more time on fetching water. This leads to a shortfall in production and poor school attendance for the children. Thus the fetching water takes up much of the time of women and girls; this limits their access to social, economic and political opportunities that can help them to get out of poverty.

189. The coverage of water needs in rural areas increased from $55 \%$ in 2001 to $59 \%$ in 2005 . However, due to the non-functioning of some structures, the real rate is estimated at about $47 \%$. As at 31 December 2005 , Niger had 25,112 modern water points, including 13,672 cemented wells, 7,167 boreholes equipped with mandriven pumps, 501 mini-drinking water supply structures, 51 autonomous water stations and 21 pastoral water pumping stations. In urban areas, the coverage of water needs increased from $65 \%$ in 2001 to $80 \%$ in 2005 .

\section{Institutional reforms}

190. The option to empower all the stakeholders of the water sector is reflected by:

- the restructuring of the urban water supply sub-sector with the creation of the "Sociéte de Patrimoine des Eaux du Niger" (SPEN, a State water corporation) and the "Société d'Exploitation des Eaux du Niger" (SEEN, a private water company bound to SPEN by a leasing and performance contract) in 2001;

- the creation in 2006 of the National Water and Sanitation Board (CNEA), an advisory and consultation organ, that provides assistance in defining the objectives and orientations of the national water and sanitation policy;

- the adoption of a water supply infrastructure management policy involving gender-sensitive village committees and private operators, particularly as regards mini-drinking water supply structures. 


\section{Livestock watering}

191. The problem of livestock watering is acute in pastoral areas $\left(227,000 \mathrm{~km}^{2}\right)$, particularly during the 9 months of the dry season, and also due to the fluctuating and unstable context of poorly assessed fodder potential. In addition to the major technical constraints of time changes and area dispersion, pastoral water supply is subject to none less important constraints at the socio-economic level (difficulty of assessing the cattle population from the stockbreeders), institutional level (two ministries, one of which is the project owner and the other principal contractor of water points, sharing the activities of the sub-sector) and socio-cultural level (individual or family or resident group ownership of the water point and space), which are specific to livestock in the pastoral zone.

\section{$\underline{\text { Water resources }}$}

192. With respect to water resources, the irregular rainfall, the extremely difficult hydrogeological context of some regions, and the excessive depth of access to the most productive level of underground water are natural constraints likely to limit the development of the huge water potential $\left(2,000\right.$ billion $\left.\mathrm{m}^{3}\right)$ because of the high costs of water control structures.

\section{(e) Urban development, housing, sanitation and poverty}

\section{Urban development}

193. Long considered as a rural country, Niger has not been left out of the urbanization process. The authorities' option to transform some small entities into towns was an important factor in post-independence urban development.

194. The overall urban structure is heterogeneous, with towns of very unequal size. Most of the urban centres are located in the southern trip of the country which has the highest agricultural potential; the urban structure is still very unbalanced.

195. According to analyses of the General Population and Housing Census of 2001, the classification of towns, based on their population, is as follows:

- eight (8) "small towns" (less than 10,000 inhabitants);

- twenty-nine (29) "average-size towns" (from 10,000 to 99,000 inhabitants);

- two (2) "big towns" (from 100,000 to 499,000 inhabitants);

- one (1) "city" namely Niamey the capital with 707,951 inhabitants in 2001.

196. The major characteristics of urbanization in Niger are:

- the economic, social and cultural gap between the urban centres;

- extremely high concentration of the population in on large centre, Niamey (39.4\% of the urban population) ;

- urban growth mainly causes irregular occupancy and building, particularly in Niamey.

197. In the 90s, population growth accelerated particularly in towns and regions conducive to trade, agriculture and stockbreeding. The proportion of urban population in the total population was trippled between 1960 and 2001 ; the urbanization rate increased from $5.2 \%$ to $16.2 \%$.

198. This increase in Niger's population in urban centres is due mainly to ecological crises ${ }^{1}$, poverty and mining. The rural populations hope to enjoy better living conditions by migrating to towns. However, they increase the social expenses of the municipalities receiving them. Social demand for infrastructures (schools, health services, housing) and sanitation (roads, waste disposal system, etc.) increases, while the available resources become scarce. Social investments then become inadequate, in a context of scarcity, or even reduction of

\footnotetext{
${ }^{1}$ Alpha Gado Boureima, 1998; Moha Hadiza, 1996 ; and Motcho Kokou Henry, 1996 ; Harouna, 2002
} 
national resources (the sector is financed mainly by internal resources). Urban facilities and jobs cannot keep pace with the population growth.

199. Consequently, even though urban poverty is less than rural poverty, the living and housing conditions in the suburban quarters are increasing precarious, a situation fostered by the shortage of employment and lack of infrastructure, basic facilities and housing. Indeed, the big towns in Niger increasing appear as large conglomerations with abject poverty in which the populations face enormous difficulties in obtaining decent housing and basic infrastructures (education, health, water, hygiene, sanitation, transport, etc.) and in which there are high rates of unemployment and social exclusion.

200. The urban planning policy is based particularly on:

- the definition of a framework in which each town (more than 10000 inhabitants according to the Economic and Social Development Plan (PDES) 1979-83) will develop in the medium and long terms: the Development and Town Planning Master Plan (SDAU);

- the programming, on this occasion, of priority investment actions (housing, equipment, infrastructure, etc.): the Priority Public Action Programme (PAPP);

- the establishment of a monitoring and implementation at the national level: the National Town Planning Workshop (ANU).

201. Accordingly, SDAUs have been prepared for the towns of Niamey, Maradi, Zinder, Tahoua, Dosso, Agadez and Mirriah. However, it should be noted that these town planning documents have, to a large extent, not been implemented and their time frames have expired. Furthermore, the high cost and delays in the studies made it difficult for the Government to prepare these tools for the other urban centres.

202. After drawing lessons from the town planning policies implemented over the 1980-1990 period, the public authorities decided to : (i) prepare and implement a new town planning reform by adopting Ordinance No. 97-005 of 17 January 1997 instituting provisional and operational town planning, as well as urban space utilization control tools and its implementing decrees; (ii) develop, test and disseminate the new simplified tools for town planning and urban investment programming, including council investments.

203. Furthermore, in order to remedy the inadequacies identified in the first version of the PRS, the Government adopted a National Urban Development Strategy (SNDU) in October 2004.

Housing

204. In Niger, due to the high concentration of the population in some areas and widespread poverty, households face enormous difficulties in obtaining decent housing and a healthy environment. Houses have been constructed by the Government and its related services in occasional operations in urban areas; from 1960 to date, the total number of houses is below 1,500, in addition to the construction of 551 housing units in Niamey during the $5^{\text {th }}$ Francophonie Games in December 2005. The housing loan granted by CREDIT DU NIGER (CDN), which is the sole financing institution in this sector since 1966 is low and targets only wage earners. Consequently, most of the houses are acquired through self-construction. In rural areas, a little more than nine households out of ten (94.2\%) are owners of their houses; on the other hand, tenant households live mainly in the Niamey Urban Community (48.6\%) while in the other urban centres, households who own their houses account for $63.9 \%$.

205. The private rental market also provides houses to households. As regards the improvement of existing housing, mention should be made of an operation to rehabilitate an old quarter in Niamey (YANTALA) with financing form some partners ${ }^{1}$ and the Government of Niger. This operation has helped to improve the housing conditions of the populations living in this quarter.

206. As concerns rural housing, interventions by the "Construction without wood" project have helped to reduce housing insecurity, by using earth instead of straw materials while preserving the environment. However, these constructions have been limited only to certain areas.

\footnotetext{
1 UNCDF, UNDP and WFP
} 
207. Earth (clay/earth) remains the most widely used material in building roofs $(58.5 \%)$; although straw roofs are less expensive, they account for $26.6 \%$ of roofs, while roofs in corrugated iron sheets are very few $(6.4 \%)$. Similarly, earth (earth/clay) is the building material most widely used by households $(76.2 \%$ of the households use it for the walls). This predominance is both observed in rural areas (78.6\%) than in urban areas $(64.2 \%)$, which show some extent of housing insecurity. Houses of cement/concrete account for only $4.2 \%$. Insecure housing exposes the population to weather hazards and natural disasters and limits their economic and social development.

208. In view of the inadequacies, Law No. 98-54 of 29 December 1998 on the National Housing Policy has been adopted to serve as reference framework in housing. Its implementation should, in particular, ensure the right to decent housing for all through: (i) the creation of a national housing fund, (ii) the creation of a housing bank, (iii) the creation of an urban rehabilitation and development agency, (iv) the institution of housing cooperatives and housing saving societies, (v) the promotion of housing loans by commercial banks, (vi) the promotion of private investment in the housing sector, and (vii) the promotion of home savings. However, most of these actions are still to be carried out; only the creation of a Housing Bank has been initiated with the current privatization of CREDIT DU NIGER.

\section{Sanitation}

209. Efforts are currently being made to implement a coherent policy in the sanitation sub-sector, particularly between the Ministries responsible for Town Planning, Housing, Surveys, Water Supply, the Environment, Health and Control of Endemic Diseases. Furthermore, a National Urban Environmental Management Strategy was adopted in 2001, and has led to the conduct of twelve (12) sectoral studies on urban environment.

210. However, according to the QUIBB survey, $78.4 \%$ of households do not have adequate toilets; the natural surrounding/bush is the most common place where people ease themselves. It is mainly in rural areas that people frequently ease themselves in the natural surroundings (about $90 \%$ of households) whereas in urban areas latrine seem to the most commonly used ( $62.7 \%$ of households outside Niamey); in Niamey, the use of latrines stands at $75.2 \%$. These proportions remained unchanged between 1998 and 2006 . As regards sanitation in rural areas, the access rate to infrastructure was $5 \%$ in 2004 . Furthermore, the proportion of households with access to an adequate sewage disposal has increased slightly; it increased from $18.1 \%$ in 2000 to $19 \%$ in 2006 .

211. Furthermore, household refuse disposal remains a crucial problem, particularly in urban areas; refuse is very often dumped around houses or sometimes in the few dustbins. Only $47 \%$ of the refuse is collected by the municipal councils and $10 \%$ are taken to the dumps, and no municipal council treats the waste.

212. Management is therefore poor at the level of sorting, on-site handling, organization of municipal refuse collection and waste treatment. Furthermore, the storm and wastewater drainage sub-sector suffers from lack of maintenance and old age of the infrastructure and facilities. The situation has negative impacts on the health of the populations.

213. To mitigate the serious threats of urbanization on the environment and ensure proper sanitation, urban development master plans (SDAU) have been prepared for the towns of Niamey, Maradi, Zinder, Tahoua, Dosso, Agadez and Mirriah, coupled with sanitation master plans (SDA) for the towns of Niamey, Tahoua, Maradi and Zinder. However, it should be noted that these town planning documents are not always respected, and are often even out of date. This situation has negative impacts on public health, and increases the risks of diseases (diarrhea, malaria, etc.).

214. Generally speaking, achievement of the targets of MDG7 is hampered by constraints relating to: (i) population growth, (ii) low financial allocations to the sector, (iii) social habits and behaviours of the population, and (iv) low incomes.

\section{(f) Access to modern energy services}

215. Niger's energy consumption is low; the energy consumption per inhabitant is estimated at 0.14 tep as against an African average of 0.5 tep. Indeed, the main source of lighting in households in Niger is kerosene ( $80.1 \%$ of households light their homes with this fuels, with $84.4 \%$ in rural areas and $59.1 \%$ urban areas). The 
gas/batteries/candles/wood group is the second source of lighting in Niger with $10.4 \%$ of households, followed by electricity which is limited to urban areas and concerns $38.7 \%$ of households. However, there has been a relative improvement in access to electricity over the past few years; the access rate to electricity at the national level increased from $6.7 \%$ to $9.3 \%$ between 1998 and 2006 .

Chart 5: Trend of Access to Electricity between 1988 and 2006

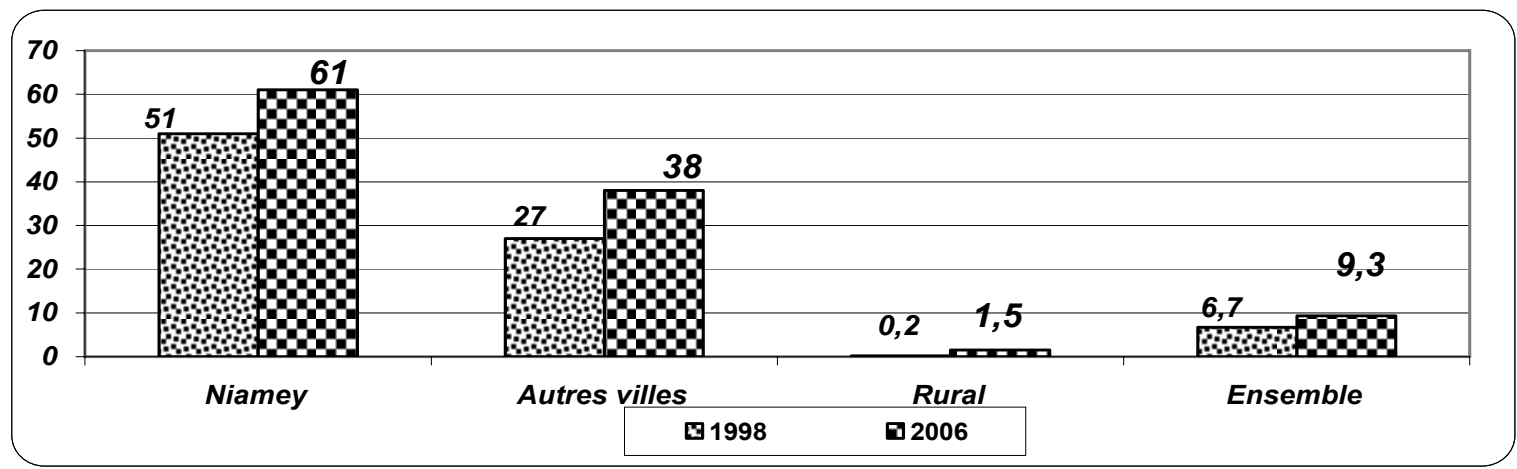

Sources: INS/MEF EDS 98 et 2006

216. Nearly all households (96.4\%) use wood/charcoal as the main cooking fuel. Electricity and kerosene are not much used by households $(0.1 \%$ and $0.9 \%$ respectively). This situation contributes to the increasing deforestation of the country. Generally speaking, in rural areas, women are responsible for fetching wood, and they are forced to cover increasingly long distances to obtain daily supplies. In the effort to promotion energy sources to replace wood, 40,000 improved fireplaces, 10,000 "TCHIP" kerosene stoves and 20,000 gas stoves have been disseminated. In 2004, a national campaign for the popularization of mineral coal was launched. In 2005, the "Société Nigérienne de Carbonisation du Charbon mineral" (SNCC) was established, thereby leading to the production of 800 tonnes of impregnated mineral coal, and 5,190 fireplaces between 2005 and 2006 . Similarly, the Société Nigérienne du Charbon de I'AZAWAK (SNCA-SA) was established in July 2006 to strengthen the capacity of national electricity production (200 MW) and mineral coal production for domestic purposes.

\section{(g) Employment and Poverty}

217. The unemployment rate is officially estimated at $16 \%$; it is higher in urban centres (19.4\%) than in rural areas $(15.2 \%)$. Women are more affected by unemployment with a rate of $25 \%$ against nearly $12 \%$ for men; the 15 - 29 age group records the highest rate (24\%). The people most exposed to unemployment are those with relatively low level of education. Furthermore, the population of child workers stood at more than $15 \%$ of the working population. This situation is partly due to the poverty of households which forces them to take away their children from education structures; this leads to a decline in the quality of labour and a vicious cycle of poverty. Accordingly, $57.6 \%$ of the children work when they are not educated.

\section{Table 12: Unemployment Rate by Region}

\begin{tabular}{|c|c|c|c|c|c|c|c|c|}
\hline Agadez & Diffa & Dosso & Maradi & Tahoua & Tillabéri & Zinder & CUN & Total \\
\hline 7.22 & 25.21 & 14.72 & 12.02 & 23.08 & 9.89 & 11.78 & 22.03 & 15.9 \\
\hline
\end{tabular}

Source: QUIBB_2005_INS_MEF_ «Etude emploi, chômage et pauvreté au Niger »

218. Furthermore, the under-employment rate is very high; it stands at $34.62 \%$, with $38.33 \%$ for women and $32.93 \%$ for men. Underemployment concerns mainly the rural populations $(86.3 \%)$ because of the seasonal nature of farming.

219. There is structural mismatch between job applications and offers because of the high population growth and the structural deficiency of job offers, particularly due to the following aspects: (i) archaic production methods, particularly in the rural sector, (ii) the embryonic nature of the secondary sector, and (iii) lack of organization of the informal sector. 
220. Generally speaking, job offers are declining while applications are increasing steadily, stimulated by high population growth. According to the National Employment Promotion Agency, in 2005 only 27\% of job applications were unfilled (against 19\% in 2000).

221. Jobs in the public services are declining steadily because of the reforms required in efforts to control the payroll (freeze on recruitment, reduction of the retirement age, etc.); the staff strength reduced by $13.3 \%$ over the 2000-2005 period; this had an impact of the quality of public service.

222. The urban informal sector, which handles about $15 \%$ of the urban working population, is growing rapidly, particularly in the transport, trade and building sectors. However, jobs in these sectors are not secure, unskilled, and unproductive with very low incomes; hence the permanent vulnerability of the actors.

223. The promotion of alternative and/or complementary activities to agriculture (income-generating activities, utilitarian handicraft) as well as remunerated mobilization of labour for collective utility works has been developed, particularly under the Special Programme of the President of the Republic.

224. Consequently, the employment challenges are mainly of two types: (i) employ the population outside the farming season (eight to nine months of the year) and (ii) offer jobs to the urban populations, particularly young graduates. Indeed, providing a lasting solution for job applications from youths from school is obviously a condition for preserving the future and opening better prospects for the youths of Niger.

\section{(h) Access to Credit and Poverty}

225. Difficult access to credit is a significant dimension of poverty. Indeed, most of the poorest, particularly actors in the primary sector, are unable to fulfill guarantee conditions.

226. Furthermore, interest rates are high in comparison to the low profitability of their activities. The QUIBB survey shows that, at the national level, households with members who borrowed money or goods account for only a little above one-quarter $(25.6 \%)$ of Niger households.

227. This proportion is higher in rural areas ( $27 \%$ of rural households) than in urban areas ( $16 \%$ in Niamey and $21 \%$ in the other towns). At the national level, $67 \%$ of loans are granted by relatives or friends and $20 \%$ by another individual. Accordingly, only $12 \%$ of loans are granted formally by a private bank (1\%), a micro-finance institution $(7 \%)$, a cooperative $(2 \%)$ or an enterprise $(2 \%)$. Furthermore, there are wide disparities between the genders for access to credit. 
Box 4: Progress made by Niger in Achievement of some MDGs

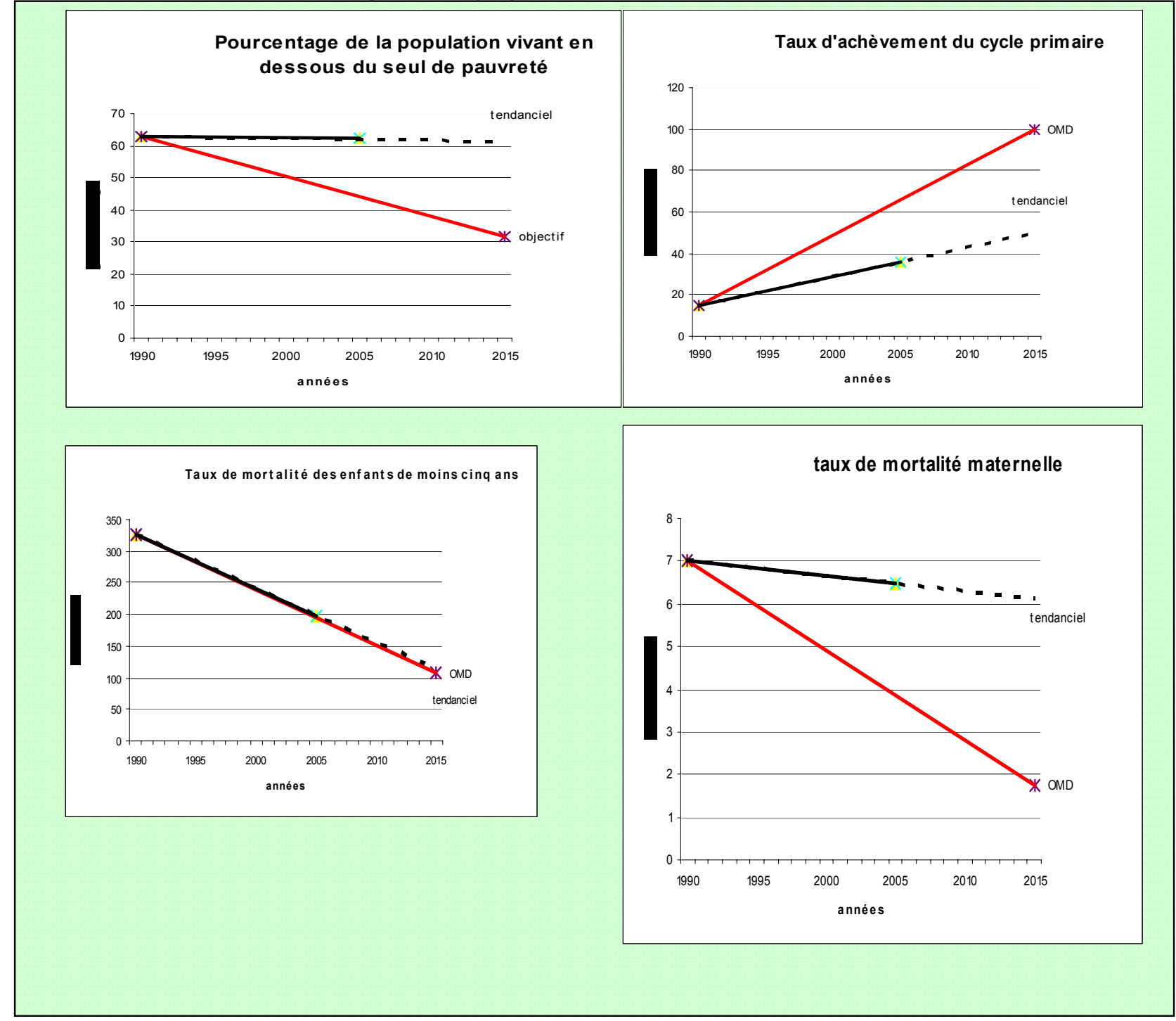

\section{I.3.3. Population and Poverty}

228. Conscious of the high population growth and its effects on development efforts, Niger in February 1992 adopted a National Population Policy (PNP) which was assessed in 2005. The expected results of the PNP consisted in controlling population growth and adapting it to that of the economy mainly by reducing the morbidity, mortality and fertility indices. Since 2005, Niger has embarked on the preparation of a new national population policy and a multi-sectoral population programme (PRODEM).

\section{Evaluation of the PNP}

229. An evaluation of the PNP highlighted the low level of achievement of the expected results, with in particular an acceleration of population growth higher than the average economic over the period, notwithstanding the implementation off some sensitization, training and capacity building activities. 
230. Specifically, mention could also be made of:

- inadequacies related to the conceptual framework, particularly the orientation of general principles and the failure to quantify the set objectives;

- difficulties related to implementation, due to socio-political and institutional instability which hampered the coordination of operations in the implementation, monitoring-evaluation and sustainability of the activities;

- inadequate capacities of civil society organizations to implement population-related programmes.

\section{$\underline{\text { Population situation }}$}

231. The population of Niger stood at nearly 13 million inhabitants in 2006 (BCR, 2005). The population structure shows a high proportion of youths $(47.6 \%$ below 15 years as against $4.5 \%$ above 60 years) and nearly perfect equal proportion of women and men (49.9\% and $50.1 \%$ respectively). The population is unevenly distributed over the national territory, with a high density on arable lands on the south-west strip of the country (100 inhabitants per $\mathrm{km}^{2}$ in some departments, as against national average of 8 inhabitants per km2). Agadez and Diffa regions, which cover more than $2 / 3$ of the total surface area of the country, have only nearly $6 \%$ of the total population, while Dosso and Maradi regions, which are smaller, have one-third of the total population. The urbanization rate is relatively low $(16.3 \%)$ with a high concentration of the urban population in the capital $(39.4 \%)$.

232. The exceptionally high population growth rate $(3.3 \%)$ is due to the continued high level of fertility $(7.1$ children per woman according to EDS-MICS 2006) and a decline in infant mortality (from 123 per thousand in 1998 to 81 per thousand in 2006). According to the results of the EDS-MICS 2006 survey, there are very wide gaps in the total fertility rate depending on the level of education of the women, and ranging from a minimum of 4.6 children per woman for those with secondary education level to more than 7.3 children for those without education. Lastly, the total fertility rate varies significantly according to whether the women belong to rich households ( 6.2 children) or poor households ( 8.0 children).

233. Continued high fertility in Niger is due to a number of factors among which traditional values and beliefs play a key role: (i) the high level of child mortality encourages many births in the hope of making up for the deaths; (ii) the high proportion of marriages due to the importance of some cultural values, low rate of girls education and low incomes of most households.

234. Marriage is widespread ( $97.4 \%$ of women of child-bearing age are married) and early ( $60 \%$ of girls from 15 to 19 years are married, as against $17 \%$ in Benin and only $12 \%$ in Morocco). The median age at first marriage is 14.9 years for girls and 24 years for boys; (iii) the use of contraceptive methods is low $(11 \%$, with $5 \%$ for modern methods) due to a decline in postpartum insusceptibility, limited availability of modern contraception services, difficult access to contraceptive means and inadequate information and education. This situation is all the more disquieting as the ideal number of children (nearly 9 children for the women interviewed) is significantly higher than the total fertility rate. 


\section{Box 5: Potential Impacts of Population Growth}

Recent population projections show that if the current trend is maintained, Niger's population would increase from 13 million inhabitants in 2006 to 17 million in 2015, and the number of expected annual births would increase from about 600,000 in 2005 to 800,000 in 2015. This high rate of population growth would lead to an explosive potential demand in all the social sectors (education, health, food security, employment, housing, drinking water, hygiene and sanitation, etc.) and high pressure on the physical natural resources.

- $\quad$ As regards agriculture and food security, cereal requirements would increase from about 3 million tonnes in 2005 to 4.2 million tonnes in 2015 , while the requirements are currently covered only to the tune of $85 \%$. The cultivable area per inhabitant would decrease from 1.45 ha in 2005 to 1.12 ha per inhabitant in 2015 , with a decline in the quality of land due to the disappearance of fallowing. The increase in the number of farmers without land is possible due to the reduction in available lands and lack of capital for the most vulnerable groups. Efforts should be made to provide safety nets for this population.

- $\quad$ As regards the physical environment, the growing need for firewood (more than $90 \%$ currently) would reduce the available forest area by $3.5 \%$ per year.

- In education, the total number of children for enrolment in the basic education cycle 1 (7-12 years) would increase from 2.3 million in 2005 to 2.9 million in 2015 , and thereby require the construction of at least 15,000 classrooms and the recruitment of as many teachers over the period.

- As regards health, with the increase in the number of women of child-bearing age, in particular and the number of children to be vaccinated, it would be necessary to train and recruit at least five hundred $(500)$ doctors more, nearly four hundred $(400)$ midwives and one thousand $(1,000)$ State registered nurses over the period; the same applies to the logistics required for the complete vaccination of children aged $0-5$ years whose total number would increase by nearly one million over the $2005-2015$ period.

- $\quad$ As regards employment and activity, in light of the projected trend of dependency ratios and occupancy rates over the next decade, one employed worker would take charge of at least two persons who are not in active employment.

- $\quad$ As regards urban development, the high urban population growth rate (3.9\% as against a national average of $3.3 \%)$ would lead to higher demand for sanitation infrastructure and low-cost housing.

- $\quad$ As regards access to drinking water, as a result of population growth which would generate requirements estimated at 1,300 modern water points per year, the investment prospects for the construction of 1,000 water points per year over the next three (3) years, will make it impossible to achieve the objective of access to drinking water for the rural populations, as defined in the MDGs. With respect to urban water supply, the current urban population growth rate, the annual quantity of drinking water require would increase from 48 million m³ in 2000 to 105 million $\mathrm{m}^{3}$ in 2009 and 153 million $\mathrm{m}^{3}$ in 2015.

Source: Studies on the sectoral impacts of population growth, DP/MPAS

\section{I.3.4. Inequalities, vulnerabilities and poverty}

\section{a) Inequalities, gender disparities and poverty}

235. Inequality is a wider concept than poverty which perceives the well-being of an individual (man or woman) or a household in terms of the relative position of the individual or household within a given group (household, community, population) or the role they play. It is the outcome of equitable distribution of resources, potentials, opportunities and capacities. It is notion closely linked to poverty on which it also has negative impacts.

236. It occurs in the following dimensions: (i) income/consumption distribution; (ii) differences between living conditions (health, education, feeding, housing, etc.); and (iii) potentials (initial physical, human, and social capital for individuals). Women, youths and children, in particular, suffer from inequalities.

237. The issue of inequality, which was not analyzed in the first PRS, is an innovation which helps to deepen knowledge of the phenomenon of poverty and identify growth-oriented activities in poverty reduction. Indeed, inequality helps to worsen poverty in almost all countries in the world. The aggravating impact of inequality on 
poverty reduces the favorable impact of growth. That is why growth promotion policies should be accompanied by redistributive measures to limit the negative impacts of inequality. Furthermore, income-generating economic activities contribute in various ways to inequality.

\section{Box 6: Growth, Inequalities and Poverty}

According to recent studies, two dimensions (growth and redistribution) are important in poverty reduction. In light of the empirical results, the impact of growth on variation of poverty tends to be higher than that of redistribution.

However, sometime the impact of growth declines to the point of being dominated by that of redistribution, making it difficult to establish an order of priority between the two dimensions. That is why it is preferable to make the factors of « growth» and «redistribution» simultaneously favourable to poverty reduction.

In this light, for growth to generate rapid favourable impacts for poverty reduction: (i) such growth should be strong or be generated mainly by sectors in which the poor are most concentrated; (ii) appropriate redistributive policies should be implemented through, for example, taxation or targeted transfers, cash or in kind, to promote the redistribution of the fruits of growth to the poor; such transfer policies are necessary when the country has a regressive redistribution unfavourable to the poor.

Source: Samuel Kaboré, Relation between, growth and inequalities, March 2005

\section{Source of income and inequalities in Expenditures}

\section{- Source of Income}

238. In the QUIBB survey, there are five main groups of sources of income as follows: (i) farm income, (ii) wages and salaries, (iii) grants and transfers, (iv) property income, and (v) other non-farm income. Subsistence farming is the highest income item, accounting for nearly $30 \%$ of the total income of households. The relative proportion of livestock in the country's total income is estimated at $10 \%$. Salaries and wages account for only $15.8 \%$ of the total income $(7.9 \%$ for the public and semi-public sector, $4.6 \%$ for the modern private sector, and $3.6 \%$ for the other sectors). The three other sources of income account for more than three-fifths of the total cash income of households; they include property income (3.6\%), grants and transfers $(15 \%)$, and the aggregated group of the non-farm income (24\%).

Table 13: Breakdown of cash and non-cash Income by Source

\begin{tabular}{|l|r|}
\hline \multicolumn{1}{|c|}{ Source of Income } & \multicolumn{1}{|c|}{ Proportion (in \%) } \\
\hline 1. Farm income & $\mathbf{4 1 . 6}$ \\
\hline Income from subsistence farming & 29.8 \\
\hline Income from livestock & 9.7 \\
\hline Income from fisheries & 0.4 \\
\hline Industrial farm income & 0.9 \\
\hline Other farm income & 0.8 \\
\hline 2. Wages and Salaries & 15.8 \\
\hline Public and semi-public salaries & 7.9 \\
\hline Modern private sector wages & 4.6 \\
\hline Wages from other private activities & 3.3 \\
\hline 3. Grants, transfers and other income & 15.0 \\
\hline 4. Interest, rents and property income & 3.6 \\
\hline 5. Other income from non-farm activities & $\mathbf{2 4 . 0}$ \\
\hline \multicolumn{1}{|c|}{ Total } & $\mathbf{1 0 0}$ \\
\hline
\end{tabular}

Source: ME/F/INS/QUIBB_2005

\section{- Inequalities in expenditures}

239. In Niger, the $20 \%$ poorest people make only $8.6 \%$ of total expenses, while the $20 \%$ wealthiest people make $42.5 \%$ of total expenses. In other words, consumer expenditures for the $20 \%$ poorest people account for only one-fifth of the consumer expenditures of the $20 \%$ wealthiest people. 
Table 14: Proportion of Consumer Expenditures in the Total Expenditure by Quintile

\begin{tabular}{|l|c|c|c|c|c|c|}
\hline & $\begin{array}{c}\text { 1st } \\
\text { Quintile }\end{array}$ & $\begin{array}{c}\text { 2nd } \\
\text { Quintile }\end{array}$ & $\begin{array}{c}\text { 3rd } \\
\text { Quintile }\end{array}$ & $\begin{array}{c}\text { 4th } \\
\text { Quintile }\end{array}$ & $\begin{array}{c}\text { 5th } \\
\text { Quintile }\end{array}$ & Total \\
\hline Total Expenditures (million) & 144000 & 209000 & 264000 & 348000 & 714000 & 1679000 \\
\hline $\begin{array}{l}\text { Proportion in total } \\
\text { expenditures }\end{array}$ & $8.6 \%$ & $12.5 \%$ & $15.7 \%$ & $20.7 \%$ & $42.5 \%$ & $100 \%$ \\
\hline
\end{tabular}

Source: ME/F/INS/QUIBB_2005

240. Similarly, inequality in consumer expenditures is more significant between households than between individuals. A comparison of the Gini Index ${ }^{1}$ between households in Benin, Burkina Faso and Niger, also shows that inequality is more significant in Niger than in Benin, irrespective of the standard of living selected, while it is more significant in Burkina Faso than in Niger.

Table 15: Comparison of Gini Index for Consumption per Capita and per Household

\begin{tabular}{|l|c|c|}
\hline \multicolumn{1}{|c|}{ Country } & Households & Individuals \\
\hline Benin & 0.3986 & 0.3838 \\
\hline Burkina Faso & 0.4630 & 0.4643 \\
\hline Niger & 0.4376 & 0.4384 \\
\hline
\end{tabular}

Source: ME/F/INS/QUIBB_2005 et rapport mondial sur le développement humain 2005

241. Inequalities are virtually the same in rural and urban areas. They are more significant in intermediate towns (Gini coefficient of 0.42 between households). Similarly, inequalities are more significant between households headed by women $(0.495)$ than between households headed by men $(0.432)$.

\section{Gender, Promotion of Women and Poverty}

242. Although women account for $50.14 \%$ of the population (RGP 2001), they benefit relatively less than men from the fruits of economic and social progress. Indeed, there are disparities between men and women in all areas: access to productive resources, employment, health, and education. The marginalization of this large group of the population slows down economic and social development. Survey findings concerning gender disparities show:

- Low participation of women in working life and a high unemployment rate. Less than three employed workers out of ten $(27.4 \%)$ are women, whereas women account for $51.14 \%$ of the total working population. Similarly, the unemployment rate is twice higher among the female working population $(25 \%)$ than for the male population (11.8\%). This disparity is even more significant between working youths, with an unemployment rate of $33.9 \%$ for girls as against $24.3 \%$ for boys, whereas they account for one-third of the working youths. However, women's work is generally under-estimated, and their contribution to national wealth is also underestimated;

- There are still significant inequalities in the division of labour: the daily workload of women, especially those in rural areas, is estimated at between 16 and 18 hours per days. The domestic workload in the daily timetable of women reduce their time for taking care of children, enrolment of girls, literacy education for women, and development of productive activities;

- Continued inequalities in access to education at all levels and in all forms of education. In rural areas, the quotient of the number of girls in comparison to the number of boys enrolled is only $70.8 \%$ (or seven girls for ten boys) in primary education. In secondary education, the ratio ranges from same to double (four girls for ten boys). Similarly, the ratio of the female population to the male population able to read and write is $35.2 \%$ (less than four girls for ten boys), with greater disparity according to the level of poverty (three girls for ten boys) ;

\footnotetext{
1 Measurement of inequality generally used: The nearer the Gini index is to one, the higher the inequality. The closer it is to zero, the lower the inequality.
} 
- the existence of disparities in terms of access to financial assets. Poor households headed by women have very low financing capacities in comparison to households headed by men; the average amount of savings hoarded per year is estimated at CFAF 13,230 for poor households headed by women as against CFAF 53,923 for poor households headed by men, leading to a higher financing gap. However, access to credit is higher for households headed by men ( $26.3 \%$ of loan applications granted) in comparison to households headed by women ( $17.5 \%$ of loan applications granted) ;

- significant disparities in terms of access to physical assets. Households headed by women have limited access to land; only $4.6 \%$ of households headed by women possess at least a farm as against $79.8 \%$ for men;

- the significant scope of violence against women, particularly early marriage, genital mutilations, and battering.

243. The reasons for continued gender disparities lie in the absence of a coherent legal framework, weak national capacities in knowledge of gender-related tools and mainstreaming them in policies, divergent approaches by the different actors, and socio-cultural resistance.

244. However, by adopting gender mainstreaming as a principle for PRS implementation and preparing a gender policy paper, Niger aimed at correcting the inequalities in access to resources, basic social services and economic opportunities to improve policy targeting. Similarly, the adoption of the "National Women's Promotion Policy» in 1996 and several texts in favour of gender equality and promotion of women, demonstrated the will to gradually correct gender disparities. Accordingly, significant progress was made in the following areas:

- in primary education, the gross enrolment rate for girls increased from $33.3 \%$ in $2001 / 2002$ to $44 \%$ in $2005 / 2006$. As for the proportion of girls enrolled in schools, it rose from $29.6 \%$ in $2000-2001$ to $41 \%$ in 2005 2006 (MEN statistical yearbook) ;

- in the area of health, measures were taken to reduce maternal mortality through : (i) free screening and treatment of breast and uterus cancers, as well as care for cesarean delivery and fibroma extraction, (ii) implementation of the reproductive health programme and STI/HIVIAIDS prevention activities, (iii) revitalization of the Extended Programme on Immunization (EPI) and malaria control activities;

- provisions to punish acts of violence against women are introduced into the Penal Code in 2004 ;

245. As regards participation, the Law on quotas (to ensure that $25 \%$ of appointments to duty posts and $10 \%$ of elective posts are granted to either sex) helped to improve the representation of women in decision-making organs. Women's representation in parliament consequently rose from 1 in 1999 to 14 in 2004 out of 113, representing $12.4 \%$, while women occupy 671 seats out of 3,747 in municipal councils; however, only 5 women are mayoresses in the 265 councils. In the Government (June 2007), women's representation stood at $25 \%$, with eight (8) female Ministers out of 32. In diplomatic representations, in 2006 there were 6 female ambassadors out of 19 , representing $32 \%$. Furthermore, several committees and focal points have been created in the Ministries and State corporations or semi-public companies in implementation of the law on quotas;

- actions to reduce domestic work for rural women were under taken by bringing essential infrastructures such as water points and grain mills closer to them;

- various actions were undertaken by the Government, development partners, NGOs and Development Associations, particularly through an intensive campaign for the education of girls, as well as the creation of an operational network for female leadership. Furthermore, lines of credit exclusively for women were opened through MECREF (Mutuelle d'Epargne et de Crédit des Femmes) (Women's Savings and Loan Society) and the Regional Solidarity Bank (BRS). The "credit to women" component of the Special Programme of the President of the Republic supports rural women by improving their incomes. Similarly, the process for creating "SARAOUNIA" bank (women's bank) has been initiated.

246. Despite all these efforts, the mainstreaming of gender as a cross-cutting issue into the various sectoral 
policies has remained inadequate mainly because of the lack of disaggregated data.

\section{Youth and Poverty}

247. As the main component of Niger's population (31\% of the total), the youths ( 15 to 35 years old), are left to themselves and prey to a multidimensional crisis characterized by unemployment, under-employment, illiteracy, begging, delinquency, exodus, immigration and low participation in development activities, various diseases, including STI/HIVIAIDS, violence, etc. Such a situation has often led to violent reactions by youths (universities, schools, unions) demanding that their grievances be solved.

248. In order to provide a lasting solution to these problems and solve the crisis of the youths; particularly, as regards unemployment and under-employment, an Inter-Ministerial Youth Integration Committee, chaired by the Prime Minister, has been set up. Similarly, a Niger Youth Parliament has been established; the activities of this structure have focused on: questioning Members of Government on children's issues, advocacy for children's rights, sensitization for registration of births, HIVIAIDS control, and reforestation activities. A youth national council and regional councils have also been put in place.

249. Furthermore, a National Youth Policy, which aims at ensuring the well-being of youths by making them the key actors and beneficiaries of local and national development, was adopted in 1998. The specific objectives of the National Youth Policy are as follows: (i) inform, educate and train youths ; (ii) protect youths ; (iii) ensure the socio-professional (economic) integration of youths; (iv) encourage the participation of youth in the community and public interest development (environmental protection, sanitation, construction of roads, schools, and dams); and (iv) promote youth associations. Furthermore, a youth socio-professional integration programme is being implemented with the following objectives: (i) contribute to growth that creates employment for youths by facilitating access to productive resources for youths; (ii) identify and develop youth training, literacy and supervision activities; (iii) ensure access to drinking water and a healthy environment; (iv) protect youths from drug addiction and increase access to reproductive health services; and (v) create a communication and recreation space.

250. Furthermore, the Government of the Republic of Niger in 2005 prepared, with the support of partners, a framework document for the National Reproductive Health Programme (PNSR) with nine components, including the management of youths and adolescents. Accordingly, activities were carried out in several operations in the country, including the implementation of the Youth Sexual and reproductive Health Initiative; the activities created conditions for greater awareness of youths of problems relating to their sexual and reproductive health and STI/HIVIAIDS issues.

\section{Child Protection and Poverty}

251. Despite the adoption of a national child protection policy in 1999, many children are still marginalized and live under particularly difficult conditions. Accordingly, as regards child survival, health and nutrition indicators have made progress; however, they are generally very low. With respect to child development, various programmes and policies have helped to improve school attendance, particularly for girls. In the area of social security, despite the lack of exhaustive statistics, many children are in difficult situations due to separation from their biological family, for some, due to the lack of security and love, for others, and due to the poverty of their families. These street children are victims of economic exploitation, engage in begging and delinquency, and are groups most vulnerable to the AIDS pandemic, harmful traditional practices, while some are in conflict with the law. The situation of children is also marked by the spread of some phenomena such as child labour $(15 \%$ of the working population according to QUIBB data). Furthermore, girls are victims of early marriages (49\%). 


\section{Box 7: Child Workers}

Several categories of children are forced to work:

- student workers: This is the case of students from rural areas to continue their education in the urban centres. Entrusted to guardians, the children are forced to engage in petty trade to satisfy their subsistence needs. This category of children are 14 to 16 years old;

- children with no schooling or who drop out from school: This category concerns children not more than 15 years old. Generally, the activities of these children are completely financed by their parents. Their activities help to socialize the children;

- children farm workers: As cheap labour, these children are recruited from among street children by farmers with the complicity of their teachers. They are employed in groundnut and olive farms or agricultural plantations. In addition, they also fetch water, firewood, etc.

- children porters: They are among the street children. They have no family ties and survive on petty jobs (de porter, dish washers, apprentices) in motor parks or markets. Children of this category are exclusively small boys aged 12 to 16 years old.

\section{Source PAN/ SPDE 2004 2010, MDS/P/PF/PE}

252. The results of EDS-MICS 2006 show that few children are registered with the civil status registry (32\% as against $45 \%$ in 2000) whereas registration of the birth of a child at the civil status registry makes him /her legally member of a family and nation, confers on him/her a nationality as well as the right to be protected by the State when there is no parental protection. It also enables him/her to enjoy social benefits from their parents, such s health insurance, and to inherit from the parents. The proportion of children registered in the civil status registry is higher where the households to which they belong are rich, from $20 \%$ for the poorest quintile to $67 \%$ for the richest.

253. Generally speaking, the following constraints hamper children's rights and protection:

- the lack of reliable data and disaggregated indicators on the situation of children, which makes it impossible to prioritize actions for the different target groups;

- inadequate collaboration between the different technical services concerned with children does not facilitate the coordinated management of children;

- the low capacity of the National Committee for the survival, protection and development of children in their role of monitoring the implementation of the CDE ;

- inadequate apprentice and social integration centres for children in difficulty;

- coexistence of three sources of law (modern, Muslim and customary) does not facilitate child protection;

- the National Child protection Policy is not adapted to the current context;

- poor operation of NGOs inn the area of children in difficulty;

- inadequate human, financial and material resources do not facilitate the management of children, particularly placement in families or reception centres.

254. However, significant progress has been made with the ratification of international and regional texts (CDE, CADBE, CEDEF) and harmonization of national laws concerning childhood, establishment of courts for minors, fight against harmful traditional practices, particularly mutilations of female genital organs, early marriages and pregnancies with the punishment of mutilations of female genital organs and decline in the prevalence rate of this practice which feel from 5\% in 1998 (EDSN2) to 2.2\% in 2006 (EDS-MICS 3). The most important achievement is the emergence of NGOs concerned with children, but unfortunately very few of them operate in favour of children in difficulty. In general, these structures are limited by the inadequacy of operating resources, human resources and ineffectiveness of field activities. 
There are strong links between the MDGs and child protection. Achievement of each of the MDGs depends on paying attention to the issue of child protection; in other areas, achievement of the MDGs will help to improve child protection. For example, the following interactions can be noted:

- MDG 1 : analyses show that child labour is the cause and consequence of poverty ; poverty is at the basis of child trafficking;

- MDG 2 : continued school attendance depends a decline in early marriages for girls and child labour;

- MDG 4 : early marriage has a negative impact on the health of children from very young mothers;

- MDG 5 : early pregnancies and mutilations of female genital organs are major causes of maternal mortality;

- MDG 6 : management of HIV orphan children is a major challenge inn the control of the disease.

\section{b) Vulnerabilities, limited social security and poverty}

255. Vulnerability is considered as the potential risk for individuals to find themselves in a situation of poverty (or to get into a worse situation in the future), to experience a period of food insecurity or be a victim of disease. This definition implies the classification of individuals on the basis of a risk threshold of becoming poor or experiencing a period of food insecurity. However, vulnerability is difficult to measure, because it is a concept so dynamic that a single observation cannot sufficiently grasp the risk. Nevertheless, it is necessary to look for a way of properly identifying vulnerable populations.

256. In 2005, more than nine persons out of ten were considered as vulnerable to poverty $(90.7 \%$ of the population against only $9.3 \%$ considered as non-poor and non-vulnerable), particularly in the categories of people who are in a situation of poverty for a long time («long-term poor $\left.{ }^{1} »\right)$ ( $55.2 \%$ of the population), « transitional poor» (6.8\%), « vulnerable non-poor» (13.4\%) and « non-poor and non-vulnerable» (15.2\%). People who live for a long time in poverty account for only $17.1 \%$ of the population in Niamey while they are $59.3 \%$ in rural areas and $47.4 \%$ in the other towns. They live in households in which the main activity of the employer is farming; long-term poverty rates are also high among individuals whose employer is the mining or energy sector $(49 \%)$, production and processing sector $(46.1 \%)$, building sector $(57.8 \%)$, trade and sales sector $(42 \%)$ and services sector $(36 \%)$.

Table 16: Classification of the Poor according to Vulnerability by Place of Residence

\begin{tabular}{|l|c|c|c|c|}
\hline & Niamey & Other Towns & Rural & Total \\
\hline “Long-term” poor & 17.1 & 47.4 & 59.3 & 55.2 \\
\hline Transitional poor & 9.9 & 8.2 & 6.4 & 6.8 \\
\hline Vulnerable and precarious non-poor & 4.8 & 2.0 & 15.4 & 13.4 \\
\hline Vulnerable non-poor & 38.2 & 13.8 & 13.6 & 15.2 \\
\hline Non-poor and non-vulnerable & 29.9 & 28.8 & 5.3 & 9.3 \\
\hline Total & 100 & 100 & 100 & 100 \\
\hline
\end{tabular}

Source: ME/F/NS/QUIBB_2005

257. The majority of households in which the head has no education (59\%) are "long-term" poor. On the other hand, the majority of categories of households in which the head have secondary education, vocational and technical training, or higher education are vulnerable non-poor (15.2\%) and non-poor non-vulnerable (9.3\%). The majority of people whose main employer is the Government (public and semi-public administration) are "non-poor and non-vulnerable" (more than 40\%). Individuals and employees of private companies (modern and informal) are mostly "long-term poor" (63.9\% and $52.5 \%)$.

1 The "long-term poor" are chronic poor people who cannot come out of their situation. In case of other shocks, they get deeper in poverty. Transitional poverty is short-term, covering the period an individual reacts to a shock which made him poor to become non-poor again. 
Table 17: Vulnerablility to Poverty for Individuals according to Employer of main job

\begin{tabular}{|l|c|c|c|c|c|c|}
\hline & Government & Parapublic & $\begin{array}{c}\text { Private } \\
\text { Company }\end{array}$ & $\begin{array}{c}\text { Private } \\
\text { Individual } \\
\text { or } \\
\text { household }\end{array}$ & Others & Total \\
\hline Long-term poor & 14.9 & 18.1 & 52.5 & 63.9 & 58.3 & 55.5 \\
\hline Transitional poor & 8.9 & 9.1 & 7.2 & 5.7 & 5.7 & 6.6 \\
\hline Vulnerable and precarious non-poor & 3.0 & 1.0 & 14.7 & 13.1 & 11.2 & 13.5 \\
\hline Vulnerable non-poor & 32.5 & 31.7 & 17.4 & 10.1 & 14.2 & 15.1 \\
\hline Non-poor and non-vulnerable & 40.7 & 40.2 & 8.3 & 7.2 & 10.7 & 9.3 \\
\hline Total & 100 & 100 & 100 & 100 & 100 & 100 \\
\hline
\end{tabular}

Source: ME/F/INS/QUIBB_2005

258. The vulnerability data confirm the results of EPP2 which show that to come out of poverty or resist external shock, the initial situation is of key importance. Indeed, the capacity of households to maintain and/or rise to a higher standard of living depends heavily on three major factors: (i) the resources and other capital held by the households, before the event; (ii) the network of relations that the households can mobilize to mitigate the constraint; (iii) the experience which the households, individuals and communities have acquired in handling hardship.

\section{Vulnerability to food insecurity}

259. Poverty and vulnerability to natural disasters are closely linked, and they reinforce each other. Disasters cause misery and distress that can temporarily push certain groups beyond the poverty line; they also contribute to persistent and chronic poverty. Natural disasters can cause deaths, destroy houses and property, destroy opportunities for earning a living, disrupt education and delivery of social services, reduce savings and create health problems, sometimes with long-term consequences.

260. Natural disasters can also disrupt ongoing poverty reduction activities and lead to the reallocation of the related financial resources to assistance and rehabilitation operations.

261. Poverty can be worsened by deliberate choices of means of subsistence made ex ante by poor households to give up the potential benefits of higher-yield or more profitable crops and choose those which resist better against vagaries of the weather.

262. On their part, poor and socially underprivileged groups are among those who run the highest risk in unstable climatic conditions, as a result of their social, cultural, economic and political environment.

263. In Niger, there are frequent food shortages due to natural disasters, like the one in 2005. The disasters mostly consist in drought, locust invasions and flooding. The main consequence of these disasters is increased food and nutritional insecurity, especially for the most vulnerable people.

264. According to the survey on the food vulnerability of households, food insecurity is a situation in which the populations do not have access to an adequate quantity of healthy and nutritive food to meet their food needs; it is mainly caused by food shortage, as a result of insufficient rainfall, low purchasing power or poor use of food in households.

265. Determining whether people are in food insecurity is based on a statistical analysis of five variables reflecting the three dimensions of food insecurity, namely availability, accessibility and use. The variable identified are: (i) food consumption of households; (ii) overall expenditures, (iii) duration of available food stocks, (iv) possession of cattle, and (v) income from the production of cash crops.

266. Accordingly, the results of the survey conducted in November 2006 by the Government of Niger, in collaboration with technical partners, show that $30 \%$ of the population of Niger are in food insecurity, with $9 \%$ in severe food insecurity and $21 \%$ in moderate foods insecurity. 
267. The most affected regions are Tahoua, Tillabéri, and Zinder, followed by Dosso, Agadez and Maradi. The breakdown according to area of residence shows that rural areas are more affected $(10.0 \%$ of severe food insecurity, $20.5 \%$ of moderate food insecurity and $30.5 \%$ with the risk of food insecurity) than the urban areas ( $4.5 \%$ of severe food insecurity, $20.1 \%$ moderate food insecurity and $24.6 \%$ with the risk of food insecurity).

268. Households in severe food insecurity (9.3\%) suffer from deficits with respect to each dimension of food insecurity, namely availability, accessibility and use. Indeed, their food situation is based on cereals, consumed irregularly (not every day continuously for lack of means). Proteins, fruits and dairy products are almost absent from their diet. There are generally very poor households who spend less than CFAF 100 (US\$ 0.2) per day and per person. They do not possess cattle or enough food stocks (less than two months' consumption) to cover their food needs. Their crop yields and the income generated by cash crops are very low.

269. Furthermore, the proportion of households in severe food insecurity headed by women is much higher. Consequently, severe food insecurity affects more the single parent households headed widowers and widows and households that depend on precarious sources of income such as the sale of wood or straw, daily-paid work, petty trade and handicraft. It also affects a high proportion of farmer households.

270. When faced with food insecurity, households adopt various survival strategies: (i) reduction of the number of daily meals (32\% of households) or daily ration ( $57 \%$ of households), (ii) sale of cattle they possess (particularly young reproductive females) or house property; (iii) mortgage of lands and contracting debts; (iv) migration or exercise of new income-generating activities. Chronic food insecurity of households is one of the main causes of malnutrition among children.

\section{Box 9: Analysis of Biophysical Risks}

In Niger, the rainfall is generally low and varies on a negative gradient from the South $(800 \mathrm{~mm}$ at most in the Sahel) to the North, where rains can be exceptional. The rainfall is very irregular in space and time with great variation in the number of days per year of rainfall. For purposes of comparison, the growing period for most rainfed crops varies from 70 to 120 days. Recurrent periods of drought accompanied by reduced rainfall constitute the key factor of the climate. Indeed, there is a general drift of isohyets to the south over a distance of 75 to $100 \mathrm{~km}$ depending on the regions, partly as a result of shortage of rainfall since 1968. This promotes encroachment by the desert, such that the proportion of desert land in the country has increased from $66 \%$ to about $77 \%$.

The consequences of climate disturbance on the environment are numerous and multifaceted, the most important of which are : (i) the general decline of the water table; (ii) reduction or modification of flora on useful pasturelands; (iii) considerable reduction of cultivable areas in the North and their development to the South to the detriment of pasturelands; (iv) overexploitation of farmlands in fallback areas, with the stoppage of fallowing leading to soil impoverishment and sterilization; (v) depletion of woody species useful for feeding, handicraft and medicine; (vi) the high sensitivity of bare grounds to wind erosion and the displacement of sterile sand by waves, covering arable lands with homogeneous layers or more or less large dune formations, depending on the obstacle encountered.

As for the negative variations of the biomass, they lead to cereal and fodder shortages, the consequences off which are famine for the populations and death of thousands of animals and trees, as was the case following the disastrous droughts in Niger in 1974 and 1984. Generally speaking, the Northern areas are more exposed to biophysical risks with the exception of Bilma district which is not an agricultural area and because the agro-pastoral system of oasis production in the area depend on water control.

The 36 departments of Niger could therefore be classified into 3 categories, according to their degree of exposure to biophysical risks:

Departments not exposed to biophysical risks: Gaya, Say, Madarounfa, Bilma and Magaria (5 departments) ;

Departments highly exposed to the risks: Arlit, Tchirozérine, N'Guigmi, Maïné Soroa, Gouré, Tanout, Tchintabaraden, Abalack, Tillabéry, Ouallam, Filingué, Loga, Tahoua, Keita, Mayahi and Dakoro (16 departments) ;

- The rest of the departments may be considered as averagely exposed: Matamèye, Aguié, Tessaoua, Mirriah, Guidan Roumdji, Madaoua, Bouza, Illéla, Doutchi, Dosso, Boboye, Kollo, Konni, Téra and Diffa (15 departments).

Source: WFP, Analysis of Food security and Vulnerability in Niger, February 2002 


\section{Vulnerability to disease and low social coverage}

271. In Niger, social security is managed exclusively by the National Social Security Fund (CNSS) in the form of family allowances, occupational hazards, pensions (old age, disability, and survivor's) and the social action fund. Over the past five yeas, the CNSS has distributed nearly CFAF 22 billion, as support to families with dependent children, annuities to victims of industrial accidents and compensation to victims of industrial accidents during the period of disablement and women during maternity leave, health care, as well as personal and survivor's pension.

272. Despite these efforts, the social security system covers less than one person out of ten in Niger, because of the weak modern economy; it does not also cover sickness and unemployment risks. Most of the people in Niger are therefore highly vulnerable to morbidity.

273. The Government has conducted an actuarial study on the CNSS and a study on the pension system in Niger. Similarly, it has embarked on a reform of the CNSS with threes (3) main objectives: (i) reduce the current and actuarial deficit; (ii) expand social coverage and develop new products; and (iii) mobilize long-term resources to finance the economy. The implementation of this reform is far behind schedule.

\section{Promotion of the rights of handicapped persons and protection of the elderly}

274. According to the results of the RGPH, 80,035 persons have a handicap; they represent $0.7 \%$ of the total resident population. At the national level, $33.4 \%$ of handicapped persons have multiple handicaps. Persons handicapped at the lower limbs represent $13.4 \%$, the blind $11.45 \%$, and the deaf $10.6 \%$. About two handicapped persons out of ten (1.85\%) suffer from leprosy and one handicapped person out of $10(10.23 \%)$ suffer from mental deficiency. Furthermore, nearly 4 handicapped persons out of $5(78 \%)$, aged 6 years or above, are not educated. Only $7.3 \%$ of handicapped persons have primary education, and $10.7 \%$ have coranic education.

275. At the national level, the activity rate of handicapped persons is $47.2 \%$. Furthermore, $58.7 \%$ of working handicapped persons are men and $31.3 \%$ are women. However, the situation varies according to the area of residence.

276. Handicapped persons are victims of marginalization and inadequate vocational and technical supervision. Within this group, the situation of persons affected by mental diseases is extremely difficult. Indeed, these persons are very often abandoned by their families. They are marginalized in the society and benefit from limited social security in terms of health services. Their survival and reintegration in case of cure are major causes for concern.

277. Furthermore, $4.5 \%$ of Niger's population are 60 or above (496,120 people, according to the third RGPH), of which $47.8 \%$ are women. Close to nine out of every ten elderly people live in rural areas (85.7\% of the elderly in rural areas and $14.3 \%$ in urban areas). These people are sometimes victims of material insecurity and/or isolation due to inadequate social security, in an environment marked by decreasing solidarity and rapid urbanization.

278. In order to address the problems of handicapped and elderly persons and other vulnerable groups, Niger has since 1998 been implementing a National Social Development Policy aimed at promoting national solidarity by fostering social justice, legal protection, social progress, social well-being and social security for vulnerable groups. Major achievements have been recorded in this area; they include: (i) the preparation and implementation of a three-year action plan of the National Technical Committee for the Promotion of Handicapped Persons; (ii) the creation and installation of regional committees; (iii) the revision of regulations; (iv) the provision of specialized equipment to supervisory structures; (v) medical assistance to handicapped persons and the needy; (vi) the creation of specialized schools and integrative classes; and (vii) the implementation of a rehabilitation programme.

279. However, despite the significant efforts made, the situation of underprivileged persons (handicapped persons, prisoners, the elderly, etc.) remains a cause for concern. This situation is due to the complexity of social problems, the low capacities of Government structures, the little attention paid to issues relating to underprivileged persons, and sociological constraints. 


\section{I.3.5. Infrastructures and poverty}

280. Inadequate infrastructure slows down the development of production capacities and access to basic social services. Indeed, transport and energy infrastructures are key factors in access to social services and transportation of production to consumption areas. Furthermore, inadequate infrastructure capital could generate high congestion losses, leading to low productivity.

281. Given its geographical location, Niger has a large expanse of land and wide population dispersion, giving it the lowest population density in West Africa $\left(8\right.$ inhabitants $\left./ \mathrm{km}^{2}\right)$. These factors weigh heavily on transport costs and pose communication problems.

282. In addition, Niger is far from maritime embarking points. The nearest point to the sea (Gaya) is $760 \mathrm{~km}$ from Cotonou port. Niamey is located $1,060 \mathrm{~km}$ from Cotonou, and Zinder $1,510 \mathrm{~km}$ from Lagos. The absence of railway, the low navigability of the Niger river and inadequate airport activities, make domestic and external transport dependent mainly on road transport (95\%).

283. In order to address the landlocked location of the national territory, a National Transport Strategy was adopted in 2004. The strategy aims at optimizing the management of infrastructures, boosting the transport industry and strengthening cross-cutting activities.

\section{(a) Transport}

\section{$\underline{\text { Road transport }}$}

284. Niger's road network covers more than $18,443 \mathrm{~km}$, comprising a registered network and a classified network. However, despite the large size of the network, according to the DSBE survey, only $20 \%$ of localities have access to tarred roads and $11 \%$ to laterite road. Furthermore, the network is denser in the south of the country, where large urban centres and the bulk of economic activity are located. A Road Maintenance Autonomous Sinking Fund (CAFER) has been created to guarantee the financing of road maintenance and sustainability of structures.

285. According to the results of the QUIBB survey (2005), motorized means of transport are very rare, and are mainly owned by households living in towns (3.9\% of the cars and $11 \%$ of mopeds), with concentration in the Niamey Urban Community (11\% of cars and $15.1 \%$ of mopeds). The public transport service is not accessible to the majority of households; on the whole, only $42.2 \%$ of households have access to the nearest transport less than 30 minutes away. The service is mainly accessible in urban areas (76.4\% as against $33.8 \%$ in rural areas). For the rural populations, the most common means of transport is on foot, by carts and by pack animals. Furthermore, the incidence of poverty is higher in remote villages and peri-urban quarters than in villages and quarters with access to roads and means of transport.

\section{Road Safety}

286. Like in other countries in the world, road safety in Niger is far from excellent. In 2006, there were 3,869 road accidents, with 386 deaths and 5,152 wounded, some of whom will remain handicapped for life. The economic losses caused by road accidents have been estimated at more than CFAF 5 billion. Indeed, road accidents are both health and socio-economic problems (cost of treatment, loss of productivity due to handicaps and poverty generated by the loss of the main wage-earner and/or head of household).

\section{Railway transport}

287. Niger does not have railway lines on its territory. It operates, in co-ownership with Benin, the Cotonou Parakou railway line $(438 \mathrm{~km})$ and its road extension to Niger through the Organisation Commune Bénin Niger (OCBN) which has embarked on a concessioning process to improve its management. Furthermore, in light of the importance of rail transport, Niger has initiated a railway interconnection project with Benin, Burkina and Togo known as "AFRICARAIL". 
288. Meanwhile, in order to reduce factor costs and ensure supplies, Niger uses several corridors from Benin, Togo, Ghana, Nigeria and Côte d'Ivoire.

\section{Maritime and river transport}

289. Most of Niger's external trade is through the sea. That is why agreements have been signed with transit countries to facilitate passage in the various ports. To that end, back-up spaces and warehouses have been created in the ports of Cotonou and Lomé. Furthermore, a Niger container terminal has been constructed in Cotonou port.

290. River transport is mainly on the Niger river which is an access route to the sea and regional trade, particularly with Nigeria, Mali and Benin. However, because of very low water levels and the existence of rocks, the navigability of the river is difficult, which facilitates the movement of only small traditional vessels.

\section{$\underline{\text { Air transport }}$}

291. The country has six (6) main airports, including three (3) international airports (Niamey, Agadez and Zinder) and three (3) national airports (Maradi, Tahoua, Diffa). Furthermore, it has 12 secondary runways. Over the 2002-2006 period, several investments were made in Niamey and Agadez to reinforce and extend the airport pavements and improve airport security. However, the low number of international flights pushes up transport costs and affects the country's competitiveness. The limited services in the country also reduce mobility of persons and do not foster the development of tourism sectors, despite the country's enormous assets.

\section{(b) Energy supply}

292. The low energy supply and the country's dependence on this factor of production increase costs for business persons and households. In particular, the limited infrastructure development in the energy sector has made it difficult to satisfy an increasing potential demand.

293. Generally speaking, the energy sector is marked by: (i) low consumption of modern energy; (ii) disparities in national coverage for energy services; (iii) low tapping of national resources; (iv) the high cost of energy services. This situation is due to several factors, in particular:

- inadequate coordination of the actors and operations;

- inadequate synergy between social and production investments;

- the country's dependence with respect to energy;

- the lack of long-term planning;

- low investments in the sector, in which the bulk of financing is provided by the State;

- low technical capacities ad human resources;

- lack of knowledge on mineral deposits;

- inadequate promotion, research/development, management and technical capacities, information and training;

- limited consideration of environmental impacts by energy projects.

\section{Electricity sub-sector}

294. The national electricity production (202 GWH in 2005) covers less than $50 \%$ of local energy consumption needs (438 GWH); the deficit is made up by importing energy from Nigeria. However, the Niger river valley has enormous electricity potential with three favourable sites, in particular Kandadji (230 MW), Gambou (122.5 MW) and Dyodyonga (26 MW). Similarly, Niger has huge mineral coal deposits, particularly in Salkadamna about 80 $\mathrm{km}$ to the North-west of Tahoua and estimated at 30 million tonnes, and in Solomi in Agadez region, of 5586 $\mathrm{Kcal} / \mathrm{Kg}$ and $5000 \mathrm{kcal} / \mathrm{kg}$ calorific power respectively.

295. The electricity coverage rate is increasing steadily, even though it is still below the expected target of $15 \%$ in 2005; it increased from $5.3 \%$ to $7.2 \%$ between 2000 and 2005 . This improvement is due to: 
- the Special Programme of the President of the Republic which facilitated the electrification of 159 localities between 2001 and 2005 ;

- the Interconnected Electric Network Development Project in Niger (DREIN) implemented by NIGELEC which extended electricity supply (medium and high voltage lines) to Tahoua region;

- the Electric Network Extension and Reinforcement Project in Niger (PERREN) which aims at connecting localities by average voltage lines to the NIGELEC general interconnected network.

296. To enhance these efforts, a structure responsible for rural electrification has been created, and a Multisectoral Regulation Authority (ARM) has been installed.

\section{$\underline{\text { Renewable Energy }}$}

297. This sub-sector, which comprises solar energy, wind energy, hydro-electric power and biogas, is underutilized (less than $0.1 \%$ of the national energy supply and disposition), despite its enormous potential. In order to enhance the development of this potential, the Government in 2004 adopted a national strategy and an action plan for renewable energy.

\section{Domestic energy sub-sector}

298. In efforts to promote the use of energy to replace wood, a nationwide campaign to popularize mineral coal was conducted in 2004. Accordingly, with the creation of SNCC (with a capacity of 20,000 tonnes), impregnated coal production will exceed the current 3,000 tonnes. Furthermore, in order to rationalize the use of wood, urban centres wood supply plans have been prepared and rural wood markets created.

\section{Hydrocarbons sub-sector}

299. Niger imports all the petroleum products it requires through the Société Nigérienne des Produits Pétroliers (SONIDEP) which has monopoly of imports with a storage capacity of $47,808 \mathrm{~m}^{3}$. The products are distributed by several private operators with a storage capacity of $11,000 \mathrm{~m}^{3}$. To reduce this dependence, the Government has embarked on promoting the petroleum potential by diversifying its partners in oil exploration. To that end, three test borings started in 2003 and several companies have obtained prospecting permits in the North of the country.

\section{(c) Information and communication technologies}

\section{$\underline{\text { Telecommunications }}$}

300. Niger has witnessed a huge telecommunications penetration, particularly as a result of mobile telephony with subscriptions increasing from 57,541 in 2002 to 546,094 in 2006; the telephone density was 4.94\% in 2006 (as against $8 \%$ recommended by NEPAD). However, despite this significant increase, $79 \%$ of the rural councils (169 councils out of 213) are not covered by fixed telephone or GSM telephony. 84\% of the rural councils (178 councils out of 213) are not covered by GSM. Furthermore, telephone communications costs remain exorbitant, especially the mobile telephone, and is becoming a limiting factor for the competitiveness of the productive sector.

\section{Information technology and Internet}

301. As regards the use of Information and Communication Technologies, the current situation shows that most public and private institutions, NGOs and IGOs have computer equipment $(78 \%)$ and a server $(62 \%)$. However, mention should be made of the low power bandwidth (31 megabits per second), low penetration of ICTs into the hinterland, and the high cost of Internet access. However, the Government has embarked on the interconnection of the Ministries. A feasibility study on an inter-Governmental Intranet has been conducted, and a call for tenders has been launched. Similarly, a wide scale optic fibre link programme has been started to connect Niger to Burkina Faso and Benin. Furthermore, Niger has since 2004 been implementing a National Development Communication Policy (PNDC), as well as a National Communication and Information Technology Development Plan (NICl). 


\section{(d) Government Buildings}

302. To date, there are no reliable data to objectively present the current situation off government buildings. The only study conducted by the State in this area dates back to 1984. The study, which focused on the management and maintenance of government buildings, was limited to determining the number of government buildings so as to facilitate their management and maintenance; no other action followed this operation. Furthermore, the most recent available information dates as far back as 1993.

303. Indeed, at that time, a commission responsible for taking stock of the situation estimated that State property was made up of 3,327 buildings for residential purposes and 1,424 buildings used as offices.

304. The number of buildings, belonging to the State, therefore stood 4,751 in $1993,91.47 \%$ of which were constructed with solid materials. Between 1983 and 2007, Niger made significant efforts in the construction of other government buildings. The disparity in the construction of these buildings and the lack of databank make it difficult to carry out a quantitative and qualitative evaluation of State property.

305. Nevertheless, it is easy to realize that State property is inadequate because several government services are in private buildings under lease contracts. Generally speaking, government buildings are in an advanced state of degradation and dilapidation, and do not meet the current requirements and needs. Furthermore, the employees are cramped in their offices. This situation is partly due to the limited means of the Government in recent years which do not allow for adequate allocations for maintenance of State property.

\section{I.3.6. Governance and Poverty}

\section{(a) Political Governance}

\section{Identification and consolidation of the rule of law}

306. The return to constitutional normality, following the presidential and parliamentary elections in December 1999 enabled Niger to get out of the vicious circle of recurrent circle of recurrent socio-political crises which greatly hampered development in the 1990s. Consequently, all the institutions of the Republic were installed, as well as four other organs, thereby consolidating democracy; they are the National Human Rights and Basic Freedoms Commission (CNDH/LF), the Higher Communication Council (CSC), the National Political Dialogue Council (CNDP), the Economic, Social and Cultural Council (CESOC), the Local Authorities High Council (HCCT), the National Social Dialogue Commission (CNDS), the National Commission for formulating AntiCorruption Strategies (CNSLCC), the National Private Investors Council (CNIP) and the National Labour Council (CNT). The major missions of these organs are to provide appropriate answers to the political, socio-economic and cultural concerns of the populations, as well as promote human rights.

307. The adoption of an Electoral Code and subsequent installation of a National Independent Electoral Commission (CENI) facilitated the holding of local, presidential and parliamentary elections in a peaceful socioeconomic atmosphere in 2004, as well as the enhancement of cohesion and dialogue between the various actors.

308. However, several factors limit the institutional development of the country, in particular: (i) the limited civic and political culture; (ii) the limited involvement of the various civil society structures in the drafting of laws concerning them; (iii) inadequate communication between government officials and the populations.

\section{(b) Legal Governance}

309. Since 2004, the Government has been implementing a Judicial Reforms Support Programme (PARJ) which facilitated adoption of the reform of the Penal Code, the Penal Procedure Code, the decree on the implementation of public utility works, as well as the organic laws on the Court of Auditors, the State Council and the Supreme Court of Appeal. Furthermore, a preliminary draft of the Civil Procedure Code has been prepared. As regards the criminal procedure, the court appearance procedure on the preliminary recognition of guilt "plead guilty" was introduced. 
310. Furthermore, this reform has provided Niger with a new judicial map by transforming Sections of the court into High Courts (TGI). New courts have been created and new magistrates and trainee judges have been recruited. Several training sessions have also been organized for the magistrates, registrars and prison staff, police and gendarmerie on various themes: OHADA law, a posteriori control of the acts of local authorities, human rights, etc.

311. Similarly, the construction of new prisons, as well as an increase in resources for their functioning, has helped to improve conditions of detention.

312. Public freedoms have been further consolidated, particularly through: regular reports of the National Human Rights and Basic Freedoms Commission (CNDH/LF), increase in the number of associations for the defence of human rights, and regular conduct of their activities, as well as an increase in the number of private press organs. Furthermore, a national conflict prevention and management strategy has been adopted to foster dialogue, consultation and the culture of peace.

313. However, despite the significant efforts made, Niger's judicial system still faces the following constraints: (i) the obsolescence of some texts; (ii) inadequate human, material and financial resources; (iii) poor supervision of magistrates; (iv) archaic management of files at a time when NICTs offer enormous possibilities of communication and management; (v) difficulty of understanding some court decisions.

\section{(c) Administrative Governance}

314. A wide range of administrative reforms have been initiated with the aim of improving the efficiency of the public administration. The creation of a High Commissioner for Modernization of the State (HCME) as a mission administration, aims, in relation with the Ministries concerned, at designing, supervising, coordinating, monitoring and evaluating all actions to modernize the State and local authorities in accordance with the policies defined by the Government.

315. To that end, a State reform support programme will be prepared and adopted. The programme will address the need to reform the State following the major changes over the last decade. Already, an Integrated Public Administration Modernization Programme (PIMAP) has been prepared, and measures have been taken to put government workers back to work, with the holding of the General Conference, time-keeping, and introduction of non-stop working day.

316. Despite the progress made, many weaknesses still affect the functioning of the public service. Indeed, there is still:

- low rate of administrative supervision, which in 1999 was one (1) employee for 223 inhabitants (as against one (1) employee for 158 inhabitants in Mali, and one (1) employee for 102 inhabitants in Côte d'Ivoire), has not changed, since the staff strength of the public service has also declined (13.3\% between 2000 and 2005). Similarly, the early retirement of competent senior and high-level staff between 1997 and 2006 did not facilitate skills transfer to younger civil servants;

- inefficient management of staff files and lack of a coherent remuneration policy;

- $\quad$ high propensity for the reorganization of Ministries leading to high management costs, many late transfers of archives and the subsequent losses of memory and professionalism as well as risks of overlapping of responsibilities;

- the politicization of the administration leading to greater mobility of senior staff in line with political changes;

- the inadequate human, material and financial resources of the decentralized administrative services;

- poor circulation of information within public services and the lack of public relations policy. 


\section{(d) Economic Governance and Fight against Corruption}

317. Several measures have been taken to strengthen economic governance in Niger; they include:

- the adoption of the PEMFAR and its action plan as the reference framework for improving the management of public finance;

- the harmonization of public finance management instruments with WAEMU directives;

- the gradual reduction of domestic arrears, improvement of the budget preparation process;

- the conduct of Public Expenditure Reviews and preparation of Medium Term Expenditure Frameworks (MTEF) in priority sectors;

- independent evaluation of the use of HIPC resources;

- the integrated computerization of the expenditure chain;

- reform and adoption of the Public Procurement Code with the creation of a Public Procurement Regulatory Agency (ARMP) and a General Directorate for Public procurement Control;

- the installation of a Multisectoral Regulatory Authority and a National Private Investors Council (CNIP);

- the establishment of a National Commission for formulating anti-corruption strategies; and

- the reinforcement of budgetary controls with the creation of a Court of Auditors and General Financial Control Directorate.

318. Furthermore, in order to moralize the management of public funds, inspections and audits were conducted in several sensitive services (revenue offices, development projects, public service, etc.). Following these inspections, about sixty (60) cases of misappropriation of public funds were identified and referred to the courts for appropriate prosecution of the persons concerned. Already, several offender, co-offenders or accomplices have been sanctioned and the Government has got back its funds.

319. Generally speaking, the shortcomings in economic governance are related to a number of factors including:

- lack of macro-economic vision in tax management;

- low capacities of external control structures (Parliament and Court of Auditors)

- inadequate institutional and legal framework for combating corruption (non-implementation of texts, lack of strategies);

- low capacities of stakeholders in the fight against corruption;

- population's inadequate knowledge of the negative impacts of corruption on economic and social development.

\section{(e) Local Governance and Decentralization}

320. The organization of municipal elections in July 2004 , as well as the installation of the deliberative and executive organs of the 265 councils in October 2004 helped to consolidate the decentralization process, based on the total communalization plan.

321. Furthermore, in order to reinforce the institutional framework of decentralization and guarantee the autonomy of local authorities, a Local Authorities High Council was created. Indeed, in view of their proximity and the areas of competences legally granted to them, local authorities are increasing in the appropriate position to operationalize policies on poverty reduction and achievement of the MDGs.

322. In order to consolidate the process and enhance the legal and institutional framework of decentralization, studies have been conducted on: (i) the definition of a deconcentration charter in Niger; (ii) the problems of decentralization and nomadic communities in Niger; (iii) the financing of investments by local authorities in infrastructures and equipment in Niger; (iv) the establishment of a Decentralization Support Fund and an Equalization Fund in Niger (v); land tenure and decentralization, (vi) operationalization of the transfer of areas of competence from the Government to the local authorities, (vii) the tax system of councils, (viii) council project ownership, and (ix) preparation of a training framework for decentralization stakeholders.

323. In addition, there are ongoing activities to review the main basic texts on decentralization so as to draft a bill on the Local Authorities General Code. 
324. Furthermore, the Government supports the preparation of the harmonized National Guide for council planning and capacity building for community organizations.

325. However, the novelty of the process poses a number of difficulties for the local authorities, in particular: (i) inadequate financial resources; (ii) low transformation of national policies and strategies into local and community guidelines; (iii) poor coordination of the various ministerial structures claiming leadership of the decentralization process; (iv) low institutional capacities of the new councils and lack of preparation of stakeholders (many of whom are illiterate, without training for their role).

\section{(f) Empowerment of the People}

326. Access to information and participation in decision-making are important dimensions in poverty. According to the QUIBB_2005 survey, most households are members of a political party (58\%), 14\% are members of a village development association and between $8 \%$ and $11 \%$ are members of a cooperative, a tontine, or an education or health committee.

327. Similarly, the survey shows that $90 \%$ of households feel that they participate in decisions concerning the life of their locality, or that they are well integrated into its social life. This proportion is higher in rural areas $(92 \%)$ than in urban areas (78\%). There are not significant differences in how they feel about participation or integration between the poor and the rich. The major reasons for the lack of integration are as follows: (i) discrimination (30\%); (ii) lack of transparency in the decision-making process (20\%); and (iii) the lack of community life $(20 \%)$. Furthermore, according to the survey, above $90 \%$ of households have a member who can express himself/herself freely during local meetings.

328. Consequently, as a result of the easing of political tensions in the late 80 s, empowerment of the people started with the emergence of several civil society organizations. In 2005, there were nearly 600 NonGovernmental Organizations and Development Organizations (NGO/DO), 600 associations, 5 trade unions, and more than 5,000 grassroots community organizations.

329. The population of Niger also enjoys easy access to information. According to the QUIBB survey, $55 \%$ of households have a radio set and $6.8 \%$ a television set. The country has about one hundred rural and community radio stations, a nationwide public radio with regional and departmental stations, about fifteen private radios broadcasting mainly in the capital and regional chief towns, about sixty private newspapers published regularly, two public television channels and four private television channels.

330. By being better informed and participating more in the debate on national policies and operating close to the grassroots communities, the civil society appears as a national development stakeholder. The local focus of NGO/DAs makes them effective instruments of the territorial development policy. Furthermore, civil society organizations (CSO) influence public action; for example, they have obtained from the Government the revision of the Finance Law in 2006, as well as price cuts for basic commodities.

331. However, despite this significant progress recognized by all, relations between the CSOs and the supervisory institutions (Ministries responsible for the Interior and Community Development) have sometimes been lukewarm. Similarly, the low capacity, administrative redtape, the concentration of decision-making centres in the capital, non-compliance with the rules of collaboration and poor coordination of support from development partners are factors that limit the smooth participation of CSOs in the development process.

332. Lastly, the emergence of CSOs in the 90s, within a changing political context, today creates confusion in responsibilities because the rule that defines their areas of intervention is diffuse and imprecise. 


\section{I.3.7.Factors limiting the implementation of the Poverty Reduction Strategy}

\section{(a) Inadequacies in PRS financing and budget implementation}

333. The problem of financing interventions of priority actions is a major challenge for the Poverty reduction Strategy. It concerns not only the capacity to manage internal resources, but also mobilization of the necessary external resources. Indeed, the stabilization of public finance and sectoral reforms, initiated since 2000, have facilitated the mobilization of domestic resources and development aid, as well as better resource allocation to PRS priority sectors.

\section{Mobilization of domestic resources}

334. The mobilization of domestic resources has recorded significant progress, particularly over the past five years. Indeed, tax pressure rose from $9.6 \%$ in 2002 to $11 \%$ in 2006 . However, this rate, which is below the WAEMU standard (17\%), is not enough to generate a substantial increase in public investments for the priority sectors. The large informal sector, which is difficult to tax, as well as the tax benefits granted by the Investment Code to investors, account for this situation.

Table 18: Trend Tax Pressure Rate in Niger and some WAEMU Countries (in $\%$ of GDP)

\begin{tabular}{|l|l|l|l|l|l|l|l|}
\hline & 2000 & 2001 & 2002 & 2003 & 2004 & 2005 & 2006 \\
\hline WAEMU & 13.7 & 14.0 & 14.6 & 14.6 & 14.8 & 14.9 & 15.9 \\
\hline Burkina Faso & 11.1 & 10.3 & 10.7 & 10.8 & 11.8 & 11.3 & 12.4 \\
\hline Mali & 11.9 & 12.3 & 13.8 & 14.2 & 14.9 & 15.4 & 14.6 \\
\hline Benin & 13.9 & 13.5 & 14.4 & 14.9 & 14.6 & 14.5 & 14.9 \\
\hline Niger & 8.3 & 9.1 & 9.6 & 9.9 & 11.0 & 10.3 & 11.0 \\
\hline
\end{tabular}

Source: Report on Multilateral Surveillance, WAEMU_June 2006; DGE/MEF

\section{Mobilization of external resources}

335. In June 2003, Niger organized the Development Partners Forum on the Poverty Reduction Strategy. The Forum reaffirmed the general TFP consensus on the strategy and obtained the commitment of all the parties to make the PRS the only reference framework for their support to the economic, financial and social policy of Niger.

336. Similarly, a number of commitments were made, relating to the adoption of the programme approach, harmonization of the procedures of partners, and development of monitoring-evaluation mechanisms.

337. Accordingly, during the PRS implementation period, international aid increased after a decline at the end of the 90s due to socio-political instability. Between 2002 and 2006, the country received the equivalent of CFAF 752.8 billion in new financing. This aid was provided mainly as grants (60\%). It contributed enormously to the achievement of PRS outputs, in particular improvement of the social indicators, development of infrastructure, and capacity building. In particular, Niger benefited from the HIPC and MDRI initiatives (CFAF 255.55 billion between 2001 and 2006).

338. In particular, Niger benefited from the HIPC and MDRI Initiatives (for CFAF 255.55 billion between 2001 and 2006). 
Chart 6: Reduced Amounts under HIPCI and MDRI (in US\$ million)

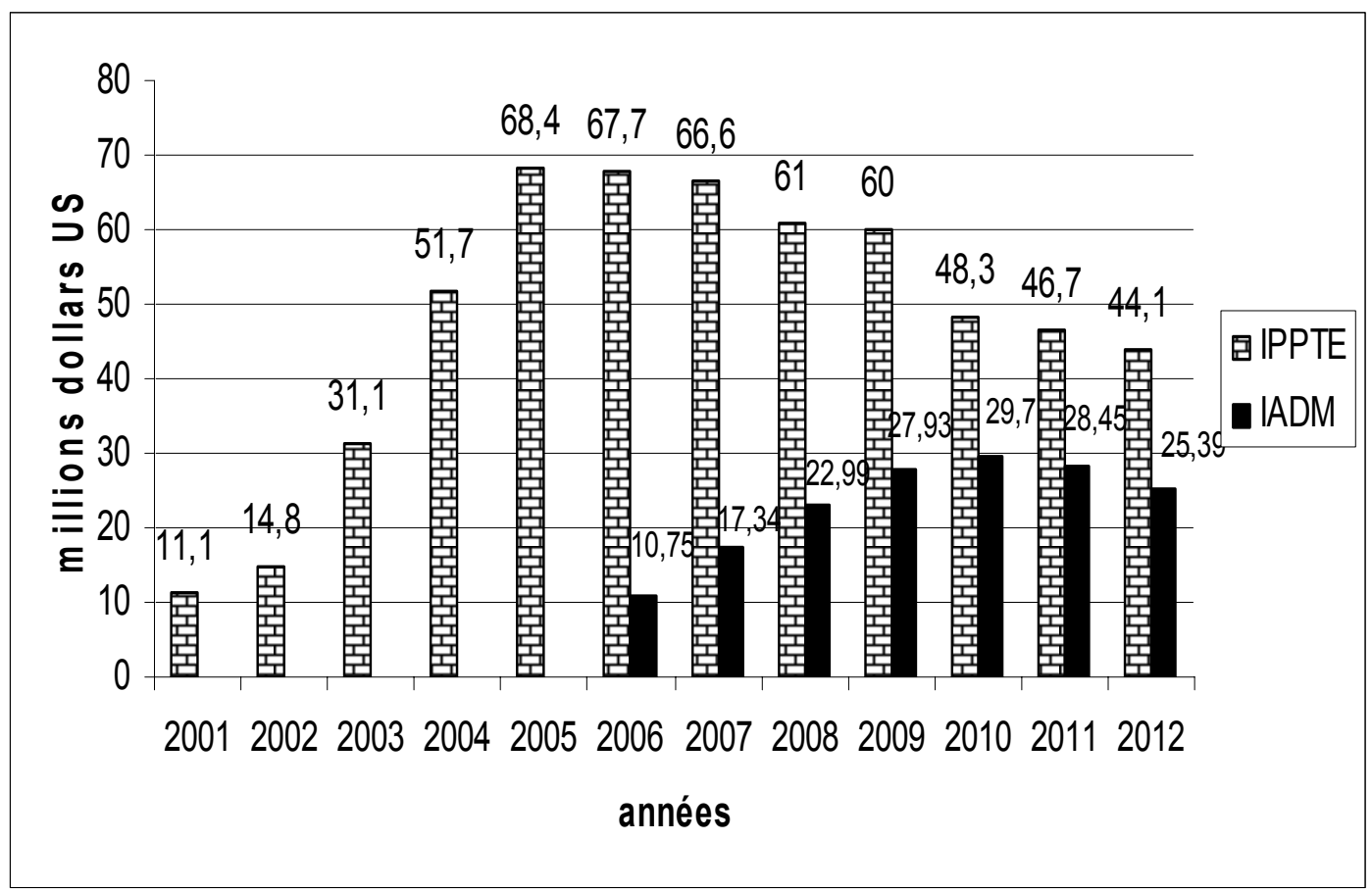

Source: World Bank

\section{Resource allocation to sectors}

339. Regarding sector allocation of budgetary resources, the allocations to education, health and the rural sector increased from $14.6 \%, 10.9 \%$ and $14.6 \%$ in 2001 to $13.3 \%, 9 \%$ and $18.2 \%$ respectively on average over the 2002-2005 period. The average implementation rate was about $75 \%$ in these sectors, whose financing depend heavily on external resources. Furthermore, resource allocation to priority sectors of the PRS fluctuated between 2002 and 2005 mainly as a result of the volatility and unpredictability of external assistance for them.

Table 19:Amount of Resource Allocations to Key Sectors over the 20022005 period (in CFAF billion)

\begin{tabular}{|l|c|c|c|c|c|}
\hline \multicolumn{1}{|c|}{ Sectors } & Allocation & $\begin{array}{c}\text { Share in the } \\
\text { Allocation } \\
\text { (in \%) }\end{array}$ & $\begin{array}{c}\text { Implementa } \\
\text { ion }\end{array}$ & $\begin{array}{c}\text { Implementation Rate } \\
\text { (in \%) }\end{array}$ & $\begin{array}{c}\text { Share in the Budget } \\
\text { at Implementation } \\
\text { (in \%) }\end{array}$ \\
\hline Education & 218.6 & $13.3 \%$ & 188.35 & $86.2 \%$ & $15 \%$ \\
\hline Health & 148.3 & $09 \%$ & 113.23 & $76.3 \%$ & $09 \%$ \\
\hline Rural development & 299.2 & $18.2 \%$ & 203.44 & $68.0 \%$ & $16.2 \%$ \\
\hline Equipment/Transport & 107.4 & $6.5 \%$ & 72.18 & $67.2 \%$ & $5.7 \%$ \\
\hline Total PRS & 773.53 & $47.2 \%$ & 577.2 & $74.6 \%$ & $45.8 \%$ \\
\hline Others & 866.49 & $52.8 \%$ & 682.06 & $78.7 \%$ & $54.2 \%$ \\
\hline Total Budget & 1.640 .0 & $100 \%$ & 1259.26 & $76.8 \%$ & $100 \%$ \\
\hline
\end{tabular}

Source : MEF/ DGB and Work on Marco-economic Framework

340. Thanks to savings made on the external debt service following eligibility for the $\mathrm{HIPCl}$, Niger initiated a vast programme of infrastructure construction, particularly in rural areas, through the Special Programme of the President of the Republic. Thee programme, which is one of the key instruments for PRS implementation, underwent independent technical and financial evaluation. The evaluation showed that major achievements have been recorded during the four years of programme implementation ( 3 years 10 months); they include :

- the construction of 1992 classes corresponding to $20 \%$ of the existing classes in solid materials ;

- the construction of 1930 community health centres to ease the action of CSIs and district hospitals (3 health centres for one CSI) ;

- the construction and/or rehabilitation of 861 modern water points, thereby increasing the number of modern water points by $4 \%$; 
- the construction of 120 control dams and manure areas for the mobilization of new water resources for watering cattle and development of irrigated and flood recession crops;

- the rehabilitation and/or creation of 20 irrigation areas for the development of 4,364 irrigated ha;

- access to micro-credit for more than 80,000 women.

341. Obviously, PS/PR has helped to increase access by the populations to basic social services. It also helps to intensify crops and revitalize regional economies. This observation is confirmed by the general appreciation of the populations. Indeed, about $62 \%$ of the respondents of the EPP2 appreciate the PS/PR approach focused on satisfaction of the priority needs of the communities, particularly basic infrastructure.

342. However, these very positive results were mitigated by some factors, including: (i) the urgency of the operation at the beginning, which led to limited integration of the programme into sectoral policies and strategies; (ii) the low financial margin of contracting enterprises making the submission less attractive for many of them; (iii) monitoring of the quality of works due to lack of resources by the technical services and limited resource allocations; (iv) repayment difficulties were also noted in the programme audit report.

343. To remedy these inadequacies, corrective measures have been initiated; they are

- the clarification of the procedures for coordination between the various actors;

- capacity building for the technical services responsible for control;

- compliance with the prescriptions of the Public Procurement Code;

- improvement of procedures by using the new budget classification;

- integration of PS/PR actions into sectoral programmes and strategies.

\section{(b) Weaknesses of the planning and programming mechanism}

344. With the PRS process, an innovative planning approach has been initiated, to define a concerted and consensual overall reference framework and put in place effective economic and social development strategies. Indeed, PRS preparation was based on a diagnosis of the situation and data from surveys, studies and opinions of the population.

345. However, the PRS process should be improved by building technical planning capacities and completing the sectoral MTEFs.

346. Similarly, there is no long-term prospective vision around which the PRS could identify and articulate medium-term priorities and strategies. Furthermore, very short time frames for the preparation of documents do not allow for investigations on certain relevant themes.

347. Inadequate application of results-based management (RBM) also limits the definition of policies, programmes and projects within a context marked by the predominance of short and medium terms in economic and financial programmes. These approaches have relegated long-term planning mechanisms to the background.

348. Although for the priority sectors, budget preparation is consistent with a macro-economic framework based on PRS objectives and existing medium term expenditure frameworks (MTEF), it is necessary to align the sector MTEFs on the State budget.

349. With respect to budget implementation, there are: (i) wide expenditure implementation gaps for capital projects on external financing due to unavailability of some implementation data, (iii) lack of annual infra analysis of budget implementation. Furthermore, these inadequacies coupled with regular and systematic analyses of the processes and results do not allow for a strategic approach to budget management.

\section{(c) Inadequacies in programme management and implementation}

350. The desire to effectively implement the PRS led to the selection of Ministries as pillars of programme implementation. Significant progress has been made at sectoral level, particularly in matters 
relating to harmonization and alignment to MDGs, with the establishment of MTEFs and Consultation Frameworks, especially in the education, rural development and health sectors.

351. However, PRS implementation has suffered from some shortcomings, in particular: (i) inadequate implementation levels of some programmes; (ii) high dependence of the Investment Budget on External Resources; (iii) inadequate coordination of development assistance and dialogue with TFPs, due mainly to poor consultation between the Government and Partners at the central and decentralized levels; (iv) limited alignment of the assistance strategies of some TFPs on those of the Government; ( v) the diversity and complexity of partners' procedures; (vi) the multiplicity of institutional actors and instability of some structures, prejudicial to the quality of dialogue with the partners; (vii) inadequacies in the participation of civil society organizations which can ensure that the investments are relevant and provide information on their own interventions; (viii) inadequacies in the participation of private sector actors whose performance is below expectations.

\section{(d) Difficulties in coordination and functioning of institutions}

352. The PRS institutional mechanism is coordinated by the PRS Permanent Secretariat at the technical level. This structure, which is the linchpin of the mechanism, has prepared various annual PRS implementation monitoring reports. The effectiveness and operation of the system largely depends on the capacity of the central structure to mobilize all the statistical data production and user structures in Government services, institutions and the civil society. However, this structure also encounters certain difficulties in carrying out its missions, in particular lethargy of certain committees of the institutions, limited material resources, poor communication between the sectors, and inadequate capacities at the top levels of the institutions. Similarly, in certain cases, the lack of sectoral policies, medium term expenditure frameworks, reference points and specific targets in the indicators make it difficult to monitor and report on the process

353. Furthermore, the high level of participation in PRS formulation declined during the implementation phase due to difficulties of application of the communication plan. This weakened the PRS ownership process for certain stakeholders.

354. Lastly, the annual PRS implementation reports have not really served as decision-making instruments for the political authorities mainly because of inadequate information and poor analyses which do not guide choices.

\section{(e) Low Capacities for Policy, Programme and Project Monitoring-Evaluation}

355. The current monitoring-evaluation mechanism is centred on a hard core represented by the Directorate general of Development Programmes Evaluation (DGEPD) of the Ministry of the Economy and Finance (MEF), the Studies and programming Departments (DEP), the Sectoral Statistics Departments of the sectoral Ministries and the Project Management Units. In addition to this hard core, there are also other structures which have their own information systems, in particular the Executive Secretariat for the Rural Development Strategy.

356. However, diagnostic studies conducted over the period show that the efforts made to ensure the operation of the monitoring-evaluation mechanism, there are still certain inadequacies, in particular: (i) lack of effective implementation of missions for structures involved in the mechanism, due mainly to inadequate human, material and financial resources; (ii) lack of clarification or ignorance of the roles of each operator due to the absence of a regulatory mechanism defining relations between the different structures; (iii) limited dissemination and use of monitoring-evaluation products; (iv) inadequate impact assessment and evaluation of public policies.

\section{(f) Inadequacies in the Statistical Information System}

357. The formulation and monitoring-evaluation of strategies and policies for PRS implementation require a lot of high quality information, better knowledge of the living conditions of the populations and reliable assessment of the results and impacts of policies and the phenomenon of poverty. During PRS implementation, several actions were taken to improve not only the monitoring-evaluation mechanism but also availability of statistical data. These actions led to the reform of the National Statistics System (SSN) with the creation of a National 
Statistics Institute and sectoral statistics departments, as well as the establishment of a National Statistics Council. This boosted the production and dissemination of statistical information.

358. In spite of this significant progress, weaknesses still exist, especially as a result of: (i) lack of strict programming of statistical activities within the SSN; (ii) limited use of the information in decision-making; (iii) inadequacies in targeting the populations; (iv) low geographical coverage; (v) obsolescence and lack of disaggregated data; (vi) failure to harmonize concepts; (vii) inadequate data analysis; (viii) limited dissemination of information.

359. These problems stem mainly from low institutional, human and material capacities and difficulties in the overall coordination of the mechanism.

\section{I.4. NIGER'S CONSTRAINTS AND RESOURCES}

\subsubsection{Constraints and threats}

360. Several factors undermine Niger's performance in accelerating economic growth and poverty reduction; they include:

361. The climatic conditions of Niger follow medium-term cycles. The country has witnessed several successive periods of low rainfall - in the early 1970s, the 1980s, and to a lesser extent, in the mid-1990s - which endangered agro-salvo-pastoral production, leading to long-term degradation of the environment and living conditions of the populations (particularly in rural areas). Moreover, climatic conditions have been deteriorating since 1960 (average of $445.8 \mathrm{~mm}$ of rainfall in the $1960 \mathrm{~s} ; 423.5 \mathrm{~mm}$ in the $1970 \mathrm{~s} ; 354.7 \mathrm{~mm}$ in the $1980 \mathrm{~s} ; 300$ $\mathrm{mm}$ in the 1990s).

362. Natural disasters and locust invasions are also frequent in Niger, thereby helping to accelerate vulnerability of agricultural production. The frequent heat (temperatures above 35 degrees for most of the year) does not foster productivity, and sometimes reduces Niger's attractiveness to foreign investors.

363. Deforestation and desertification are progressing unrelentingly. Natural forests reduced from about 16 million hectares in 1982 to about 5 million hectares in 2006, due to farmland requirements and climate change.

364. Low soil fertility and the effects of human action, animals and climatic phenomena on the earth reduce yields. Indeed, the population is concentrated on a very small area of land, particularly on the southern strip of the country conducive to agriculture. Consequently, there is a strong pressure on land availability which forces people to use increasingly marginal lands. Furthermore, in view of the archaic production methods and limited use of agricultural inputs, the possibilities of improving farm yields are limited.

365. The geographic size $(1,267,000 \mathrm{~km} 2$ two-thirds of which is desert land) generates high transport costs and increased difficulties in providing the territory with economic and social infrastructures.

366. The country's landlocked position is a serious handicap for the import of inputs and capital goods, as well as for exports, and is therefore unfavourable for the country.

367. Vulnerability to shocks in terms of trade continues to affect the country, due to lack of economic diversification and heavy dependence on export of a limited number of products (particularly uranium and agropastoral products).

368. Raid population growth (3.3\% per year) makes Niger one of the countries with the highest fertility rate in the world (7.1 children per woman, which doubles the population every 21 years), generates low per capita income and high poverty rates. Indeed, due to low levels of income and capital stock, rapid population growth is a major constraint on economic growth, because the net per capita savings rates are not enough to allow for capital accumulation. Furthermore, the poor populations, in rural or periurban areas with very large families, very often have the lowest resources and consequently cannot afford adequate health and education services, as well as drinking water or sanitation. Consequently, in these areas, poverty increases and becomes a self-sustained phenomenon. 
369. The narrow domestic market is a handicap. With an annual per capita income of CFAF 141,800 (US\$ 284), a low solvent middle class and a population of nearly 13 million inhabitants, Niger's market is narrow and is not conducive to large scale production that can reduce unit production costs and make products competitive against similar Nigerian products.

370. Difficulties in the promotion of women and gender mainstreaming into policies are also major constraints. Beliefs and values affect the position of women in society, limiting access by girls to quality education and by women to employment; and thereby reducing the country's human capital potential.

371. Low level of literacy $(28.7 \%$ in 2005$)$ and education (45.9\% primary education net enrolment rate in 2006), as well as health and nutrition conditions of the population affect the quality of human capital and overall factor productivity, possibilities of access to employment and income-generating activities, as well as the hygiene, health and environmental behaviour of the populations. All these factors make it difficult to achieve poverty reduction indicators.

372. A combination of these different factors "traps" Niger in a weak economic growth balance and in a "poverty trap". Indeed, the cause and effect relation between poverty and growth is bidirectional. Accordingly, growth is required to reduce poverty; a high incidence of poverty can also be a major constraint on growth. Niger's challenge is to transform this vicious circle by using its resources to generate strong sustainable growth that is favourable to the poor.

\subsubsection{Niger's Resources and Opportunities}

373. Despite Niger's difficult economic and social situation in the 90 s, a better future is possible thanks to its resources and opportunities:

374. Political stability. Indeed, Niger is today a very stable, democratic and well-governed country. In 7 years, the country has organized two presidential elections, two parliamentary and municipal elections generally recognized as fair and transparent, thereby leading to the establishment of several institutions, enduring peace in the country and improvement of dialogue between political actors, the civil society, the private sector and development partners.

375. The youthfulness of the population is also a major asset for the country (31\% of the population is aged 15 to 35 years). Indeed, the youthfulness is a lever for boosting economic recovery in Niger, especially if the youths are more involved in the formulation of economic and social policies and benefit from better targeted training actions, enabling them to obtain decent jobs, and even lines of credit to start their own businesses and thereby become employers in turn.

376. The country's historical and cultural heritage is very rich and varied. The existence of rare species of animals, manuscripts, cave sculptures, dinosaur bones and regular organization of cultural and sports events (music, dances, fashion, traditional wrestling) offer opportunities to develop tourism in Niger.

377. Ingenuity of Niger craftsmen: Niger's handicrafts are highly appreciated at the regional and international levels for their value and quality.

378. Niger's rich subsoil : Niger has considerable potential in minerals: uranium, petroleum, lime stone, coal, gold, gypsum, marble, phosphate, iron, cassiterite, and copper that can be exploited because the investment conditions are very attractive.

379. The water resource potential in Niger comprises water systems, surface water of more than 32 billion $\mathrm{m}^{3}$ /year, large ground water reserves of about 2.5 billion $\mathrm{m} 3$ renewable and 2,000 billion $\mathrm{m} 3$ non-renewable. This water potential is underexploited with less than $1 \%$ mobilized for agricultural purposes. The irrigated lands potential is estimated at about 270,000 ha, located in the river valley (52.6\%), Dallols Valley (14.4\%), the AderDoutchi-Maggia (10.4\%), the Komadougou Yobé, Lake Chad and oasis basins (7.4\%), the Goulbi Valley $(3.9 \%)$, the Koramas (3.7\%), Airr Plains and oases (3.7\%), Tarka Low Valley (2.6\%). 
380. The livestock potential is considerable: The livestock population, according to the General Agriculture and Cattle Census (RGAC) 2004/2005, is estimated at nearly 29 million head of cattle. The livestock population is dominated by goats $(38 \%)$, sheep (31\%), cattle $(25 \%)$, donkeys $(5 \%)$, and horses $(1 \%)$.

381. The high social capital and willingness of Niger's people to live together is also a guarantee for stability. Indeed, cousin relationships, marriages between several ethnic groups and the spirit of solidarity, are values which consolidate national unity.

382. Regional integration is a factor for development, stability and solidarity between peoples. Niger shares borders with 7 African countries, on the four cardinal points, and can transform its natural junction location into a strategic advantage to become a sub-regional hub for trade, investment and international transport.

383. Renewed interest of the international community in Niger, motivated by the improved political, economic and social situation in the country, gives Niger additional capacities to accelerate development and reduce poverty.

\section{I.5. SCENARIOS OF THE FUTURE}

384. A strategic diagnosis of Niger shows a trend scenario, marked by continued average economic growth, but vulnerable to climatic shocks and terms of trade within a context of population growth.

385. This unambitious scenario is not sustainable in the long term and runs a major risk - threat to social cohesion; it would mean that the majority of Niger's population would continue to be poor and vulnerable, would not have access to quality social services, and would be deprived of the benefits of the ongoing globalization. Consequently, it is necessary to identify measures that could rapidly change the future of Niger and place it among countries with rapid economic growth and reduced poverty.

386. To that end, four key factors determine the possibility of bringing about great change in Niger: (i) intensification and modernization of agriculture and stockbreeding; (ii) diversification of sources of economic growth; (iii) control of population growth; (iv) establishment of effective social programmes.

387. A combination of these four factors led to the formulation of a trend scenario, an intermediate scenario of agricultural intensification and MDG achievement scenario by 2015. They are presented below:

388. First, a trend scenario or "Niger PMA" based on the implementation of a policy of coherent economic and financial reforms to consolidate the macro-economic framework. It is based on the following main assumptions:

- continued political stability;

- continuation of reforms (public finance, financial sector, public enterprises, legal business environment) ;

- average rainfall well distributed in space and time;

- a phytosanitary situation under control;

- maintenance of the current level of demand for agro-pastoral products from Nigeria ;

- non-degradation of the uranium market;

- limited mining diversification;

- continuation of programme to reinforce economic and social infrastructures;

- capacity building of the administration for better supervision of various policies;

- mobilization of external resources.

389. Based on these assumptions, the projected average growth rate is $4.2 \%$. It will be driven mainly by the agricultural sector which would grow at an average rate of $4.1 \%$ as against $3.6 \%$ for the $2000-2005$ period.

390. The main result will be an improvement of per capita GDP which would stand at an average of $0.9 \%$, implying a poverty rate of $57.7 \%$ in 2012 and de $56.3 \%$ in 2015 . With this assumption, the country would not achieve the MDGs by 2015. The other sustainable human development indicators would remain low. 
391. Secondly, an intermediate scenario « Developing Niger» based on the following assumptions:

- continued macro-economic stability;

- strengthening of political stability;

- very favourable climatic conditions for agro-pastoral production;

- SDR implementation (acceleration of implementation of the irrigation policy, intensification of investments, attraction of private investors to the rural development sector) ;

- creation of new modern production enterprises that would increase domestic demand for agrosylvo-pastoral products;

- increase in external demand with a favourable economic situation for Nigeria (increase in export of Niger products to Nigeria) ;

- domestic price levels maintained;

- increase in credits to the economy for the rural development sector in general and for the agricultural sector in particular (currently $1 \%$ ) ;

- favourable trend of the uranium market and moderate effort towards mining and energy diversification (start of oil exploitation, discovery and exploitation of new gold deposits) ;

- acceleration of implementation of reforms (public finance, financial sector, legal business environment) ;

- acceleration of capacity building for the administration for better supervision of various policies;

- increased mobilization of external resources.

392. Based on these assumptions, the average growth rate would be $5.7 \%$. It would be driven first, by the agricultural sector which would grow at an average rate of $7 \%$. The mining sector would also contribute to the projected overall growth with an average rate of $8 \%$ over the 2008-2012 period. It would be stimulated by upward trend of the demand and prices of uranium, the start and exploitation of new deposits as well as start of oil exploitation and phosphate project in Tahoua and coal project in Salkadama.

393. The main results will be an improvement of per capita GDP which would stand at an average of $2.4 \%$, and poverty rate reduced to $53 \%$ in 2012 and $49.5 \%$ in 2015 . Despite significant progress, some MDG targets would not be achieved.

394. Third, an MDG achievement scenario or «Emerging Niger» based on the same assumptions as for the "Developing Niger" scenario in addition to:

- Greater diversification of sources of growth (through development of handicraft, tourism and agroindustry) and modernization of the rural sector;

- $\quad$ effective oil exploitation as from 2008 or 2009;

- firm commitment of partners to support Niger in achievement of MDGs through effective mobilization of expected resources;

- successful implementation of social programmes targeting the poor and seeking to reduce inequalities;

- decline in population growth rate (from $3.3 \%$ to $3.1 \%$ on average over the period) ;

- good governance within a context of social cohesion.

395. This scenario counts on an average economic growth of 7\% over the 2008-2012 period, driven by rapid, intensive and sustainable growth in the agro-pastoral sector, stronger growth in the diversification sectors (Mining, Handicraft, Tourism, Petroleum).

396. The main expected results are significant improvement of per capita GDP (which would average at $3.9 \%$ ) and reduction of poverty to $42 \%$ in 2012 and to $32 \%$ in 2015 . Under these conditions, Niger would achieve the MDGs in 2015 and the concept of "Niger's miracle" would be recorded in economic literature. Niger would become one of the emerging countries, and would be harmoniously integrated into the world economy and benefit from good sustainable human development indicators.

397. Niger is determined and willing to transform this MDG achievement scenario into reality. 


\section{PART TWO: VISION, OBJECTIVES AND STRATEGIC ORIENTATIONS}

\section{II.1. MAJor Challenges}

398. Despite major achievements, especially as a result of the Special Programme of the President of the Republic, and significant progress made in PRS implementation, a diagnosis of poverty and assessment of policies show that the impact of the indicators on the living conditions of the population and the economy is limited. If the current trend persists, Niger will not be able to achieve the MDGs by 2015.

399. Indeed, poverty is still widespread, particularly in rural areas (nearly two people out of three in Niger live below the poverty line). The level of education is low, malnutrition is common among a large part of the population, mortality rates are high, access to drinking water is inadequate, access to energy, transport, and communication infrastructures, as well as markets is low. This situation is worsened by gender disparities in access to services and opportunities, and great vulnerability to risks relating to natural or economic shocks.

400. That is why the new Strategy should make a clean break with some dichotomic approaches so as to find coherent solutions to the following challenges:

- peace consolidation, social cohesion, and democratic achievements;

- reducing vulnerability to external shocks, (socio-economic situation, natural disasters, etc.) and dependence of the economy on climate;

- modernizing and intensifying agriculture and stockbreeding, as well as guaranteeing food security,

- sustainable management of natural resources;

- diversifying sources of Economic Growth, especially job-creating sectors;

- ownership of knowledge of technological developments in the world, as well as developing endogenous technological capacities;

- balanced territorial development in terms of economic and social infrastructures;

- gender mainstreaming in policies which will ultimately reduce inequalities between the poor and nonpoor, between men and women, between girls and boys, between regions and between rural and urban areas;

- controlling population growth;

- upgrading education and promoting training adapted to the realities of the country and in line with the requirements of the Economy;

- improving the health and nutrition status of the population;

- creating decent jobs for the entire working population, particularly for the youths and women;

- safeguarding and developing the cultural heritage;

- promoting good governance, particularly through transparent and efficient management of public resources, guaranteeing individual and collective freedoms, fight against corruption, injustice and impunity;

- consolidating and strengthening the ongoing decentralization, while empowering Local Authorities in order to promote the emergence of genuine local economies;

- institutionalizing results-based management;

- boosting public investments coupled with the implementation of objectives-based budgeting;

- pursuing the stabilization of public finance and mobilization of greater domestic revenues;

- boosting private investments;

- deepening structural reforms through implementation of ambitious sectoral policies;

- $\quad$ ensuring smooth entry of Niger into the sub-regional and regional integration process. 


\section{II.2. VISION AND OVERALL GOALS IN 2015}

401. In order to meet the numerous challenges outlined above, Niger has embarked on the revision of its Poverty Reduction Strategy (PRS) so as to make a new start and give fresh impetus to its economic and social development policy.

402. The analysis of poverty characteristics, the lessons drawn from PRS implementation, as well as International and/or Regional Commitments made by Niger require a forward-looking and innovative vision of National Development.

403. Consequently, Niger has adopted a long-term vision of «becoming an emerging country, founded on a dynamic, diversified and sustainable economy, harmoniously distributed on the national territory, a modern, civil, democratic and well-governed republic, a nation rich in its culture and shared values, a society open to the world and attached to knowledge and technological innovation, free from corruption and poverty, a nation that is prosperous, equitable, and respectful of ethics, united, peaceful and committed to African integration"

404. Realizing this vision of the Niger of tomorrow is a long and exacting task. It is necessary for all the people of Niger, at all levels, to stay the course, and lay the bases required for its realization, while avoiding any pause or back tracking in the onward march towards the ultimate goal of integral development. That is why the vision has been translated into an Accelerated Development and Poverty Reduction Strategy (ADPRS) 20082012) whose existing sectoral policies and programmes, and/or those still being developed, will serve as operational framework.

405. Consequently, the overall goal assigned new ADPRS consists in improving the well-being of the population. Specifically, Niger has the firm determination to reduce all dimensions of poverty and achieve all the MDGs for 2015. Accordingly, the incomes of the population will be increased, their health and nutrition status will be improved, their level of education will be enhanced, environmental balances will be preserved, access to modern energy services and drinking water will be reinforced, participation in decision-making will be institutionalized, towns and villages will be opened up through adequate infrastructure and universal access to NICT will be provided.

406. Furthermore, since poverty can never be completely eliminated, ways will be sought to prevent risks and mitigate their impacts on the vulnerable population. Similarly, the reduction of inequalities between the populations, irrespective of their place of residence, and the promotion of a society governed by gender equality and equity in all areas and at all levels, will be the mainstay of the strategy. In this way, national cohesion will be consolidated and each citizen will live in peace and be guaranteed social security.

407. The ADPRS aims at effectively building a New Economy for Niger and promoting strong growth (annual average of at least $7 \%$ ) favourable to the poor and sustainable human development. Indeed, in order to reduce poverty, it is vital to seek for strong and sustained growth; the pace and conditions of such growth will offer opportunities and sufficient aptitudes to the poor to participate in economic activity and benefit more from it.

408. To be sustainable, growth should have as wide a base as possible, include all the sectors and high potential areas which have the largest proportions of the working population and preserve biodiversity. In this light, the mainstreaming of cross-cutting issues, such as gender, population, youth employment, human rights and the natural environment are unavoidable imperatives. Special attention will also be paid to adequate resource allocation to the social sectors and levers of economic growth.

409. Achieving these strategic orientations will be supported through the implementation of the Rural Development Strategy (SDR), particularly through the expansion of irrigation and modernization of agriculture, the development 0 economic infrastructures, boosting of the mining sector, human and institutional capacity building, efficiency and transparency in public resource management, the fight against corruption, compliance with the basic principles of good governance and the rule of law, decentralization and territorialization of public policies.

410. To that end, regional peculiarities will be amply integrated into sectoral strategies and actions. This regionalization will be based on the orientations of the national territorial development community development 
and decentralization policy so as to reduce regional and intra-regional imbalances and give impetus to local development. It will also promote the emergence of a harmonized coordination framework for partners' interventions at all levels.

411. Convinced that the only way of significantly improving the well-being of the poor is to define poverty reduction programmes and implement them effectively, new approaches and new procedures will be gradually introduced in ADPRS management. To institutionalize these new practices, the new ADPRS has given a greater role to the management of action plans and monitoring-evaluation.

412. Besides, special attention was paid to the ADPRS alignment on the Millennium Development Goals (MDG) defined by the International Community and on the integration and poverty reduction strategies formulated at the continental level (African Union - NEPAD) and at the regional and sub-regional levels (CENSAD, ECOWAS, WAEMU).

413. In particular, ECOWAS and WAEMU have prepared Regional Poverty Reduction Strategy (RPRS) which aims at providing: (i) to regional organizations a strategic framework for better prioritizing regional programmes and combining with national programmes to maximize the impacts of growth and poverty reduction; (ii) to member States better visibility of all the regional programmes so that they can take them into account when preparing national strategies; and (iii) to partners, a strategic framework for better structuring external assistance to the countries and to the integration process so as to maximize the effectiveness of the support.

414. The regional strategy orientations and policies are centred on four pillars:

- the management of transnational challenges, particularly conflicts, migratory movements and the promotion of democracy and good governance to strengthen social cohesion in the country;

- in-depth integration into the economic space to reduce costs and increase competitiveness so as to accelerate diversification and strengthen growth;

- the development/interconnection of infrastructures to support integration into the economic space and improvement of its competitiveness;

- enhancement of human capital and facilitation of its mobility through the common space to support growth and make it also distributive.

415. Niger has adopted the guidelines of the regional Poverty Reduction Strategy and those of the Regional Economic Programme (REP). The ADPRS will also be consistent with the regional priorities defined in the community sectoral programmes and policies, in particular: (i) the construction of infrastructures (roads and railways, river); (ii) the development of air transport infrastructures; (iii) the strengthening of regional energy integration through electric interconnections, and (iv) the programme to protect the Niger river basin against silting.

416. Similarly, the principles of good governance and actions to promote African integration defined by the African Union - NEPAD are guides for Niger's ADPRS.

417. That is why the ADPRS actions and expenditures has been programmed on the basis of the targets of 2015 concerning the various MDGs and complying with the convergence criteria defined at the sub-regional and regional levels; the time frame of five years selected for the ADPRS (2008-2012) is an intermediate phase in the achievement of these targets and other national and regional development indicators.

418. Based on the vision defined, Niger seeks, in particular, to attain the following targets by 2012:

i. an annual economic growth rate of at least $7 \%$;

ii a poverty rate of $42 \%$ for individuals;

iii a malnutrition rate (underweight) of $24 \%$;

iv a gross primary education enrolment rate $94 \%$;

$\checkmark$ an adult literacy rate of $45 \%$ ensuring gender parity;

vi a child mortality rate of $108 \%$;

vii a maternal mortality rate of 200 for 100,000 life births;

viii HIVIAIDS prevalence rate kept below $0.7 \%$; 
ix a drinking water access rate of $80 \%$;

$x$ increase the electricity access rate to $3 \%$ in rural areas and $46 \%$ in urban areas;

xi a $35 \%$ utilization rate of impregnated mosquito nets for children and pregnant women ;

xii a total fertility rate of 6 children per woman;

xiii area of protected lands at least equal to $8 \%$ of the national territory;

xiv $110 \%$ coverage of national cereal requirements.

419. The key to success of this new national ambition to speed up development remains the determination to achieve the goal and change mentalities, so that each citizen and each official at every level, internalizes these virtues and values of a democratic society, productive work, the virtues of peace and stability and those of an environment conducive to production and transparent management practices in the private and public sectors.

420. To achieve these objectives, the ADPRS will be implemented on the basis of seven (7) pillars:

- Pillar 1: Search for strong, diversified, sustainable and job-creating growth;

- Pillar 2: Equitable access to quality social services;

- Pillar 3: Control of population growth;

- Pillar 4: Reduction of inequalities and strengthening of social security of the vulnerable groups;

- Pillar 5: Infrastructure development;

- Pillar 6: Promotion of good governance;

- Pillar 7: Effective implementation of the strategy. 


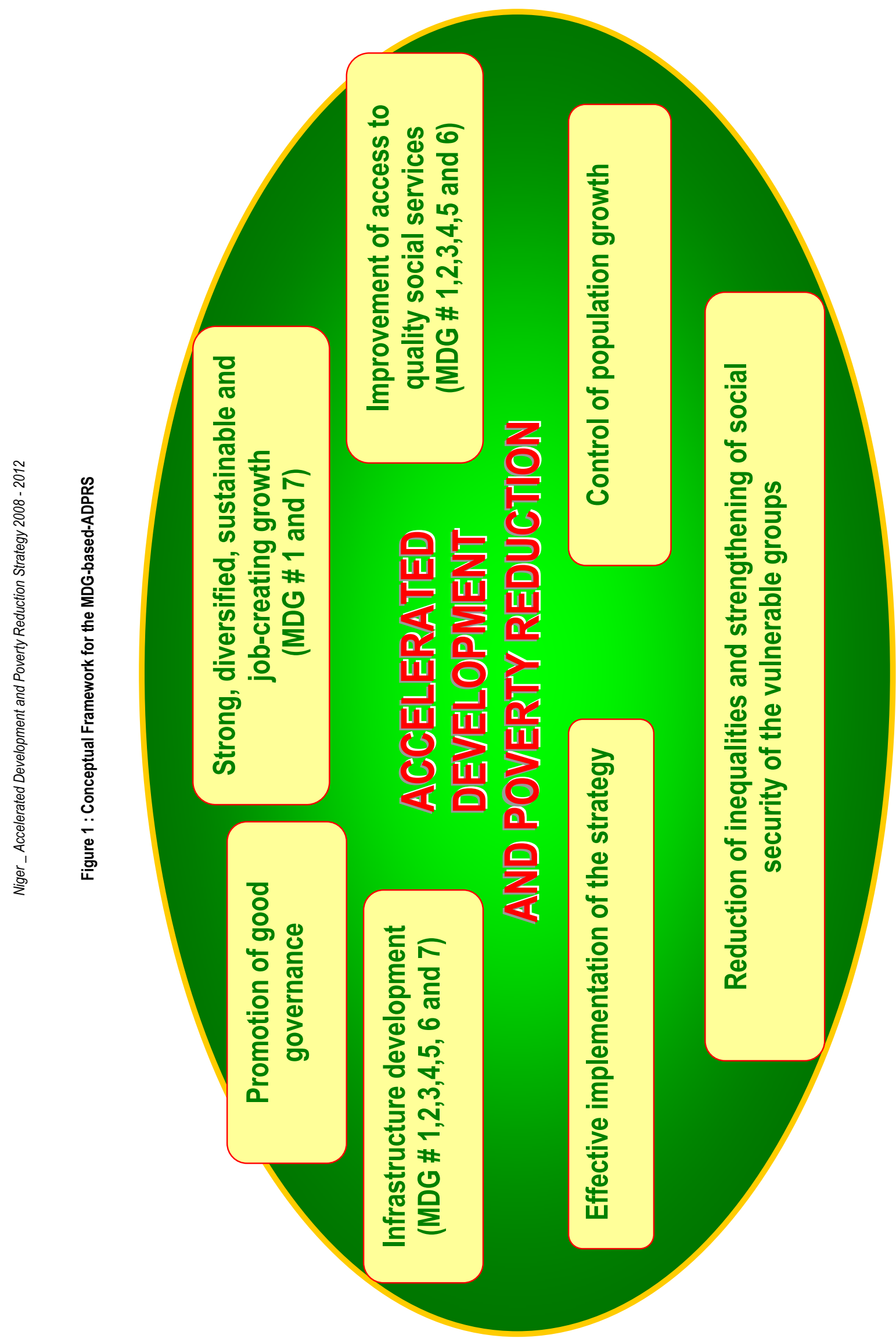




\section{II.3. STRATEGIES FOR POVERTY REDUCTION AND MDG ACHIEVEMENT}

421. The specific objectives and lines of action for each of thee seven (7) pillars are outlined below.

\subsubsection{Search for strong, diversified, sustainable and job-creating growth}

\section{$\checkmark$ Baseline case of the pillar:}

422. The baseline case is as follows:

- Economic growth is low and erratic

- The productive base is narrow

- Per capita GDP virtually stagnated between 1993 and 2006, making it impossible to reduce poverty

- Environmental resources are threatened.

423. Strategic objective of the pillar: Accelerate economic growth, diversify its sources and make it benefit the poor equitably and sustainably

D MDG Indicators for 2012 and 2015:

\begin{tabular}{|c|l|l|l|r|r|}
\hline $\begin{array}{c}\text { Corresponding } \\
\text { MDG }\end{array}$ & \multicolumn{1}{|c|}{ Adopted MDG Targets } & Adopted Indicators & $\begin{array}{c}\text { Current Level } \\
\text { (2006) }\end{array}$ & $\begin{array}{c}\text { Projected } \\
\text { Level in 2012 }\end{array}$ & $\begin{array}{c}\text { Projected } \\
\text { Level in 2015 }\end{array}$ \\
\hline $\begin{array}{c}\text { Goal 1. Eradicate } \\
\text { extreme poverty } \\
\text { and hunger }\end{array}$ & $\begin{array}{l}\text { Target 1. Reduce by half the } \\
\text { proportion of people living below the } \\
\text { poverty line by 2015. }\end{array}$ & $\begin{array}{l}\text { Proportion of the population below the } \\
\text { poverty line (in \%) }\end{array}$ & $60.7^{12}$ & 32 \\
\hline $\begin{array}{c}\text { Goal 7. Ensure } \\
\text { environmental } \\
\text { sustainability }\end{array}$ & $\begin{array}{l}\text { Target 9. Integrate the } \\
\text { principles of Sustainable } \\
\text { Development into country } \\
\text { policies and reverse the } \\
\text { current trend of loss of } \\
\text { environmental resources }\end{array}$ & $\begin{array}{l}\text { Surface area of protected lands for } \\
\text { biodiversity (in \% of the national territory) }\end{array}$ & & & \\
\hline
\end{tabular}

424. Other performance indicators for 2012:

- Achieve average economic growth of $7 \%$ over the $2008-2012$ period;

- Achieve average annual production growth of $8.7 \%$ in the agriculture sector;

- Achieve average annual production growth of $4.2 \%$ in the livestock sector ;

- Achieve average annual production growth of $4.5 \%$ in the forest and fishery sector;

- Achieve annual growth of $8.9 \%$ in the modern mining sector;

- Achieve annual growth of $6.8 \%$ in the trade and hotel industry sector;

- Achieve annual growth of $6.9 \%$ in the modern manufacturing industry;

- Ensure the country's cereal requirement coverage rate of at least $110 \%$

- Be one of the 100 best countries in terms of the quality of the business environment (Classification of the Doing Business Annual Report);

- $\quad$ Meet the WAEMU convergence criteria.

\section{$>$ Brief analysis of the strategy to be implemented:}

425. Over the past few years, economic growth has not been enough to finance investments to satisfy the essential social needs of the populations, due mainly to the dependence of the economy on the vagaries of the weather, poor performance of an embryonic private sector and many obstacles that hamper the competitiveness of Niger's economy. Job creation will be a major challenge in the quest for growth. The acceleration of sustainable economic growth will be initiated in six (6) areas of action:

12 This level has been estimated 
- the development of high potential and job-creating growth clusters;

- the promotion of regional development poles;

- consolidation of the macro-economic framework;

- improvement of the overall competitiveness of the economy;

- better integration into regional and world trade;

- promotion of art and culture.

\section{(a) Development of high potential and job-creating growth clusters}

426. Today, Niger's economy is based mainly on livestock, agriculture and mining, including uranium. These three sub-sectors account for $40 \%$ of GDP and $80 \%$ of the country's exports. It is vulnerable to exogenous shocks (unstable climate and the international market situation), hence the he volatility of Niger's economic growth. New sources of growth are therefore required to implement an effective poverty reduction policy in a sustainable manner.

427. Niger has great potential in agro-pastoral and natural resources. Its subsoil contains considerable mineral reserves (uranium, petroleum, iron, copper, gold, phosphate, cassiterite, lime stone, gypsum, marble, coal, etc.). it is necessary to develop this potential as soon as possible so as to initiate genuine efforts for strong growth and give a better living conditions to the poor. That is why in 2003 adopted the Rural Development Strategy (SDR) and in 2006 its action plan and MTEF. The SDR, which has three (3) strategic pillars, will be implemented through ten (10) structure programmes and four (4) priority sectoral programmes.

428. In this light, the ADPRS will rapidly conduct a study and form sectoral working groups for the establishment of an Accelerated Growth Strategy based on the development of the highest growth-oriented clusters ${ }^{13}$ which will be considered as part and parcel of the ADPRS. Each cluster group will:

- identify the strengths and weaknesses of the cluster;

- conduct strategic diagnosis and analyze the positioning of the cluster;

- propose a future vision for the cluster;

- outline strategic pillars and priority actions to be developed in the cluster, as well as a monitoringevaluation mechanism.

429. The priority clusters will be selected on the basis of a number of criteria including: (i) the long-term progress margin (growth potential) ; (ii) the potential and the generated added value; (iii) the competitiveness potential; (iv) the export potential; (v) the potential for creating new jobs, particularly for the poor.

430. Already, four priority clusters appear as sources of growth favourable to the poor: the "Rural Development» cluster (Livestock/ byproducts and Agriculture/related products), the « Handicraft » cluster and the «Tourism» cluster. Another high potential cluster is emerging ${ }^{14}:$ the «Mining» cluster.

\section{$\underline{\text { The « Rural Development » Cluster }}$}

431. In line with the role assigned to the rural sector as the engine of economic growth, Government activities in this area will fall within the Rural Development Strategy (RDS) adopted in 2003 (Decree No. 003-310/PRN/ of November 142003.

432. The RDS has the following objectives:

(i) promote access by the rural population to economic opportunities to create conditions for sustainable economic growth in rural areas;

(ii) prevent risks, improve food security, and manage natural resources in a sustainable manner so as to improve the living conditions of the population;

\footnotetext{
${ }^{13}$ The clusters are networks of enterprises, institutions, customers, all linked in a production chain that creates added value. They go beyond the sectoral approach and focus on competitiveness and creation of value.

${ }^{14}$ The strategic study on sources of growth, which will draw on existing relevant studies will deepen the identification of priority clusters.
} 
build the capacities of public institutions and rural organizations so as to improve management of the rural sector.

433. Under the SDR implementation, the lines of priority interventions are as follows:

- Access by rural producers to natural resources, in particular land is secured ;

- Products harvested from the natural environment are produced and fishery increased on a sustainable basis ;

- Management of water and other natural resources is improved and sustained.

- Conflicts relating to natural resources are reduced;

- Environmental protection practices are adopted by rural producers ;

- Water and wind erosion are reduced.

- The silting of infrastructures and water points is contained ;

- The biodiversity of wild and domestic species is preserved.

- The populations of animal and plant species are increased.

434. These interventions will be transformed into actions, particularly in the agriculture, livestock and natural resource management sectors.

435. Livestock and byproducts: Niger has already established its position in the sub-region as exporter of products such as life animals. The strategy to be developed will encourage access by rural producers to economic opportunities and create conditions for sustainable economic growth. In this light, the country will position itself in the export of processed products, particularly meat, hides and skins, for which there is potential solvent demand in the sub-region. Nigeria, which imports the bulk of the livestock products processed in Niger, may be an asset. Furthermore, there seems to growing demand in Europe and Asia for hides and skins. Efforts will focus on:

- the improvement of productivity and animal production;

- $\quad$ the promotion of modern and intensive stockbreeding;

- the improvement of water and cattle feed supply, as well as animal health;

- the promotion of competitive industries for milk, meat, and hides and skins,

- the development of storage, conservation and export facilities.

436. Agriculture and related products: The choice is based on the need to prevent risks, improve food security and manage natural resources sustainably, so as to obtain sustainable economic growth which will be the linchpin of the strategy. Indeed, a study conducted by the Ministry of the Economy and Finance in Niger ${ }^{15}$ shows that when grows by $1 \%$, GDP grows by more than $1.03 \%$. Similarly, a World Bank study ${ }^{16}$ shows that an increase in agricultural productivity (particularly, irrigated food and export crops) by $1 \%$ of GDP would have an impact on GDP ranging from $1.9 \%$ to $2.6 \%$, thereby helping to reduce poverty in Niger significantly.

437. The priority actions in Agriculture and related products will concern in particular:

- the development of structures, particularly irrigation infrastructure, including minor irrigation;

- providing farmers with appropriate technological packages and advisory services;

- $\quad$ promoting the consolidation of parcels ;

- investment in soil fertility;

- promotion of food crops (particularly millet, sorghum and vegetable crops), so as to eliminate inertia in cereal production and each year meet all the country's cereal requirements;

- diversification of production, targeting niche products for which Niger has a comparative advantage (onion, cowpea, Arabic gum, nut sedge) ;

- reduction of post-harvest losses, by reinforcing conservation capacities;

- processing of agricultural products to give them added value;

- $\quad$ the protection of biodiversity ;

- the promotion of research and its operational link with education and agricultural extension;

\footnotetext{
${ }^{15}$ Ministry of the Economy and Finance, Commissioner for the Economy, Marc-economic Management Support Group, « Study on sources of growth », Dr Tarno Mamane, October 2004, on financing from the African Development Bank, Pages 23-24.

${ }^{16}$ World Bank, Niger Office, « Economic Memorandum for Niger », July 2006.
} 
- control of desertification and environmental degradation;

- enhancement of management of the sector and organization of the actors ;

- improvement of access to decentralized financial services;

- better circulation of information on markets.

438. Improvement of natural resource management: In view of environmental degradation which endangers the sustainability of productive bases and sources of income for households, the Government will implement actions to preserve productive capital through significant improvement of the practices of rural producers by establishing and promoting durable farming systems. In addition to the intensification of production system, new forms of resource management will be sought through individual or collective empowerment of the main users, particularly rural producers. Similarly, actions to promote environmental protection will be pursued by expanding classified areas, improving conditions for their management (regulatory aspects, material and human resources, association of riparian populations and integration into the territorial development plans) and reinforcing interventions around and in protected areas to improve the integration of agricultural, pastoral and harvesting activities, with those of the protection of biodiversity and sensitive species.

439.Priority will be given to the establishment of local governance mechanisms for natural resources so as to create conditions conducive to the introduction of sustainable farming methods and restoration of some degraded species; this will concern in particular securing access for the rural population to land resources and preventing conflicts. Sustainable management of water resources requires improvement of knowledge about them and institutional framework of their management.

440.To that end, the regulatory framework provided by the Rural Code will be supplemented, disseminated and implemented throughout the country. As part of decentralization, the role of local authorities in the management of natural resources will be specified and gradually reinforced. In particular, the concessioning of forest resource management to organized local structures will be developed. The integrated management of water resources will be established in the catchment basins. At the sub-regional level, consultation on the management of shared resources will be reinforced (management of shared waters, management of transhumant cattle).

441.The substitution of fuel wood through the promotion of renewable energy, butane gas and mineral coal will be pursued. The control of all types of pollutions will also be pursued, particularly through sensitization, regulations and control. Cases of environmental degradation beyond the management capacities of the affected populations will require appropriate public intervention (control of invading plants, dune fixation, restoration of degraded soils, particularly in catchment basins, reforestation, treatment of koris etc). Efforts will also be made to preserve the biodiversity of wild and domestic species through " in situ " and " ex situ " conservation in threatened areas.

442. Specifically, SDR implementation will promote the programme approach to streamline conditions for public intervention in the sector. The fourteen programmes below are gradual convergence frameworks for interventions through ten (10) structure programmes and four (4) priority sectoral programmes:

\section{- Priority Sectoral Programmes:}

1. Local and Community Development Programme

2. Local Natural Resource Governance Programme (land, water, vegetation, wild life) »

3. Professional Organizations and Sector Structures Programme (interprofessional consultation frameworks, strengthening and structuring of professional organizations, marketing of agro-sylvo-pastoral products, capacity building for economic agents and development of the rural economic fabric)

4. Rural Infrastructure Programme (irrigation infrastructures, transport infrastructures, communication infrastructures, rural electrification)

5. Rural Financial Systems Programme

6. Research Training Extension Programme

7. Programme for the Strengthening of public institutions of the rural sector (Restructuring of public institutions of the rural sector, information systems and knowledge of the rural sector)

8. Drinking Water and Sanitation Programme

9. Programme for reducing the vulnerability of households (Prevention and management of crises and natural disasters, Health - nutrition, increase in incomes of the most vulnerable)

10. Environmental Protection Programme 


\section{- Priority Sectoral Programmes:}

1. Irrigation Development Programme

2. Pastoral Development and Security for Pastoral Systems Programme

3. Land Restoration and Reforestation Programme

4. «Kandadji: Regeneration of ecosystems and development of the Niger River Valley » Programme

443. Furthermore, since Niger's economy greatly depends on agricultural and pastoral productions (greatly dependent on climatic factors), mainstreaming of weather and climatic information into sustainable socioeconomic development and disaster prevention activities is of special importance. To that end, the Government undertakes to : (i) reinforce the weather observation and surveillance networks, (ii) improve the collection, processing, and archiving of weather and climatic data, (iii) make weather and climatic products available to the users, (iv) rehabilitate equipment (weather radars in Niamey and Zinder).

444. Handicraft Cluster: Handicraft provides many jobs. According to the RGP/H 2001 results, there are nearly 367,000 micro and small handicraft enterprises (MPEA), in more than 115 activities employing more than 600000 persons. The proportion of women handicraft is $52 \%$. They are engaged in weaving, pottery, exploitation of gypsum, basket making and processing. The promotion of small-scale mining (gold washing, salt works, and gypsum) is a priority for Niger. The same applies to small-scale fishery, whose potential is under-exploited today. A national handicraft development strategy will be established around the following priorities:

- Capacity building for operators in organization, technical skills, management and innovation ;

- Modernization of equipment and working tools for craftsmen;

- Establishment of new financial instruments for the handicraft sector;

- Adaptation of the tax system and social coverage to the specificities of the sector;

- Strengthening and modernization and handicraft areas and parks;

- Development and promotion of handicraft products on the markets.

445. Tourism Cluster; A National Sustainable Tourism Development Strategy (NSDST), together with a fiveyear operational action plan, is currently being prepared. Its implementation pillars will concern: (i) identification and development of new tourism sites; (ii) training and improvement of the quality of service; (iii) promotion and marketing; (iv) institutional support; and (v) development of local activities

446. The Mining Cluster; With the explosion of the spot price of Uranium since 2004, deposits considered as marginal a few years, will be exploited in a profitable manner. Under these conditions, uranium export forecasts for Niger should increase as from 2009 (4,703 tonnes) to 8,843 tonnes in 2012, as against 3,600 tonnes in 2007. Niger will try to gradually develop the local processing of the product so as to increase the added value of the " uranium » cluster. Efforts to protect the environment and control health risks in uranium exploitation will be pursued.

447. Similarly, Niger has embarked on promoting its petroleum potential by attracting several partners in exploration. To that end, three boreholes started in 2003 and others should follow in coming months. Petroleum production will start in 2009-2010. it will open new prospects for growth for the country. Special attention will be paid to the good use of petroleum resources, drawing on best practices at the international level.

448. Furthermore, small scale mining (gold, tin, gypsum, salt...) in several regions of the country employs thousands of people and give them significant incomes. That is why the Government will try to improve and sustain this activity by: (i) organizing the small scale mining sub-sector (EMPE), (ii) providing support to EMPE developers, (iii) eliminating the worst forms of child labour in the sector, (iv) protecting the mining environment, (v) improving the health status of EMPE developer, and (vi) controlling marketing.

\section{(b) Promotion of regional development poles:}

449. Taking regional specificities into account is a priority for the ADPRS. This has the advantage of reinforcing the localization of national and international development objectives. In particular, the implementation of the Rural Development Strategy (SDR) at the regional and local level is consistent with the guidelines defined in the national territorial development policy and in the national local and community development policy which, 
both aim at minimizing regional and intra-regional imbalances, controlling rural exodus, promoting the rational exploitation of natural resources and better developing regional potentials. Accordingly, each of the eight (8) regions prepared a document during the revision of the PRS.

450. Regional development poles will emerge according to economic opportunities, especially agro-sylvopastoral potentials, as well as mining, handicraft, tourism and cultural resources. (See Table 21).

Table 20 : Regional Potentials and Priority Areas of Intervention

\begin{tabular}{|l|l|l|}
\hline Regions & Potentials & Potential Comparative Advantages \\
\hline Agadez & $\begin{array}{l}\text { Onion, garlic, potatoes, date, grape, } \\
\text { citrus fruit, salt, cattle, uranium, coal, } \\
\text { petroleum, handicraft and tourism }\end{array}$ & $\begin{array}{l}\text { Mining, Irrigation, Export of cattle, Handicraft } \\
\text { and tourism }\end{array}$ \\
\hline Diffa & $\begin{array}{l}\text { Onion, Arabic gum, pepper, fish, rice, } \\
\text { maize, sorghum, petroleum, cattle, } \\
\text { natron, date, handicraft and tourism }\end{array}$ & $\begin{array}{l}\text { Irrigation, fisheries, cattle, handcraft and } \\
\text { tourism }\end{array}$ \\
\hline Dosso & $\begin{array}{l}\text { Fish, rice, maize, groundnut, sugar } \\
\text { cane, sesame, Arabic gum, cotton, } \\
\text { small ruminant and poultry, handicraft } \\
\text { and tourism }\end{array}$ & $\begin{array}{l}\text { Irrigation, Cotton, groundnut, maize, sesame } \\
\text { fisheries, poultry, handicraft and tourism }\end{array}$ \\
\hline Maradi & $\begin{array}{l}\text { Groundnut, cotton, sedge, sesame, } \\
\text { Arabic gum byproducts, tobacco, } \\
\text { small ruminant, iron }\end{array}$ & $\begin{array}{l}\text { Irrigation, groundnut, sedge, cotton, sesame } \\
\text { Export of small ruminant, handicraft and } \\
\text { tourism }\end{array}$ \\
\hline Tahoua & $\begin{array}{l}\text { Onion, cotton, fish, cattle, Arabic } \\
\text { gum, phosphate, gypsum, limestone, } \\
\text { coal, handicraft and tourism }\end{array}$ & $\begin{array}{l}\text { Irrigation (onion,) Cotton, Export of cattle, } \\
\text { Mining, handicraft and tourism }\end{array}$ \\
\hline Tillabéri & $\begin{array}{l}\text { Arabic gum, rice, fish, sugar cane, } \\
\text { sedge, cattle, iron, gold, phosphate, } \\
\text { coal, handicraft and tourism, } \\
\text { hydroelectricity }\end{array}$ & $\begin{array}{l}\text { Irrigation (sugar cane, rice) and hydro- } \\
\text { electricity, sedge, fisheries, bee farming, } \\
\text { Mining, handicraft and tourism }\end{array}$ \\
\hline Zinder & $\begin{array}{l}\text { Groundnut, sugar cane, Arabic gum, } \\
\text { cattle, gold, handcraft and tourism }\end{array}$ & $\begin{array}{l}\text { Irrigation (sugar cane), groundnut, bee } \\
\text { farming, export of cattle, mining, handicraft } \\
\text { and tourism }\end{array}$ \\
\hline Niamey Urban Community & $\begin{array}{l}\text { Arabic gum, rice, fish, small ruminant, } \\
\text { poultry, }\end{array}$ & $\begin{array}{l}\text { Irrigation, fisheries, poultry, handicraft and } \\
\text { tourism }\end{array}$ \\
\hline Source: Contributions by the & regions to PRS revision & \\
\hline
\end{tabular}

Source: Contributions by the regions to PRS revision

\section{(c) Consolidation of the macro-economic framework}

451. The consolidation of a sound macro-economic framework to promote growth and reduce poverty is a prerequisite for the success of any accelerated growth policy. The various IMF evaluations of the WAEMU multilateral surveillance mechanism conclude that Niger has a relatively good macro-economic framework. The stabilization of public finance since 2000 , coupled with BCEAO prudent monetary management has helped to contain the budget deficit, the external deficit and inflation within acceptable levels (average of below 3\% for inflation). The effort to control deficits will be pursued to meet all the WAEMU convergence criteria.

452. Similarly, efforts will be made to improve public revenue, by modernizing tax services and broadening the tax base, improving recovery and reinforcing controls. Furthermore, the programming of public expenditures will be improved so as to better target the priority sectors in poverty reduction (health, education, rural development and infrastructures) and support the development of pillars and levers of economic growth.

453. Public debt management will be consolidated and Niger will give priority to concessional loans to fill its financing gap. To that end, a national public debt committee will regularly update the debt reduction strategy to ensure viability of the debt. To improve relations between the State and economic operators, the domestic arrears clearance policy will be accelerated. 


\section{(d) Strengthening of the overall competitiveness of Niger's economy:}

454. Niger can attract substantial investments in its growth clusters only if it strengthens the overall competitive edge of its economy. Priority reforms will therefore be carried to achieve this goal. Efforts will specifically focus on:

- improving the micro-economic business environment;

- setting up a support mechanism for the private sector;

- improving the financing of the economy;

- pursuing implementation of the National Micro-finance Strategy.

455. The improvement of the micro-economic business environment will give to issues with the greatest impact on investors' perception of Niger. To that end, actions will aim at the following aspects: (i) Preparation, adoption and implementation of an action plan to improve the business climate on the basis of indicators (creation of enterprises, taxation, access to land, external trade, regulations in construction, stop of business activity, performance of contracts, obtaining credit, protection of investors, labour market), (ii) Preparation and implementation of a national industrial property policy, (iii) Establishment of a technological and regulatory monitoring, (iv) Conduct of a study on factor costs, (v) technical capacity building for agro-pastoral industries, (vi) implementation and monitoring of national standards and documentary management, (vii) preparation of regulations certification system for products, (viii) preparation and implementation of a reforms communication, sensitization and dissemination plan and regulatory and institutional measures, (ix) Organisation of dialogue with the private sector to lay the bases for a fruitful public-private partnership.

456. The private sector support mechanism will be streamlined to make it more efficient, as well as upgrade it to the level of similar mechanisms in other countries. This reorganization will take place along with the establishment of a reference institution for each specific function of private sector development: (i) strengthening of the Investment promotion Centre (CPI) and the Corporate Formalities Centre (CFE), (ii) Creation of the Approved Management Centre (CGA) and strengthening of the Exports promotion Agency of Niger (ANIPEX), (iii) establishment of a mediation and arbitration court, (iv) strengthening of the National Management Development Centre ( CNPG), (v) Construction of a National fairs and Exhibition Park, (vi) Establishment of a monitoring mechanism for the SME charter and creation of a SME Observatory, (vii) Preparation and implementation of the Enterprises Upgrading Programme, (viii) creation and development of industrial lands, (ix) Creation of a National Industrial Property Centre, $(x)$ consolidation of «Entreprendre au Niger » (EAN), (xi) establishment of an agency to verify compliance of imports with local standards, (xii) Creation of business incubators, (xiii) human capacity building/training of senior staff of the Ministry of Trade, Industry and Standardization, the Chamber of Commerce and Industry, and support institution. The Private Sector Recovery Priority Programme, which is being updated, will contribute to it.

457. Improvement of financing of the economy is indispensable to increase the access rate to financial services to a convenient level (the credit to the economy/GDP ratio was $6.3 \%$ in Niger in 2006, as against the WAEMU average of $14.8 \%$ ).

458. The Government will pursue reforms to improve the legal environment. Similarly, capacity building actions (training, technical assistance) will be pursued to improve banking and financial management and ensure better communication between the legal professions and representatives of financial institutions. The clearing of arrears to financial institutions by the State will continue as part of the drive to clear domestic debt.

459. Furthermore, a SME/SMI promotion fund (with components for refinancing, guarantee, risk capital...) and an Exports Financing Fund (FADEX) will be put in place.

460. The Government will also pursue the privatization of Crédit du Niger as well as the restructuring of CPCT. To that end, a financial mechanism to accompany the decentralization process will be put in place to offer financing instruments to local authorities, particularly for investments. Due to the low institutional and financial capacities of the local authorities, priority will be given to grants; this financing method and technical assistance would help to remedy the inadequacies of local authorities so as to consolidate and develop their solvency. 
461. The implementation of the Financial Sector Development Project (PDSF) will be pursued, by completing the restructuring of Crédit du Niger and Niger Poste. The PDSF will intensify its actions to non-banking financial institutions, particularly insurance and restructuring of social security. A financing development programme will be established, comprising new support facilities for SME-SMI (refinancing fund, guarantee fund, risk capital, etc.). A study will be conducted to define its operating procedures.

462. Furthermore, the National Micro-finance Strategy, adopted in March 2004, will continue to be implemented. The measures concern, in particular: (i) stabilization of non-viable micro-finance institutions, supported by strict application of the regulations, particularly the operationalization of the Micro-Finance Regulation Agency (supervision and control institution); (ii) consolidation and development of professionalism, through internal organization support, provision of adequate management tools and improvement of equity capital; (iii) facilitation of access to refinancing; (iv) increase and diversification of MFI products to improve the penetration rate and bring credit nearer the poor; ( $v$ ) creation of a national consultation framework, to facilitate dialogue with the professionals of the sector.

463. The Government will pursue reform of the CNSS within an overall coherent process comprising, in particular:

- Updating of the files of the employees, employers and beneficiaries of the CNSS ;

- Updating of the institutional audit conducted and/or conduct of a new actuarial study to determine the reforms required within a programme and coherent action plan;

- Implementation of these reforms, particularly by holding tripartite negotiations between social partners, the employers and the retired persons to come to an understanding on common concerns (new parameters, unfreezing of CNSS assets in the Treasury, institution building, reduction of operating costs, etc).

464. Similarly, the National Retirement Fund (FNR) will be transformed into a State Employees Retirement Autonomous Fund (CARENI).

\section{(e) Better integration into regional and world trade}

465. In view of the continental aspirations of the country and its narrow market, Niger needs to participate in the creation of a common economic space that is large, open and promotes economies of scale and competition through the free movement of persons and goods. Such a space, which is more competitive, will promote local and foreign private investment and help to accelerate the diversification of the economy and intensify growth to meet the challenge of poverty reduction. To that end, Niger will support « aid for trade » which aims at building supply and infrastructure capacities relating to trade, so as to create conditions to attract private investments.

466. Consequently, special attention will be paid to the implementation of integrating projects (road, hospital, water mobilization infrastructures, energy, higher education, etc.), as well as bringing together the economic operators of the sub-region so as to draw maximum benefit from the potential advantages of integration.

467. A diagnostic study on Niger's trade integration is being conducted under the aegis of the Integrated Trade Framework, comprising several specialized United Nations agencies ${ }^{17}$. The study will facilitate the preparation of a sectoral trade development programme, accompanied by an action plan and a medium-term sectoral expenditure framework

468. The objectives will be to : (i) create and operate a national consultation framework, (ii) prepare, validate and implement the action matrix of the Integrated Framework for technical assistance to trade for LDCs ( EDIC), (iii) build the institutional, technical and logistic capacities under Economic partnership Agreements (EPA) with the European Union, (iv) conduct a study on the regional market, prepare and implement a strategy to consolidate Niger's position and ensure rational use of the regional market, especially Nigeria, (v) improve internal trade channels; ensure specialization and construct modern markets, (vi) establish a trade surveillance mechanism, (vii) reinforce trade infrastructures, (viii) actively explore foreign markets.

\footnotetext{
17 UNDP, World Bank, WTO, UNIDO, IMF, UNCTAD, CCI.
} 


\section{(f) Culture and Arts}

469. Since culture is the most valuable heritage of any people, it is the key factor of its identity. In this respect, the national authorities will make efforts rehabilitation of the positive values of Niger's culture. Such rehabilitation will encourage artists, writers and playwrights, musicians, film producers, painters and craftsmen to produce and show, in line with the requirements of quality and modernity, the national socio-cultural heritage, in its richness and diversity, and its vision to the rest of the world. Culture and arts will also be considered as a job-creating sector.

\subsubsection{Equitable access to quality social services}

\section{$\checkmark$ Baseline case of the pillar :}

470. The baseline case of the pillar is as follow:

- $\quad$ The high population growth (3.3\% per year) coupled with a high total fertility rate (average of 7 children per woman) exacerbates an ever increasing social demand;

- The inadequate human capital marked by a low level of social indicators and low social security (low enrolment rate, literacy rate, particularly for women) ;

- An education and vocational training system that is not in line with the requirements of the productive sector;

- Recurrent food insecurity and feeding habits that create nutritional problems among vulnerable groups;

- A precarious health status and limited integration of HIVIAIDS control activities in the PMAs of health services;

- A high proportion of deaths due to malaria; according to SNIS, $30 \%$ in 2005 , with $52 \%$ children below 5 years;

- High pressure on environmental resources, particularly wood which is the main source of domestic energy;

- Job offers do not match with the demand (unemployment rate 16\% in 2005) ;

- Limited availability of decent housing for households;

- Gender disparities inaccessibility to social services.

471. Strategic Objective of the pillar: Promote universal access to social services and make the poor benefit from them in a sustainable manner 


\section{MDG Indicators for 2012 and 2015:}

\begin{tabular}{|c|c|c|c|c|c|}
\hline $\begin{array}{l}\text { Corresponding } \\
\text { MDG }\end{array}$ & Adopted targets & Adopted indicators & $\begin{array}{l}\text { Level in } \\
2006\end{array}$ & $\begin{array}{l}\text { Desired } \\
\text { Level in } \\
2012\end{array}$ & $\begin{array}{l}\text { Desired } \\
\text { Level in } \\
2015\end{array}$ \\
\hline $\begin{array}{l}\text { 1. Eradicate } \\
\text { extreme poverty } \\
\text { and hunger } \\
\end{array}$ & $\begin{array}{l}\text { 2. Reduce by half the proportion } \\
\text { of people suffering from } \\
\text { malnutrition by } 2015\end{array}$ & $\begin{array}{l}\text { 2. Proportion of children under } 5 \\
\text { years of age who are under weight } \\
\text { (in } \% \text { ) }\end{array}$ & 44 & 24 & 18 \\
\hline \multirow{2}{*}{$\begin{array}{l}\text { 2. Achieve universal } \\
\text { primary education }\end{array}$} & \multirow{2}{*}{$\begin{array}{l}\text { 3. Provide primary education to } \\
\text { all children of school age by } \\
2015\end{array}$} & $\begin{array}{l}\text { 3. Gross enrolment rate in primary } \\
\text { education (in \%) }\end{array}$ & 54 & 94 & 105 \\
\hline & & $\begin{array}{l}\text { 4. Completion rate in primary } \\
\text { education (in \%) }\end{array}$ & 40 & 93 & $100 \%$ \\
\hline \multirow{3}{*}{$\begin{array}{l}\text { 4. Reduce mortality } \\
\text { of children under } 5 \\
\text { years }\end{array}$} & \multirow{3}{*}{$\begin{array}{l}\text { 5. Reduce by } 2 / 3 \text { the under } 5 \\
\text { mortality rate between } 1990 \text { and } \\
2015\end{array}$} & $\begin{array}{l}\text { 12. Mortality rate of children under } \\
5 \text { years (per thousand) }\end{array}$ & 198 & & 108.7 \\
\hline & & $\begin{array}{l}\text { 13. infant mortality rate (per } \\
\text { thousand) }\end{array}$ & 81 & & 42 \\
\hline & & $\begin{array}{l}\text { 14. } \% \text { of } 1 \text { year old children } \\
\text { vaccinated against measles }\end{array}$ & 38.3 & & $90 \%$ \\
\hline \multirow{3}{*}{$\begin{array}{l}\text { 5. Improve maternal } \\
\text { health }\end{array}$} & \multirow{3}{*}{$\begin{array}{l}\text { 6. Reduce by } 3 / 4 \text { the maternal } \\
\text { mortality rate between } 1990 \text { and } \\
2015\end{array}$} & $\begin{array}{l}\text { 15. Maternal mortality rate (per } \\
1000 \text { births) }\end{array}$ & 6.48 & 2 & 1.75 \\
\hline & & $\begin{array}{l}\text { 16. Proportion of births assisted by } \\
\text { qualified health staff (in \%) }\end{array}$ & 17.2 & 40 & $50 \%$ \\
\hline & & $\begin{array}{l}17 \text { Modern contraceptive } \\
\text { prevalence rate }\end{array}$ & 5 & 14 & 18 \\
\hline \multirow{2}{*}{$\begin{array}{l}\text { 6. Combat } \\
\text { HIVIAIDS, malaria } \\
\text { and other diseases }\end{array}$} & $\begin{array}{l}\text { 7. Halt the spread of HIVIAIDS } \\
\text { and reverse the current trend by } \\
2015\end{array}$ & $\begin{array}{l}\text { 17. HIVIAIDS prevalence rate } \\
\text { among persons } 15-49 \text { years of age }\end{array}$ & 0.7 & 0.7 & 0.7 \\
\hline & $\begin{array}{l}\text { 8. Control malaria and reverse } \\
\text { the trend }\end{array}$ & $\begin{array}{l}\text { 18. Death rate due to malaria (in } \\
\% \text { ) }\end{array}$ & 2.7 & 1.5 & 1 \\
\hline \multirow{2}{*}{$\begin{array}{l}\text { 7. Ensure } \\
\text { environmental } \\
\text { sustainability }\end{array}$} & $\begin{array}{l}\text { 10. Reduce by } 1 / 2 \text { the } \% \text { of } \\
\text { population without access to } \\
\text { drinking water by } 2015\end{array}$ & $\begin{array}{l}\text { 20. Proportion of the population } \\
\text { with access to drinking water (in } \\
\% \text { ) }\end{array}$ & 68.7 & 72 & 75 \\
\hline & $\begin{array}{l}\text { 11. Facilitate access to decent } \\
\text { and safe housing }\end{array}$ & $\begin{array}{l}\text { 21. } \% \text { of urban households with } \\
\text { adequate sanitation facilities }\end{array}$ & 70.3 & & \\
\hline
\end{tabular}




\section{Other performance indicators adopted:}

- Increase the proportion of enrolled girls from $41 \%$ of the total enrolment in 2006 to $47 \%$ in 2012, (with $43 \%$ in 2008 and $44 \%$ in 2009);

- Increase the proportion of the population who successfully completed literacy cycles from $63 \%$ in 2006 , to $80 \%$ in 2012, breaking it down by gender (with $63 \%$ in 2008 and $66 \%$ in 2009);

- Increase DTC3immunization coverage for children below 12 months from $34.718 \%$ in 2006 to $80 \%$ in 2010 and $90 \%$ in 2012;

- Attain a utilization rate of $35 \%$ in 2012 for impregnated mosquito nets for children and pregnant women;

- Increase the treatment of malnutrition cases among children under 5 years from $17 \%$ in 2005 to $50 \%$ in 2010;

- Increase the national coverage of drinking water requirements in rural areas from $61 \%$ in 2006 to $80 \%$ in 2015;

- Increase the national coverage of drinking water requirements in urban areas from $80 \%$ in 2005 to $100 \%$ in 2015;

- Increase sanitation coverage in urban and rural areas to $70 \%$ and $50 \%$ respectively in 2015 ;

- Reduce consumption of plastic packages by $20 \%$ by 2011 and recycle at least $35 \%$ by 2011 ;

- Increase the access rate to electricity services for rural areas to 3\% and urban areas to $46 \%$;

- Increase the utilization of modern fuel service (GPL, Kerosene, mineral coal) or improved fireplace to $100 \%$;

- Reduce the proportion of traditional biomass in the country's average energy balance from $98 \%$ to $20 \%$.

\section{$>$ Brief analysis of strategies to be implemented:}

472. The Government is ready to take the necessary steps to provide appropriate responses for human capital development and quality of life. Emphasis will be laid on improving access by the population to basic social services through the implementation of policies and/or strategies in the following areas:

- development of education as well as vocational and technical training;

- improvement of health;

- reduction of malnutrition;

- extension of access to drinking water ;

- improvement of the living environment, especially housing and sanitation;

- increased access to modern energy services;

- promotion of decent employment and income-generating activities.

\section{(a) Education and Training of Human Resources}

473. Faced with a growing social demand, limited budget capacities and training not geared towards labour market demands, Niger has opted to build a training system through implementation of the Ten-year Education Development Programme (2003-2013) which aims at contributing to poverty reduction by improving the level of education and training of the population, especially the professionalization of young graduates, in terms of quality and quantity.

474. Emphasis will be laid on: (i) acceleration of enrolment by providing universal access to quality basic education particularly for children in rural areas, girls and the poor; (ii) reduction of illiteracy; (iii) improvement of the quality and relevance of education and training, particularly the level of pupils entering higher education; (iv) strengthening of social and economic utility of post-primary education, particularly adaptation of supply to the needs of the country by improving vocational and technical training; (v) optimization of the use of available means.

\footnotetext{
${ }^{18}$ According to EDSN-2006
} 
475. In this respect, the strategic options adopted to satisfy the education requirements include:

expansion strategies based on efficient allocation of State resources to the education sector, improvement of efficiency in the use of allocated resources and improvement of access and retention, particularly through the promotion of enrolment in rural areas for girls;

strategies relating to the quality and relevance of education based mainly on the reorganization of cycles, renovation of initial and continuous training, overhaul of the curricula and provision of teaching aids;

cross-cutting strategies which comprise improvement of planning, management and monitoring of the education system at the central and decentralized levels.

476. To ensure harmonious development of young children and instill attitudes and skills which will facilitate future learning, preschool education will, over the next few years: (i) increase access and accessibility by raising the gross preschool enrolment rate from 1.4\% in 2006 to $5 \%$ in 2012 and $7 \%$ in 2015; (ii) improve the contexts and conditions of teaching and learning by providing initial and continuous training for preschool teachers, by adapting teaching aids to the preschool environment, and by providing health protection and security for pupils.

477. As regards basic education 1 (primary), the PDDE seeks to : (i) ensure access and accessibility to the greatest number of children by improving and diversifying education, and by raising the gross enrolment rate from $54 \%$ in 2006 to $94 \%$ in 2012, (ii) provide pedagogical, human and material resources by improving the quality of initial and continuous training for teachers and supervisor, by developing new curricula in national teacher training schools, restructuring Pedagogic Units, procuring of school textbooks, developing a health and social environment conducive schooling; (iii) involve the community in the school's management through COGES; (iv) better manage human resources; and (v) create school canteens in schools.

478. With respect to informal education, the objective in adult literacy and training is to: (i) raise the adult literacy rate from $28.7 \%$ in 2005 to $45 \%$ in 2012 and (ii) provide education in reading, writing, arithmetic and daily skills to at least $80 \%$ of those leaving the renovated coranic schools. To that end, actions will be geared towards the construction of Permanent Education Centres (FEP), the recruitment of FEP instructors and literacy officers and literacy officers, the renovation of curricula, continuous training for inspectors and specialists (evaluation, adult education and socio-economics). Inclusion of coranic education as an innovation in the aims at restructuring and developing the coranic school on the basis of strategic studies (strengths and weaknesses, constraints and potentials), as well as improving the quality of training of teachers in the 8 regions in curriculum design.

In post-basic education, the following activities will be carried out:

479. As regards secondary education, the objective is to: (i) develop public education so as to cope with the inflow of pupils from the primary cycle, by raising the admission rate into college from $22.7 \%$ in 2005 to $35 \%$ in 2015 through building and equipping class rooms and recruiting teachers; (ii) raise the private sector enrolment to $20 \%$ of the total in 2012; (iii) raise the retention rate of girls to $80 \%$ by providing support and lodging to girls in rural CEGs, awarding prizes of excellence to deserving girls and providing school kits to girls from poor families; (iv) improve the learning conditions of students, teachers and supervisors; (v) increase the school retention rate to $60 \%$ in the first cycle, to $80 \%$ in high schools in 2015 , and to $29 \%$ in private institutions; (vi) recruit confirmed and contractual teachers (to replace those who have gone on retirement).

480. Concerning vocational and technical education and training, in the coming years, Niger will seek to increase its economic and social performance through a training mechanism adapted to the needs of the forma land informal productive sector. Training will be expanded to meet the qualification requirements of youths from the education system. Moreover, the syllabus in vocational and technical training institutions will be revised, and sandwich vocational courses will be developed to facilitate productivity gains in the informal sector. EFPT students will represent $12 \%$ of secondary education enrolment in 2015 as against $2.4 \%$ en 2005 . 
481. In support of the promotion of growth and employment, the following actions will be carried out:

- creation of new centres and/or new training modules in trades in the high-potential growth clusters;

- development of vocational training engineering;

- rehabilitation and coordination of the national training system;

- strengthening of higher institutes of technical training and 3 IUTS;

- strengthening and modernization of the informal sector in the creation of decent jobs;

- development of initial job-oriented training and/or sandwich courses through apprenticeship ;

- Sustained financing of the Continuous Vocational Training and Apprenticeship Support Fund (FAFPCA) by paying into the fund the apprenticeship tax paid by enterprises ;

- Development of continuous vocational training and apprenticeship to upgrade the skills of worker in enterprises and vulnerable groups (craftsmen, rural women, youth not educated and those who dropped out of school and job seekers).

482. Similarly, in response to the overly general nature and inadequacy of formal basic education in polyvalent practical training adapted to the needs of grassroots communities, Niger will reinforce basic joboriented education of youths and adults in Community Development Training Centres (CDFC) and alternative rural schools by conducting studies on training needs in the eight regions of the country, evaluating the existing experimental CFDCs, preparing the organic statutes of CFDCs as basic components of technical and vocational education and training, providing continuous training for trainers and creating CFDCs. Efforts will be made to promote access to basic vocational training for uneducated people and those who dropped out from school.

483. In higher education, Niger's policy aims at increasing the sector's capacity to produce qualified senior staff and technicians required for the economic and social development of the country and at promoting basic and applied scientific research. Thus, the education will become more relevant, as a result of the reconfiguration of training and research. Furthermore, greater efficiency of this cycle of education will require improvement of the quality of training and conditions of apprenticeship, as well as modernization of its management. Consequently, the number of students per 100,000 habitants in public schools under MESS/R/T will increase from 99 in 2005 to 127 in 2009. Similarly, the number of students in UAM and in the 3 UITs will increase from 8,710 in 2005 to 12,194 in 2009; that of students enrolled in the 3 UITs will be 400 in 2007 and 800 in 2009.

484. Lastly, all orientations in the education and training will become operational following implementation of a Complete Education Development Programme as reference framework for all interventions in the area (including post-primary education components).

\section{b) Improvement of health}

485. The adoption of the Health Development Plan 2005-2010 aims at improving the efficiency and quality of the health care system so as to produce a better impact on the health conditions of the most vulnerable groups of the population. In particular, efforts will be made to reduce maternal and infant mortality through the following actions:

- improve the supply, demand and quality of health care for the poorest;

- reduce morbidity and mortality due to the major diseases;

- develop an equitable policy for access to basic services and care;

- create a favourable health environment;

- promote information, education and communication (IEC), and Communication for a Change in Behaviour (CCB) ;

- pursue decentralization of health services so as to ensure greater involvement and effective empowerment of communities in the management of health activities;

- increase the availability of resources;

- $\quad$ pursue public expenditure reviews to evaluate costs and analyze the impact on beneficiaries;

- increase access to modern energy services so as to offer better quality care.

486. To that end, great attention will be paid to improving the functioning of the current system and preferential treatment of rural areas so as to reduce the existing disparities. Interventions will focus on the first level of health care with the health district as operational unit and vertical programmes will be integrated. At all 
levels of the system, community participation will be required, and activities will be streamlined (protocols, supervision, public activities, etc.) to do better and more with the existing resources.

\section{$\underline{\text { Reproductive health }}$}

487. In accordance with the guidelines of the National Reproductive Health Programme 2005-2009, an integral part of the PDS, the objective will be to : (i) accelerate the decline of maternal and neonatal mortality by promoting prenatal and postnatal observation, as well as providing adequate obstetric and neonatal care, (ii) contributing to the control of population growth through the promotion of family planning, and (iii) promoting the sexual and reproductive health of youths and adolescents (SSRAJ).

488. To that end, interventions will focus on three (3) components:

- strengthening of risk-free maternity through monitoring of pregnancies, assisted births, treatment of obstetrical fistulas ;

- enhancement of family planning, particularly through the delivery and use of services;

- promotion of sexual and reproductive health for youths and adolescents.

\section{Maternal Health}

489. Maternal mortality (6.48 per thousand in 2006) is among the highest in Africa. Niger intends to reduce this rate by three-quarters (by bringing it down to 2 per thousand) by 2012. The strategy for achieving these objectives will concern: (i) improvement of reproduction health status of the populations, (ii) facilitation of access by the poorest and most vulnerable to reproductive health care; (iii) assignment of adequate health staff, in terms of numbers and qualification, throughout the country; (iv) sensitization of pregnancy on the importance of pre and post-natal consultations.

\section{Infant health}

490. Despite the average decline of 6.4 percentage points per year in the child mortality rate (198 per thousand in 2006), efforts will be pursued, particularly to reduce child mortality by two-thirds by 2015. Special attention will be paid to the downward trend, the mortality rate for children below one year old, which was 81 per thousand in 2006.

491. As regards children's diseases, priority will be given to: (i) the prevention of diseases affecting children; (ii) systematic support to EPI and complementary vaccination activities; (iii) extension of PCIME to all districts (prevention and treatment of diseases, particularly diarrheas, malaria, measles IRA and malnutrition) ; (iv) IEC to improve knowledge and family and community practices to facilitate adoption of behaviours favourable for children's health.

\section{Control of diseases and essential interventions}

\section{Malaria control}

492. Malaria is the primary cause of death in Niger; the death rate due to malaria stands at 27 per thousand. To reverse the trend of this disease by 2015 , the following strategies will be implemented: (i) acceleration of control to reduce infant mortality, in particular; (ii) expansion of coverage in health infrastructures through effective decentralization of health services; (iii) stronger sensitization on the use of impregnated mosquito nets and on sanitation measures such as wastewater drainage and treatment of breeding sites, (iv) intensification of intermittent presumptive treatment.

\section{HIV/AIDS control}

493. HIVIAIDS control took place in 2006 within a context of stabilization of the epidemic, with a prevalence rate of $0.70 \%$ and continued disparity between rural areas $(0.5 \%)$ and urban areas $(1.5 \%)$. However, this disease is toady a serious threat, particularly for women and youths. The Government intends to implement, over the next five years, the new National AIDS Control Strategic framework (2007-2011) to reverse the trend. 
Interventions will focus on consolidating achievements, correcting inadequacies and implementing new strategic guidelines in response to determinants of the infection and aimed at achieving the objectives set to effectively control HIVIAIDS infection.

494. In this respect, halting the spread and reversing the current trend of HIVIAIDS by 2015 will be done by: (i) preventing HIVIAIDS transmission through large scale sensitization; (ii) ensuring secure blood transfusion promotion of research; (iii) assistance to persons infected by the disease, particularly through access to ARVs ; (iv) availability of reagents for voluntary screening in all the regions ; (v) training of health staff; (vi) conduct of regular surveys among vulnerable groups to monitor the disease, (vii) enhanced monitoring of co-infection and PMTCT.

495. Similarly, the multisectoral approach will be reinforced for public sector bodies with special attention to the following sectors: youth, transport, Defence and Security Forces, Education (basic and higher), Promotion of Women and Social Action, Rural Development, and Trade. AIDS control activities will be decentralized to the 42 health districts and will be included in the formulation of regional and departmental health development plans.

\section{Tuberculosis control}

496. In order to effectively control tuberculosis, interventions will focus on: (i) screening and treatment of cases; (ii) reinforcement of laboratories; (iii) capacity building for staff; (iv) increased availability and access to anti-tuberculosis drugs (DOTS strategy).

497. The screening rate will be increased to $70 \%$ and the cure rate to $85 \%$ in 2012 . In this light, the quality constraints of the services will be eliminated by increasing geographical access, acceptability, availability of drugs and IEC, as well as reducing stigmatization of the disease.

\section{Accessibility, use of services and quality of care}

498. Accessibility by the populations to services and quality care will be improved by extending health coverage from the current rate of $65 \%$, particularly through gradual transformation of health centres of the PS/PR into CSIs and supply of PMA/PCA in the 42 health districts of the country. Similarly, special emphasis will be laid on the establishment of innovative mechanisms for sickness risk coverage, namely the creation of health mutual companies, health insurance and a health social fund.

499. By 2012, efforts will be made to: (i) increase the number of health services offering PMA /PCA, as well as the number of national and regional referral centres offering quality care according to the standards; (ii) develop approaches for managing chronic and hereditary diseases such as high blood pressure (HTA), diabetes, drepanocytosis, epilepsy; (iii) ensure the screening and proper management of tuberculosis patients; and (iv) develop quality private initiatives.

500. Increasing the use of services by the populations requires the implementation of the national IEC/CCC strategy developed in MSP. It will also extend services, enhance the quality of care, increase the supply of services, take into account community demand and effectively apply the texts instituting free treatment for some care and health services as well as their support measures.

501. The strategies will also focus on reinforcing the supply and distribution system, as well as restructure the purchasing pool (ONPPC) and liberalize the market. Furthermore, a human resources master plan will be put in place and the National Health Information System (SNIS) will be strengthened to enable its to produce relevant and quality statistical data.

\section{c) Reduction of malnutrition}

502. Despite the progress made in reducing acute malnutrition (10.0\% in 2006) in Niger, underweight is still prevalent in high proportions (44.4\% in 2006 for children below 5 years). In this respect, in order to take up the challenge of halving the number of malnourished people by 2015 and contributing the achievement of MDG No.1, Niger will implement: 
- preventive strategies, namely: (i) fight against food and nutrition insecurity in households (pregnant and breastfeeding women), (ii) promotion of suitable nutrition education, in particular for vulnerable groups, including children below five years and pregnant women, (iii) encouraging exclusive breastfeeding of babies for the first six months of their lives, then breastfeeding supplemented by appropriate and adapted infant feeding up to the age of two or above, (iv) promotion of the production of food rich in micronutrients, community nutrition surveillance, meals for youths in schools, (v) promotion of development and use of adequate food supplements, and (vi) fortification and diversification of foods;

- curative strategies such as : (i) improvement of access to treatment and dietetic and medical recovery ; (ii) control of interaction between nutrition and HIV; (iii) treatment of emerging diseases related to overfeeding, diabetes, obesity, hypertension and cardio-vascular diseases;

- cross-cutting strategies including development of an overall approach to nutrition problems (under nutrition and over nutrition) through: (i) development of effective nutrition communication; (ii) increase in incomes and improvement of the status of women ; (iii) search for operational integration between the services responsible for nutritional issues in MSP, dissemination structures of MDA, MRA and MEN and the communication and education services; (iv) coordination of nutrition and development activities; (v) strengthening of human resources; (vi) national capacity building for the management and prevention of malnutrition; (vii) involvement and participation of community structures; (viii) creation of industrial plants to manufacture micronutrients-enriched flour. The national Nutrition Action Plan (PNAN) will be updated to include these new strategies.

\section{d) Improving access to safe drinking water}

\section{Access to safe drinking water}

503. In order to achieve the Millennium Development Goals, in particular with reference to access of THE populations to safe drinking water, Niger will undertake significant action to optimize existing water infrastructure, as well as put in place new ones.

504. Village water systems: Gross coverage rate of water requirements for village water systems will be increased to $65 \%$ in 2009 and $80 \%$ in 2015. Emphasis will thus be placed on the following: (i) optimizing existing modern water points through rehabilitation exercises (4,448 modern water points and 243 mini drinking water supply systems [AEP]); (ii) setting up independent water sources and mini water drinking water supply systems (693 AEPs); (iii) construction of new, cemented and appropriate village boreholes and wells (9040 MWPs); (iv) effective integration of a sanitation component in village water programs; (v) improving management of village water infrastructure and dewatering means; (vi) education on hygiene for communities and in schools; (vii) organizing maintenance through the standardization of water supply equipment; (viii) creating an adequate spare parts supply system and setting up networks of skilled repairmen and divers.

505. Pastoral water systems: In order to give impetus to pastoral development in accordance with the place of livestock rearing in the national economy; to prevent the often deadly conflicts between communities, and to guarantee better management of Niger's fragile ecosystems, a real program to create a network of water points (PC, SPP, reservoirs) throughout the country will be implemented on the basis of an updated inventory of the needs in the pastoral zone.

506. Urban water systems: In the 52 centres that constitute the contract area of the water company (SEEN), coverage of water requirements, which was estimated at $80 \%$ in 2005 , will be increased to $100 \%$ in 2015 . Nevertheless, considerable efforts will be deployed to guarantee quantitative and qualitative availability of the resource, as well as access of poorer populations to an adequate water service. In addition, some village mini drinking water supply systems will be transferred to the SEEN holdings.

507. With the setting up of the National Commission on Water and Sanitation (CNEA), activities to be carried out will focus on: (i) adapting the water regime to the national legal framework; (ii) continuing with the installation of the six remaining water management units (UGE), and (iii) improving the sector management institutional framework through the reform of the Water Administration. 
508. In addition to the activities carried out within the framework of implementing the rural development strategy, the urban environment management strategy, and the plastic waste management national operational strategy, efforts will continue to make the national urban development strategy operational, in order to provide the population with a decent living environment.

\section{Urban development, housing, and sanitation}

\section{Urban development and housing}

509. In the area of urban development and housing, Government action will be aimed at promoting improved network of links between towns and the countryside, ensuring better urban and land management, enhancing the level of equipment of urban centers, and increasing the supply of decent housing (new construction and renovation) through the implementation of the national housing policy.

510. To this end, a vast program will be undertaken in relation to: (i) strengthening the institutional framework for urban development, (ii) local governance and urban management, (iii) local economic development, (iv) urban social integration, (v) construction of accommodation and improving existing housing, (vi) fostering better socioeconomic integration for poorer population groups, and (vii) improving the habitat. The following action will be undertaken under this framework:

- Construction of low-cost housing in particular with the creation of a housing bank, a national housing fund and public bodies to promote housing; setting up of housing cooperatives and building societies; stimulating provision of real estate loans by commercial banks, and encouraging private investment in the housing sector.

- Rehabilitation of old or under-integrated neighborhoods.

- Improving the rural habitat.

- Rehabilitation and/or construction of urban infrastructure.

- Strengthening project ownership and supervision by local communities.

- Enhancing equipment and improving communications as well as transportation of goods and persons.

- Developing strategies to preserve the environment, aimed at the sustainable development of urban and rural communities; reorganization of household waste collection and processing practices, as well as rainwater and wastewater evacuation strategies, and educating all actors about environmental issues.

- Adapting the regulatory framework and standards of urban planning and urban and land management to the reality of decentralization by adopting an urban planning code and an urban land management code that take into account the competences of decentralized local authorities.

511. Furthermore, with the implementation of decentralization, priority will be given to the drafting of planning and programming tools, in particular with a view to boosting the dynamism of new communes. In the same vein, community infrastructure will be increased with the setting up of community kindergartens, sports and cultural facilities, and leisure areas.

\section{Improving sanitation}

512. Government efforts will be directed at raising the rate of sanitation coverage in both urban and rural areas respectively to $70 \%$ and $50 \%$ in 2015 . To this end, the following action will be taken:

- Drafting of a sanitation and hygiene education policy.

- Drafting of a communication plan aimed at encouraging local authorities and users to take ownership of and responsibility for the management of sanitation infrastructure (in line with the law on decentralization).

- Construction of facilities in schools, health centers, and markets.

- Construction of sanitation infrastructure (rainwater evacuation network, sewerage system, wastewater treatment plants).

- Polluting industrial units to be equipped with pre-processing plants for residual water.

513. In addition, as part of the implementation of the sanitation development plan (PDS), a number of hygiene and sanitation activities will be given fresh impetus, in particular: (i) setting up the higher council on public 
hygiene; (ii) implementation of the biomedical waste management plan; (iii) strategic support to communities for waste management; (iv) strengthening various departments to deal with emergency situations (epidemics, floods, famine, etc.); (v) applying the texts dealing with sanitary policy, and (vi) adoption of a national IEC strategy in the area of health.

\section{Control of environmental and other forms of pollution}

514. Niger will seek to reduce consumption of plastic packaging by $20 \%$ between now and 2011 , and recover $35 \%$ of plastic waste by the same date. To this end, the following measures will be applied:

- Drafting and implementation of solid waste management master plans.

- Construction of controlled landfills for urban solid waste.

- Construction and equipment of laboratories to carry out pollution and water quality tests.

- Monitoring of classified establishments.

- Environmental audit of industrial and crafts plants.

\section{f) Improving access to modern energy services}

515. Access to energy has become a major factor for attaining the objectives of economic and social development and poverty reduction in particular, in particular those related to income, health, education, safe drinking water, agriculture, gender, and the environment. In this regard, the DPRS will be implemented in full accordance with the national and regional priorities that have been defined as part of the construction of power generating and transport infrastructure, as well as the enhancement of regional power integration through interconnection of electricity networks, and the promotion of the use of mineral coal for domestic purposes.

516. A strategy on access to modern energy services was drafted in January 2006. Its objective is to improve significantly the rate of access to modern energy services in the country through the following:

- $\quad 43 \%$ access to modern energy services (MES) in the social sectors (health, water, and education).

- $\quad 10 \%$ access to MES for the productive sector (Agriculture: Irrigated land)

- $80 \%$ access to MES for local communities (rural areas).

- $24 \%$ access to MES for IGA in rural areas (motive power, etc.).

- $\quad 33 \%$ access to modern cooking fuel.

- Access to electricity service increased to $3 \%$ in the rural areas and $46 \%$ in urban areas.

- $40 \%$ strengthening of energy infrastructure.

517. A rural electrification strategy was also drafted between May and December 2004. Among other things, it aims to take stock of the present situation and draw up a plan and an outline for rural electrification.

518. Furthermore, implementation of the strategy and plan of action on renewable sources of energy, which was adopted by government in January 2004, will be continued, in order to preserve the environment.

\section{g) Promoting decent employment and income-generating activities}

519. The National employment policy, which is currently being reviewed for adoption, aims at several objectives. These are:

- Developing human resources and technical and professional training.

- Promoting small-sized enterprises.

- Improving the visibility of the market through the setting up of the labor and professional training observatory.

- Improving the legislative and institutional frameworks relating to child labor, and to strategies for the promotion of decent employment.

- Promotion of job-creating programs likely to reduce poverty in the rural world, in the urban informal sector, for young graduates or school dropouts, and for women.

- Setting up a national volunteer program to absorb and involve young graduates while also transferring to them top quality professional expertise. 
- Promotion of healthcare and social protection.

520. In addition, quite apart from the efforts being made to promote employment in state, para-statal, and private modern sectors, specific activities will be carried out to mobilize local, unskilled labor. With this in mind, employment intensive activities that have already been tried and tested in several other major poverty reduction programs and programs to control underemployment of youth and women ,and rural-urban migration, will be pursued and developed systematically. Similarly, a national agency on community work will be set up.

\section{h) Promoting the practice of sports}

521. Practicing a sport promotes a healthier life and is an effective means of conflict prevention and the promotion of peace. Sports also contribute to reaching the objectives in the education, training, labor and economic market sectors, as a tool for combating poverty. Government efforts here will focus on:

- Promoting the economic function of sports (organizing national, regional, and international level sporting events that will have a real impact in the economic, social, tourist, and press sectors, and more generally in terms of sustainable development for Niger.

- Enhance the economic weight of sports.

- Promote health through sports.

- Promote mass sports activities.

- Promote high level sports activities.

- Promote traditional sports and games.

- Promotion of peace through sports.

\subsubsection{Control of population growth}

\section{$\checkmark$ Reference situation under this pillar:}

522. The average growth rate of the population is estimated at $3.3 \%$. This represents one of the highest rates in the world and could jeopardize all government efforts to reduce poverty and attain the MDGs.

Strategic objective under this pillar: Gradually slow down population growth.

\section{$>$ Performance indicators:}

523. The following indicators have been selected:

- Reduce the average number of children per woman from seven (7.1) to six (6) in 2012, and five (5) in 2015.

- Increase modern contraceptive prevalence from 5\% in 2006 to $14 \%$ in 2012, and 18\% in 2015.

- Reduce the proportion of early marriages by one third, bringing it down from $59 \%$ to $40 \%$.

- Maintain the average duration of maternal breastfeeding at 21 months, including six months of exclusive breastfeeding.

\section{$>$ Brief analysis of the strategy to be implemented:}

524. If the annual rate of population growth is maintained at its present level, it could compromise any development efforts undertaken in the years ahead. It is for this reason that a number of measures are to be taken under the framework of the government statement on population policy (DGPP), adopted in February 2007. The DGPP aims at achieving improved control of population growth, in order to make it more appropriate to the economic development of the country.

525. In order to attain the overall objective of controlling population growth, the government intends to guarantee access to safe, effective, affordable, and acceptable local reproductive health services by 2012, and the use of methods of contraception is expected to increase by one percentage point per year starting from 2008.

526. The strategies will focus mainly on promoting changes in attitudes and behavior in relation to childbirth, so as to gradually induce within the population a significant increase in the use of contraception and a reduction 
in early marriages. These measures will make it possible to start off a gradual slowing down of the country's population growth.

527. Strategic intervention will therefore be carried out on the following aspects:

- Renewed launch of reproductive health and family planning programs that provide an effective response to the needs of the population.

- Combating early marriages and all forms of discrimination against women.

- Develop the practice of maternal breastfeeding in order to improve the health of children and women, by helping the latter have better control over the frequency of pregnancies, as well as the size of their families.

- Carrying out advocacy and communication activities targeted at opinion leaders and local communities in order to bring about behavior change in relation to reproduction.

528. More specifically, the following five priority programmes will be implemented under the framework of the DGPP:

Advocacy and awareness raising programme on issues of population and development. The objective of this program is to provide better information and raise awareness among decision-makers, opinion leaders, technical officials, and the population about population issues and the links between population and development. The aim on the one hand is to spark greater interest on the part of decision-makers and opinion leaders in the subject of population so that demographic variables are taken into account in all general, sectoral, and regional development policies and programs, and on the other to get decision-makers and opinion leaders more involved in raising awareness within the population to enable it to adopt forms of behavior that will foster greater control over population growth.

Program of information, education, and communication for behavior change (IEC/BCC) in reproductive health and family planning. This programme will contribute to promoting family planning, reducing the proportion of early marriages, and strengthen the practice of prolonged maternal breastfeeding.

Programme to promote accessibility and use of reproductive health services, in particular family planning. This programme will contribute to bringing about significant changes in behavior in relation to childbirth, in particular through the accessibility and use of safe, effective, affordable, and acceptable local reproductive health services.

Programme on empowerment of couples and economic empowerment of women. The aim of this programme is to promote equality and equity through advocacy/awareness raising on human rights, and the revision/adoption and application of legislative texts that promote the elimination of all forms of discrimination against women. This programme also seeks to enhance the economic independence of women, through access to political office and positions of responsibility, as well as the promotion of income-generating activities.

Coordination, monitoring, and evaluation programme. This programme seeks to guarantee effective implementation and better understanding of the impact of the abovementioned programmes through the setting up of a technical and institutional mechanism for coordination, monitoring, and evaluation.

\subsubsection{Reduction of inequalities and strengthening of social protection for vulnerable groups}

\section{$\checkmark$ Reference situation under this pillar:}

529. The situation as revealed by current indicators is as follows:

- Low girl-boy ratio in primary education (100 boys to 70 girls)

- Ratio of literate women to men, 15 years and above (with a ratio of the male and female populations who know how to read and write, around 35.2\%)

- Percentage of women in wage employment in public service $(25 \%)$

- Proportion of seats held by women in national parliament (12.4\% of seats in the National Assembly). 
- Percentage of female members of government $(26 \%)$.

- Number of female municipal advisors (671 out of 3747 ).

- Proportion of child workers in the labor force $(15 \%)$.

530. Strategic objective under this pillar: Reduce societal inequalities and vulnerabilities in Niger

> MDG indicators for 2012 and 2015:

\begin{tabular}{|c|c|c|c|c|c|}
\hline $\begin{array}{c}\text { Corresponding } \\
\text { MDG }\end{array}$ & Selected MDG targets & Selected indicators: & Current level & $\begin{array}{l}\text { Desired level } \\
\text { in } 2012\end{array}$ & $\begin{array}{l}\text { Desired level } \\
\text { in } 2015\end{array}$ \\
\hline $\begin{array}{l}\text { Promote gender } \\
\text { equality and } \\
\text { empower women }\end{array}$ & $\begin{array}{l}\text { Eliminate gender disparity } \\
\text { in primary and secondary } \\
\text { education if possible, and } \\
\text { at all levels }\end{array}$ & $\begin{array}{l}\text { - Girl-boy ration in primary } \\
\text { education } \\
\text { - Girl-boy ration in secondary } \\
\text { education } \\
\text { - Literacy rate of women aged } \\
15-24 \text { years } \\
\text { Proportion of seats held by } \\
\text { women in national parliament }\end{array}$ & $\begin{array}{l}69 \% \text { in } 2005 \\
64 \% \text { in } 2005\end{array}$ & & $\begin{array}{l}100 \% \\
100 \% \\
\end{array}$ \\
\hline $\begin{array}{l}\text { Develop a global } \\
\text { partnership for } \\
\text { development }\end{array}$ & $\begin{array}{l}\text { In cooperation with } \\
\text { developing r countries, } \\
\text { develop decent and } \\
\text { productive work for youth. }\end{array}$ & $\begin{array}{l}\text { Unemployment rate of young } \\
\text { people aged } 15-24 \text { years }\end{array}$ & & & \\
\hline
\end{tabular}

\section{Other performance indicators set for 2012:}

- The proportion of child workers in the labor force goes from 15\% in 2006 to $10 \%$ in 2012.

- The proportion of children registered at birth goes from 32\% in 2006 to $90 \%$ in 2012 .

- Proportion of child victims of female genital mutilations (0\% in 2012).

- Number of policies that integrate the gender approach reaches $50 \%$.

\section{Brief analysis}

531. Inequalities have a negative effect on growth and its contribution to poverty reduction. In the same way, risk and vulnerability factors diminish the capacity of poor people to participate in the creation of wealth. Setting up effective mechanisms to mitigate the risk factors and provide social protection will thus make it possible to create the enabling conditions for pro-poor growth. Similarly, several measures will be taken in the different sectors to ensure better distribution of productive resources and increase the possibilities for women, men, children, young people, the elderly and disabled people to participate in economic activity and derive benefits from such activity.

532. The DPRS can only truly attain its objectives if gender is effectively mainstreamed into all forms of intervention. Indeed, equality and equity between men and women are not only a constitutional requirement. They also contribute to the promotion of human rights and to combating poverty.

533. As an instrument of implementation of the DPRS, gender policy must thus face the challenge of correcting gender inequalities and iniquities, in a spirit of complementarity. In doing so, it will also be correcting the inequalities and iniquities in the social relations of production in a society where socio-cultural burdens still weigh heavily.

534. In addition, with a view to fostering the emergence of a mature, informed, and responsible youth in 
Niger, the government will continue the implementation of the programme of social protection for children, as well as the programme on training and professional integration for the youth. The success of these programmes should prevent young people from falling into idleness, banditry, drug abuse, and delinquency.

\section{a) Guaranteeing gender equity}

535. The national gender policy will translate the government's vision for gender equality and equity in all areas. To this end, the strategic pillars will be based on an integrated approach that takes into account the needs of both men and women, the diversity of the sectors of life where a balance needs to be restored, and the various forms of obstacles to be overcome.

536. The objectives in implementing the national gender policy are the following:

- Ensure the mainstreaming of the gender dimension in all areas and at all levels.

- Guarantee equal chances and equal access to, and control of resources for men and women.

- Create an enabling environment for the implementation of strategies aimed at mainstreaming gender.

- Revise the national policy for the promotion of women.

- Implement a strategy aimed at ensuring improved coordination of gender activities.

- Promote research and dissemination of disaggregated data in all areas in order to define the contribution of men and women to development, and also to enable the adoption of appropriate corrective measures.

- Support the application of international conventions and the recommendations of world summits on the rights of children and women.

- Strengthen the legal, judicial, institutional, and social framework in order to allow for the application of the CRC, CEDAW, and the ICPD.

- Prevent and sanction cases of abuse, violence, and discrimination against children and women (domestic violence, repudiation, early marriage, FGM, children in conflict with the law, child labor, child trafficking, slavery, prostitution, etc.). ;

- Educate families and enhance the capacities of associations and non-governmental organizations to be the defenders and promoters of children and women's rights.

- Carry out advocacy for resource mobilization in favor of children and women.

- Promote the participation of women and young people in decision-making and management processes.

\section{b) Ensuring the protection of children}

537. Priority intervention in this area will be aimed at the following:

- Guaranteeing the availability of reliable disaggregated data on children.

- Ensure that care is provided to street children, children in conflict with the law, victims of child trafficking, child victims of sexual and economic exploitation (put an end to employment of minors), and child victims of domestic maltreatment.

- Ensure the revision of the national policy on child protection (1999).

- Adopt and implement a children's code; the national policy against sexual exploitation of children; the national policy on care of orphans and other vulnerable children; the policy for the development of young children, and the national plan for the survival, protection, and development of children.

- Adopt alternative strategies to the incarceration of minors in prisons.

- Promote socio-economic integration of vulnerable child victims.

- Reduce violence against children, in particular young girls (early marriage, FGM, etc.).

\section{c) Promoting youth development}

538. The clear political will to promote the development of young people has led to growing interest in this very important sector of the population. As a result, a national youth council has been created and a youth parliament has been set up in order to keep the youth informed about the management of public affairs and allow them to equip themselves better to contribute to the development of the country.

539. In order to boost their participation in the development process and guarantee that Niger holds its rightful 
place in the development millennium, a series of consultations will be held with all the representative groups of young people, in order to collect their proposals relating to the difficulties that they encounter. Within this framework, a number of reforms will be initiated following this forum. These will include the review of the youth policy to adapt it to the national context and priorities. A series of measures targeting the youth will be adopted and will focus on the following areas:

- Youth mobilization and participation.

- $\quad$ Promoting youth association activities

- Preparing the youth for skills training and employment.

- Improving the health and social integration of young people.

- Promoting socio-educational activities and sound leisure activities for young people.

- Access to economic resources and to means of production for the benefit of young people.

- Promoting extracurricular education and daily life skills learning for young people.

- Promoting youth access to information and documentation.

- Strengthening the capacities of the Niger youth parliament.

\section{d) Developing social protection for disadvantaged people}

540. The national social development policy will serve as the operational framework for implementing various measures to mitigate risks and provide social protection. Particular emphasis will be placed on measures such as the promotion of labor intensive work, and fighting against all forms of discrimination against disabled persons. These measures are aimed at preventing situations of extreme destitution. In the same vein, a number of targeted safety nets are expected to be put in place, in particular through the distribution of food rations, ensuring low sales prices, setting up contributory pension schemes, and mutual health insurance companies, in order to contribute to mitigating the effects of natural or economic upheavals on vulnerable persons. The specific objectives pursued are as follows:

- Provide legal protection for disabled people.

- Ensure the social promotion of disabled people.

- Promote income generating activities (IGA) for poor families.

- Provide social protection to prisoners.

- Provide social protection for the mentally ill and others.

- Provide support to the elderly.

- Contribute to the gradual and permanent reintegration of people affected by disasters, the displaced, and refugees.

541. In response to the low level of social security coverage in the country, the lack of any form of coverage against the risks of ill health and loss of employment, and the inadequate levels of social security benefits, the government intends to boost the social security system. The objective would be: (i) to promote employment both in the formal and informal sectors; (ii) to have tripartite consultations and greater involvement of government and private sector workers in issues relating to social security, and (iii) provide support to funding social security schemes. To do this, it will be necessary to study the possibility of extending social security to those sectors of the population that are not covered by the current system; to envisage the setting up of a system of health insurance, and to support the promotion of an employment policy. Other measures would be to raise the current levels of benefits paid, and to move towards a supplementary pension scheme based on a system of accumulation, in order to allow workers to set aside a greater part of their income for the purpose of improving their standard of living when they retire, and also to encourage a participatory approach to the setting up of micro health insurance schemes.

\section{e) Preventing the risks of natural disasters}

542. In line with the 2005 Hyogo framework for action, which promotes a concerted and general approach to the prevention of risks of natural disasters in order to ensure sustainable development, government undertakes to implement the following measures: 
- Integrating disaster management and risk mitigation into policies, institutions, and the development process.

- Institutional capacity building on issues of disaster management and risk mitigation.

- Improving knowledge management, in particular with reference to the sharing and use of information.

- Community capacity enhancement, in relation to disaster risk mitigation.

\subsubsection{Infrastructure Development}

\section{$\checkmark$ Reference situation under this pillar:}

543. The present situation is characterized by the following:

- Low levels of basic infrastructure.

- Low level of construction of regional infrastructure aimed at opening up the country.

- Inadequate access to energy services and to ICTs, both in urban and in rural areas.

- Low level of energy consumption ( 0.14 toe).

544. Strategic objective under this pillar: Equip the country with economic infrastructure in order to boost growth and facilitate access to social services

> Energy indicators linked to the MDGs for 2012 and 2015:

\begin{tabular}{|c|c|c|c|c|c|}
\hline $\begin{array}{l}\text { Corresponding } \\
\text { MDG }\end{array}$ & Selected MDG targets & Selected indicators: & Current level & $\begin{array}{l}\text { Desired level } \\
\text { in } 2012\end{array}$ & $\begin{array}{l}\text { Desired level } \\
\text { in } 2015\end{array}$ \\
\hline \multirow{3}{*}{$\begin{array}{l}\text { Access to modern } \\
\text { energy services } \\
\text { (MES) in the social } \\
\text { sectors } \\
\text { (healthcare, water, } \\
\text { and education). }\end{array}$} & Healthcare & $80 \%$ of $\mathrm{IHCs}$ have access to MES & $410 \mathrm{IHCs}$ & $981 \mathrm{IHCs}$ & $1381 \mathrm{lHCs}$ \\
\hline & Safe drinking water (motive power) & $20 \%$ of $\mathrm{IHCs}$ have access to MES & $\begin{array}{l}501 \text { mini water } \\
\text { supply points }\end{array}$ & \begin{tabular}{rr|}
1432 & mini \\
water & supply \\
points & \\
\end{tabular} & $\begin{array}{lr}7162 & \text { mini } \\
\text { water } & \text { supply } \\
\text { points } & \\
\end{array}$ \\
\hline & Education & $30 \%$ of IHCs have access to MES & 362 schools & 2823 schools & 9409 schools \\
\hline $\begin{array}{l}\text { Access to MES for } \\
\text { the productive } \\
\text { sector (Agriculture: } \\
\text { irrigated land) }\end{array}$ & & $10 \%$ of IHCs have access to MES & 14000 ha & 27000 ha & 270000 ha \\
\hline $\begin{array}{l}\text { Access to MES for } \\
\text { local communities } \\
\text { (rural areas). }\end{array}$ & & $80 \%$ of IHCs have access to MES & 10 communes & 155 communes & 194 communes \\
\hline \multirow[t]{2}{*}{$\begin{array}{l}\text { Access to MES for } \\
\text { IGA in rural areas } \\
\text { (motive power, } \\
\text { etc.). }\end{array}$} & Multi-functional platforms (MFP) & $3.5 \%$ of MFPs created & 5 MFPs & 974 MFPS & 13909 MFPS \\
\hline & Other IGA (mills, crafts, trade, etc. & $45 \%$ of IGA created & 3520 IGA & 12518 IGA & 13909 IGA \\
\hline \multirow[t]{2}{*}{$\begin{array}{l}\text { Access to modern } \\
\text { cooking fuels. }\end{array}$} & Mineral coal & $\begin{array}{l}20 \% \text { of rural households and } 30 \% \text { of } \\
\text { urban households }\end{array}$ & 21124 households & $\begin{array}{l}524536 \\
\text { households }\end{array}$ & $\begin{array}{l}1029451 \\
\text { households }\end{array}$ \\
\hline & Butane gas & $\begin{array}{l}10 \% \text { of rural households and } 70 \% \text { of } \\
\text { urban households }\end{array}$ & 27659 households & $\begin{array}{l}488838 \\
\text { households }\end{array}$ & $\begin{array}{l}1029451 \\
\text { households }\end{array}$ \\
\hline $\begin{array}{l}\text { Access } \quad \text { to } \\
\text { electricity }\end{array}$ & & $\begin{array}{l}0.28 \% \text { of rural households and } 41 \% \text { of } \\
\text { urban households }\end{array}$ & 161986 households & $\begin{array}{l}249639 \\
\text { households \& } \\
275 \\
\text { communities } \\
\end{array}$ & $\begin{array}{l}852705 \text { rural } \\
\text { households and } \\
353492 \text { urban } \\
\text { households }\end{array}$ \\
\hline $\begin{array}{l}\text { Strengthening } \\
\text { energy } \\
\text { infrastructure. }\end{array}$ & & $25 \%$ power produced & $50 \mathrm{MW}$ & $105 \mathrm{MW}$ & $262 \mathrm{MW}$ \\
\hline $\begin{array}{l}\text { Accelerate } \\
\text { development of } \\
\text { ICTs in urban and } \\
\text { rural areas }\end{array}$ & $\begin{array}{l}\text { Access to communication } \\
\text { infrastructure (telephone, internet) } \\
\text { Extend coverage by local information } \\
\text { infrastructure (community radio } \\
\text { stations) }\end{array}$ & $\begin{array}{l}\text { Number of phone centers or cybercafés } \\
\text { created } \\
\text { Number of rural communities equipped } \\
\text { with a community radio station }\end{array}$ & & & \\
\hline
\end{tabular}




\section{Other performance indicators:}

- $1666 \mathrm{~km}$ of tarred roads rehabilitated between 2008 and 2012.

- Continued maintenance of the road network (18 $884 \mathrm{~km}$ in 2007).

- $\quad 4775 \mathrm{~km}$ of modern earth roads to be constructed between 2008 and 2012.

- $2.0002000 \mathrm{~km}$ of new railroads linking the networks of Benin, Burkina Faso, and Togo, via Niamey.

\section{Brief analysis of the strategy to be implemented:}

545. Not only does Niger have to increase public investment in economic infrastructure, it also has to target such investment better, specifically in the areas with a strong capacity to support growth and avoid the pitfall of poverty.

546. Indeed, improving and developing public infrastructure (roads, energy, telecommunication, etc.) contributes to economic and social development by improving access of the population to the market, promoting private investment, and stimulating a spirit of entrepreneurship. It also improves the productivity of private production factors and thus creates the enabling environment for accelerating growth. Similarly, infrastructure development contributes strongly to improving access of the population to basic social services (healthcare, education, water supply, etc.), and to food security.

\section{a) Transport}

547. Niger will continue to implement its National Transport Strategy - Roads and Road Transport, which will be supplemented by strategies on other means of transport, within an appropriate legal framework.

548. The implementation of the National Transport Strategy - Roads and Road Transport, which is broken down into a Sectoral Programme on Transport will cover the following areas:

- Opening up to the outside and within the country.

- Preserving existing assets.

- Modernization of the transport industry.

- Improving road safety.

- Resolving cross-cutting issues such as HIVIAIDS control, environmental protection, and the gender approach.

549. The national road transport strategy contributes to poverty reduction by facilitating access of the most underprivileged to services through: (i) enhancement of the role of the private sector through liberalization of passenger transport activities and carrying out road maintenance; (ii) modernization of transport and road traffic regulations; (iii) enhancing the capacities of administrative units and economic operators in the sector; (iv) developing the sector with routine maintenance and construction of new structures; (v) facilitating transport and transit along the main corridors; (vi) setting up a sustainable funding mechanism for road maintenance; (vii) opening up the rural areas to facilitate access of the population to production zones and to basic social services, and (viii) reducing road insecurity.

550. As far as opening up the country to the outside is concerned, the government will strongly support the implementation of the investments provided for in the framework of the WAEMU Regional Economic Programme and NEPAD. These investments are aimed at: (i) improving the level of service in the different corridors linking Niger to the other capitals of the Union by developing and tarring stretches of road, constructing highway structures, as well as the construction and equipment of side-by-side checkpoints; (ii) interconnecting existing railway lines with the construction of $2000 \mathrm{~km}$ of new railroads between the rail networks of Benin, Burkina Faso, and Togo, and going through Niamey; (iii) the construction of all the community links (Trans-Saharan and TransSahelian) located in Niger.

551. In addition, the community projects set out in the WAEMU REP and which relate to the territory of Niger; 
form an integral part of the present DPRS.

552. In the area of air transport, there will be the need to (i) provide service to the country's main towns; (ii) further open up the skies of Niger to international air traffic by signing agreements; (iii) set up a viable national airline; (iv) seek funding to develop the airports of Agades and Zinder to comply with ICAO standards for widebody aircraft; (v) rehabilitate national airports, (vi) purchase search and rescue equipment, and (vii) draft and implement a national air transport policy.

553. In the area of inland waterway transport, the river must be made navigable with the construction of appropriate infrastructure, and landings along the river. There is also a need to make the river sector more professional and draft a national inland waterway transport strategy.

554. As far as maritime transport is concerned, activities will focus on rationalizing road checks; improving port and transit operations; removing unilateral taxes along the different corridors; monitoring the effective implementation of the regulation abolishing rotations, in particular in the transit ports.

\section{Box 10: The WAEMU Regional Economic Program}

The eighth ordinary session of the Conference of Heads of State and Government of WAEMU, held on January 102004 decided on the drafting of a Regional Economic Programme (REP). The REP aims at three main objectives, i.e.:

- To promote strong growth and sustainable development within the Union.

- To promote the emergence of a competitive regional economy, capable of ensuring the integration of the Union within the world economy.

- To reduce poverty and inequalities in the Union.

Implementation of the REP is expected to accelerate the emergence of an integrated economic area within which the various economies can organize their efforts to adapt to the requirements of globalization and the need to improve the living conditions of the populations of the Union.

The Regional Economic Programme is organized around a group of 63 integrating projects that were selected at regional level on the basis of their catalyzing effect for the achievement of WAEMU growth and development objectives. The selected projects concern the following sectors: (i) transport, (ii) energy, (iii) information and communication technologies, (iv) human resources, (v) agriculture and industry, and (vi) sound political and economic governance.

The WAEMU Commission recommended that the REP be taken into account in Public Investment Programmes (PIP) and in the Poverty Reduction Strategy Papers (PRSP) of WAEMU member States. A steering and monitoring and evaluation mechanism for the REP will soon be set up and will be expected to be in consistency with similar mechanisms of national PRSPs.

\section{b) Developing Information and Communication Technologies}

555. The setting up of the National Policy on Communication for Development and the NICI Plan in 2004 was aimed at bringing Niger up to speed with the second global technology revolution that was characterized by the link that was established between IT, telecommunications, and audiovisual services. The activities to be implemented in this framework will make the following possible: (i) improve the rate of penetration of NICTs by increasing the number of community communication centers; (ii) increase radio and TV coverage; (iii) extend the use of NICTs to all levels of society (private sector, public administration, citizens, etc.). Communication and information services (ICT services) will thus be able to play their role fully as instruments of development (entrepreneurship, citizenship), of poverty reduction (food security, health, education), and of good governance (electronic administrative services, decentralization). 
556. To this end, Niger will ensure that the prevailing environment of communication and information services is improved, by drafting and implementing the strategy for universal access to communication and information in rural and peri-urban areas.

557. The strategy for universal access will be implemented within the framework of five priority axes of intervention, including capacity strengthening programmes. More specifically, the following action will be undertaken: (i) extend coverage of communication infrastructure; (ii) facilitate access to communication services

(telephone, Internet), in particular through drastic cost reduction; (iii) extend coverage of community information infrastructure (community radio stations); (iv) offer ICT services with appropriate content for the local context; (v) educate decision-makers, politicians, entrepreneurs, and civil society on the benefits of ICTs.

558. In addition, an "information and ICT" dimension will be included in all new public policies.

\section{c) Developing energy supply}

559. Development of the energy supply will be carried out within the framework of the energy policy statement adopted by government in 2004, and in conformity with the ECOWAS/WAEMU regional policy (White Paper) adopted in January 2006. The energy policy seeks to create a framework that makes it possible to meet energy needs for sustainable development.

560. The energy policy is presented along the following main axes:

- Guaranteeing the security of long-term supply.

- Social and territorial cohesion through the provision of access to energy for all at an affordable price.

- Developing national energy resources.

- Ensuring the protection of the environment.

- Enhancing the capacities of all actors.

\section{d) Consolidating public real estate assets}

561. Consolidating public real estate assets will be achieved through improvements in management, and the construction of new buildings. The following specific action will be undertaken:

- Carry out an inventory and diagnosis of all State-owned real estate.

- Establish a database for all administrative buildings.

- Draw up a programme for rehabilitating or renovating real estate holdings.

- Carry out an overall estimate of the current value of real estate holdings.

- Assess the real capacity of existing holdings to meet real estate needs.

- Equip the various State institutions with appropriate and sufficient infrastructure for their needs, by construction more modern and functional buildings.

\subsection{Promotion of good governance}

562. Strategic objective under this pillar: Entrench the rule of law in a democratic society and ensure effectiveness and transparency in economic and financial management.

\section{Brief analysis of the strategy to be implemented:}

563. The institutional, economic and social reforms undertaken by Niger over the past few years have been aimed at promoting good governance. As a result, all development action will now be conducted on the basis of the principles of responsibility and accountability, transparency, respect for the law, combating corruption, and ensuring participation. This innovative approach can only be effective if there is a modernization of the administration and reform of the legal apparatus. In addition, implementing decentralization appears to be a vital aspect of entrenching good governance and regional and local development. 


\section{a) Consolidating political governance}

564. Government will strengthen the democratic gains by organizing local, presidential, and parliamentary elections, as well as by boosting and operationalizing existing instruments for consultation such as: The National Council for Political Dialog, the National Council for Social Dialog, the National Council of Private Investors, the National Labor Council, and the National Committee on Conflict Prevention and Management.

565. Furthermore, other major areas of action to ensure full participation of all in the design and implementation of public policy will include providing education for a culture of peace, capacity building for various actors, and civic education for better citizenship awareness.

\section{b) Enhancing the rule of law, and reform of the justice system}

566. Reform of the system of justice will be actively pursued. It is aimed at promoting the ideals of social justice, equity, and integrity, by accelerating the implementation of the Programme of Assistance for Legal Reforms (PARJ), in order to set up an independent, competent, professional, equitable, and credible system of justice. These are a prerequisite for improving the economic environment, promoting free enterprise, guaranteeing the rights and freedoms of citizens, and consolidating the confidence of citizens who are subject to trial.

567. To achieve this end, the process of reforming texts will be accelerated, while ensuring that they are harmonized with regional (OHADA) or international conventions and treaties ratified by Niger. The various specialized courts will be strengthened and revitalized. Furthermore, with the decriminalization of breaches of the press law, it will be possible to instill an atmosphere of trust between the State and the communication world. Similarly, measures will be undertaken to improve the conditions of detention; ensure that the principles of human rights and humanization of prisons are complied with, and to facilitate the training and social integration of detainees.

\section{c) Strengthening of administrative governance}

568. Niger would like to claim a modern administrative service that is equipped with skilled and committed human resources, in order to face the challenges of social and economic development. In order to achieve this objective, a real programme of administrative governance, capacity enhancement, and State reform must be put in place. This programme is in response to the need for State reform, following the significant changes that have taken place in the last decade. The programme is centered on the following three (3) strategic axes:

- Reorganization of public administration and strengthening of the public service system. This entails redefining the missions and organization of government in line with the adopted deconcentration plan.

- Develop and enhance the capacities of government bodies through the definition of a coherent human resources development strategy.

- Promoting communication and links with public service users in order to promote the idea of a public administration that is open to citizens.

- $\quad$ Promoting the deconcentration and rationalization of administrative structures.

569. To this end, a strategic study will be carried out with a view to identifying concrete measures and changes to be introduced. It will also consider the modernization of public administration and the introduction of a new administrative culture based on productivity, output, and quality of public service, as well as the use of modern working tools.

570. The new human resources management policy to be put in place will include: (i) continuing professional training for public servants at all levels; (ii) adoption of a new performance evaluation system; (iii) setting up of a transparent and equitable recruitment, incentive, and promotion system; (iv) revision of the general status of the public service, in line with the changes; ( $v$ ) reform of the retirement and pensions scheme, and (vi) promotion of good conduct and ethics, as well as the fight against corruption. 


\section{d) Improving economic governance}

\section{Public financial management}

571. Government will continue to modernize public financial management through the implementation of the PEMFAR priority plan of action by: (i) improving budget preparation (gradual drafting of sectoral MTEFs); (ii) improving budget implementation; (iii) strengthening internal control and monitoring of budget implementation (traceability of public expenditure); (iv) strengthening the capacities of the units in charge of economic and financial management instruments, by providing them with human resource and the requisite tools; (v) improving external controls (audit of the Court of Accounts and parliamentary oversight), and (vi) rendering accounts regularly.

572. In addition, particular attention will be paid to capacity building by introducing a gender budgeting approach, in order to contribute further to doing away with inequalities and promote equity in public resource allocation.

\section{Monetary policy}

573. Niger is a member of WAEMU. It is therefore bound by the regional monetary policy implemented by the $\mathrm{BCEAO}$, and which is aimed specifically at ensuring (i) an adequate level of liquidity to support economic activity; (ii) macroeconomic stability and the convertibility of the common currency, and (iii) competitiveness of all the economies in the Zone.

Improving consultation on development

574. The Economic, Social, and Cultural Council, which serves as a forum for consultation among the different components of the nation was set up in 2006. Its competences will be enhanced in order to make it a credible body and an important medium for the executive power thanks to the opinions that it will be required to hand down on issues of an economic, social, and cultural nature.

\section{Corporate governance}

575. In the area of corporate governance, a draft bill will be submitted to the National Assembly for adoption. The bill includes provisions relating to: (i) the rights of shareholders; (ii) fair treatment of all shareholders (in particular respect of the rights of small investors); (iii) the role of shareholders in corporate governance; (iv) the responsibilities of the Board, which must render account to the company and to shareholders, and (v) information dissemination and transparency.

\section{Fighting corruption}

576. Niger is determined to combat corruption in all its forms, and to fight against impunity. Strategies to be implemented to this end relate to: (i) educating the population on the phenomenon of corruption; (ii) rationalizing administrative procedures and the rules governing public procurement, in order to limit the possibilities of corrupt practices; (iii) enforcing existing anti-corruption laws and legal texts, as well as ratifying international conventions on combating corruption and incorporating them into national law; (iv) upgrading the skills of civil society in fighting against corruption, and (v) effectively setting up the High Authority on Corruption Control.

\section{c) Strengthening local governance}

577. At regional and local levels, implementing the DPRS will lead to the drafting of regional strategies and local development plans. These documents will be drafted using a participatory approach, and will be consistent with the achievement of the MDGs. More specifically, the following areas of action will be pursued: (i) continuation and extension of capacity building programmes for agents of decentralization; (ii) increased resource mobilization for local authorities; (iii) development of decentralized cooperation; (iv) definition of a consistent strategic framework for decentralization, in order to define the vision, objectives and expectations of government in relation to the decentralization reform. This framework will make it possible to define the roles of all public and private agents, as well as those from third party sectors who to one extent or another are involved in the area of 
decentralization; ( $v$ ) drawing up a national programme of support for local authorities, which should make it possible to mobilize the resources required for their development; (vi) organization and strengthening of the decentralization exercise in order to improve support to the project and arrive at real partnership between government, local authorities, and other local agents, at the grass roots level, and (vii) support and consolidation of decentralization through the strengthening of the legal framework and definition of a national structure to provide effective support and empowerment to local authorities by organizing the gradual, consistent, and functional transfer of competences.

\section{f) Social participation}

578. Support will be provided to the increased participation of civil society in development action through: (i) upgrading of the human and technical capacities of civil society organizations, in particular in the area of project design, implementation, and monitoring-evaluation; (ii) total involvement of civil society organizations in the design and popular oversight of public policies, including at local level; (iii) overhaul of the institutional monitoring and consultation framework with NGOs.

\subsubsection{Effective implementation of DPRS}

579. Strategic objective under this pillar: Ensure effective implementation of the DPRS and promote development results based management.

\section{$>$ Performance indicators set for 2012:}

580. Selected indicators in this area are as follows:

- Number of meetings of the coordinating committees that are held according to schedule.

- The percentage of monitoring and evaluation reports published on time and which lead to action will reach $100 \%$.

- $\quad 100 \%$ of all sectors will have a sectoral policy and a MTEF that is in line with the objectives of the DPRS.

- Existence of an overall MTEF.

- $\quad 100 \%$ of all regions and communes will have a development plan that is in line with the objectives of the DPRS.

- Existence of a prospective study entitled "Niger - Vision 2030".

- $\quad 100 \%$ of all studies are carried out on schedule and provide quality reports.

- Aid predictability increases from $74 \%$ in 2005 to $100 \%$.

- Effective resource distribution among sectors is implemented.

- Number of parallel programme and project implementation bodies.

- Number of common procedures and arrangements implemented.

- Number of joint missions carried out.

- The percentage of programmes in line with the DPRS reaches $100 \%$.

\section{$>$ Brief analysis of the strategy to be implemented:}

581. The key to the success of the Accelerated Development and Poverty Reduction Strategy is in sound implementation of the activities defined. Thus, responsibility for the management of the strategy will be shared and carried out within a partnership framework, in line with the principle of redefining the roles of various players that was spelled out in the first phase of the PRS. Particular attention will therefore be paid to developing partnerships, and to strengthening the capacities of both the public and the private sectors, as well as those of civil society. Also, the capacities of the national statistics system (SSN) will continue to be strengthened through the implementation of a national strategy for the development of statistics. In particular, this is aimed at ensuring the implementation of the plan of action of the Paris declaration. 
582. Priority activities to be carried out in this context include in particular:

- Improving the formulation of public policies.

- Increased and efficacious resource allocation to DPRS priority areas.

- Providing quality services to the poor.

- Setting up a results based monitoring and evaluation system.

- Enhancing the capacities of all actors.

- Risk anticipation and management.

\section{a) Improving the formulation of public policies}

583. The practical measures to be implemented here will include defining a coherent framework to ensure effective development, with practical tools for strategic planning, risk management, progress monitoring, and results assessment. In order to do this, planning will be rehabilitated and given new impetus in ministries and programme and project offices.

584. In addition, efforts will be made to ensure that there is consistency between long term vision, medium term strategies, and short term priorities. A long term forward looking study will thus be initiated. It will be carried out by a multidisciplinary team and should make it possible to adapt sector strategies to the expectations of the population and the real capacities of the country.

585. Drawing up of integrated sector programmes will be generalized to all areas of activity. These will be accompanied by medium term expenditure frameworks and programme budgets. With the drafting of medium term expenditure frameworks, it will thus be easier to allocate budget resources, in line with the DPRS objectives. In addition, the MTEFs will serve as a tool to assess the effectiveness of public expenditure and the performance of programmes implemented. In the regions, development plans will serve as the basis for all intervention.

586. Gender will be taken into account at both the planning and the budget phases, in order to take account of the needs of men and women in the process of economic and social development.

\section{Increased and efficient resource allocation to DPRS priority areas}

\section{Budgetary framework}

587. The DPRS budgetary framework was drafted with the aid of an MTEF module contained in the AYEROU model that is used for budget preparation. The framework also draws on the medium term expenditure frameworks of certain sectors, as well as the estimates of amounts required in order to attain the Millennium Development Goals. This work was further supplemented by a long term analysis of the sustainability of Niger's foreign debt. The results of the different simulations are as follows:

- Total expenditure to implement the MDG/PAP scenario would be almost twice the basic level of budgetary expenditure. In the case of the intermediate scenario, total expenditure would increase by $10 \%$, compared to expenditure levels in the basic scenario.

- Strong resource allocation and restructuring of public expenditure in favor of those sectors that promote the implementation of the MDG/PAP scenario, to the detriment of other sectors. Indeed, the share of priority spending in this scenario would represent $72 \%$ of total expenditure, as compared to $46.6 \%$ in the basic scenario.

- The share of investment spending in priority sectors would be increased to $86 \%$ of total expenditure in the MDG/PAP scenario, as compared to $62 \%$ in the basic scenario. 
Table 21: Summary of the Different Growth Scenarios - Total cost in millions of CFAF for the period 2008 - 2012

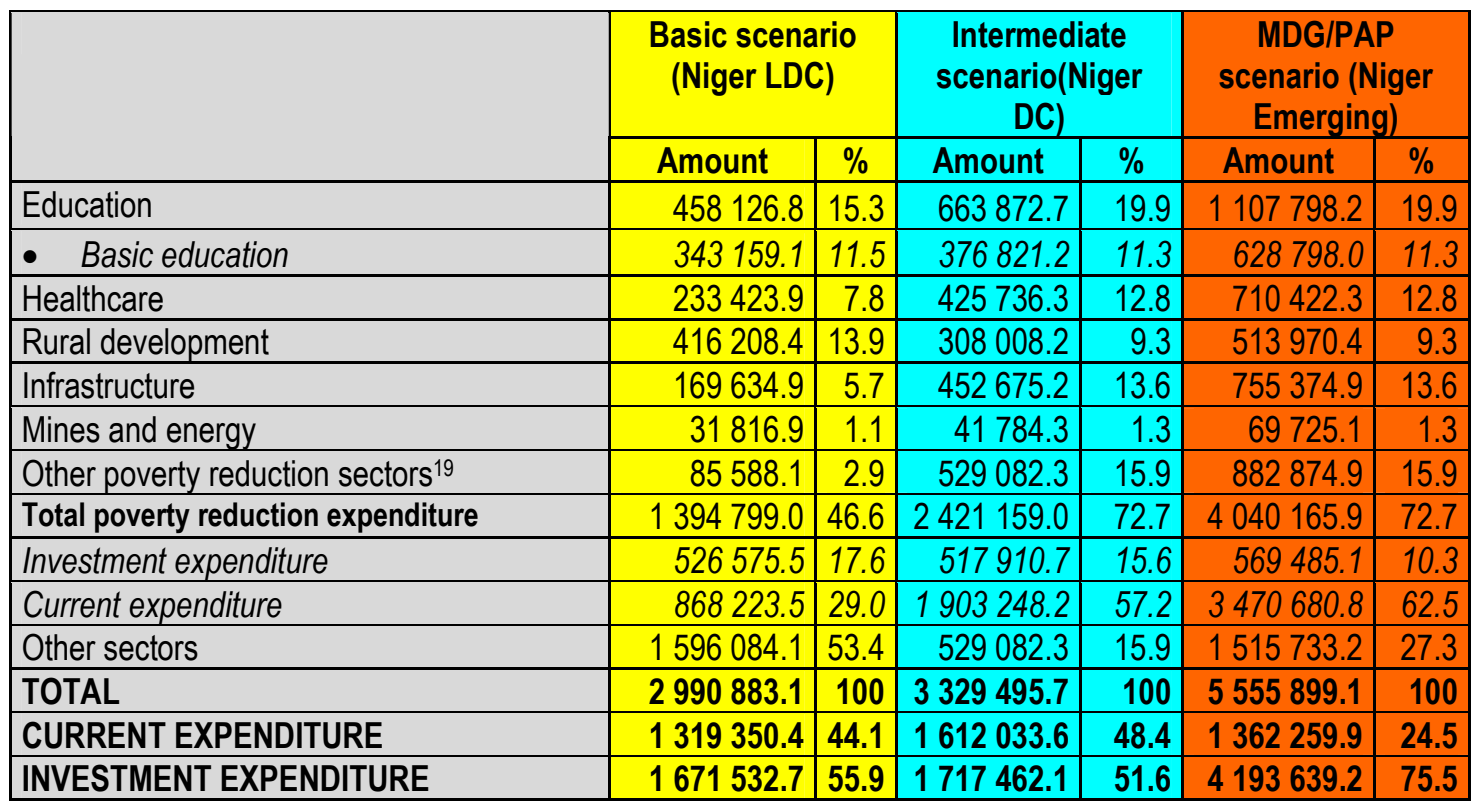

Source: Work of the thematic group on the "Macroeconomic Framework" and the "MDG quantification" team - PRS review, March 2007

588. Implementation of the strategy will require a high level of mobilization of both internal and external resources, in particular:

- $\quad$ Total funding of 2991 billion CFAF for the basic scenario.

- Total funding of 3330 billion CFAF for the intermediate scenario.

- Total funding of 5556 billion CFAF for the MDG/PAP scenario.

589. Looking at past public budget implementation, in particular with regard to internal and external financial resource mobilization (excluding debt alleviation, i.e., grants and concessional loans), Niger would need to increase its basic level of domestic resource mobilization by at least $40 \%$ in order to implement the MDG/PAP.

590. As far as external resources expected from the international community are concerned, these are estimated at 1031 billion and 3258 billion per year respectively, for the intermediate scenario and for the MDG/PAP scenario. Development partners would have to more than double (increase 2.5 times) their basic levels of financial contribution to the country's development. Expected additional external resources are estimated at nearly 1939 billion CFAF (an average of 388 billion annually, over the period).

591. The priority action plan defines activities to be carried out in order to attain the objectives of the DPRS.

\footnotetext{
${ }^{19}$ Employment, art/culture, population, private sector promotion, youth/sports, crafts/tourism
} 
Table 22: Financing requiriements - Annual amount in billions of CFAF

\begin{tabular}{|c|c|c|c|c|c|c|c|}
\hline & 2008 & 2009 & 2010 & 2011 & 2012 & $\begin{array}{c}\text { Total } \\
\text { (2008-2012) }\end{array}$ & $\%$ \\
\hline \multicolumn{8}{|c|}{ Basic scenario } \\
\hline Total cost & 529797.1 & 577797.8 & 603002.3 & 627645.1 & 652640.9 & 2990883.1 & 100 \\
\hline Internal resources & 269300.0 & 303600.0 & 332484.9 & 363720.1 & 403311.8 & 1672416.8 & 55.9 \\
\hline External resources & 260497.1 & 274197.8 & 270517.3 & 263925.1 & 249329.1 & 1318466.3 & 44.1 \\
\hline \multicolumn{8}{|c|}{ Intermediate scenario } \\
\hline Total cost & 572378.9 & 646797.3 & 670039.2 & 703038.8 & 737241.6 & 3329495.7 & 100 \\
\hline Internal resources & 343214.1 & 401049.3 & 465208.2 & 516299.3 & 572500.8 & 2298271.8 & 69.0 \\
\hline External resources & 229164.8 & 245747.9 & 204830.9 & 186739.4 & 164740.8 & 1031223.9 & 31.0 \\
\hline \multicolumn{8}{|c|}{ MDG/PAP scenario } \\
\hline Total cost & 814835.8 & 1145049.6 & 1209030.2 & 1179306.2 & 1207677.3 & 5555899.1 & 100 \\
\hline Internal resources & 343214.1 & 401049.3 & 465208.2 & 516299.3 & 572500.8 & 2298271.8 & 41.4 \\
\hline External resources & 471621.7 & 744000.3 & 743821.9 & 663006.9 & 635176.6 & 3257627.3 & 58.6 \\
\hline
\end{tabular}

592. These efforts will be supplemented by better control of current expenditure, enhanced absorption of allocated budgets, and improvements in the quality of public spending. At the same time, priority will be given to sectors that support growth, to attaining the MDGs, and to poverty reduction in general terms.

\section{$\underline{\text { Resource mobilization strategies }}$}

593. More than in the past, increased efforts will be deployed to mobilize internal resources, in order to face these challenges. This commitment will be illustrated in the continuation of the programme for restoring fiscal health. Stringent measures will thus be adopted to improve the tax ratio, increase tax collection from the informal sector, reduce exemptions, and extend the tax base. In addition, with continued efforts to restore fiscal health, it is expected that the conditions will be created for mobilizing resources on the regional financial market.

594. A much higher amount of external resources will be mobilized in the form of grants ( $80 \%$ of funding) or concessional loans (at least 35\% grant element), through bilateral, multilateral, and decentralized cooperation, in order to cover the better part of the funding required by the DPRS. This is in contrast to the current situation where funding is well below the levels required for the type and volume of investments that will support strong and sustained growth, a prerequisite for attaining the MDGs.

595. In the same vein, programme based management, which takes into account the concerns of partners, government priorities, and the needs expressed by the population will be implemented systematically. This approach will be strengthened by vitalizing the government/technical and financial partners committee, which will serve as a forum for appropriate dialog. In addition, the private sector will be invited to contribute in different ways (public/private partnerships, setting up foundations, funding social programmes and projects).

\section{Aligning partner assistance with government priorities and harmonization of procedures}

596. In accordance with the recommendations of some international summit meetings (Monterrey, Paris, Rome, etc.), Niger, which is a pilot country for the harmonization of procedures has undertaken, with its partners, to attain the objectives of the Paris declaration and monitor the fulfillment of commitments by measuring them against selected indicators.

597. Within this framework, government, in collaboration with its partners, will implement the recommendations of the Conference on ownership, alignment, and harmonization of aid. They will focus in particular on the following: (i) aligning assistance strategies of TFPs with the PRS and MDGs; (ii) harmonizing TFP intervention policies and procedures; (iii) ensuring that resources are allocated on the basis of tangible results, and (iv) setting up a performance assessment system between government and its partners, based on the principles of mutual accountability and shared responsibility for the results of development aid. 


\section{c) Providing quality services to poor people}

598. The DPRS can only have a real impact on target populations if those involved in implementation ensure that they deliver good quality services to poor people. It is therefore essential to have a good knowledge of the situation of poor people. To this end, specific surveys will be carried out in all regions, departments, towns, and villages to make sure that there is a precise definition of the different categories of poor people and thus design the appropriate strategy for each such category (small rural farmers, livestock breeders, women, urban slum inhabitants, etc.)

599. Poor people must also participate actively in identifying programmes that involve them; describe their real situation, and have a say in relation to the most appropriate areas of intervention to improve their living conditions. All this will allow poor people to have a better understanding or their role, and take ownership of programmes.

600. A proactive approach will also be adopted in order to allow programme managers to anticipate issues and go out to meet the population. Civil society must play an important role in organizing people. Poverty will be tackled using a multi-sector approach. The various aspects of the multidimensional issue of poverty will be taken into account with a view to designing forms of intervention that complement each other on the best programmes that serve the real needs of poor people. Sector-wide programmes should thus complement each other and be integrated only where this will allow for maximum effectiveness. Existing programmes will be adjusted where necessary to comply with this requirement.

601. Strategies for urban and rural areas will be differentiated in order to provide each zone with an appropriate integrated programme, with clearly defined poverty indicators (poverty line, standard of living index, etc.).

602. Each region, department, town, or rural community will be required to draft its own poverty reduction programme in harmony with the orientations of the national programme. These decentralized entities will be classified according to their level of well-being. The most impoverished zones will receive an integrated development programme aimed at drawing them more quickly out of poverty. The integrated programme will include several modules: capacity building; provision of basic social infrastructure and services; distribution of nutrition products; implementation of programmes to increase productivity directly (provision of technical packages, small-scale irrigation, consolidation of smallholdings in order increase yield, increasing livestock productivity, improving product marketing mechanisms, credit facilities, etc.).

603. Each poor person will be offered a complete service package, rather than a range of partial programmes. Poor households will be able to simultaneously enjoy access to credit, training, technical and technological assistance, etc. 
The 2004 edition of the World Development Report, published by the World Bank, and entitled "Making Services Work for Poor People", highlighted a number of factors limiting access of poor people to quality public services. After a survey carried out in several countries, the report revealed that poor people are deprived of services because of a bias in favor of non-poor people, very often for political reasons; poor resource allocation to basic services; absenteeism of staff who receive little incentive, and the distance to educational and healthcare facilities, in particular in rural areas.

Although many countries boast of giving priority to social services in their budget programmeming, they often fail in implementation, as is shown by the fact that public expenditure has limited impact on improving social indicators.

The report also points out three other areas of weakness, which correspond to three sides of a triangle:

The first side relates to the dysfunction of the democratic link between citizens and those in government, who are not subjected to sufficient pressure and who do not render adequate account about their responsibilities. Doing away with this constraint requires literacy, and informing people so that they are capable of selecting public officials who will truly serve their interests, and capable of fulfilling their role of overseeing the work of elected officials. The media and civil society can play a significant role in this regard.

The second side of the triangle illustrates the relations between government and service providers who are subcontracted to provide service to users. While developing subcontracting with the private sector, NGOs, and local communities, governments must ensure that they demonstrate firm and determined leadership in taking into account the needs of the poor, and set up effective systems for monitoring and evaluation, including using NICTs. In selecting service providers, government must also promote those who fundamentally, wish to serve poor populations. In certain cases, it will be necessary to create special measures as incentive for service providers to target poor population groups located in regions that have insufficient coverage.

The third and final side translates the link between users and service providers. This remains the weak link because of the fact that citizens tend to allow the public authority to play the role of mediator. If the influence of users is increased, this could imply an increase in the number of service providers, a guarantee of healthy competition and good quality supply. It is also important to increase participation of users in service management by allowing them to play a role in identifying the precise demands of people, and ensuring direct supervision of service providers through community associations.

All in all, it is the balance in the three sides of the triangle that will make it possible to instill renewed hope in the poor population and reinstate the social contract that is the cornerstone of the nation.

\section{d) Setting up a results based system of monitoring and evaluation}

604. The DPRS information and monitoring and evaluation system will draw inspiration from lessons learned and will be based on the principles of development results based management (RBM) This mechanism will make it possible to produce reliable information that will improve the design and implementation of policies, and guarantee rational use of public resources. The system will make it possible to: (i) monitor programme and project implementation; (ii) assess the effects and living standards of households; and (iii) assess the impact of development policies and programmes.

605. Monitoring will be carried out along the following two levels: Monitoring of implementation and results monitoring. Monitoring of implementation will focus simultaneously on means and strategies (resources, activities, and the products or goods and services delivered). Results monitoring for its part, will assess the extent to which the results have been attained. The link between these two levels is established by the interaction between means and strategies on one hand, and the performance targets on the other. Results targets must be set on the basis of means and strategies.

606. To this end, the system will be based on the following guiding principles: Compliance with the mandate of various bodies; definition of manuals of procedure and precise performance indicators; generation of quality data (reliability, regularity, and usefulness); use of data to inform decision-making, and partnership in the design and management of the system. 
607. More specifically, priority action will focus on the following: (i) supplying all actors with quality products; (ii) developing communication centered on outcomes; (iii) enhancing the statistical information system; (iv) making the coordinating and monitoring-evaluation mechanisms dynamic.

608. An Evaluation Development Policy will be drafted. The purpose, among others, is to improve the supply and demand of evaluation by improving evaluation practices, promoting evaluation, and strengthening the human, material, and institutional capacities involved. Under this framework, a capacity building programme will be implemented. The programme will focus on the following areas: (i) improving the organizational and institutional environment; (ii) increasing human and financial resources; (iii) setting up facilities; (iv) defining standards and methodologies, and (v) enabling the publication of reports on monitoring and evaluation.

609. A pilot system of participatory monitoring of poverty will be set up. As a result of decentralization, major responsibilities in the area of managing the development of their administrative entities have been devolved to communes. The various bodies of the national monitoring and evaluation apparatus therefore need to be represented at that level. Nevertheless, due to its limited resources, setting up a decentralized DPRS can only be carried out gradually, through sound programming. Here, the setting up of a pilot system of participatory monitoring is aimed at promoting local capacities for planning and monitoring and evaluating poverty reduction measures. In the long run, it will provide information for the drawing up of communal development plans. It will also make it possible to develop the skills of the NIS in relation to participatory surveys.

\section{Defining the different products of monitoring and evaluation}

610. The system will provide the following products in a timely manner, in order to inform decision-making: The annual DPRS results based monitoring report; the national monitoring report on development projects and programmes; impact assessment reports, and the tables of monitoring indicators.

611. The annual DPRS implementation monitoring report will focus on results. This report, which is prepared by the PRS/PS, will serve as an instrument for sharing results, and for resource mobilization. It will provide information about the results obtained as compared to the expected results and resources allocated. It will also report on the principal achievements, the identified risks, and future prospects. It will be drafted on the basis of sector reports; of the report on the programme of economic and financial reforms; the project and programme performance monitoring report, and additional information on the living standards of households. In addition, each region will provide a results-based monitoring report, which will be used in the drafting of the sector reports. The annual monitoring report will be approved by the national steering committee prior to being submitted to government for adoption.

612. The national development projects and programmes monitoring report will enable an assessment of the performance through the analysis of the concrete and financial implementation of programmes under the government investment budget. Project and programme monitoring will first be carried out at sector level. Information in those reports will then be aggregated in a national report on the performance of projects and programmes.

613. The DPRS will be evaluated several times over the period. During the period between 2008 and 2012, a mid-term review will be carried out in 2010 , followed by a final review in 2012. The latter will provide assessments of all the changes that have taken place in the well-being of the people of Niger, and make it possible to update the strategy. Similarly, sectoral policies will be evaluated to assess the effects of intervention measures, using various criteria on effectiveness, efficaciousness, and sustainability. To this end, new projects and programmes will have to be drawn up, whose design includes impact assessment.

614. Ex-ante programme assessment will be made systematic in all sectors. Projects and programmes of technical and financial partners (TFPs) and NGOs will thus be assessed with keen attention before implementation, to ensure that they are consistent with the long-term objectives of Niger. The application of integrated sector and/or local programmes could facilitate this coordination of activities.

615. The various instruments will be based on the table of DPRS monitoring and evaluation indicators. For this purpose, a minimal list of indicators has been updated and refined on the basis of criteria relating to availability, reliability, and relevance. In addition, the choice of DPRS implementation monitoring indicators is the 
result of the application of an iterative method focusing on results based management, gender, and the multidimensional vision of poverty. As part of this exercise, and in order to have a better annual assessment of the progress made, a national standard of living index (grouping together the different socio-economic indicators) will be designed and measured.

\section{Promoting communication of results}

616. Communication has been the weak link in the system that has been focusing on information production. When well managed, communication makes it possible to obtain better outcomes and results by promoting information sharing, awareness, participation, and ownership of the DPRS process by all actors.

617. A communication plan will be implemented and will make it possible to identify the information requirements of different players, as well as the most appropriate format for each user. This communication plan will also make it possible to strengthen dialog and debate on key aspects of the strategy, while promoting the dissemination of information at all levels. With this in view, the DPRS web site will be updated regularly to facilitate information sharing. A DPRS information bulletin will also be circulated.

618. The NIGERINFO databank will be used to stock and present the indicators that are required for monitoring the various sector strategies and the DPRS. The databank will receive sector data and data from the various surveys. Sector databases will therefore have to be upgraded.

\section{Development of the statistical information system}

619. This will be done mainly through the implementation of the national statistics development strategy (SNDS); the regular generation of data to monitor the PRS, and the development of a geographical information system.

620. The national statistics development strategy (SNDS) will eventually make it possible to set up a "statistics" function that has all the human, material, and financial resources required to allow it to contribute effectively to the monitoring and evaluation of development policies, programmes, and projects. The specific objectives here are mainly to contribute to ensuring the availability of reliable, up to date, and relevant data. To do this, there is a need to (i) develop the institutional capacities of the statistics system; (ii) promote the generation of statistical indicators in response to the requirements of users; (iii) develop the capacity to analyze and use statistical data, and (iv) promote conditions for storing, archiving, and disseminating statistical information. The design of the SNDS will be inspired by recent statistics philosophy, offering information that pays greater attention to demand. It endorses the principles and values of the African Charter on Statistics.

621. Generating statistical data in response to strategy requirements There is a need for information relating to household standards of living; coverage, access and use of services; production of goods and services and their distribution, and prices. Standard of living surveys will therefore make it possible to improve knowledge about the phenomenon of poverty and ensure regular updating of data. The surveys will also provide information that will make it possible to define a reference situation, measure changes, and carry out comparisons among certain groups. The National Institute of Statistics will have to draw up poverty maps regularly, and carry out the relevant analysis of the various dimensions of poverty.

622. The various ministerial statistics departments will also be enhanced, in order to collect, use and publish regularly all the relevant information on their areas of competence, in response to the needs of users. The system should also be decentralized in order to allow it to meet the new requirements in poverty monitoring in a timely manner. 
623. During the period of implementation of the DPRS, material, financial, and human resources must be made available, in order to carry out the following activities, among others, according to the timetable below:

Table 23: Programme of Surveys 2007 - 2012

\begin{tabular}{|l|l|l|l|l|l|l|}
\hline & 2007 & 2008 & 2009 & 2010 & 2011 & 2012 \\
\hline Monitoring employment \& unemployment & & & & & & \\
\hline Multiple Indicator Cluster Survey & & & & & & \\
\hline National budget \& consumption survey & & & & & & \\
\hline $\begin{array}{l}\text { Survey on governance, access to basic } \\
\text { services and user satisfaction }\end{array}$ & & & & & & \\
\hline $\begin{array}{l}\text { General Census of the Population and } \\
\text { Habitat }\end{array}$ & & & & & & \\
\hline Survey of businesses & & & & & & \\
\hline Harvest forecast \& estimates survey & & & & & & \\
\hline Survey on food security and vulnerability & & & & & & \\
\hline
\end{tabular}

Source: Thematic discussions "Monitoring and Evaluation Group" - PRS review, March 2007

624. The purpose of developing a Geographical Information System (GIS) will be to improve targeting of beneficiary populations in carrying out programmes relating to land-use management, road and highway construction, mining, rural development, national security, and construction of social infrastructure.

625. A national plan for the use of a comprehensive geographical information system will be drafted and implemented. The plan will describe the way in which information, technology, as well as the various bodies, will be linked together to make up the GIS. At the same time, the following activities will be carried out: (i) setting up of a digital database of basic maps; (ii) revitalization of the national mapping and remote-sensing committee (CNC/T); (iii) modernization of the center for documentation and geographical information.

\section{$\underline{\text { Redefining monitoring-evaluation mechanisms }}$}

626. In order for the DPRS to be successful, it is vital that the highest authorities of the country and elected officials take full ownership of the strategy and be closely involved in steering its implementation. Thus, in order to guarantee the effective implementation of the DPRS, its institutional arrangements will be revitalized and made more participatory, while at the same time, the responsibilities of different bodies are clarified. The various bodies will meet regularly to provide orientation and take stock of results obtained in the implementation of the DPRS. On this basis, the new institutional arrangement is founded on the existing structure, with new concerns being tackled. It includes various bodies, one of which is a coordinating unit. The different bodies are listed below:

627. The national steering committee, chaired by the Prime Minister and Head of government. Its mission is mainly to set the policy and strategic orientations of the DPRS, to ensure compliance with DPRS priorities in budget programmeming, and to assess the effects of its implementation on economic and social development.

628. The national committee of government and technical and financial partners: This committee is chaired by the minister in charge of finance, and its mission is to promote the coordination and harmonization of interventions by different actors; facilitate financial and technical resource mobilization, and ensure the alignment of budgetary assistance. It also serves as the forum for dialog between government and partners on the process of preparing and monitoring the implementation of the DPRS. In particular, it is in charge of ensuring that the results of reviews are taken into account in allocating resources to identified priorities, in line with the plan of action for the implementation of the Paris declaration. This committee is thus in charge of validating the report on monitoring aid coordination.

629. The national technical committee is presided over by the Coordinator of the DPRS Permanent Secretariat, assisted by a vice president in the person of the permanent secretary of the ministry of finance and economy. The other members are one representative each of the sector committees of the ADPRS/PS. The technical committee is mainly in charge of: (i) promoting synergy between the different sectors; (ii) drafting, implementing, and monitoring and evaluating sector-wide plans of action and reforms; (iii) approving the action monitoring reports drafted by the sector committees; (iv) ensuring the consolidation of the ADPRS participatory approach, and also ensuring that the ADPRS/PS has the required technical capacities for coordinating its 
activities; (v) promoting ownership of the ADPRS by all players at sector level; (vi) coordinating the organization of ADPRS review and revision exercises; (vii) reporting to the National Steering Committee and maintaining operational relations with the other bodies in charge of ADPRS monitoring and evaluation, and (viii) validating and monitoring the annual development policies, programmes and projects evaluation programme.

630. The sector committees are chaired by technical officials from the sector. They are in charge of drawing up reports on the implementation of the different sector policies and programmes. They will ensure that sector policies are consistent with the ADPRS, and also that projects and programmes are consistent with policy. The committee for consultation and dialog is under the responsibility of the Secretary General in charge of community development. Its mission is to ensure the active participation of civil society agents in the process of drafting, implementing, and monitoring and evaluating the ADPRS. It also ensures that the aspirations of civil society are taken into account in the drafting and implementation of the ADPRS.

631. Regional PRS steering committees, which are presided over by governors, are in charge of planning, as well as the monitoring and evaluation of activities in the regions. They will define the annual programmes and provide an annual regional ADPRS monitoring report. They will also serve as a forum for consultation and information, bringing together all regional actors.

632. PRS steering committees in the départements, which are presided over by prefects, are in charge of planning, as well as the monitoring and evaluation of activities in the départements. They will provide an annual ADPRS monitoring report for the département. They will also serve as a forum for consultation and information, bringing together all sub-regional actors.

633. Communal monitoring committees will gradually be set up in each commune, and new supervisory structures for the rural areas will be created. They will be given significant responsibilities in poverty reduction, and will be provided with the appropriate human and financial resources.

634. The PRS permanent secretariat (PRS/PS) is entrusted with the task of coordinating the ADPRS preparation process and monitoring its implementation, as well as carrying out regular reviews of the strategy. To carry out its mission, it enjoys the support of various bodies at both central and decentralized levels, which provide it with sector and regional reports that serve to draft the annual monitoring report. It will ensure that information on outcomes is circulated both horizontally (to all the units involved), and vertically (from the central to the decentralized levels). It will serve as the secretariat of the committees at central level in relation with the sector bodies, and provide technical support to the committees at the decentralized level. In addition, it will ensure that information is used to improve the design and implementation of the ADPRS. The secretariat will also act as a relay for monitoring the Regional Poverty Reduction Strategy of WAEMU and ECOWAS. 


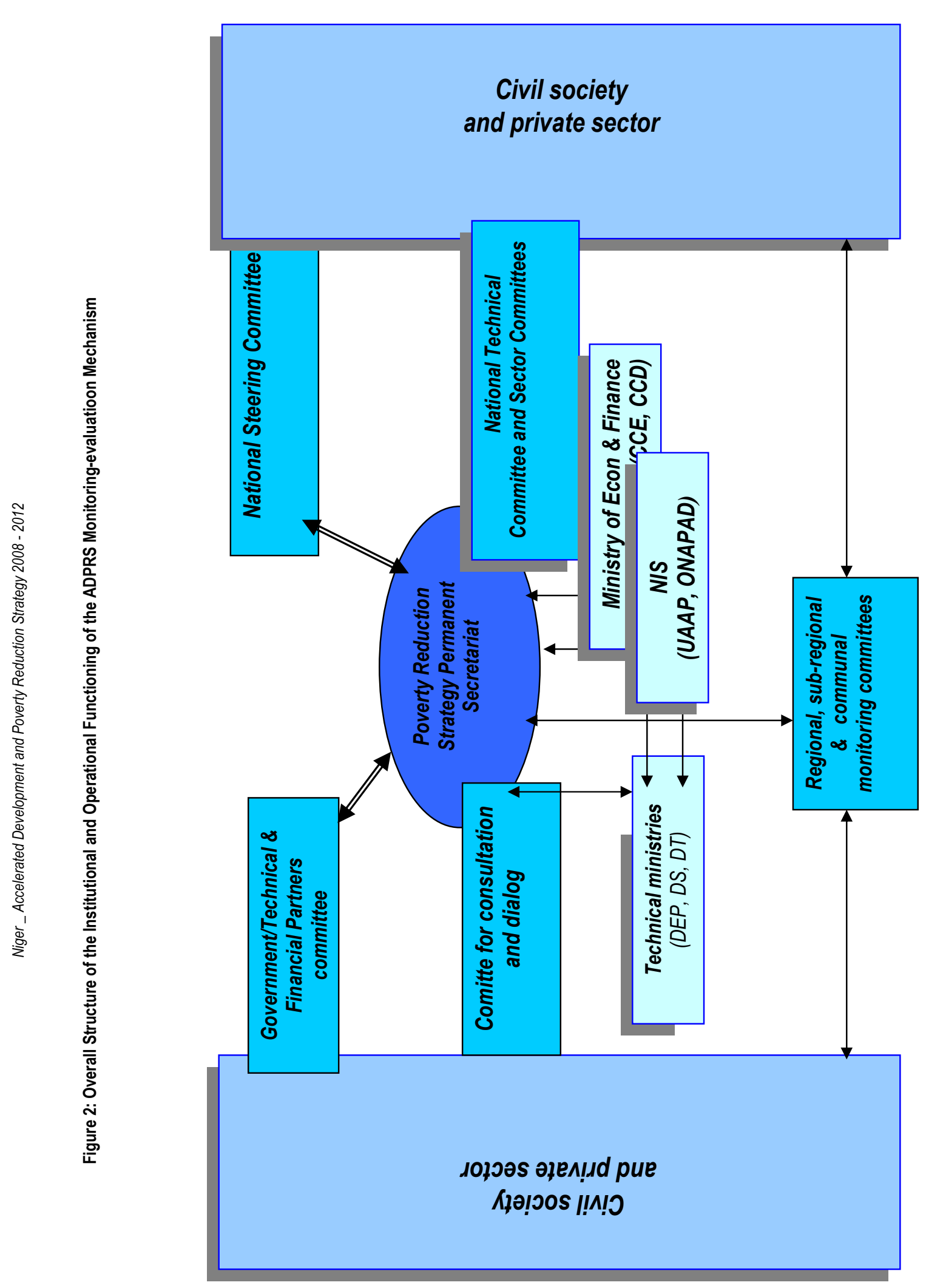




\section{e) Human, material, and institutional capacity building}

635.

The precondition for effective implementation of the ADPRS is still to ensure that the human, institutional, and material capacities required are put in place. This can be done through implementing an integrated programme. Capacity building will focus mainly on planning, management, and monitoring and evaluation.

636. Indeed, the government is determined to implement a national capacity building plan, to tackle the grave need for both individual and institutional capacity building, and identify relevant and sustainable approaches.

637. The development analysis and forecasting unit (CAPED), the high commission for government modernization, (HCME), and the national school of administration and the judiciary (ENAM) will all be called upon to train officials in the areas of formulation, management, and monitoring of economic and social policies, as well as in the use of decision-making tools. Under this heading, the following activities will be carried out: (i) training on drafting a MTEF and macroeconomic modeling; (ii) purchase of specific equipment and software; (iii) exchange of experience and building on the expertise acquired by those sectors that already have a MTEF; (iv) capacity building on gender budgeting and integrating demographic variables in sectoral policies.

638. Similarly, given the important role played by the private sector in economic growth, job creation, and the provision of certain social services, measures will be taken to strengthen existing businesses and foster the emergence of new, modern economic operators, under the framework of the private sector promotion programme. These measures will deal particularly with enhancing the capacities of operators and those involved in governance, and will gradually eliminate the constraints related to infrastructure, regulations, and financing.

639. In addition, efforts will be made to build the capacity of the population as a whole, in order to create an enabling environment and favorable conditions for the promotion, professionalization, and smooth functioning of community-based organizations (cooperatives, groups, non-governmental organizations, associations, etc.). Since these organizations work closely with the population, they can play a vital role within the institutional apparatus for technical supervision.

640. A more specific capacity building programme for NGOs and associations will also be implemented. The aims here will be to: (i) promote the setting up of an information system on development NGOs and associations; (ii) enhance the integration of development NGOs and associations in the decentralization process; (iii) develop lobbying on the part of NGOs; (iv) adopt and apply a code of ethics for NGOs, and (v) develop partnership between NGOs and the public administration.

\section{f) Risk anticipation and management}

All actors must be mobilized to reduce major risks that could jeopardize the expected results.

641. Climate risks and natural disasters The vagaries of the weather regularly have a disastrous effect on production in the rural sector, and they represent the most formidable risk that threatens the attainment of ADPRS objectives. These risks may take diverse forms, but they all endanger agro-sylvo-pastoral production, and thus lead to long-lasting degradation of the environment and of the living conditions of rural populations in particular. The best way to tackle this is to reduce the vulnerability of the economy to climate variations by developing irrigation, and diversifying the sources of growth.

642. Market risks On the domestic market, the imbalance in information about the market often affects the intentions of different actors. Government will therefore ensure that there is increased transparency on the market, and that prices play fully their role as market signals.

643. On the international market, fluctuations in the prices of imported energy products or the falling prices of export products have an impact on the economic growth of Niger. Steps will therefore be taken to have proactive monitoring of international prices and set up adjustment mechanisms. 
644. Socio-political risks There is a need to preserve the regained situation of constitutional normalcy, democracy, and peace at all times, in order to allow the country to travel unhampered along the road to economic and social advancement.

645. Risks related to implementation One of the major risks to effective and efficacious public spending is the low ability to take up financial resources, which may or may not be explained by the cumbersome procedures and disbursement mechanisms, as well as administrative malfunctions. To prevent this type of risk, the reforms identified in the PEMFAR and in other fora relating to financial management of programmes and projects will be implemented speedily.

646. The fact that local authorities and their various organs are limited in their ability to integrate the process of DRPS implementation could also have a negative effect on the quality of participation of the population, while at the same time affecting the quality and effectiveness of intervention. It is therefore vital to strengthen the capacities of elected officials.

647. If bold measures are not taken to curb corruption and the culture of impunity, these two phenomena could constitute grave handicaps for good governance. It is thus even more necessary to set up the Independent National Commission for the Control of Corruption, and provide it with appropriate resources.

648. Risks in monitoring and evaluation The most serious risks in the area of monitoring and evaluation remain those related to lack of adequate resources, insufficient buy-in by actors, delays in transferring information, and the fact that the bodies in charge of the system have no obligation to produce results.

649. The second group of risks is linked to the very high mobility of the human resources in charge of managing and steering the system that has been set up, and to the fact that the various units do not appear to seek the necessary synergy and collaboration to ensure the smooth functioning of the work expected of them. The best way to mitigate these risks is to develop their capacity and effectively monitor the performance of each agent involved in implementation.

650. Risks related to international cooperation The contribution of international aid to Niger's development remains essential. Low levels of mobilization of this aid can thus compromise the chances of attaining the objectives of growth, poverty reduction, and the MDGs. Inadequate alignment of aid on national priorities could also jeopardize success in attaining the objectives. In addition, poor coordination of official development aid could seriously hamper the programme approach, which aims at integrating and harmonizing the intervention of technical and financial partners. Government will thus make sure that it strengthens the dialog with technical and financial partners, in order to work together to implement the recommendations of the Paris declaration. 


\section{CONCLUSION}

651. After having implemented a first generation poverty reduction strategy (PRS, 2002 - 2006), the government has now drafted an Accelerated Development and Poverty Reduction Strategy (ADPRS) for the period 2008 - 2012. The strategy, which focuses on attaining the Millennium Development Goals by 2015 and was drafted through a highly participatory process, also constitutes the reference framework for policy on economic, social, and cultural development. It seeks to improve the standard of living of all the inhabitants of Niger through the following seven strategic pillars:

i. Search for strong, diversified, and sustainable growth that leads to job creation.

ii. Equitable access to quality social services.

iii. Controlling demographic growth.

iv. Reducing inequalities and providing social protection to vulnerable groups.

v. Developing infrastructure.

vi. Instituting good quality governance.

vii. Effective implementation of the strategy.

652. The accelerated development and poverty reduction strategy will be implemented in a regional and an international context that are characterized by increased economic integration and the search for effectiveness of official development aid, as well as the promotion of good governance. On the domestic front, the ADPRS will be implemented against the backdrop of decentralization, consolidation of democracy, and enhanced participation of citizens. It will also serve as the crucible for achieving pro-poor growth; taking into account growing social demands, as well as integrating a human rights approach into policy.

653. The ADPRS will be implemented on the basis of the guiding principles that constitute the keys to its success. Among these principles, the following may be noted:

654. Consistency and synergy in development action: The ADPRS is the consistent and federating framework for all existing and/or future sector strategies. It serves as a permanent forum for consultation and budget planning, bringing together the public administration, local authorities, technical and financial partners, and civil society organizations. In addition, priority will be given to efforts to ensure greater effectiveness of aid through simplifying the procedures, aligning aid on national priorities, rationalizing and harmonizing action, and ensuring predictability of resources.

655. Making results based management (RBM) systematic: The implementation and monitoring-evaluation of the ADPRS will be guided by the objectives of improving performance, achieving results, and using good quality information in decision-making. In this sense, the strategy will be founded on the principles of ownership, alignment, partnership, learning, and a culture of results.

656. Promoting good governance and fighting corruption: The implementation and monitoring-evaluation of the ADPRS will also be based on the principles of responsibility, accountability, transparency, participation, effective and efficient resource allocation in public expenditure management, and providing quality public services.

657. Consolidating peace and instituting a social covenant: One of the guarantees for the success of the various programmes is the consolidation of peace and the stability of institutions. Indeed, enduring implementation of development programmes is only possible if there is appeasement on the social front. This can be achieved through constructive dialog, which requires both government and social partners to be more ready to listen responsibly to each other.

658. Mainstreaming the gender dimension: From this point forward, it must be recognized that gender inequalities and inequities are an obstacle to the advancement of society as a whole. The ADPRS is resolved to combat such inequities and inequalities in all forms and to promote complementarity between the sexes. It is also 
strongly attached to the universal values of dignity, justice, democracy, peace, respect for human rights, freedom, equality, development, and prosperity, and will guarantee equal participation of men and women in development.

659. Transforming attitudes and behavior change: The success of public policies will require an in-depth transformation of attitudes relating to collective work culture; technological efforts and innovation; the perception of the state and its role; the duty of citizens vis-à-vis the state, and the implementation of development action. It will also require changes in the behavior of the population.

660. The ADPRS will be implemented through the President's Special Programme and through sector strategies and policies that themselves are broken down into programmes and projects. At regional level, it will also lead to activities that enable the creation of growth poles and integration of regions in a process of ensuring equitable development.

661. Given the massive financial resources that are required if the objectives of the ADPRS are to be attained, government will continue its efforts to mobilize internal and external resources, and to improve public finance management. As part of this, a national resource mobilization strategy will soon be drafted.

662. Finally, the ADPRS will be monitored regularly and periodic evaluations will be carried out according to the modalities to be set out in the monitoring-evaluation guide. The information produced by the monitoring and evaluation system will serve to update the Priority Action Plan regularly. 


\section{BIBLIOGRAPHY}

- $\quad$ AFRISTAT, ONU, PNUD: Cadre de référence et support méthodologique minimum commun pour la conception d'un système d'information pour le suivi des DSRP et des OMD. Février 2006.

- Afristat: Common minimum statistical programme prosmic, avril 2002.

- Banque Mondiale. Améliorer les résultats en matière de santé, nutrition et démographie en Afrique subsaharienne.

- Banque Mondiale: Analyse d'une répartition du niveau de vie. №371 Août 1997.

- Banque Mondiale: Genre et développement économique. Québec Canada 2002

- Banque Mondiale. Inégalité des sexes, croissance et réduction de la pauvreté. 1999.

- Banque Mondiale. L'initiative de la stratégie de réduction de la pauvreté

- Banque Mondiale : Nourrir, éduquer et soigner tous les nigériens : la démographie en perspective

- Cabinet du Premier Ministre. Stratégie de Réduction de la Pauvreté, rapport de mise en œuvre, Juin 2003.

- Cellule d'Analyse et de Prospective en Développement : la compétitivité du secteur manufacturier au Niger, juin 2005

- CILSS: Norme de consommation des principaux produits alimentaires dans les pays du CILSS, juillet 2004.

- CILSS: Profil démographique et socio-économique du Niger 1960-2000.

- Comité interministériel de pilotage de la SDR : Plan d'action de la Stratégie de développement rural, novembre 2006

- Conférence des Nations Unies sur le commerce et le développement: Echapper au piège de la pauvreté, New York et Genève 2002.

- Ministère du Développement Social, de la Population, de la Promotion de la Femme et de la Protection de l'Enfant : Politique Nationale de Développement Sociale du Niger, décembre 1998.

- Ministère de l'Aménagement du Territoire et du Développement Communautaire. Loi n²001-032 portant orientation de la politique d'aménagement du territoire, 2006.

- Ministère de l'Economie et des Finances (INS): Le commerce extérieur, janvier 2006.

- Ministère de l'Economie et des Finances (INS, Niger): Bulletin trimestriel de statistique, octobre 2006.

- Ministère de l'Economie et des Finances (INS): Education et pauvreté au Niger, octobre 2006.

- Ministère de l'Economie et des Finances (INS): Comptes économiques de la nation, février 2007.

- Ministère de l'Economie et des Finances (INS): Emploi, chômage et pauvreté au Niger, novembre 2006.

- Ministère de l'Economie et des Finances (INS): Enquête démographique et de santé et à indicateur multiple EDSN/MICS-3, 2006.

- Ministère de l'Economie et des Finances (INS): Santé et pauvreté au Niger, novembre 2006.

- Ministère de l'Economie et des Finances (INS): Statistique du commerce extérieur, juillet 2004.

- Ministère de l'Economie et des Finances (INS): Statistiques du commerce extérieur, juillet 2006.

- Ministère de l'Economie et des Finances: Balance des paiements année 2004.

- Ministère de l'économie et des finances: Annuaire statistique, juillet 2003.

- Ministère de l'Economie et des Finances (INS): Bulletin trimestriel des statistiques, août 2006.

- Ministère de l'Economie et des Finances, Institut national de la statistique et Banque Mondiale: Questionnaire des Indicateurs de Base du Bien-être (QUIBB_2005), rapport sur les indicateurs sociaux, mars 2006

- Ministère de l'économie et des finances, Institut national de la Statistique (INS) : Comptes économiques de la nation, août 2006.

- Ministère de l'Economie et des Finances: Mission d'évaluation technico-financière indépendante des dépenses financières sur les ressources d'allègement de la dette en vue de la réduction de la pauvreté, juin 2005.

- Ministère de l'Economie et des Finances: Niger mémorandum économique, juillet 2006

- Ministère de l'Economie et des Finances: Note de présentation des résultats définitifs du RGP/H-2001, février 2005.

- Ministère de l'Economie et des Finances: Projections de la population du Niger de 2005 à 2050, avril 2005.

- Ministère de l'Education de Base 1 et de l'Alphabétisation: Statistiques de l'Education de Base 20052006, août 2006. 
- Ministère de l'Education de Base 1 et de l'Alphabétisation: Annuaire statistique 2002-2003. Niamey, septembre 2003.

- Ministère de la Santé Publique et de la Lutte Contre les Endémies: Plan de Développement Sanitaire 2005-2009, Novembre 2004.

- Ministère de la Santé Publique et de la Lutte Contre les Endémies: Evaluation du système national d'information sanitaire -SNIS et plan opérationnel 2005-2009., Juin 2005.

- Ministère des Enseignements Secondaire et Supérieur, de la Recherche et de la Technologie: Recensement scolaire 2005-2006, Janvier 2007.

- Ministère du Développement Agricole (PAC) .Cadre de suivi-évaluation du PAC, Janvier 2006.

- Ministère du Développement Agricole (PAC): Aide- mémoire huitième mission conjointe de supervision du 31 mars 13 avril 2007, Niamey et Washington, avril 2007.

- Niger Enquête démographique et de santé et à l'indicateur multiple, 2006.

- OCBE et Banque mondiale: Les bonnes pratiques émergentes pour une gestion axée sur les résultats de développement.

- OCDE: Vers une croissance pro pauvres, $N^{\circ} 83824,2006$.

- Paris 21 et OCDE: Stratégie Nationale de Développement de la Statistique (SNDS). Novembre 2004.

- PNUD: Rapport mondial sur le développement humain 2005.

- Programme bonne gouvernance et croissance mieux repartie: Rapport provisoire de synthèse de révision de la SRP, Groupe thématique infrastructures ( sous groupe : technologies de l'information et de la communication). Juillet 2006

- République du Niger, Unicef. Enquête à indicateurs multiples de la fin de la décennie (MICS2), Décembre 2000.

- République du Niger, Stratégie de Développement Rural, novembre 2003

- République du Niger, Unicef: Rapport National sur le progrès vers les Objectifs du Millénaire pour le Développement, Niger 2003.

- Secrétariat Permanent de la SRP: Etude sur le dispositif de suivi-évaluation de la SRP, mars 2005.

- Secrétariat Permanent de la SRP: rapports de mise en œuvre, juin 2003, juillet 2004, juin 2006

- Secrétariat Permanent de la SRP: Document de révision de la Stratégie de Réduction de la Pauvreté. Groupe thématique «infrastructure». Juillet 2006.

- Secrétariat Permanent de la SRP: Document de Révision de la Stratégie de Réduction de la Pauvreté. Groupe thématique « suivi-évaluation ». Juillet 2006.

- Secrétariat Permanent de la SRP, CAB/PM: Proposition d'un dispositif de suivi-évaluation de la Stratégie de Développement Rural (tome1). Avril 2004.

- Secrétariat Permanent de la SRP - CAB/PM - . Rapport de synthèse final. Juin 2002

- Secrétariat Permanent de la SRP - CAB/PM -: Stratégie de Réduction de la Pauvreté. Janvier 2002.

- Secrétariat Permanent de la SRP - Cabinet du Premier Ministre - : Révision SRP, Groupe thématique mine et énergie (sous groupe mine). Avril 2006.

- Secrétariat Permanent de la SRP, Cabinet du Premier Ministre: Rapport sectoriel des travaux du groupe thématique nutrition. Juillet 2006.

- Secrétariat Permanent de la SRP, Cabinet du Premier Ministre : Révision de la SRP : rapport du groupe secteur financier. Juillet 2006.

- Secrétariat Permanent de la SRP, Cabinet du Premier Ministre : contributions des régions à la révision de la SRP, juin 2006 (Agadez, Diffa, Dosso, Maradi, Tahoua, Tillabéri, Zinder, Communauté Urbaine de Niamey)

- Secrétariat Permanent de la SRP et INS - Niger. Profil de la pauvreté au Niger 2004 (application de la méthode de Degré de Satisfaction des Besoins Essentiels DSBE). Janvier 2006.

- Secrétariat Permanent de la SRP et INS : Gouvernance, démocratie et lutte contre la pauvreté au Niger : le point de vue de la population de la capitale, enquête 1-2-3. Décembre 2005.

- Secrétariat Permanent de la SRP: Révision de la SRP. Groupe thématique «Education», mai 2006.

- Stratégie de Développement Rural: Plan d'action. Novembre 2006.

- UEMOA: L'emploi, le chômage et les conditions d'activité dans les principales agglomérations des sept états membres de L'UEMOA. Décembre 2004.

- UEMOA. Le secteur informel dans les principales agglomérations de sept Etats membres de L'UEMOA: performances, insertion, perspectives. Décembre 2004. 
- UNICEF: L'évaluation responsabilisante: proposition visant à renforcer la fonction et la culture d'évaluation. Janvier 2000.

- Vers une culture du résultat, Jody Zall Kusek, Ray C. Rist. Québec Canada 2006.

- World Bank, Beyond the numbers: understanding the institutions for monitoring poverty reduction strategies. Tara Bedi , Aline Coudouel, Marcus Cox, Markus Goldstein and Nigel Thornton., 2006 


\section{ANNEXES}


Annex 1 : Trend of PRS Monitoring Indicators

\begin{tabular}{|c|c|c|c|c|c|}
\hline \multicolumn{2}{|c|}{ Indicator } & \multirow{2}{*}{$\begin{array}{c}\begin{array}{c}\text { PRS1 } \\
\text { Reference }\end{array} \\
63 \% \text { en } \\
1992 / 1993\end{array}$} & \multirow{2}{*}{$\begin{array}{l}\text { Objectives } \\
59 \% \text { in } 2005 \\
\end{array}$} & \multirow{2}{*}{$\begin{array}{c}\text { Results obtained } \\
62 \% \text { in } 2005\end{array}$} & \multirow{2}{*}{$\begin{array}{c}\text { Data Source } \\
\text { QUIBB2005 and ENBC } \\
\text { 89/90-92/93 }\end{array}$} \\
\hline $\begin{array}{l}\text { Incidence of } \\
\text { monetary }\end{array}$ & National & & & & \\
\hline & $\begin{array}{l}\text { Urban other than } \\
\text { Niamey }\end{array}$ & $58 \%$ & & $55.5 \%$ in 2005 & $\begin{array}{l}\text { QUIBB2005 and ENBC } \\
89 / 90-92 / 93\end{array}$ \\
\hline & Rural & $66 \%$ & $62 \%$ in 2005 & $65.7 \%$ in 2005 & $\begin{array}{l}\text { QUIBB2005 et ENBC 89/90- } \\
92 / 93\end{array}$ \\
\hline \multirow[t]{3}{*}{ Depth of poverty } & National & $\begin{array}{l}21.7 \% \text { in } \\
1992 / 1993\end{array}$ & $20.3 \%$ in 2005 & $24.1 \%$ in 2005 & $\begin{array}{c}\text { QUIBB } 2005 \text { and ENBC } \\
89 / 90-92 / 93\end{array}$ \\
\hline & $\begin{array}{l}\text { Urban other than } \\
\text { Niamey }\end{array}$ & $20.7 \%$ & & & $\begin{array}{c}\text { QUIBB } 2005 \text { and ENBC } \\
89 / 90-92 / 93\end{array}$ \\
\hline & Rural & 22.5 & & & $\begin{array}{c}\text { QUIBB } 2005 \text { and ENBC } \\
89 / 90-92 / 93\end{array}$ \\
\hline \multirow[t]{3}{*}{$\begin{array}{l}\text { Severity of } \\
\text { poverty }\end{array}$} & National & 10.1 & $9.5 \%$ in 2005 & 12.3 in 2005 & $\begin{array}{c}\text { QUIBB } 2005 \text { and ENBC } \\
89 / 90-92 / 93\end{array}$ \\
\hline & $\begin{array}{l}\text { Urban other than } \\
\text { Niamey }\end{array}$ & 9.8 & & & $\begin{array}{c}\text { QUIBB } 2005 \text { and ENBC } \\
89 / 90-92 / 93\end{array}$ \\
\hline & Rural & $10.4 \%$ & & & $\begin{array}{c}\text { QUIBB } 2005 \text { and ENBC } \\
89 / 90-92 / 93\end{array}$ \\
\hline \multicolumn{2}{|c|}{ Average GDP growth rate } & $\begin{array}{l}2.5 \% \text { between } \\
1995-2000\end{array}$ & $\begin{array}{l}4 \% \text { between } \\
2002-2005\end{array}$ & $\begin{array}{l}4.9 \% \text { between } 2002- \\
2005\end{array}$ & National economic accounts \\
\hline \multicolumn{2}{|c|}{ Coverage rate for cereal requirements } & $99.8 \%$ in 2002 & & $100.7 \%$ in 2005 & MDA \\
\hline \multirow{6}{*}{$\begin{array}{c}\text { Production of } \\
\text { main cash crops }\end{array}$} & Sesame & 9864 in 2002 & - & 42199 in 2005 & MDA \\
\hline & Cotton & 8260 in 2002 & - & 28000 in 2005 & MDA \\
\hline & Onion & 5074 in 2002 & - & & MDA \\
\hline & Groundnut & $\begin{array}{l}153729 \mathrm{t} \text { in } \\
2002\end{array}$ & - & $139035 \mathrm{t}$ in 2005 & MDA \\
\hline & Tiger nut & $\begin{array}{l}23214 \mathrm{t} \text { in } \\
2002\end{array}$ & - & $8095 \mathrm{t}$ in 2005 & MDA \\
\hline & Cowpea & $\begin{array}{l}654232 \mathrm{t} \text { in } \\
2002\end{array}$ & - & $586078 \mathrm{t}$ in 2005 & MDA \\
\hline \multicolumn{2}{|c|}{ Protected acreage } & $\begin{array}{l}4100000 \text { ha } \\
2002\end{array}$ & - & 4100000 in 2006 & MELCD/DE \\
\hline \multicolumn{2}{|c|}{ Planted acreage } & $\begin{array}{l}9354.56 \text { in } \\
2002\end{array}$ & - & 24242.24 in 2006 & MELCD/DE \\
\hline \multicolumn{2}{|c|}{ Acreage of degraded land recovered } & $\begin{array}{c}13433.19 \\
\text { ha in } 2002\end{array}$ & - & 45664.6 in 2006 & MELCD/DE \\
\hline \multicolumn{2}{|c|}{ Average annual inflation rate } & $\begin{array}{l}2.42 \text { between } \\
1997-2001\end{array}$ & $3 \%$ & $\begin{array}{l}1.8 \% \text { between } 2002- \\
2006\end{array}$ & NIS price statistics \\
\hline \multicolumn{2}{|c|}{ Budgetary balance as $\%$ of GDP } & $-3.4 \% \ln 2000$ & -1.2 & $-1.5 \%$ in 2005 & National economic accounts \\
\hline
\end{tabular}




\begin{tabular}{|c|c|c|c|c|c|}
\hline \multicolumn{2}{|c|}{ Indicator } & $\begin{array}{c}\text { PRS1 } \\
\text { Reference }\end{array}$ & Objectives & Results obtained & Data Source \\
\hline \multicolumn{2}{|c|}{ Revenue to GDP ratio } & $8.3 \%$ in 2002 & $10.8 \%$ in 2005 & $10.3 \%$ in 2005 & National economic accounts \\
\hline \multicolumn{2}{|c|}{ Debt service/GDP ratio } & $5 \%$ in 2001 & $1 \%$ en 2005 & $1.4 \%$ en 2005 & National economic accounts \\
\hline \multicolumn{2}{|c|}{ Current expenditure/GDP ratio } & $\begin{array}{c}12.31 \% \text { in } \\
2000\end{array}$ & 10.8 & 9.52 & National economic accounts \\
\hline \multicolumn{2}{|c|}{$\begin{array}{l}\text { Average investment rate } \\
\text { over the period }\end{array}$} & & $\begin{array}{l}15 \% \text { between } \\
2002-2005\end{array}$ & $\begin{array}{l}\text { 18.4\% between } \\
2002-2006\end{array}$ & National economic accounts \\
\hline \multirow{4}{*}{$\begin{array}{l}\text { Gross primary } \\
\text { school } \\
\text { enrolment rate }\end{array}$} & National & $\begin{array}{c}42 \% \text { in } 2001- \\
2002\end{array}$ & $57 \%$ & $54 \%$ in $2005-2006$ & MBEL yearbook \\
\hline & Urban & $\begin{array}{c}52 \% \text { in } 2001- \\
2002\end{array}$ & - & $57 \%$ in $2005-2006$ & MBEL yearbook \\
\hline & Rural & $\begin{array}{c}38 \% \text { in } 2001- \\
2002\end{array}$ & $\begin{array}{l}54 \% \text { in } 20005- \\
2006\end{array}$ & $52 \%$ in $2005-2006$ & MBEL yearbook \\
\hline & Girls & $\begin{array}{c}33.3 \text { in } 2001- \\
2002\end{array}$ & 49 in 2005-2006 & $44 \%$ & MBEL yearbook \\
\hline \multirow{3}{*}{$\begin{array}{l}\text { Gross enrolment } \\
\text { rate in basic } \\
\text { cycle level } 2\end{array}$} & National & $\begin{array}{c}10 \% \text { in } 2001- \\
2002\end{array}$ & $18 \%$ in 2006 & $17.1 \%$ in $2005-2006$ & MSHE yearbook \\
\hline & Girls & $\begin{array}{c}7.5 \% \text { in } 2001- \\
2002\end{array}$ & - & $12.5 \%$ in $2005-2006$ & MSHE yearbook \\
\hline & Boys & $\begin{array}{c}12.8 \% \text { in } \\
2001-2002 \\
\end{array}$ & - & $22.3 \%$ in $2005-2006$ & MSHE yearbook \\
\hline \multicolumn{2}{|c|}{ Girl-boy parity ratio at primary level } & 0.66 & - & 0.69 & MSHE yearbook \\
\hline \multirow[t]{2}{*}{$\begin{array}{l}\text { Gross intake } \\
\text { rate }\end{array}$} & Primary & $\begin{array}{l}50 \% 2001- \\
2002\end{array}$ & $63 \%$ & $59 \% 2005-2006$ & MSHE yearbook \\
\hline & Secondary (1st year) & $\begin{array}{c}16.4 \% \text { in } \\
2001-2002\end{array}$ & - & $31 \%$ in $2005-2006$ & MESS/RT \\
\hline \multicolumn{2}{|c|}{ Primary cycle completion rate } & $\begin{array}{c}26 \% \text { in } \\
2001 / 2002 \\
\end{array}$ & $46 \%$ & $40 \%$ in $2005 / 2006$ & MBEL yearbook \\
\hline \multirow{2}{*}{$\begin{array}{l}\text { Adult literacy } \\
\text { rate }\end{array}$} & Total & $19.9 \%$ in 2000 & $28 \%$ in 2005 & 28.7 en 2005 & QUIBB 2005 and MICS2000 \\
\hline & Women & $10.6 \%$ & - & $15.1 \%$ & QUIBB 2005 and MICS2000 \\
\hline \multicolumn{2}{|c|}{ Life expectancy at birth } & $\begin{array}{l}48 \text { years in } \\
2000\end{array}$ & 50 years in 2005 & 55 years & $\begin{array}{c}\text { Mortality analysis report } \\
\text { GCPH }\end{array}$ \\
\hline \multicolumn{2}{|c|}{ Infant mortality } & $\begin{array}{c}123 \text { per } \\
\text { thousand in } \\
1998 \\
\end{array}$ & $\begin{array}{c}94.5 \text { per } \\
\text { thousand in } 2005\end{array}$ & $\begin{array}{c}81 \text { per thousand in } \\
2006\end{array}$ & EDS/MICS \\
\hline \multicolumn{2}{|c|}{ Child mortality } & $\begin{array}{c}274 \text { per } \\
\text { thousand in } \\
199 \\
\end{array}$ & $\begin{array}{l}205 \text { per thousand } \\
\text { in } 2005\end{array}$ & $\begin{array}{l}198 \text { per thousand in } \\
2006\end{array}$ & EDS/MICS \\
\hline \multicolumn{2}{|c|}{ Maternal mortality (per 100 000) } & $\begin{array}{l}652 \text { per } 100 \\
000 \text { in } 1992\end{array}$ & $\begin{array}{l}500 \text { per } 100000 \\
\text { in } 2005\end{array}$ & $\begin{array}{c}648 \text { per } 100000 \text { in } \\
2006\end{array}$ & EDS/MICS \\
\hline \multicolumn{2}{|c|}{ Health infrastructure coverage rate } & $48 \%$ in 2000 & $60 \%$ in 2005 & $65 \%$ & MSP \\
\hline \multicolumn{2}{|c|}{ Immunization coverage } & $18.4 \%$ & $36.8 \%$ in 2005 & $29 \%$ in 2006 & EDS-MICS \\
\hline
\end{tabular}




\begin{tabular}{|c|c|c|c|c|c|}
\hline \multicolumn{2}{|c|}{ Indicator } & $\begin{array}{c}\text { PRS1 } \\
\text { Reference }\end{array}$ & Objectives & Results obtained & Data Source \\
\hline \multicolumn{2}{|c|}{$\begin{array}{l}\% \text { of underweight children under three } \\
\text { years of age }\end{array}$} & $50 \%$ in 1998 & - & $43 \%$ in 2006 & EDS-MICS \\
\hline \multirow{2}{*}{$\begin{array}{l}\text { Contraceptive } \\
\text { prevalence }\end{array}$} & All methods & $8 \%$ in 1998 & - & $11.6 \%$ in 2006 & EDS-MICS \\
\hline & Modern methods & $4.6 \%$ in 1998 & - & $5 \%$ in 2006 & EDS-MICS \\
\hline \multicolumn{2}{|l|}{ Total fertility rate } & 7.5 in 1998 & 5.5 in 2005 & 7.1 in 2006 & EDS-MICS \\
\hline \multicolumn{2}{|c|}{ Malaria-related mortality } & $\begin{array}{l}16 \text { per } \\
\text { thousand }\end{array}$ & - & 27 per thousand & MPH \\
\hline \multicolumn{2}{|c|}{$\begin{array}{l}\% \text { of births attended by trained health } \\
\text { personnel }\end{array}$} & $44 \%$ in 1998 & & $33 \%$ in 2006 & EDS-MICS \\
\hline \multirow[t]{3}{*}{$\begin{array}{c}\text { HIVIAIDS } \\
\text { prevalence rate }\end{array}$} & Total & 0.87 in 2002 & - & $0.7 \%$ in 2006 & $\begin{array}{l}\text { EDS-MICS and } \\
\text { seroprevalence survey }\end{array}$ \\
\hline & Men & & - & $0.7 \%$ in 2006 & $\begin{array}{c}\text { EDS-MICS and } \\
\text { seroprevalence survey }\end{array}$ \\
\hline & Women & & - & $0.7 \%$ in 2006 & $\begin{array}{c}\text { EDS-MICS and } \\
\text { seroprevalence survey }\end{array}$ \\
\hline \multicolumn{2}{|c|}{$\begin{array}{c}\text { Number of km of rehabilitated tarred } \\
\text { roads }\end{array}$} & - & $\begin{array}{l}1000 \mathrm{~km} \mathrm{2002-} \\
2006\end{array}$ & $\begin{array}{l}1732.62 \mathrm{~km} \text { between } \\
2002-2007\end{array}$ & $\begin{array}{l}\text { Public works department } \\
\text { (DGTP) }\end{array}$ \\
\hline \multicolumn{2}{|c|}{$\begin{array}{c}\text { Number of km of roads constructed, } \\
\text { including rural roads } \\
\text { Total }\end{array}$} & - & $\begin{array}{l}6000 \mathrm{~km} \\
\text { between 2002- } \\
2006\end{array}$ & $\begin{array}{l}4017 \mathrm{~km} \text { between } \\
\text { 2002-2007 }\end{array}$ & DGTP \\
\hline \multicolumn{2}{|c|}{ Sanitation coverage in rural areas } & $4 \%$ in 1997 & $50 \%$ in 2005 & $3 \%$ in 2005 & $\mathrm{MH}$ \\
\hline \multicolumn{2}{|c|}{$\begin{array}{l}\text { Percentage of population with access to } \\
\text { sanitary means of excreta disposal }\end{array}$} & $18 \%$ in 2000 & - & $19 \%$ in 2006 & EDS-MICS \\
\hline \multirow{3}{*}{$\begin{array}{l}\text { Access to } \\
\text { electricity }\end{array}$} & National & $6.7 \%$ in 1998 & $25 \%$ in 2005 & $9.3 \%$ in 2006 & EDS-MICS \\
\hline & Urban & $36.5 \%$ in 1998 & - & $47 \%$ in 2006 & EDS-MICS \\
\hline & Rural & $0.2 \%$ in 1998 & - & $2 \%$ in 2006 & EDS-MICS \\
\hline \multirow{2}{*}{$\begin{array}{l}\text { Coverage of } \\
\text { water } \\
\text { requirements }\end{array}$} & Urban & $65 \%$ in 2001 & - & $80 \%$ in 2005 & $\mathrm{MH}$ \\
\hline & Rural & $55 \%$ in 2001 & $70 \%$ in 2005 & $59 \%$ in 2005 & $\mathrm{MH}$ \\
\hline \multirow{2}{*}{$\begin{array}{l}\text { Number of } \\
\text { telephone } \\
\text { subscribers }\end{array}$} & Mobile & 35142 in 2002 & - & 508860 in 2006 & ARM \\
\hline & Fixed & $\begin{array}{l}22399 \text { in } \\
2002\end{array}$ & - & 37234 in 2006 & ARM \\
\hline \multirow[t]{3}{*}{$\begin{array}{l}\% \text { of households } \\
\text { that own a radio }\end{array}$} & National & $\begin{array}{l}33.3 \% \text { in } \\
1998\end{array}$ & - & $51 \%$ in 2006 & EDS-MICS \\
\hline & Urban & $\begin{array}{l}55.8 \% \text { in } \\
1998\end{array}$ & - & $73.5 \%$ in 2006 & EDS-MICS \\
\hline & Rural & $\begin{array}{l}28.6 \% \text { in } \\
1998\end{array}$ & - & $46.6 \%$ in 2006 & EDS-MICS \\
\hline
\end{tabular}



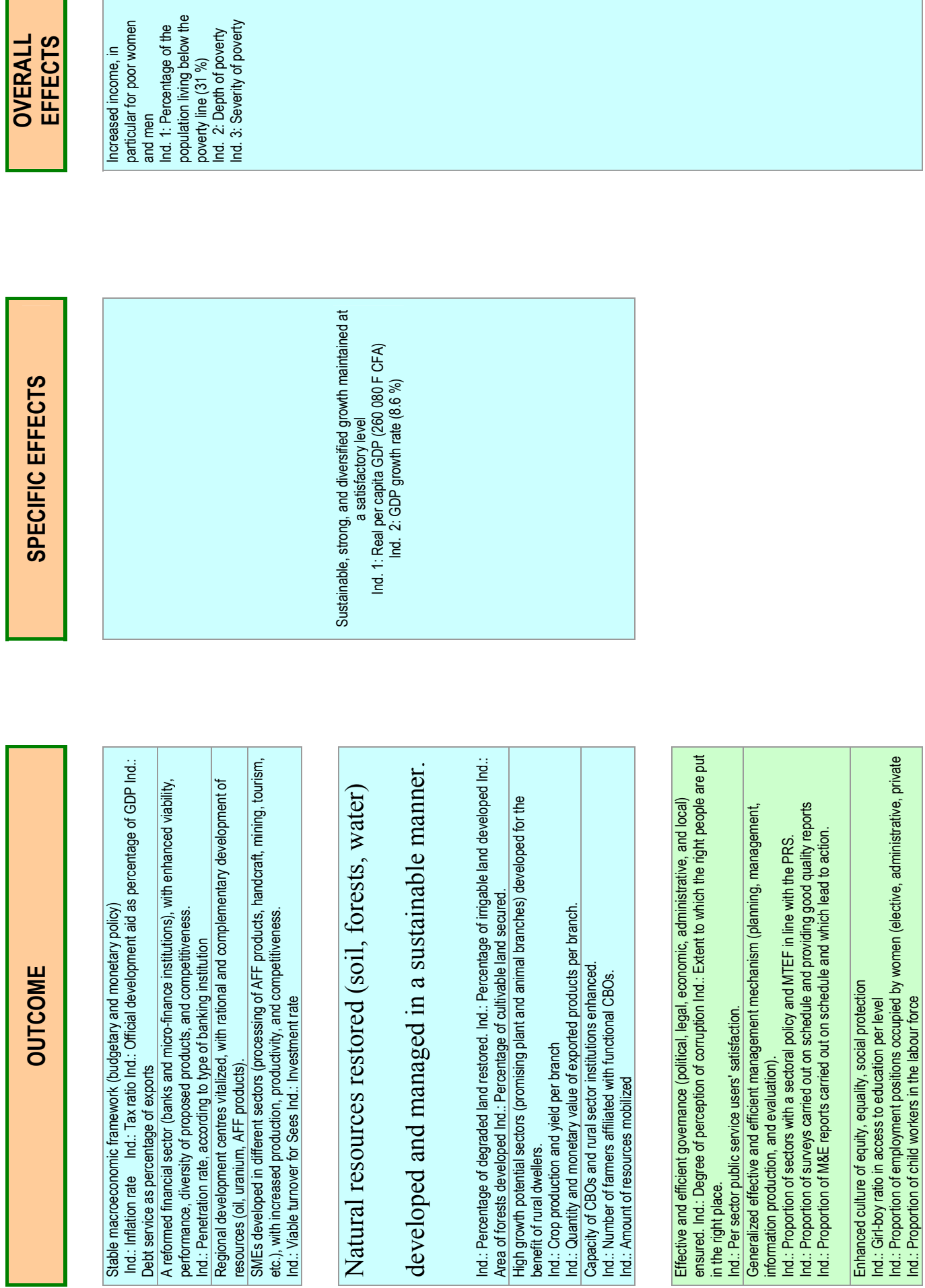

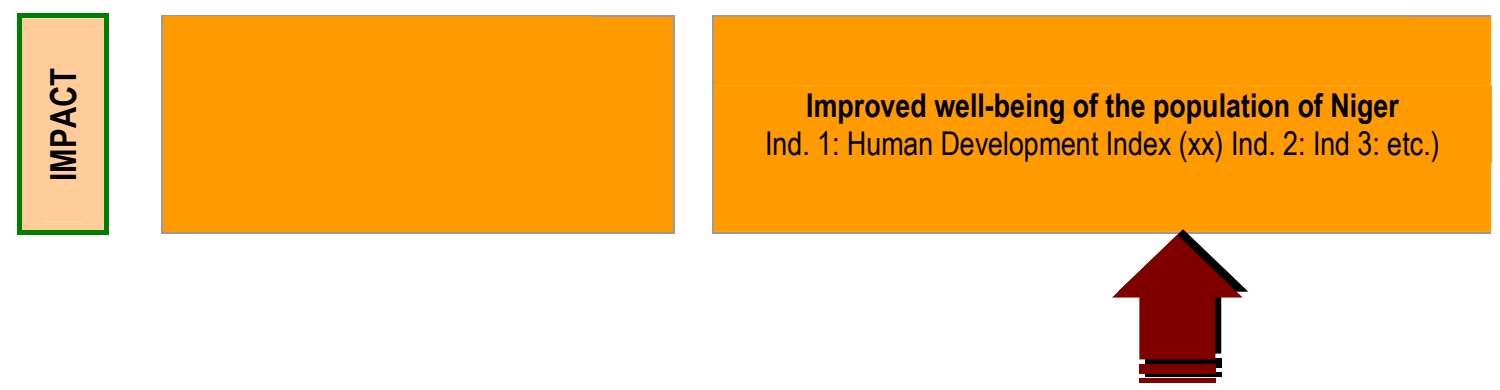

$\overline{9}$
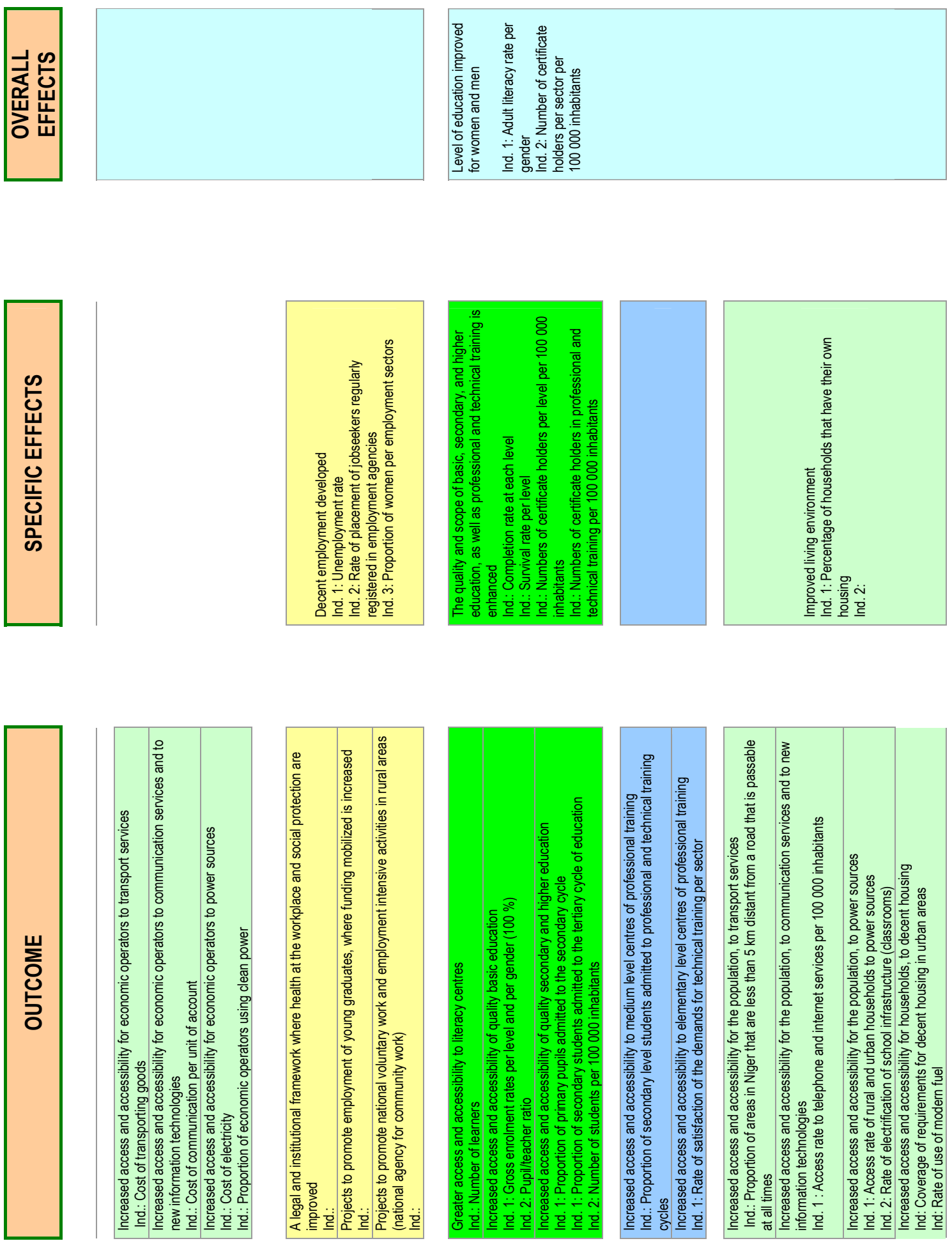

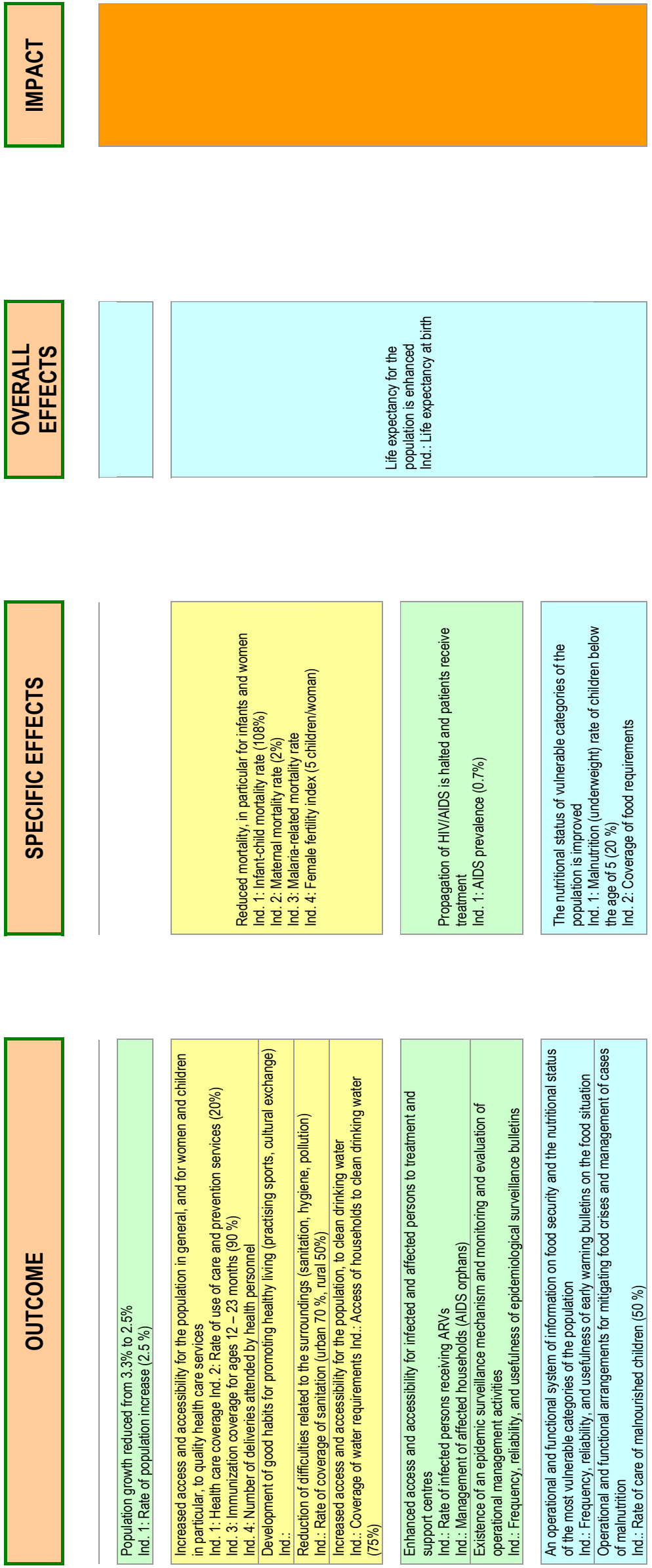


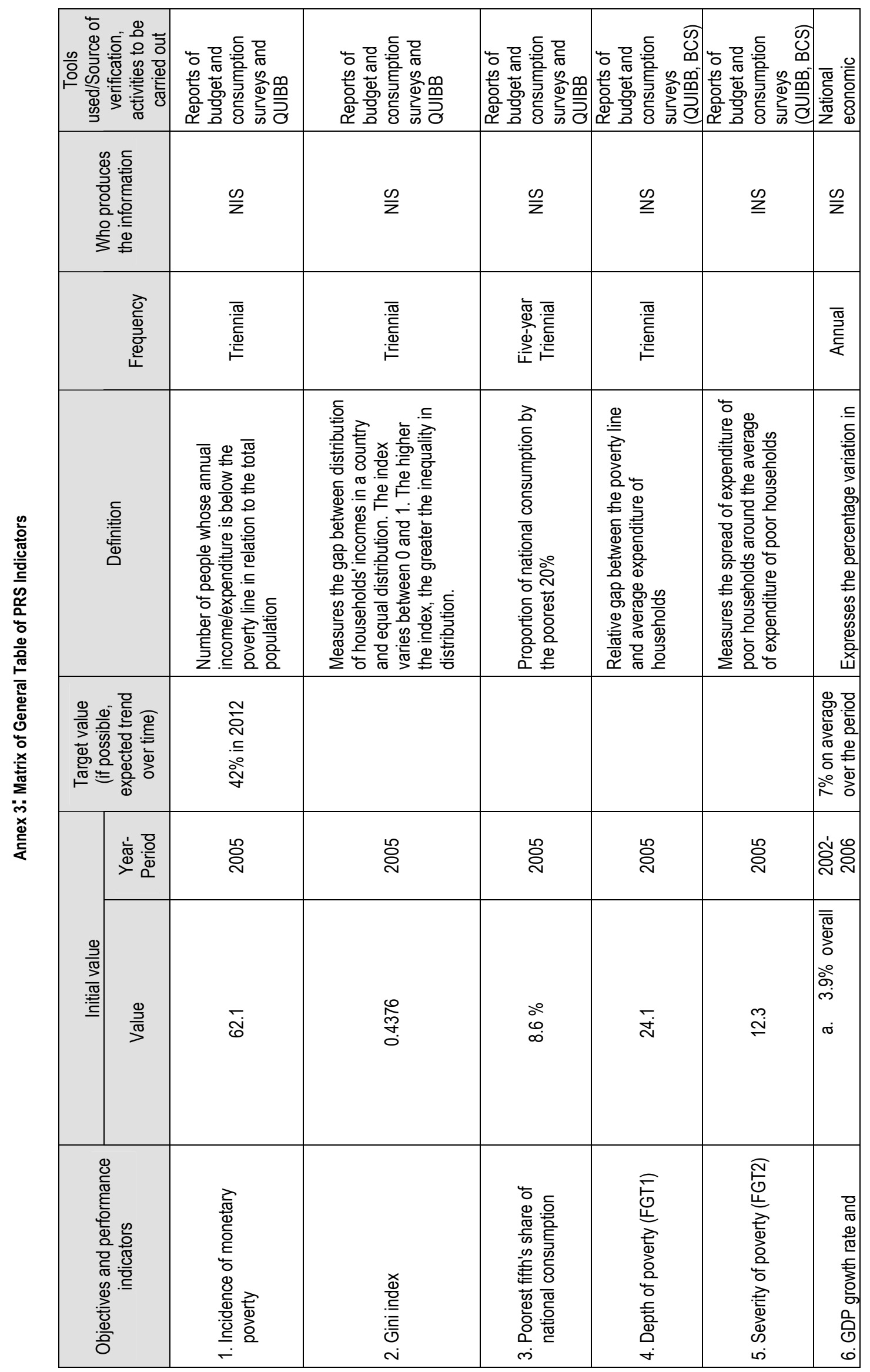




\begin{tabular}{|c|c|c|c|c|}
\hline 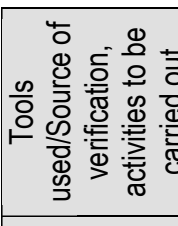 & 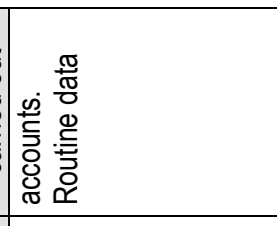 & 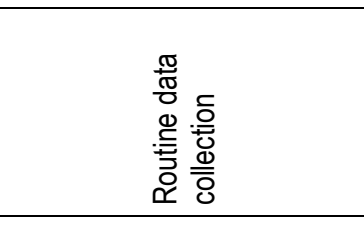 & 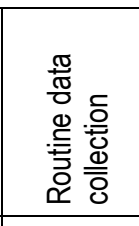 & 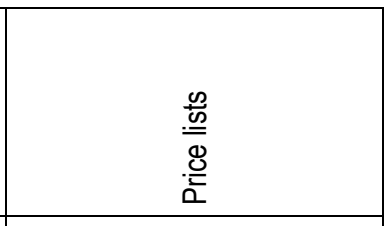 \\
\hline 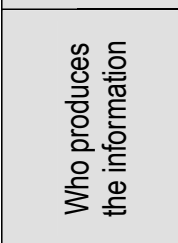 & & 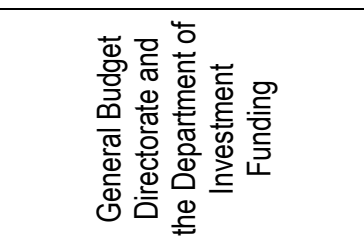 & 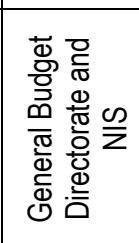 & $\frac{\infty}{Z}$ \\
\hline 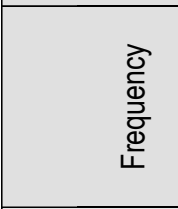 & & 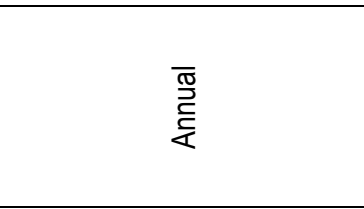 & $\begin{array}{l}\overline{\mathrm{g}} \\
\text { 㞼 }\end{array}$ & 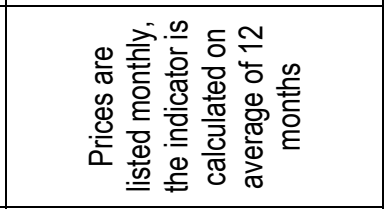 \\
\hline 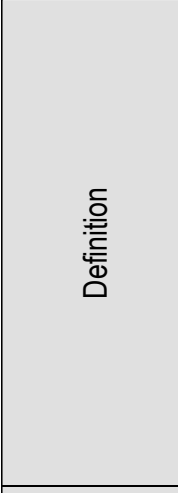 & 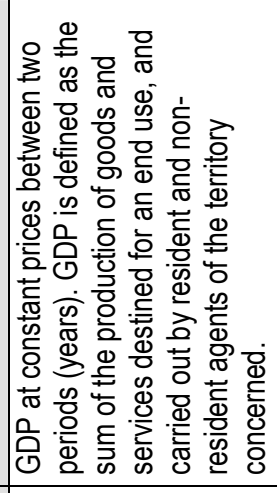 & 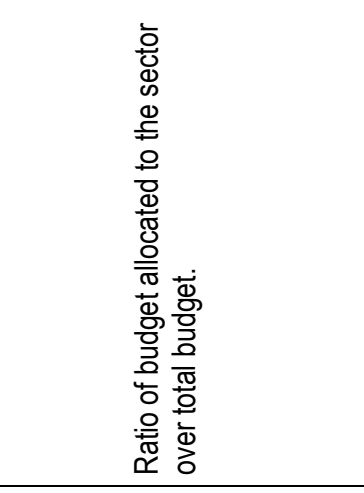 & 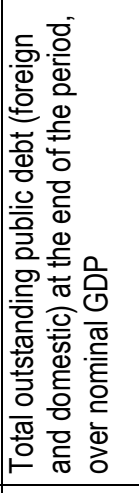 & 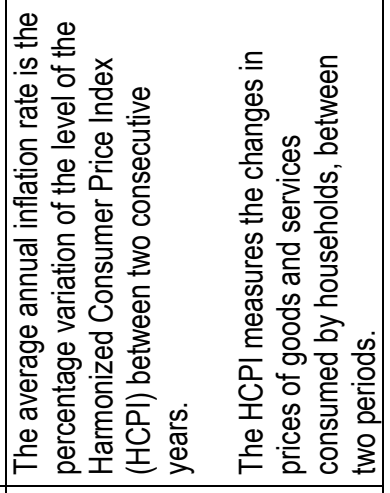 \\
\hline 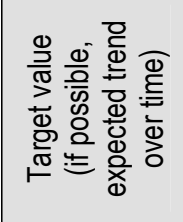 & 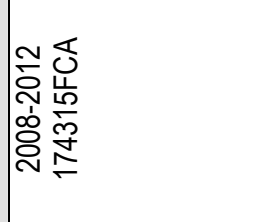 & 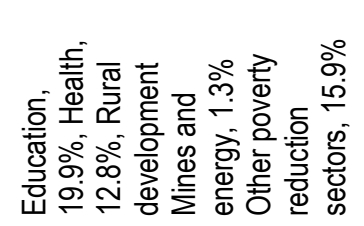 & & 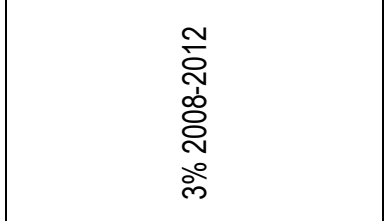 \\
\hline \begin{tabular}{l}
$\frac{1}{\Phi}$ \\
$⿱ 亠 乂$ \\
\hdashline
\end{tabular} & \&্ণ & 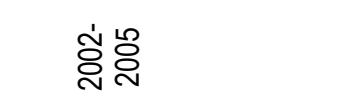 & 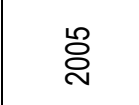 & ठั்่ \\
\hline 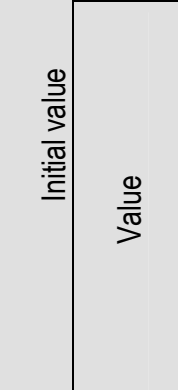 & 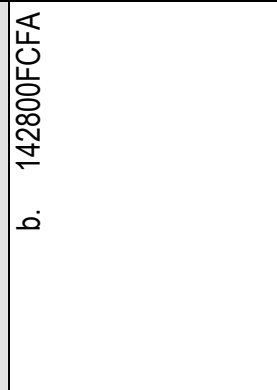 & 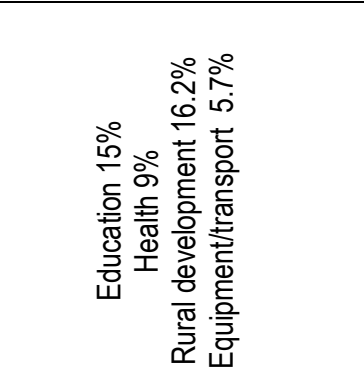 & $\stackrel{\circ}{\stackrel{\circ}{\circ}}$ & 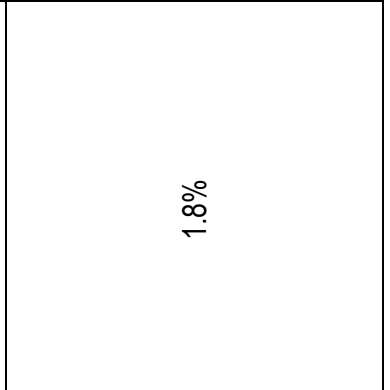 \\
\hline 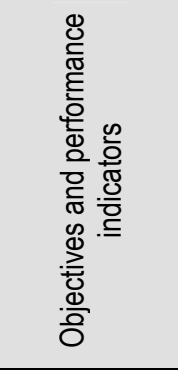 & 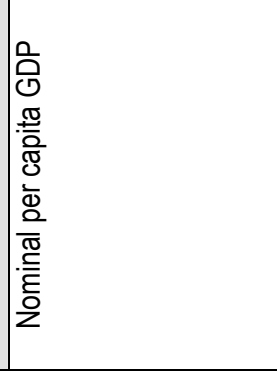 & 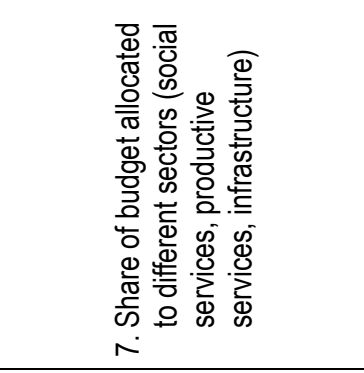 & 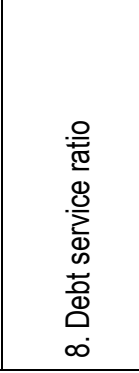 & 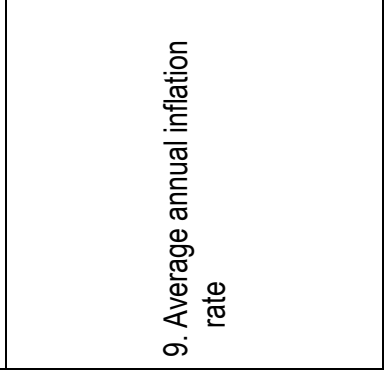 \\
\hline
\end{tabular}




\begin{tabular}{|c|c|c|c|c|c|c|}
\hline 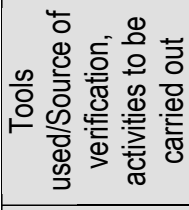 & 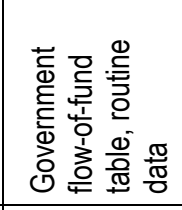 & 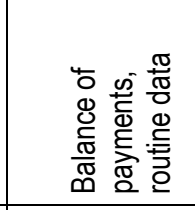 & 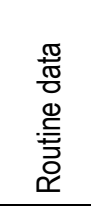 & 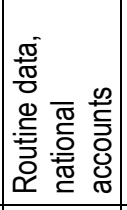 & 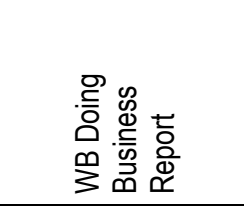 & 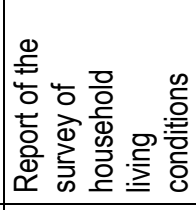 \\
\hline 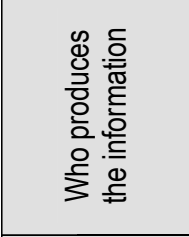 & 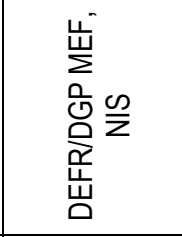 & 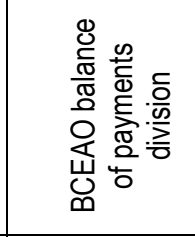 & 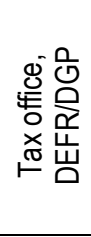 & $\frac{\infty}{Z}$ & 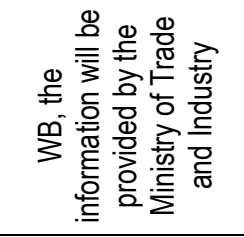 & $\frac{\infty}{Z}$ \\
\hline 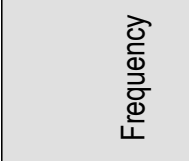 & 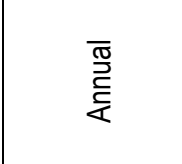 & 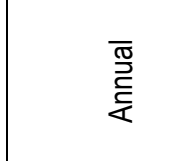 & 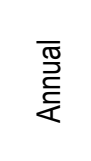 & $\begin{array}{l}\overline{\text { Tू}} \\
\text { 定 }\end{array}$ & $\begin{array}{l}\overline{\widetilde{T}} \\
\stackrel{\frac{1}{5}}{ }\end{array}$ & 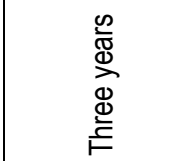 \\
\hline 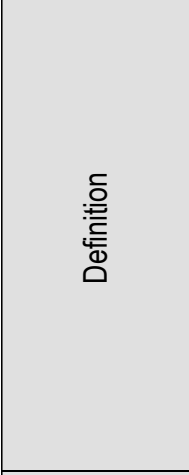 & 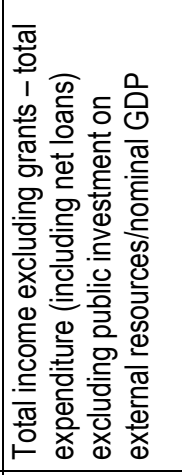 & 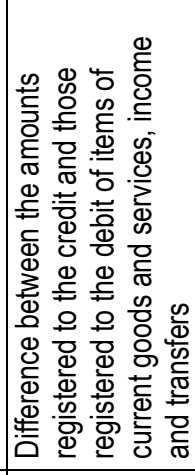 & 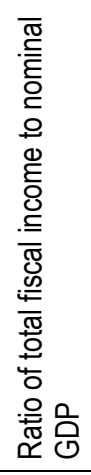 & 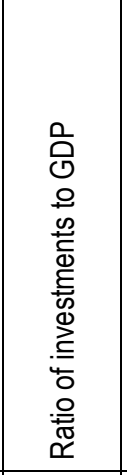 & 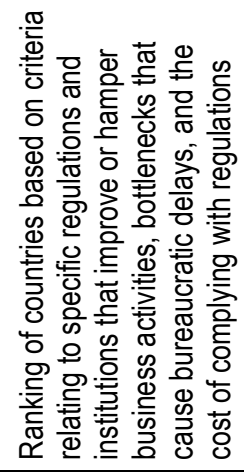 & 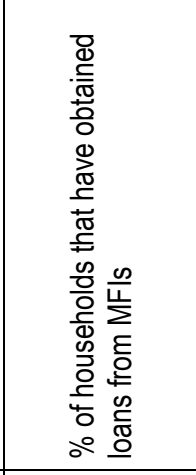 \\
\hline 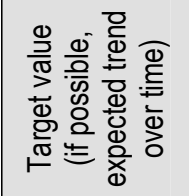 & & & $\begin{array}{l}\text { ָे } \\
\stackrel{ }{\Xi} \\
\circ\end{array}$ & 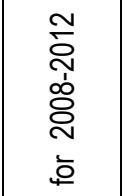 & 음 & \\
\hline 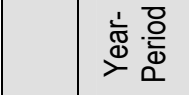 & 옹 & ষ্ণ & ๕ి & ઠิં & ষ্ণ & \\
\hline 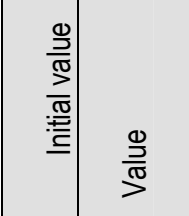 & ํํํ & $\begin{array}{l}\stackrel{0}{0} \\
\infty \\
\infty\end{array}$ & $\stackrel{\circ}{\stackrel{\circ}{\rightleftarrows}}$ & $\begin{array}{l}\stackrel{\circ}{+} \\
\stackrel{\infty}{\circ}\end{array}$ & $\stackrel{\odot}{\circ}$ & \\
\hline 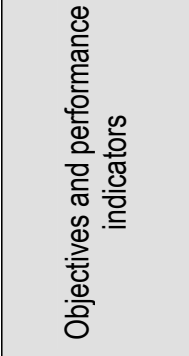 & 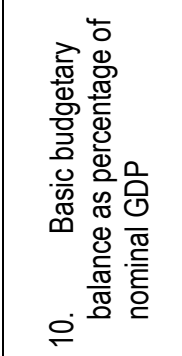 & 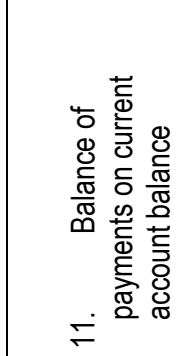 & 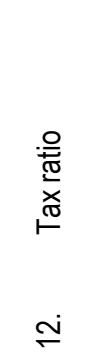 & 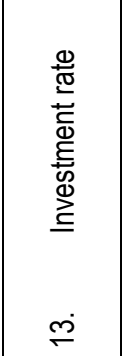 & 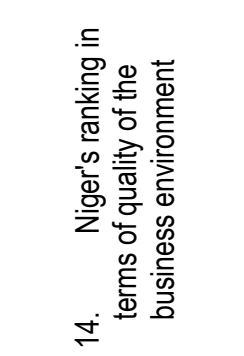 & 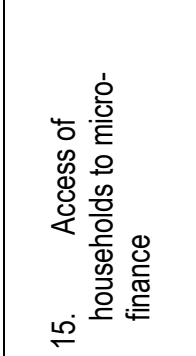 \\
\hline
\end{tabular}




\begin{tabular}{|c|c|c|c|c|}
\hline 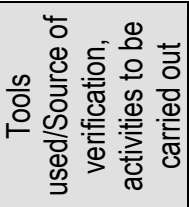 & 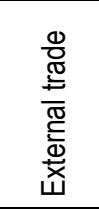 & 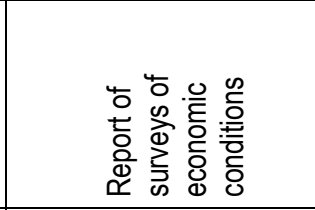 & 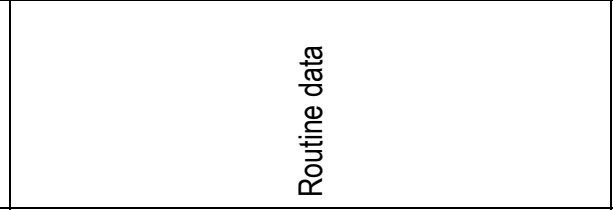 & 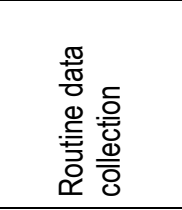 \\
\hline 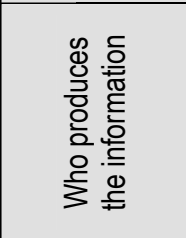 & $\frac{\infty}{Z}$ & 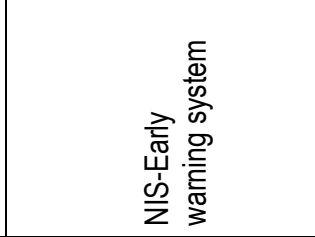 & 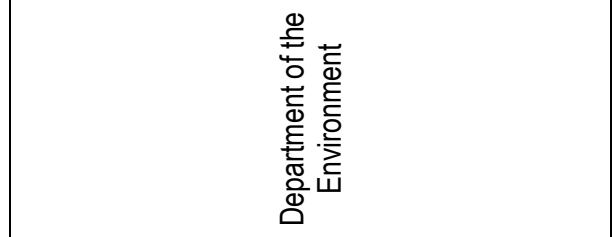 & 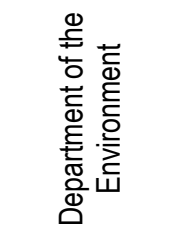 \\
\hline 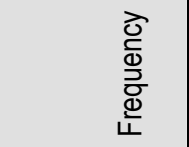 & 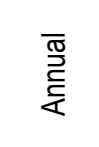 & 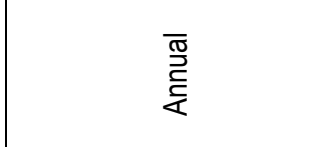 & 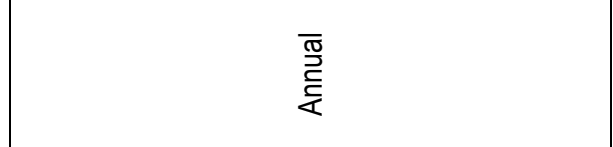 & 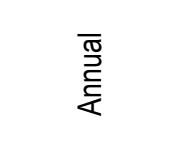 \\
\hline :흘 & 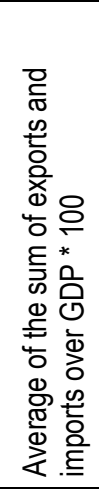 & 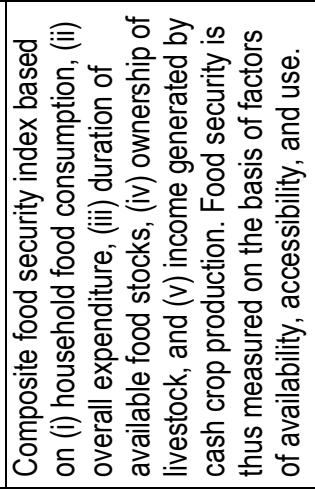 & 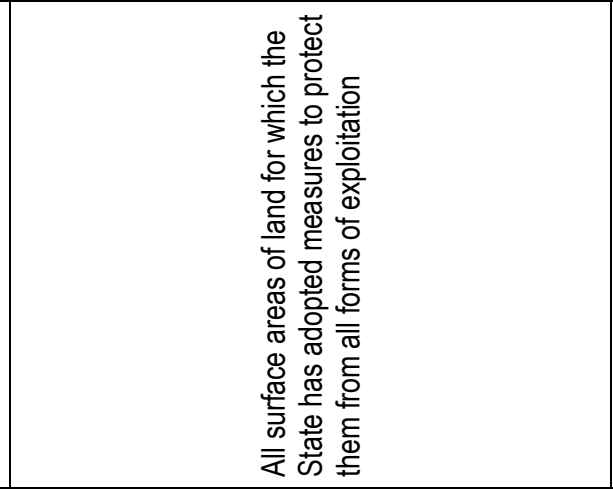 & \\
\hline 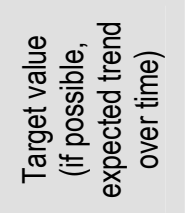 & & & 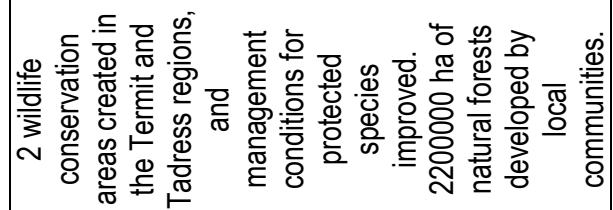 & 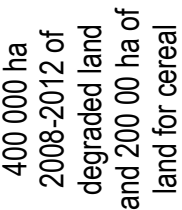 \\
\hline 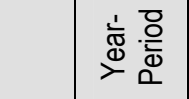 & & ષ্ণ & ষ্ণ & ¿̊ి \\
\hline 婄 & & 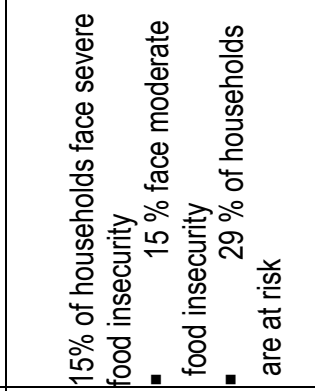 & $\begin{array}{l}\frac{8}{8} \\
\frac{8}{+} \\
\frac{\square}{+}\end{array}$ & 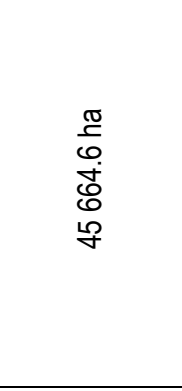 \\
\hline 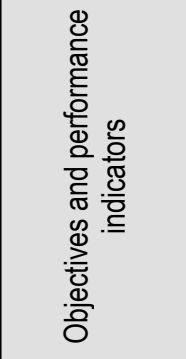 & 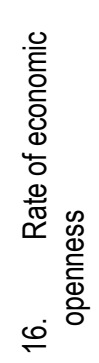 & 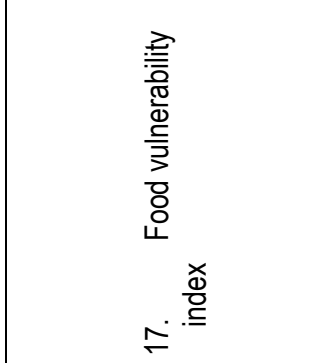 & 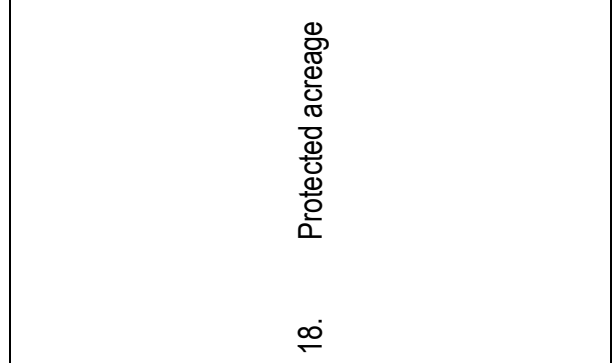 & 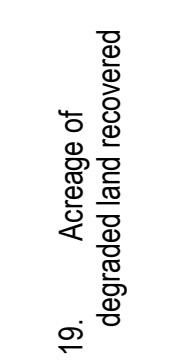 \\
\hline
\end{tabular}




\begin{tabular}{|c|c|c|c|c|c|c|c|}
\hline \multicolumn{2}{|c|}{ 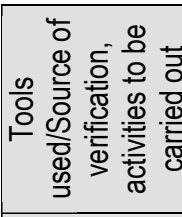 } & & 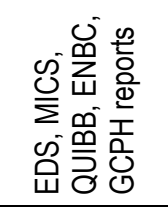 & \multicolumn{2}{|c|}{ 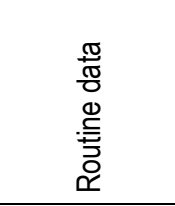 } & 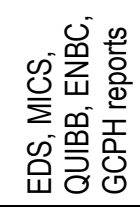 & 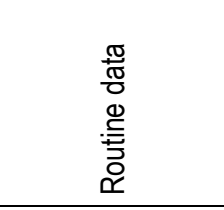 \\
\hline \multicolumn{2}{|c|}{ 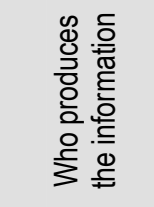 } & & $\frac{\infty}{Z}$ & & 茎 & $\frac{\infty}{Z}$ & 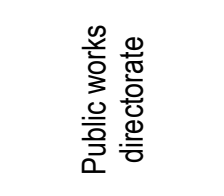 \\
\hline & 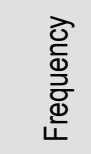 & & 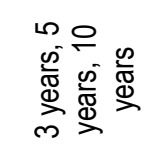 & & 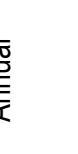 & 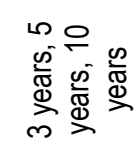 & 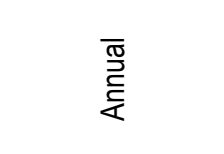 \\
\hline \multicolumn{2}{|c|}{ 毫 } & & 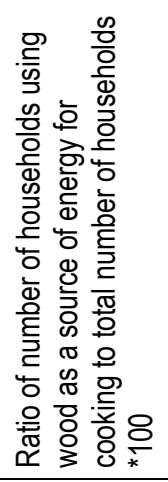 & \multicolumn{2}{|c|}{ 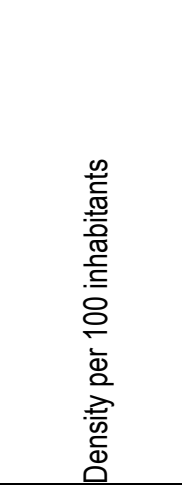 } & 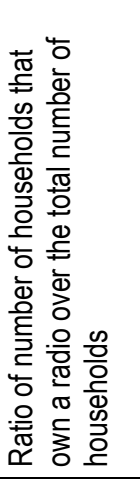 & 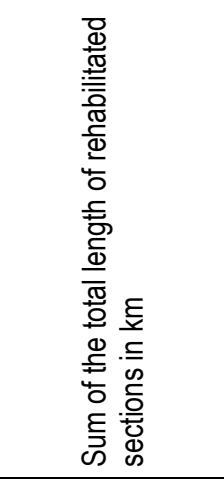 \\
\hline \multicolumn{2}{|c|}{ 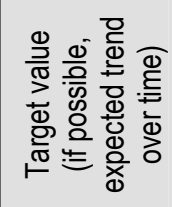 } & 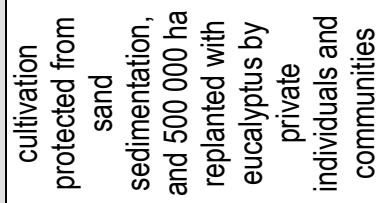 & & 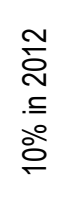 & 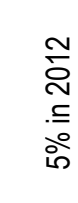 & ઠे & 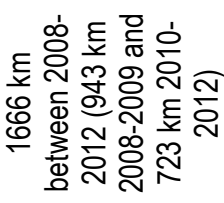 \\
\hline \multirow[b]{2}{*}{ 离 } & $\begin{array}{l}\frac{1}{\Phi} . \\
\stackrel{\infty}{\infty}\end{array}$ & & 옹 & 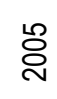 & 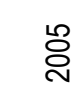 & ๕ & هั่ \\
\hline & $\stackrel{\frac{\Phi}{\pi}}{\frac{\pi}{5}}$ & & $\begin{array}{l}\stackrel{\circ}{+} \\
\text { षें }\end{array}$ & $\underset{\mathbb{N}}{\mathbb{N}}$ & $\stackrel{\infty}{\circ}$ & $\frac{\circ}{i n}$ & 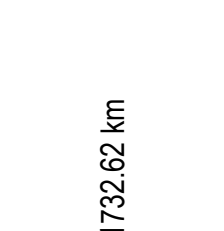 \\
\hline \multirow{2}{*}{\multicolumn{2}{|c|}{ 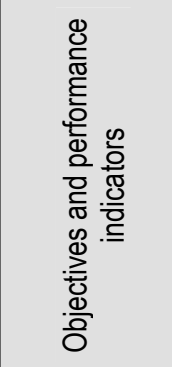 }} & & 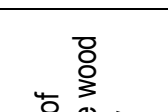 & $\frac{\stackrel{0}{0}}{\overline{0}^{\circ}}$ & 离 & \multirow[b]{2}{*}{ 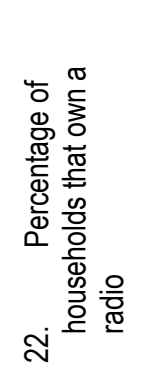 } & \multirow{2}{*}{ 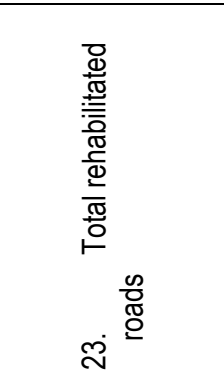 } \\
\hline & & & 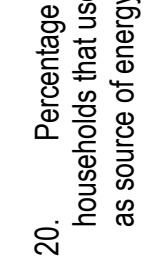 & \multicolumn{2}{|c|}{ 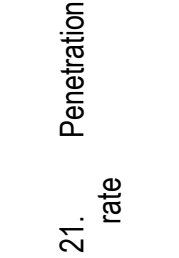 } & & \\
\hline
\end{tabular}




\begin{tabular}{|c|c|c|c|c|c|}
\hline 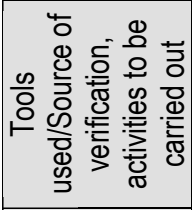 & 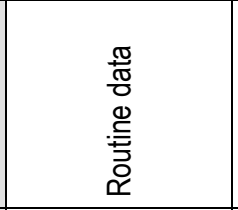 & 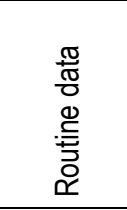 & 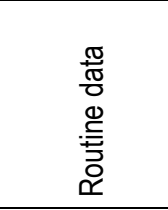 & 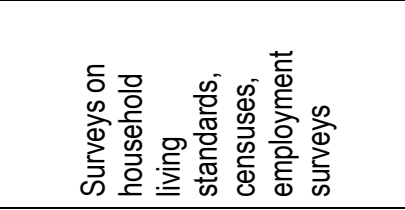 & 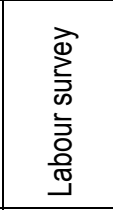 \\
\hline 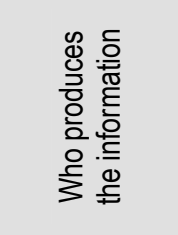 & 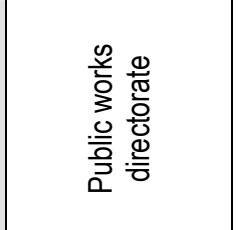 & 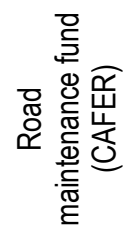 & 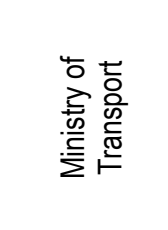 & 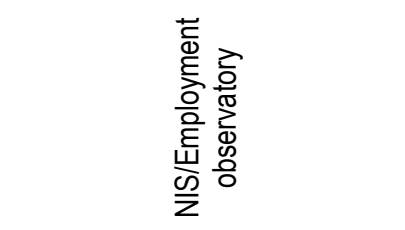 & 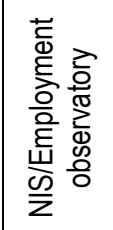 \\
\hline 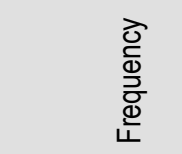 & 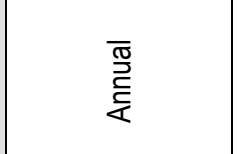 & 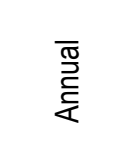 & 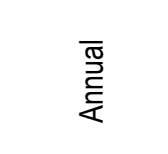 & 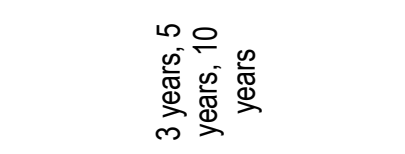 & 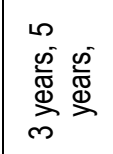 \\
\hline 들 & 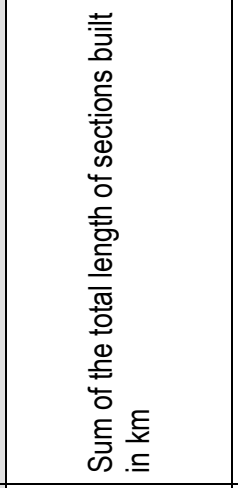 & 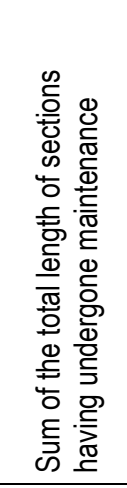 & 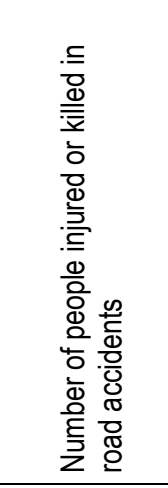 & 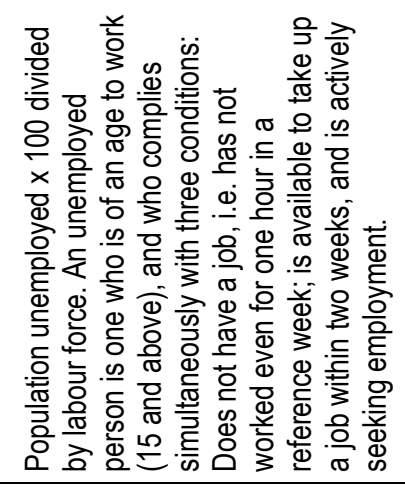 & 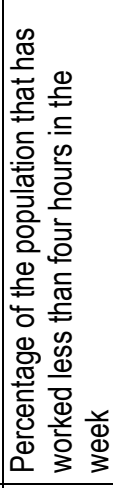 \\
\hline 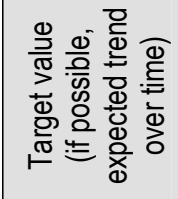 & 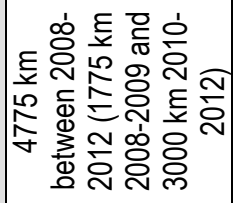 & & & $\begin{array}{l}\stackrel{\sim}{\bar{N}} \\
\stackrel{.}{\circ} \\
\stackrel{\circ}{\circ}\end{array}$ & 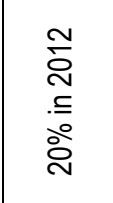 \\
\hline 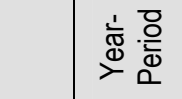 & ઠ̊ં & ઠิં & 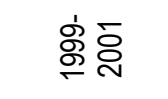 & 苂 & 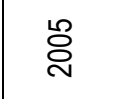 \\
\hline 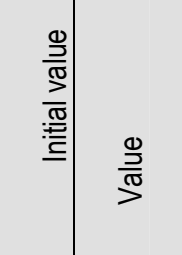 & $\begin{array}{l}\frac{E}{5} \\
\stackrel{5}{\circ} \\
\stackrel{+}{\sigma}\end{array}$ & $\begin{array}{l}\frac{\xi}{5} \\
\frac{0}{0} \\
\text { 은 }\end{array}$ & 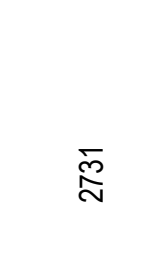 & $\begin{array}{l}\text { 今े } \\
\text { هి }\end{array}$ & ӊे \\
\hline 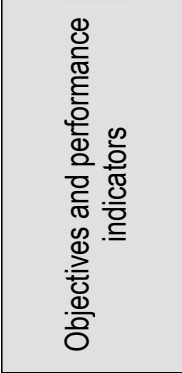 & 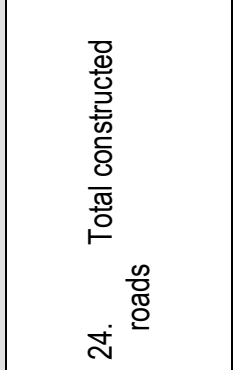 & 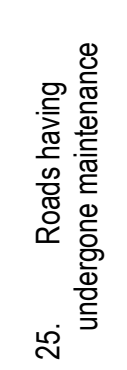 & 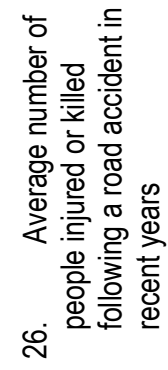 & 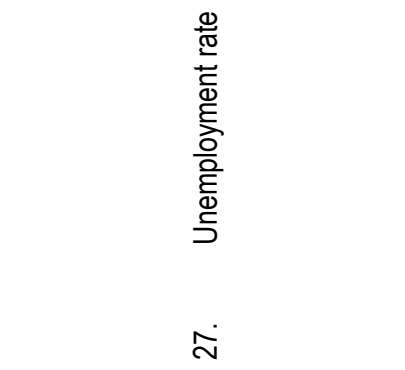 & 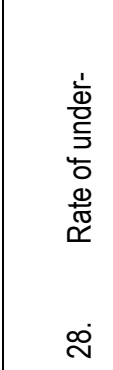 \\
\hline
\end{tabular}




\begin{tabular}{|c|c|c|c|c|c|c|}
\hline 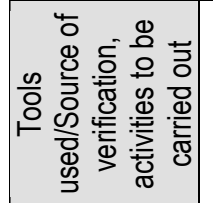 & & 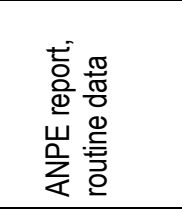 & 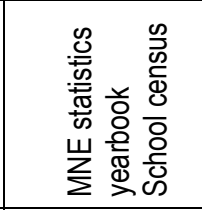 & 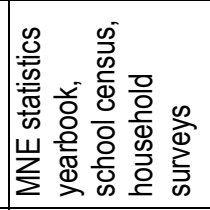 & 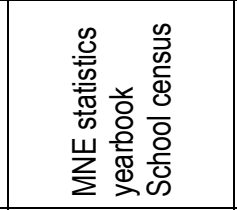 & 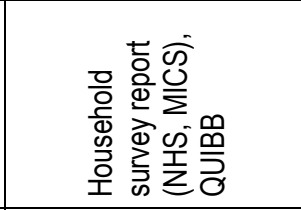 \\
\hline \multicolumn{2}{|l|}{ 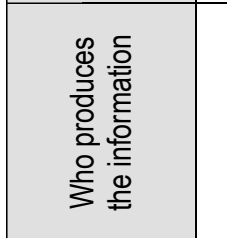 } & 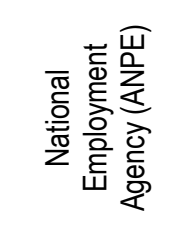 & 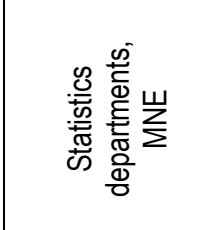 & 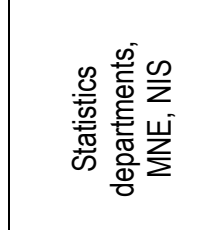 & 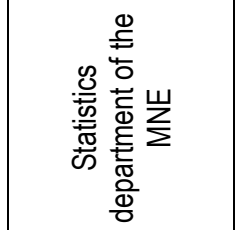 & 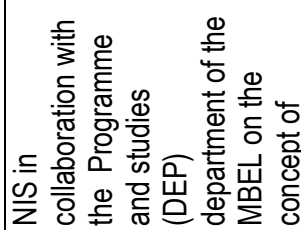 \\
\hline 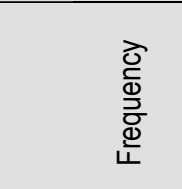 & & 㳬 & 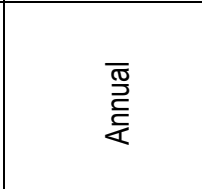 & 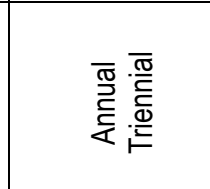 & 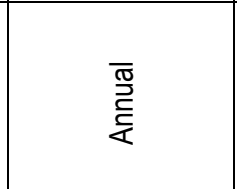 & 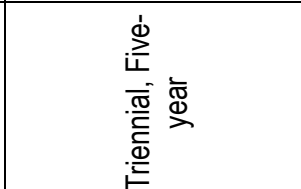 \\
\hline 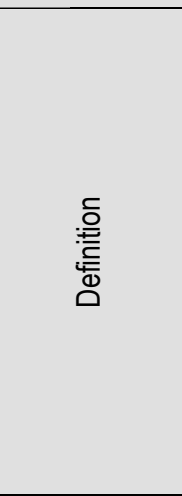 & & 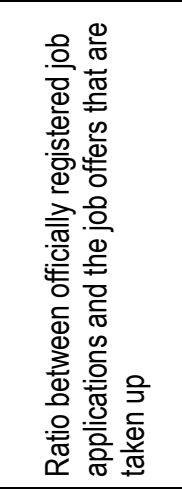 & 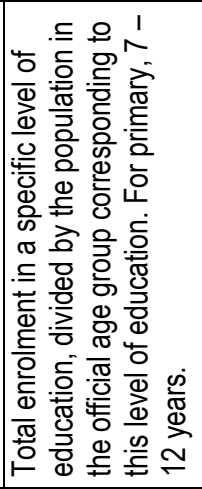 & 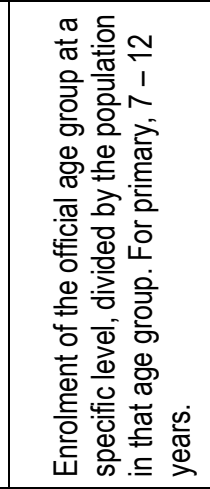 & 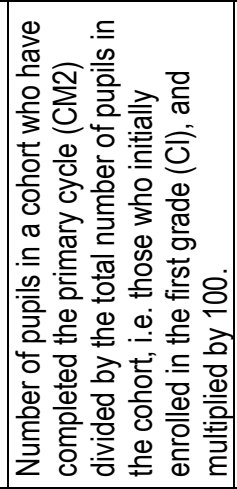 & 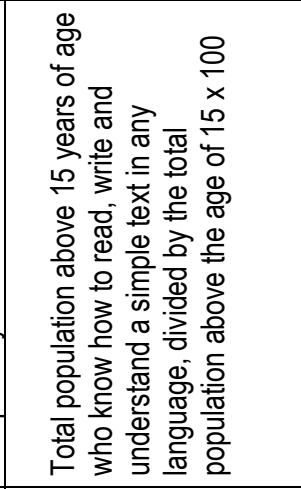 \\
\hline 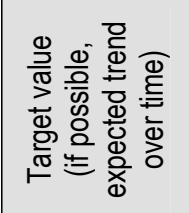 & & 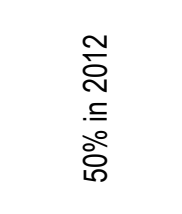 & 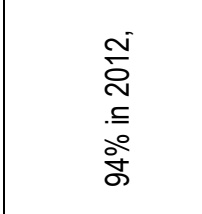 & & 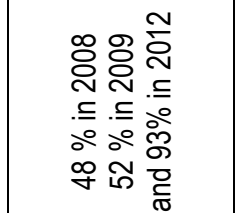 & 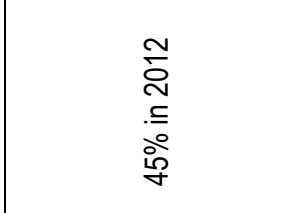 \\
\hline \multirow[b]{2}{*}{ 竞 } & & 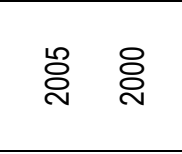 & 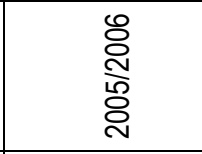 & 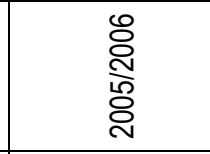 & 客 宫 & ஜి \\
\hline & & 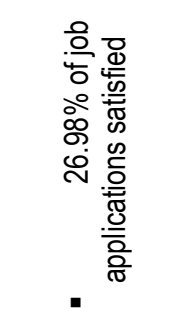 & 过 & 今े & $\begin{array}{l}\text { ㅇ } \\
\text { ᄋ }\end{array}$ & $\begin{array}{l}\stackrel{0}{\stackrel{0}{0}} \\
\stackrel{\infty}{\sim}\end{array}$ \\
\hline 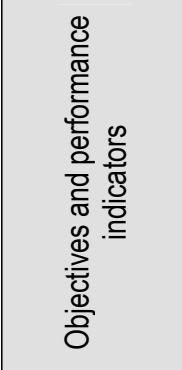 & 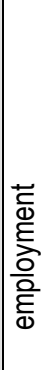 & 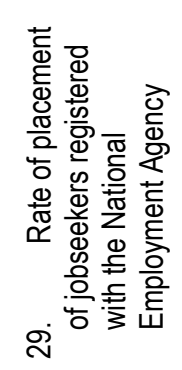 & 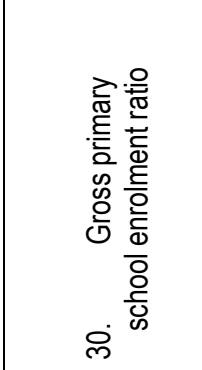 & 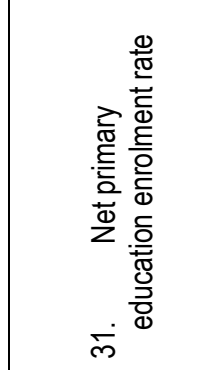 & 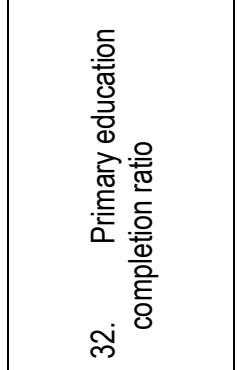 & 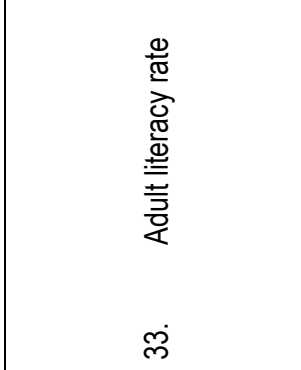 \\
\hline
\end{tabular}




\begin{tabular}{|c|c|c|c|c|c|c|c|c|}
\hline \multicolumn{2}{|c|}{ 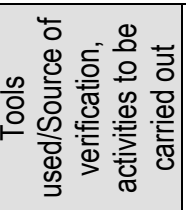 } & & 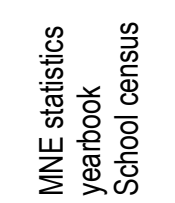 & 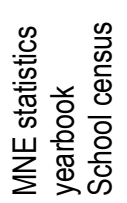 & 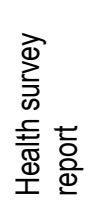 & $\begin{array}{l}\frac{T}{0} \\
\frac{0}{0} \\
\frac{\omega}{2} \\
\frac{T}{Z}\end{array}$ & $\begin{array}{l}\frac{T}{5} \\
\frac{0}{0} \\
\frac{0}{2} \\
\frac{D}{2}\end{array}$ & $\begin{array}{l}\frac{T}{1} \\
\text { O } \\
\text { o } \\
\text { T) } \\
\frac{1}{2}\end{array}$ \\
\hline \multicolumn{2}{|c|}{ 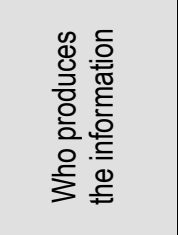 } & 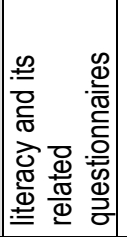 & 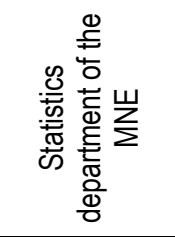 & 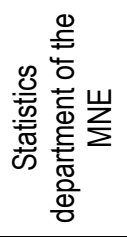 & $\frac{\infty}{Z}$ & $\begin{array}{l}\frac{\infty}{1} \\
\sum_{0} \\
\sum_{i}^{0}\end{array}$ & $\frac{\infty}{\frac{\infty}{Z}}$ & $\frac{\infty}{Z}$ \\
\hline \multirow{2}{*}{\multicolumn{2}{|c|}{ 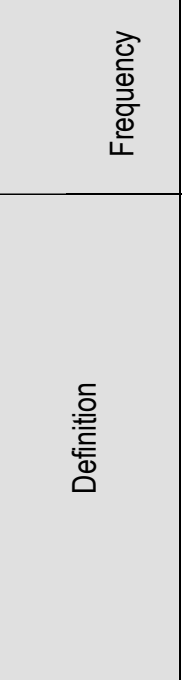 }} & & 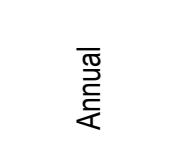 & 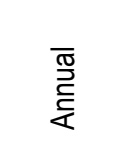 & 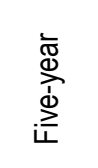 & 丞 & & 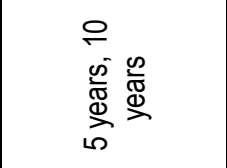 \\
\hline & & & 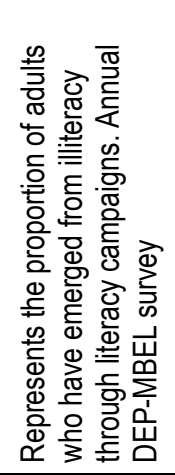 & 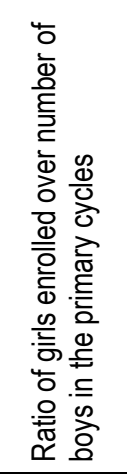 & 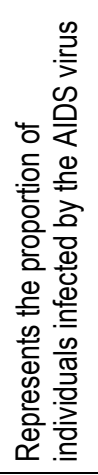 & 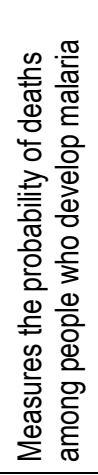 & 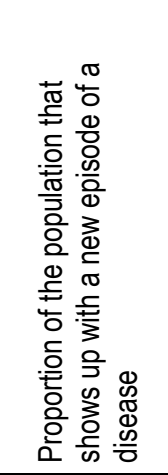 & 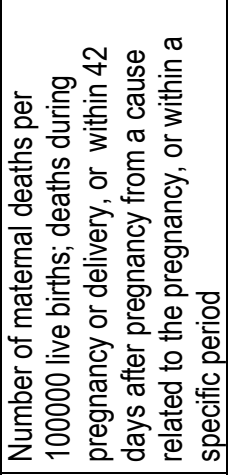 \\
\hline \multicolumn{2}{|c|}{ 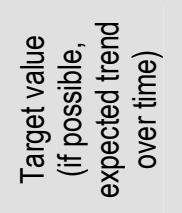 } & & 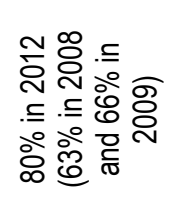 & ○े & 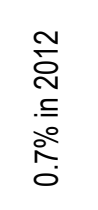 & & $\begin{array}{l}\stackrel{\sim}{\circ} \\
\stackrel{N}{\leftrightarrows} \\
\stackrel{\circ}{0} \\
\stackrel{0}{0}\end{array}$ & 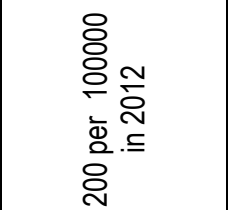 \\
\hline \multirow[b]{2}{*}{ 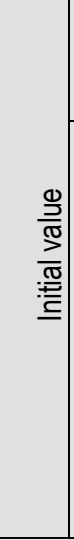 } & \begin{tabular}{l}
$\frac{1}{\Phi} . \frac{0}{\Phi}$ \\
$⿱ 亠 凶$ \\
\hdashline
\end{tabular} & & ஜ̊ & 客 完 & ஜ̊̊ & & 용 & ષ্ণ \\
\hline & $\frac{\frac{0}{7}}{\frac{\pi}{\pi}}$ & & ஜें & จิ & 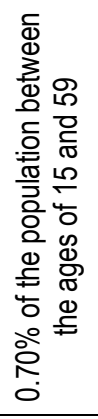 & & $\begin{array}{l}\text { خे } \\
\text { ò } \\
0\end{array}$ & 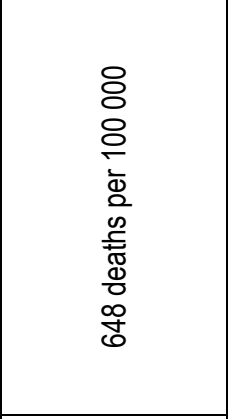 \\
\hline \multicolumn{2}{|c|}{ 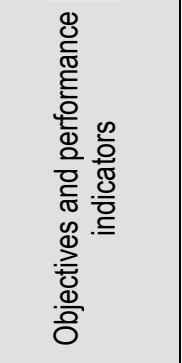 } & & 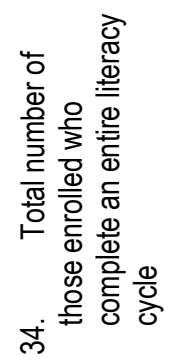 & 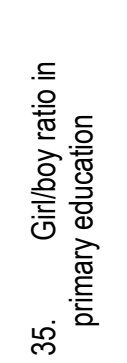 & 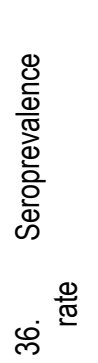 & 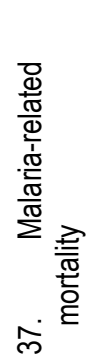 & 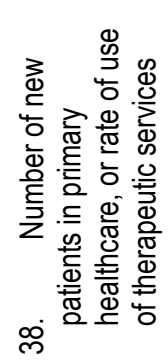 & 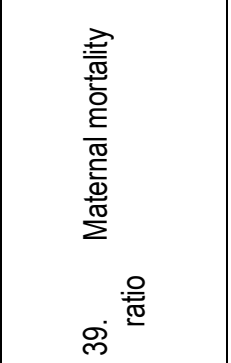 \\
\hline
\end{tabular}




\begin{tabular}{|c|c|c|c|c|c|c|c|}
\hline \multicolumn{2}{|c|}{ 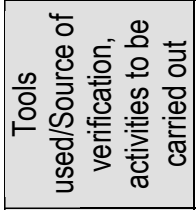 } & 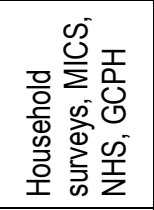 & 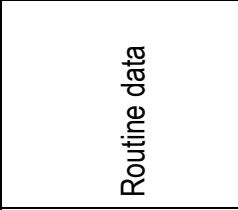 & 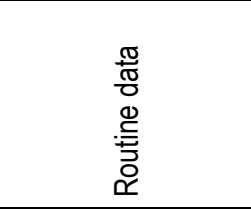 & 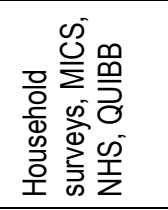 & 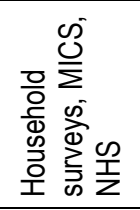 & 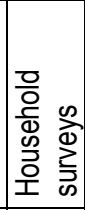 \\
\hline \multicolumn{2}{|c|}{ 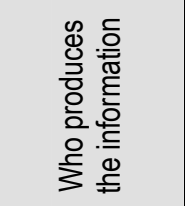 } & $\stackrel{\mathscr{N}}{\underline{2}}$ & $\frac{\infty}{\frac{N}{Z}}$ & $\frac{\infty}{\frac{D}{Z}}$ & $\frac{\infty}{Z}$ & $\frac{\infty}{Z}$ & $\frac{\infty}{Z}$ \\
\hline & 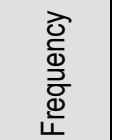 & 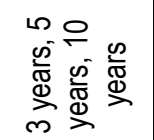 & 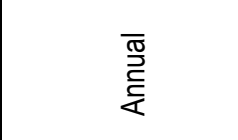 & 㕫 & 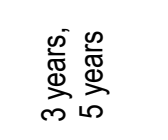 & 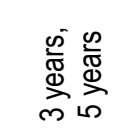 & 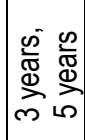 \\
\hline \multicolumn{2}{|c|}{ 亭 } & 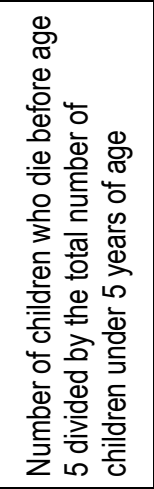 & 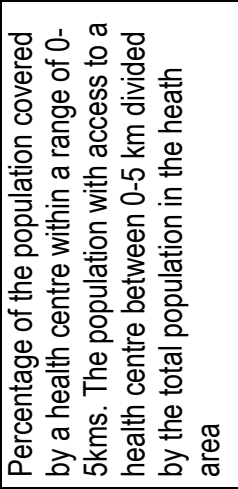 & 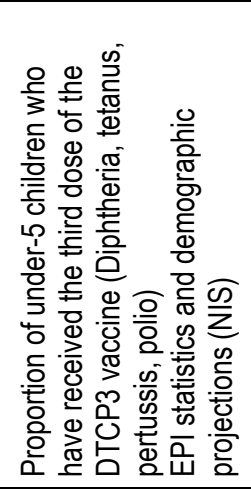 & 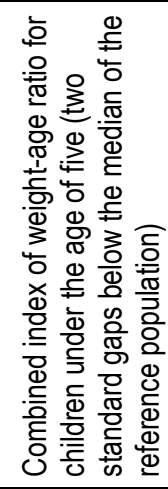 & 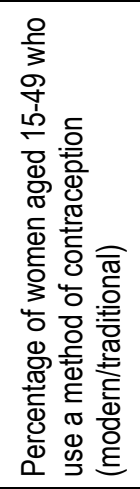 & 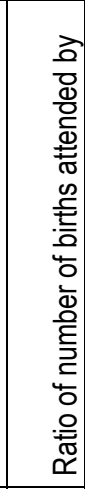 \\
\hline \multicolumn{2}{|c|}{ 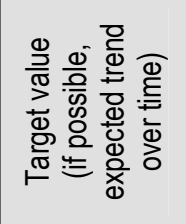 } & 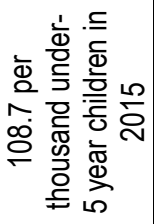 & & & 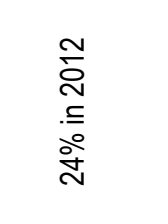 & 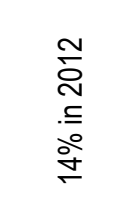 & $\begin{array}{l}\stackrel{\sim}{\grave{2}} \\
\stackrel{\text { I }}{\circ} \\
\text { oे }\end{array}$ \\
\hline \multirow[b]{2}{*}{ 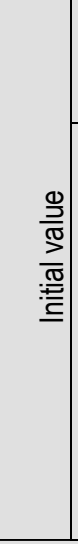 } & 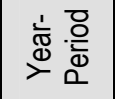 & ஜ̊ి & 苂 & ષ્ণ & ષ্ণ & ષ্ণ & ஜ̊ \\
\hline & 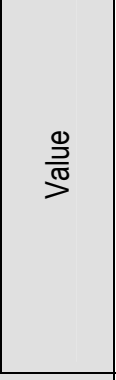 & 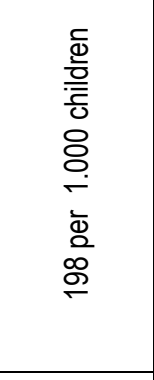 & ㅇํㅇ & 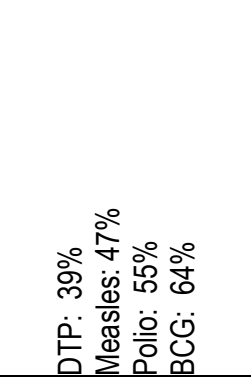 & $\stackrel{\circ}{\stackrel{9}{+}}$ & i̊ & 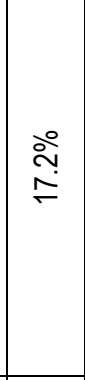 \\
\hline \multicolumn{2}{|c|}{ 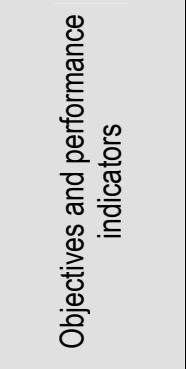 } & 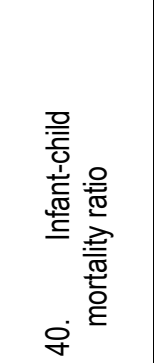 & 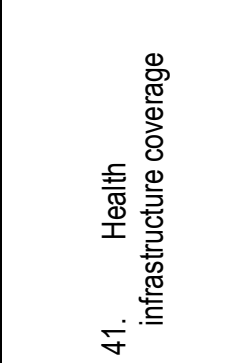 & 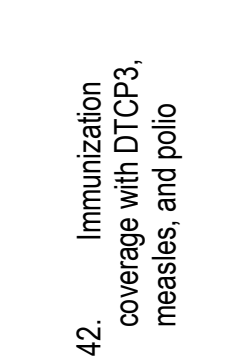 & 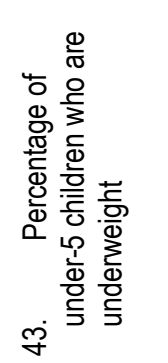 & 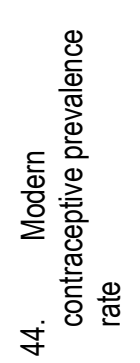 & 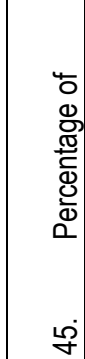 \\
\hline
\end{tabular}




\begin{tabular}{|c|c|c|c|c|c|c|c|}
\hline 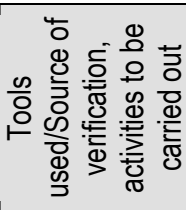 & & 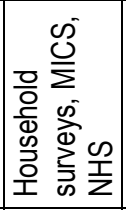 & 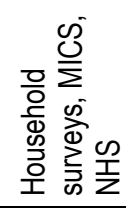 & 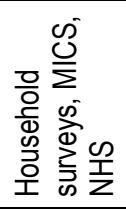 & 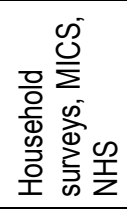 & 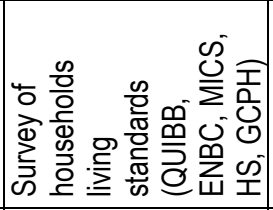 & 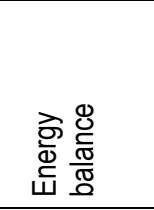 \\
\hline 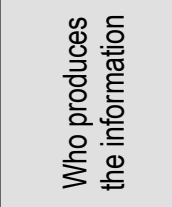 & & $\frac{\infty}{Z}$ & $\frac{\infty}{Z}$ & $\frac{\infty}{Z}$ & $\stackrel{\mathscr{N}}{\underline{2}}$ & $\frac{\infty}{Z}$ & $\sum_{\underset{\omega}{\omega}}$ \\
\hline 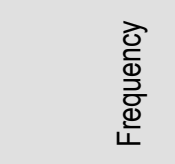 & & 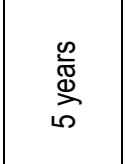 & 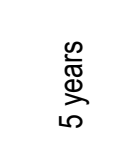 & 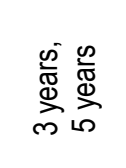 & 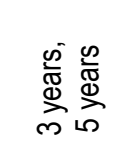 & 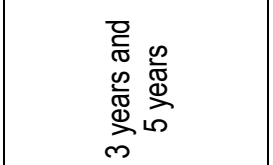 & 可 \\
\hline 亭 & 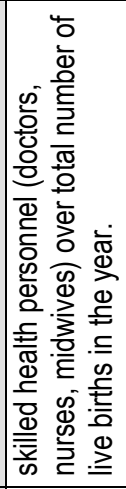 & 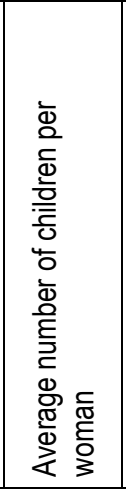 & 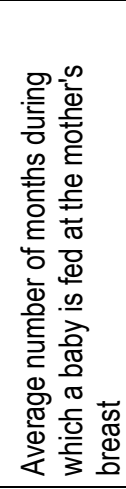 & 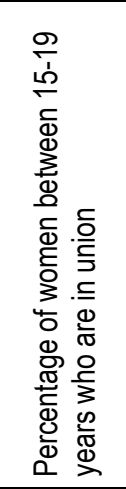 & 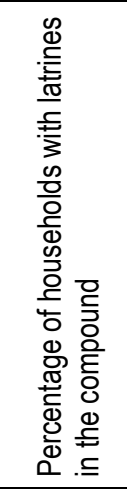 & 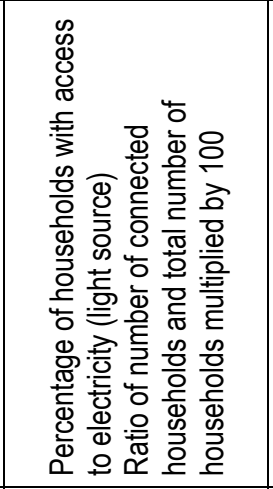 & 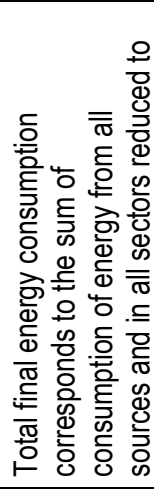 \\
\hline 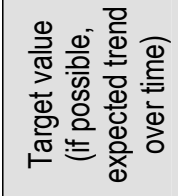 & & 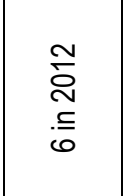 & 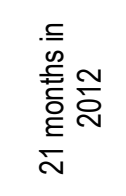 & 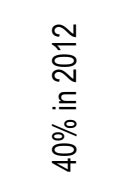 & & & \\
\hline 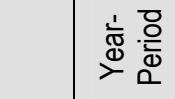 & & ષ্ণ & ષ্ণ & ષ্ণ & & ષ্ণ & 必 \\
\hline 竞 & & $\check{\tau}$ & 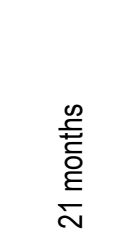 & ০ั & & ळें & $\underset{\stackrel{D}{+}}{\stackrel{Ð}{+}}$ \\
\hline 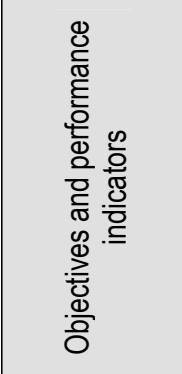 & 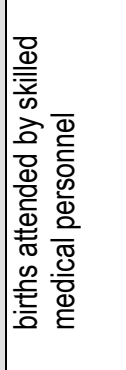 & 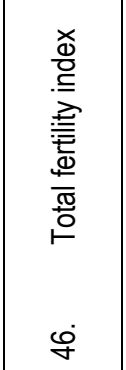 & 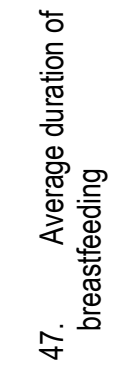 & 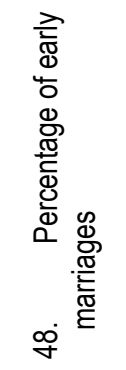 & 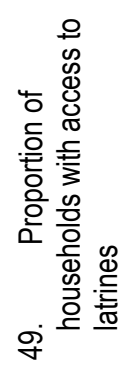 & 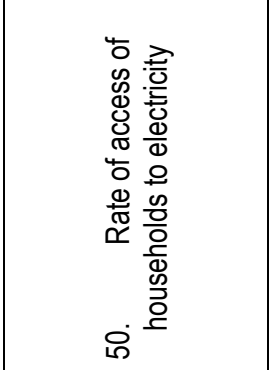 & 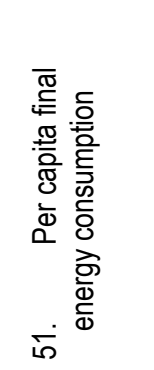 \\
\hline
\end{tabular}




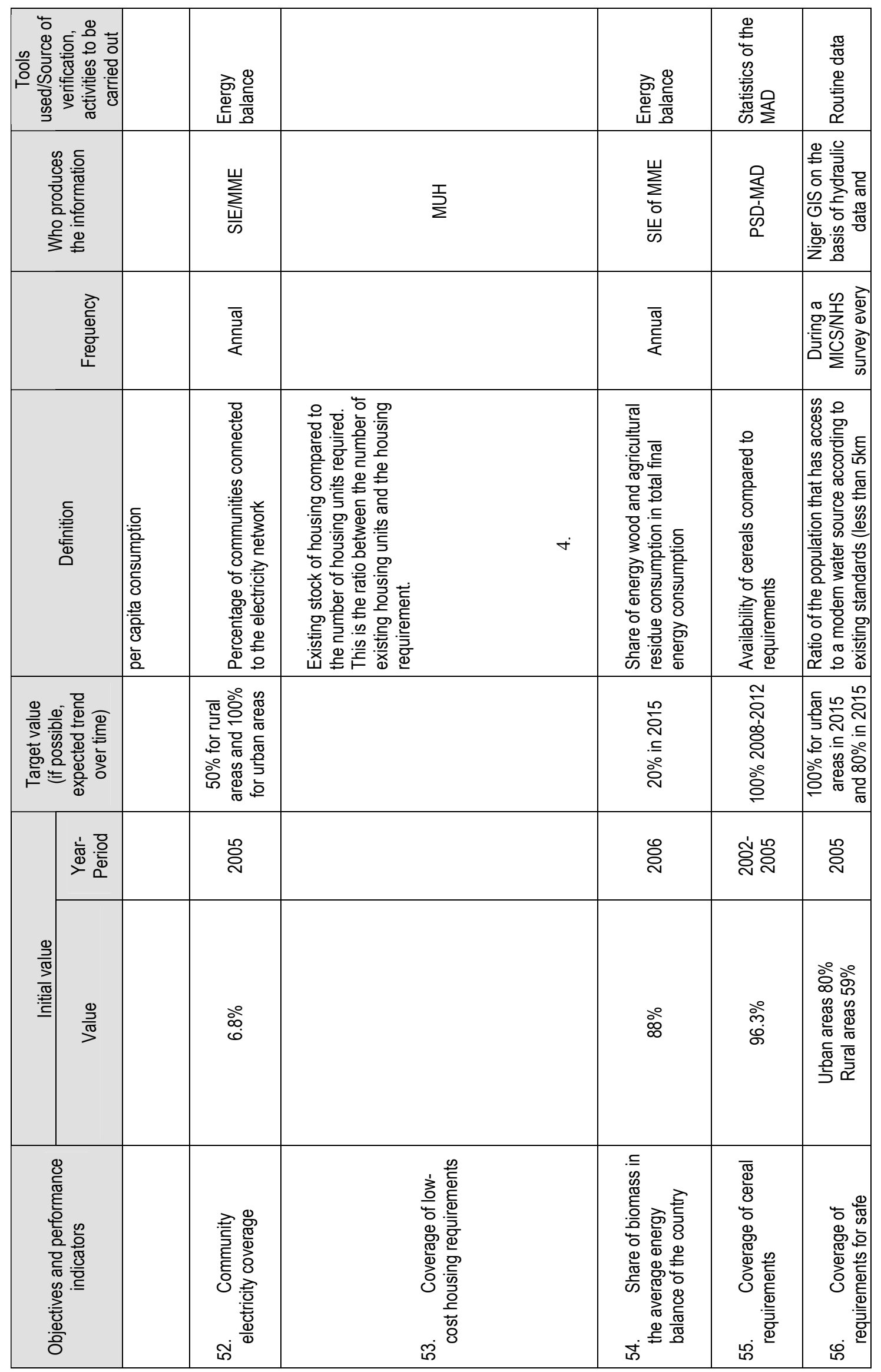




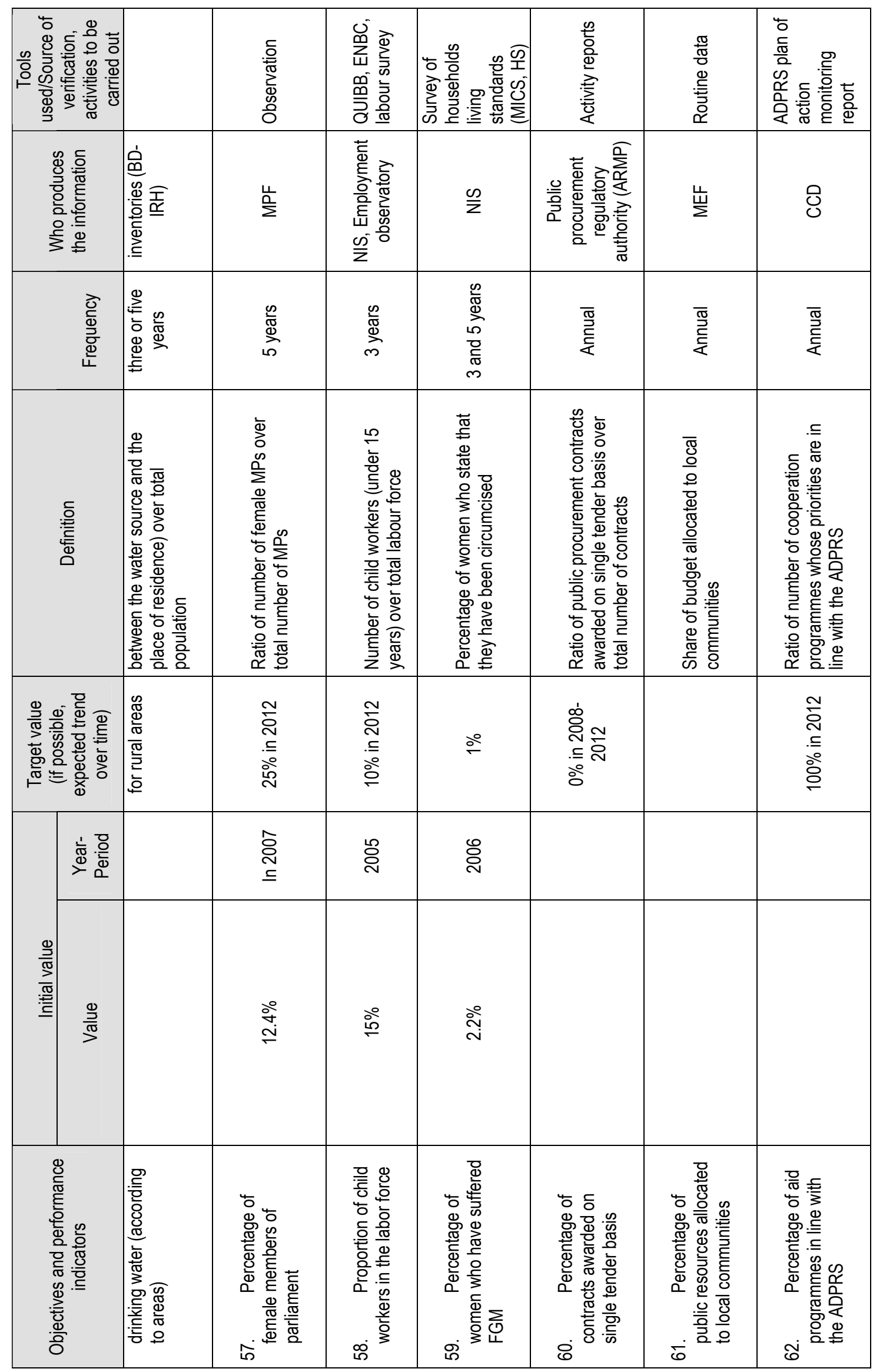




\begin{tabular}{|c|c|c|c|c|}
\hline 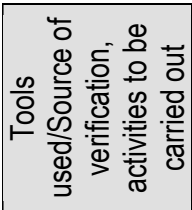 & & 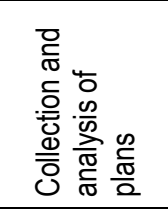 & 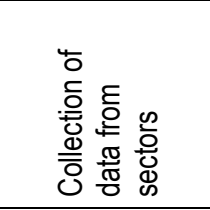 & 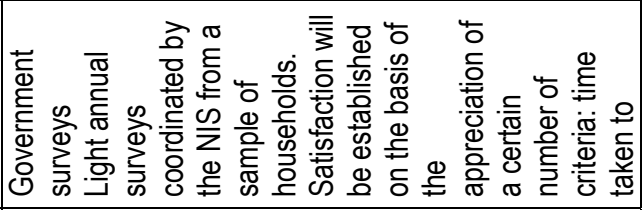 \\
\hline 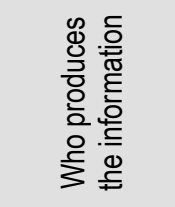 & & 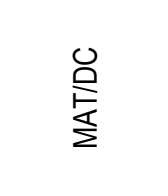 & 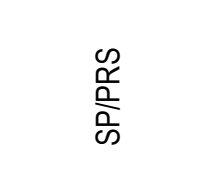 & $\frac{\infty}{Z}$ \\
\hline 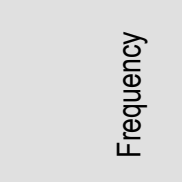 & & $\underset{⿱ \infty}{\stackrel{\infty}{\Phi ల}}$ & $\begin{array}{l}\overline{\frac{\pi}{T}} \\
\stackrel{\frac{1}{2}}{\frac{\alpha}{2}}\end{array}$ & 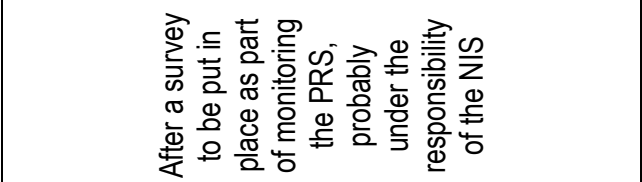 \\
\hline 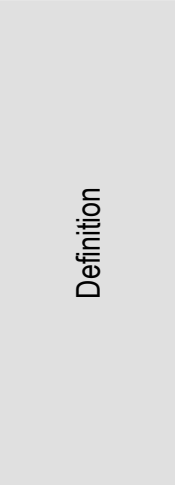 & & & 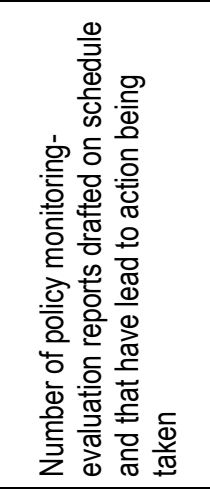 & 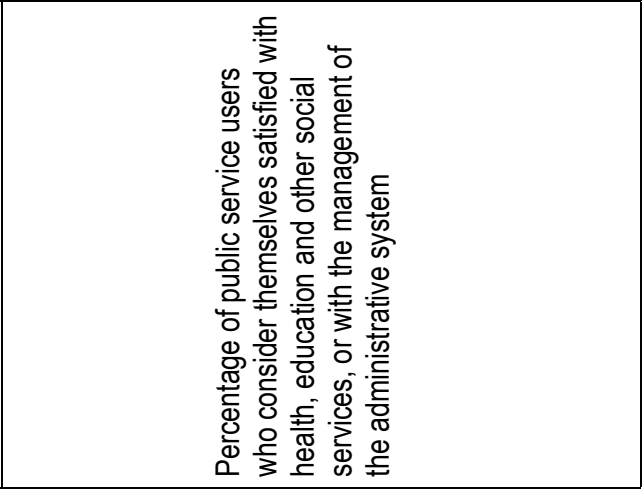 \\
\hline 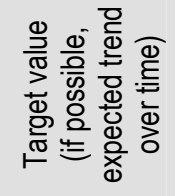 & 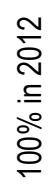 & 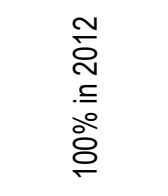 & 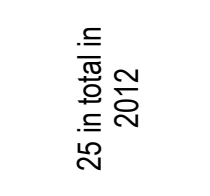 & \\
\hline 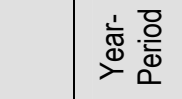 & 苂 & & ' & \\
\hline 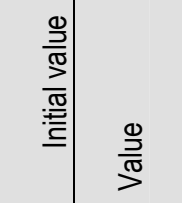 & 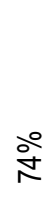 & & ' & \\
\hline 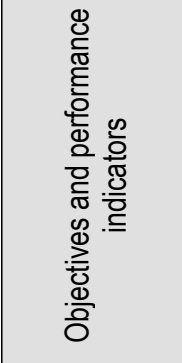 & 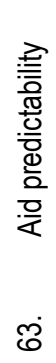 & 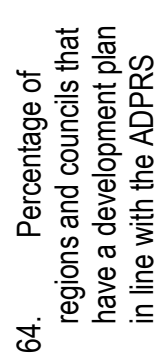 & 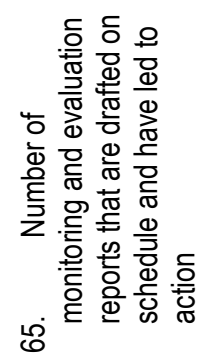 & 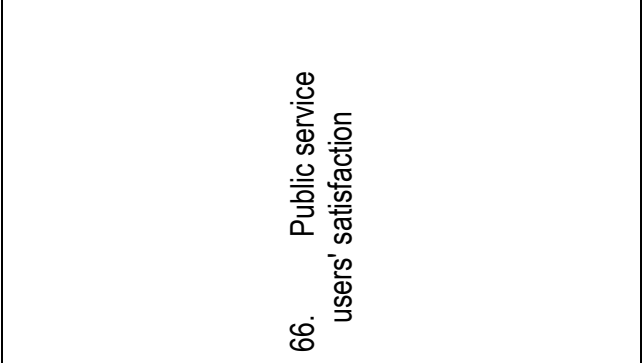 \\
\hline
\end{tabular}




\begin{tabular}{|c|c|c|c|c|c|}
\hline 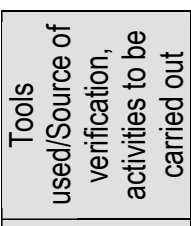 & 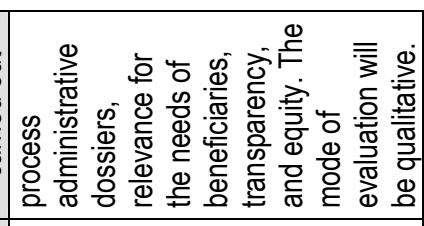 & 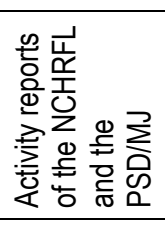 & & 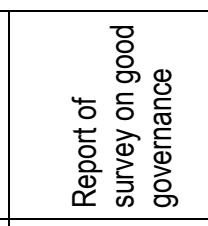 & 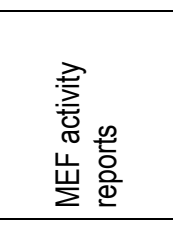 \\
\hline 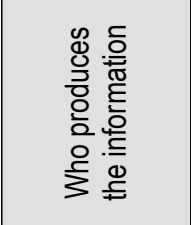 & & 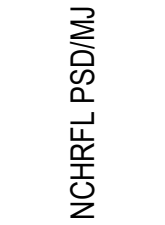 & 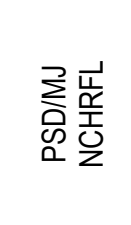 & $\frac{N}{Z}$ & 岀 \\
\hline 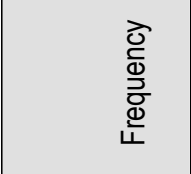 & & & 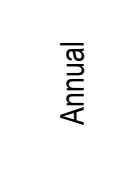 & 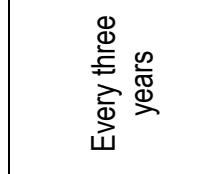 & \\
\hline 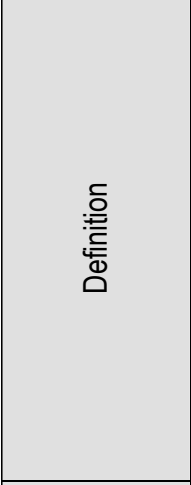 & & & 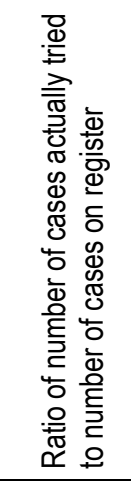 & 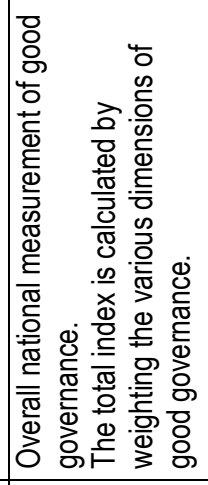 & 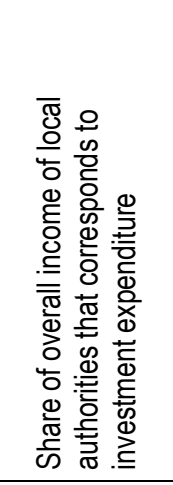 \\
\hline 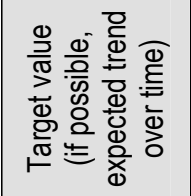 & & & & & \\
\hline 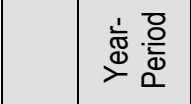 & & & & & \\
\hline 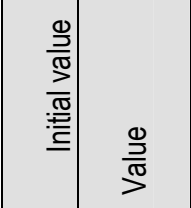 & & & & & \\
\hline 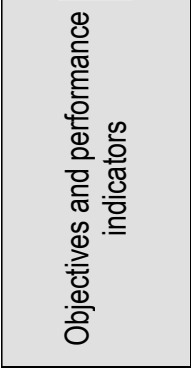 & & 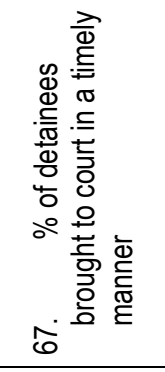 & 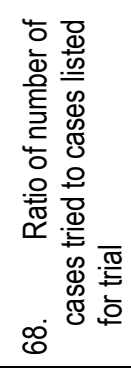 & 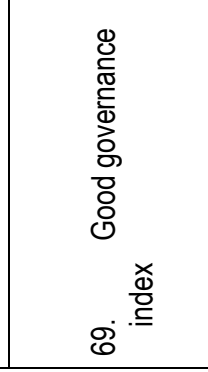 & 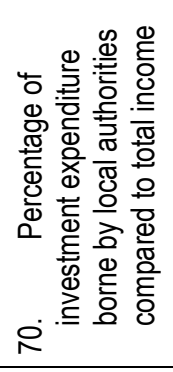 \\
\hline
\end{tabular}




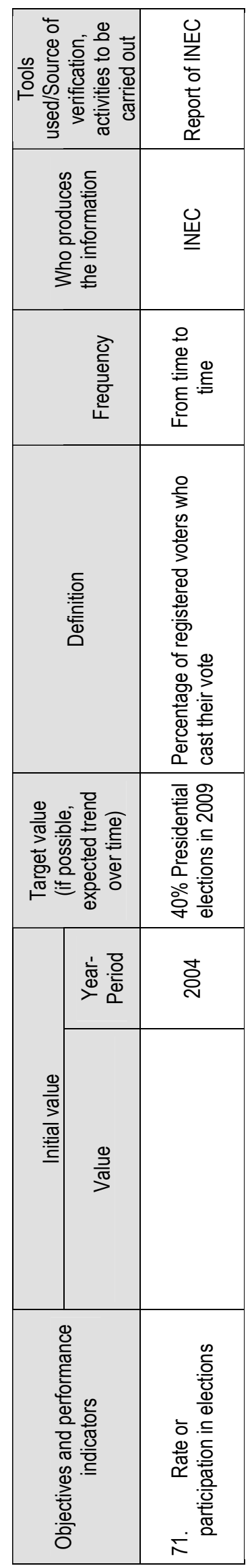

Ð 
Annex 4 : Macroeconomic Framework Table

\section{1. a. SECTORAL CONTRIBUTION TO GROWTH (in percentage): RESOURCES}

\begin{tabular}{|l|r|r|r|r|r|r|r|}
\hline MDG scenario & & \multicolumn{5}{|c|}{ Forecast } \\
\hline Years & 2006 & 2007 & 2008 & 2009 & 2010 & 2011 & 2012 \\
\hline INFORMAL SECTOR & $5.9 \%$ & $4.3 \%$ & $6.0 \%$ & $6.3 \%$ & $6.9 \%$ & $7.3 \%$ & $7.5 \%$ \\
\hline & & & & & & & \\
\hline Agriculture & $3.0 \%$ & $5.0 \%$ & $8.0 \%$ & $8.2 \%$ & $8.7 \%$ & $9.2 \%$ & $9.5 \%$ \\
\hline Livestock & $3.0 \%$ & $3.3 \%$ & $3.3 \%$ & $3.3 \%$ & $4.8 \%$ & $4.8 \%$ & $4.8 \%$ \\
\hline Forests and fisheries & $3.7 \%$ & $4.1 \%$ & $4.1 \%$ & $4.1 \%$ & $4.8 \%$ & $4.8 \%$ & $4.8 \%$ \\
\hline Other sectors & $2.6 \%$ & $4.2 \%$ & $5.5 \%$ & $6.0 \%$ & $6.5 \%$ & $6.8 \%$ & $7.0 \%$ \\
\hline Extractive industries & $-4.2 \%$ & $3.5 \%$ & $3.5 \%$ & $3.5 \%$ & $5.0 \%$ & $5.0 \%$ & $5.0 \%$ \\
\hline Manufacturing industries & $2.9 \%$ & $4.2 \%$ & $4.2 \%$ & $4.2 \%$ & $5.0 \%$ & $5.0 \%$ & $5.0 \%$ \\
\hline Construction & $3.5 \%$ & $4.3 \%$ & $5.8 \%$ & $6.4 \%$ & $6.8 \%$ & $7.2 \%$ & $7.5 \%$ \\
\hline Trade, hotel industry & $3.5 \%$ & $4.1 \%$ & $5.6 \%$ & $6.2 \%$ & $6.6 \%$ & $7.0 \%$ & $7.3 \%$ \\
\hline Transport and communication & $-1.9 \%$ & $4.0 \%$ & $5.8 \%$ & $6.4 \%$ & $6.9 \%$ & $7.2 \%$ & $7.5 \%$ \\
\hline Other services (real estate and service/business activities) & $3.5 \%$ & $4.7 \%$ & $6.1 \%$ & $6.6 \%$ & $7.0 \%$ & $7.4 \%$ & $7.7 \%$ \\
\hline MODERN SECTOR & $7.4 \%$ & $8.0 \%$ & $8.2 \%$ & $10.9 \%$ & $9.8 \%$ & $9.5 \%$ & $8.2 \%$ \\
\hline & & & & & & & \\
\hline Mines & $10.1 \%$ & $6.0 \%$ & $7.0 \%$ & $8.0 \%$ & $9.0 \%$ & $10.0 \%$ & $10.5 \%$ \\
\hline Manufacturing industries & $-1.1 \%$ & $6.6 \%$ & $5.6 \%$ & $6.1 \%$ & $8.0 \%$ & $7.6 \%$ & $7.4 \%$ \\
\hline Water and electricity & $8.4 \%$ & $5.9 \%$ & $7.4 \%$ & $7.0 \%$ & $7.5 \%$ & $8.0 \%$ & $8.3 \%$ \\
\hline Construction and public works & $5.8 \%$ & $17.6 \%$ & $24.9 \%$ & $51.0 \%$ & $20.5 \%$ & $13.0 \%$ & $1.4 \%$ \\
\hline Trade and hotel industry & $4.1 \%$ & $5.3 \%$ & $5.2 \%$ & $6.0 \%$ & $7.9 \%$ & $7.6 \%$ & $7.4 \%$ \\
\hline Transport & $9.0 \%$ & $7.3 \%$ & $7.3 \%$ & $8.1 \%$ & $10.2 \%$ & $10.3 \%$ & $10.2 \%$ \\
\hline Other services & $6.2 \%$ & $5.6 \%$ & $5.4 \%$ & $6.2 \%$ & $8.5 \%$ & $7.9 \%$ & $7.7 \%$ \\
\hline & & & & & & & \\
\hline NON MARKET GDP & $-4.2 \%$ & $5.5 \%$ & $5.6 \%$ & $5.6 \%$ & $5.6 \%$ & $5.6 \%$ & $5.6 \%$ \\
\hline Internal administration & $-0.8 \%$ & $4.0 \%$ & $4.0 \%$ & $4.0 \%$ & $4.0 \%$ & $4.0 \%$ & $4.0 \%$ \\
\hline External administration & $-16.7 \%$ & $6.0 \%$ & $6.0 \%$ & $6.0 \%$ & $6.0 \%$ & $6.0 \%$ & $6.0 \%$ \\
\hline Other non market services & $2.9 \%$ & $7.0 \%$ & $7.0 \%$ & $7.0 \%$ & $7.0 \%$ & $7.0 \%$ & $7.0 \%$ \\
\hline & & & & & & & \\
\hline GDP at factor cost & $4.8 \%$ & $4.9 \%$ & $6.2 \%$ & $6.9 \%$ & $7.2 \%$ & $7.4 \%$ & $7.4 \%$ \\
\hline Import taxes and duties & $4.6 \%$ & $7.0 \%$ & $7.0 \%$ & $7.0 \%$ & $7.0 \%$ & $7.0 \%$ & $7.0 \%$ \\
\hline & & & & & & & \\
\hline GDP at market price & $4.8 \%$ & $4.9 \%$ & $6.3 \%$ & $6.9 \%$ & $7.2 \%$ & $7.4 \%$ & $7.4 \%$ \\
\hline Source: Review of the PRS and MDG figures & & & & & & & \\
\hline
\end{tabular}


4.1.b. Financial Operations of the Central Government:

(In billions of CFA Francs)

\begin{tabular}{|c|c|c|c|c|c|c|c|}
\hline \multirow[b]{2}{*}{ PAP/MDG scenario } & \multirow[b]{2}{*}{2006} & \multicolumn{6}{|c|}{ Projection } \\
\hline & & 2007 & 2008 & 2009 & 2010 & 2011 & 2012 \\
\hline Total revenue & 247.2 & 236.2 & 343.2 & 401.0 & 465.2 & 516.3 & 572.5 \\
\hline Tax revenue & 203.8 & 224.3 & 325.5 & 379.3 & 441.3 & 490.1 & 543.9 \\
\hline Taxes on external trade & 95.9 & 102.1 & 141.5 & 180.7 & 189.9 & 208.1 & 228.2 \\
\hline Taxes on goods and services & 56.5 & 60.7 & 103.1 & 104.3 & 134.3 & 139.4 & 143.8 \\
\hline Taxes on income and profit & 39.8 & 47.2 & 61.0 & 72.5 & 93.1 & 116.4 & 143.2 \\
\hline Other tax receipts & 11.6 & 14.3 & 19.9 & 21.8 & 23.9 & 26.2 & 28.6 \\
\hline Non tax revenue & 38.5 & 9.3 & 13.3 & 14.5 & 16.0 & 17.5 & 19.1 \\
\hline Annual fiscal revenue + special accts. & 4.9 & 2.6 & 4.4 & 7.3 & 8.0 & 8.7 & 9.5 \\
\hline Offsetting revenue (memorandum item) & 0.0 & 0.0 & 0.0 & 0.0 & 0.0 & 0.0 & 0.0 \\
\hline Total expenditure & 356.8 & 477.9 & 814.8 & 1145.0 & 1209.0 & 1179.3 & 1207.7 \\
\hline Overall current expenditure & 174.2 & 230.8 & 250.2 & 262.9 & 276.5 & 311.5 & 293.4 \\
\hline Current budgetary expenditure & 163.8 & 217.1 & 235.6 & 247.2 & 259.8 & 293.5 & 274.2 \\
\hline Wages and salaries & 68.0 & 73.3 & 82.7 & 85.5 & 86.4 & 88.8 & 92.2 \\
\hline Equipment and supplies & 47.4 & 63.0 & 64.3 & 91.0 & 95.1 & 101.7 & 95.2 \\
\hline Subsidies and transfers & 43.5 & 75.3 & 80.7 & 60.9 & 74.6 & 98.9 & 82.8 \\
\hline Interests due & 4.9 & 5.5 & 7.9 & 9.8 & 3.7 & 4.1 & 3.9 \\
\hline External debt & 3.7 & 3.8 & 3.9 & 4.8 & 3.1 & 3.6 & 3.5 \\
\hline Internal debt & 1.2 & 1.7 & 4.0 & 5.0 & 0.6 & 0.5 & 0.4 \\
\hline Annexed budgets/special accounts & 10.4 & 13.7 & 14.6 & 15.7 & 16.8 & 17.9 & 19.2 \\
\hline Capital expenditure and net loans & 182.6 & 247.1 & 564.5 & 882.2 & 935.1 & 897.5 & 914.4 \\
\hline Equipment & 182.6 & 247.1 & 564.5 & 882.2 & 935.1 & 897.5 & 914.4 \\
\hline From budgetary resources & 51.5 & 70.2 & 180.1 & 279.1 & 287.8 & 322.1 & 325.3 \\
\hline From external resources & 131.1 & 176.9 & 384.5 & 603.1 & 647.3 & 575.4 & 589.1 \\
\hline including: HIPC resources & 15.6 & 18.7 & 18.0 & 18.0 & 0.0 & 0.0 & 0.0 \\
\hline Net loans & 0.0 & 0.0 & 0.0 & 0.0 & 0.0 & 0.0 & 0.0 \\
\hline \multicolumn{8}{|l|}{ Adjustment } \\
\hline Overall balance (commitment base) & -109.6 & -241.7 & -471.6 & -744.0 & -743.8 & -663.0 & -635.2 \\
\hline Basic balance & -58.1 & -171.5 & -291.6 & -464.9 & -456.0 & -340.9 & -309.9 \\
\hline Variation in arrears (reduction -) & -14.0 & -15.8 & -15.0 & -15.0 & -15.0 & -15.0 & -15.0 \\
\hline Internal arrears & -14.0 & -15.8 & -15.0 & -15.0 & -15.0 & -15.0 & -15.0 \\
\hline \multirow[t]{2}{*}{ External arrears } & 0.0 & 0.0 & 0.0 & 0.0 & 0.0 & 0.0 & 0.0 \\
\hline & 7.5 & -80.6 & -102.2 & -155.9 & -111.5 & -102.6 & -61.1 \\
\hline Overall balance (cash base) & -123.6 & -257.5 & -486.6 & -759.0 & -758.8 & -678.0 & -650.2 \\
\hline Primary balance (commitment base) & -104.7 & -236.2 & -351.0 & -806.5 & -925.8 & -1003.9 & -933.9 \\
\hline Financing & 123.6 & 257.5 & 486.6 & 759.0 & 758.8 & 678.0 & 650.2 \\
\hline External financing & 215.3 & 250.1 & 251.7 & 490.1 & 563.9 & 615.2 & 540.3 \\
\hline Grants & 878.4 & 175.5 & 205.4 & 396.2 & 456.6 & 502.8 & 444.9 \\
\hline Budget support & 18.6 & 65.6 & 0.0 & 0.0 & 0.0 & 0.0 & 0.0 \\
\hline
\end{tabular}




\begin{tabular}{|c|c|c|c|c|c|c|c|}
\hline Grants for projects & 75.5 & 109.9 & 205.4 & 396.2 & 456.6 & 502.8 & 444.9 \\
\hline HIPC assistance & 784.3 & 0.0 & 0.0 & 0.0 & 0.0 & 0.0 & 0.0 \\
\hline Loans & 59.8 & 76.0 & 51.3 & 99.1 & 114.2 & 125.7 & 111.2 \\
\hline Budget & 19.8 & 27.4 & 0.0 & 0.0 & 0.0 & 0.0 & 0.0 \\
\hline Projects & 40.0 & 48.6 & 51.3 & 99.1 & 114.2 & 125.7 & 111.2 \\
\hline Amortization due & -726.0 & -4.8 & -5.0 & -5.2 & -6.9 & -13.2 & -15.7 \\
\hline Debt alleviation & 0.0 & 0.0 & 0.0 & 0.0 & 0.0 & 0.0 & 0.0 \\
\hline Current debt service & 0.0 & 0.0 & 0.0 & 0.0 & 0.0 & 0.0 & 0.0 \\
\hline Arrears & 0.0 & 0.0 & 0.0 & 0.0 & 0.0 & 0.0 & 0.0 \\
\hline HIPC assistance & 0.0 & 0.0 & 0.0 & 0.0 & 0.0 & 0.0 & 0.0 \\
\hline Debt under discussion & 3.1 & 3.4 & 0.0 & 0.0 & 0.0 & 0.0 & 0.0 \\
\hline Domestic financing & -91.2 & 7.4 & -3.5 & -2.3 & -3.0 & -3.0 & -3.1 \\
\hline Banking sector & -82.8 & 7.4 & -3.5 & -2.3 & -3.0 & -3.0 & -3.1 \\
\hline Non banking sector & -8.4 & 0.0 & 0.0 & 0.0 & 0.0 & 0.0 & 0.0 \\
\hline Privatization, net income & 0.0 & 0.0 & 0.0 & 0.0 & 0.0 & 0.0 & 0.0 \\
\hline Overall balance & 0.5 & 0.0 & 0.0 & 0.0 & 0.0 & 0.0 & 0.0 \\
\hline Exceptional requirements & -0.5 & 88.3 & 125.7 & 343.5 & 383.6 & 410.9 & 415.6 \\
\hline Total foreign borrowings & 59.3 & 136.9 & 177.0 & 442.6 & 497.7 & 536.6 & 526.9 \\
\hline
\end{tabular}

Source: CCE/DGE/ME/F 


\section{1.c. SUMMARY OF KEY INDICATORS}

\begin{tabular}{|c|c|c|c|c|c|c|c|}
\hline \multirow{2}{*}{$\begin{array}{l}\text { PAP/MDG } \\
\text { Years }\end{array}$} & \multicolumn{7}{|c|}{ Projection } \\
\hline & 2006 & 2007 & 2008 & 2009 & 2010 & 2011 & 2012 \\
\hline \multicolumn{8}{|l|}{ Gross domestic product \& prices } \\
\hline Nominal GDP (in billions of CFA) & 1850 & 2047 & 2217 & 2418 & 2661 & 2911 & 3183 \\
\hline Per capita GDP (annual growth) & $1.5 \%$ & $1.6 \%$ & $3.0 \%$ & $3.6 \%$ & $3.9 \%$ & $4.1 \%$ & $4.1 \%$ \\
\hline \multicolumn{8}{|l|}{ (Growth rate) } \\
\hline Per capita GDP & $1.5 \%$ & $1.6 \%$ & $3.0 \%$ & $3.6 \%$ & $3.9 \%$ & $4.1 \%$ & $4.1 \%$ \\
\hline Consumption per capita & $2.3 \%$ & $1.8 \%$ & $0.8 \%$ & $1.9 \%$ & $2.9 \%$ & $2.5 \%$ & $4.0 \%$ \\
\hline GDP at constant prices & $4.8 \%$ & $4.9 \%$ & $6.3 \%$ & $6.9 \%$ & $7.2 \%$ & $7.4 \%$ & $7.4 \%$ \\
\hline Informal sector & $5.9 \%$ & $4.3 \%$ & $6.0 \%$ & $6.3 \%$ & $6.9 \%$ & $7.3 \%$ & $7.5 \%$ \\
\hline including Agriculture & $3.0 \%$ & $5.0 \%$ & $8.0 \%$ & $8.2 \%$ & $8.7 \%$ & $9.2 \%$ & $9.5 \%$ \\
\hline Modern sector & $7.4 \%$ & $8.0 \%$ & $8.2 \%$ & $10.9 \%$ & $9.8 \%$ & $9.5 \%$ & $8.2 \%$ \\
\hline \multicolumn{8}{|l|}{ Prices } \\
\hline GDP deflator & $0.6 \%$ & $5.4 \%$ & $1.9 \%$ & $2.0 \%$ & $2.6 \%$ & $1.9 \%$ & $1.8 \%$ \\
\hline Consumer prices & $3.0 \%$ & $3.0 \%$ & $2.0 \%$ & $2.0 \%$ & $2.0 \%$ & $2.0 \%$ & $2.0 \%$ \\
\hline \multicolumn{8}{|l|}{ As percentage of GDP } \\
\hline & & & & & & & \\
\hline Consumption & $89.6 \%$ & $98.3 \%$ & $95.6 \%$ & $93.8 \%$ & $92.0 \%$ & $91.2 \%$ & $91.5 \%$ \\
\hline Private & $80.6 \%$ & $79.0 \%$ & $77.5 \%$ & $79.0 \%$ & $77.5 \%$ & $76.9 \%$ & $77.4 \%$ \\
\hline Public & $15.0 \%$ & $14.8 \%$ & $14.5 \%$ & $14.8 \%$ & $14.5 \%$ & $14.3 \%$ & $14.1 \%$ \\
\hline Investment & $21.8 \%$ & $19.5 \%$ & $20.8 \%$ & $24.5 \%$ & $24.3 \%$ & $24.4 \%$ & $23.3 \%$ \\
\hline Gross fixed capital formation & $20.3 \%$ & $19.5 \%$ & $20.8 \%$ & $24.5 \%$ & $24.3 \%$ & $24.4 \%$ & $23.3 \%$ \\
\hline Private & $14.5 \%$ & $13.4 \%$ & $13.6 \%$ & $13.9 \%$ & $14.1 \%$ & $14.4 \%$ & $14.7 \%$ \\
\hline Public & $5.8 \%$ & $6.1 \%$ & $7.2 \%$ & $10.6 \%$ & $10.2 \%$ & $10.0 \%$ & $8.6 \%$ \\
\hline GDP at market price & $100.0 \%$ & $100.0 \%$ & $100.0 \%$ & $100.0 \%$ & $100.0 \%$ & $100.0 \%$ & $100.0 \%$ \\
\hline \multicolumn{8}{|l|}{ Public finance } \\
\hline & & & & & & & \\
\hline Total revenue & $13.4 \%$ & $11.5 \%$ & $13.8 \%$ & $16.3 \%$ & $16.9 \%$ & $17.9 \%$ & $19.0 \%$ \\
\hline Tax revenue & $11.0 \%$ & $11.0 \%$ & $13.0 \%$ & $15.4 \%$ & $16.0 \%$ & $17.0 \%$ & $18.1 \%$ \\
\hline Total expenditure & $19.3 \%$ & $23.4 \%$ & $30.0 \%$ & $50.0 \%$ & $51.9 \%$ & $52.6 \%$ & $48.4 \%$ \\
\hline Current expenditure & $9.4 \%$ & $11.3 \%$ & $14.6 \%$ & $24.0 \%$ & $26.6 \%$ & $27.2 \%$ & $27.3 \%$ \\
\hline Capital expenditure & $9.9 \%$ & $12.1 \%$ & $15.4 \%$ & $26.0 \%$ & $25.3 \%$ & $25.4 \%$ & $21.1 \%$ \\
\hline Overall balance (commitment base) & $-5.9 \%$ & $-11.8 \%$ & $-16.2 \%$ & $-33.8 \%$ & $-34.9 \%$ & $-34.6 \%$ & $-29.5 \%$ \\
\hline Basic overall balance & $1.2 \%$ & $-3.2 \%$ & $-4.6 \%$ & $-13.3 \%$ & $-34.9 \%$ & $-34.6 \%$ & $-29.5 \%$ \\
\hline Primary balance (commitments) & $-5.7 \%$ & $-11.5 \%$ & $-15.8 \%$ & $-34.4 \%$ & $-35.5 \%$ & $-35.1 \%$ & $-29.9 \%$ \\
\hline Overall balance (cash base) & $-6.7 \%$ & $-12.6 \%$ & $-16.9 \%$ & $-34.4 \%$ & $-35.5 \%$ & $-35.1 \%$ & $-29.9 \%$ \\
\hline \multicolumn{8}{|l|}{ WAEMU convergence criteria } \\
\hline \multicolumn{8}{|l|}{$(\ln \%)$} \\
\hline Basic balance over GDP & $1.2 \%$ & $-3.2 \%$ & $-4.6 \%$ & $-13.3 \%$ & $-34.9 \%$ & $-34.6 \%$ & $-29.5 \%$ \\
\hline Tax ratio & $11.0 \%$ & $11.0 \%$ & $13.0 \%$ & $15.4 \%$ & $16.0 \%$ & $17.0 \%$ & $18.1 \%$ \\
\hline Wage bill/tax revenue & $33.4 \%$ & $32.7 \%$ & $46.8 \%$ & $46.8 \%$ & $74.0 \%$ & $81.1 \%$ & $78.4 \%$ \\
\hline $\begin{array}{l}\text { Capital expenditure from own } \\
\text { resources/tax revenue }\end{array}$ & $25.3 \%$ & $31.3 \%$ & $29.4 \%$ & $29.4 \%$ & $35.9 \%$ & $23.7 \%$ & $22.2 \%$ \\
\hline
\end{tabular}




\section{2.a. SECTORAL CONTRIBUTION TO GROWTH: RESOURCES}

(At constant prices, annual growth)

\begin{tabular}{|l|r|r|r|r|r|r|r|}
\hline Intermediate scenario & & \multicolumn{5}{|c|}{ Projection } \\
\hline Years & 2006 & 2007 & 2008 & 2009 & 2010 & 2011 & 2012 \\
\hline INFORMAL SECTOR & $5.9 \%$ & $5.3 \%$ & $5.3 \%$ & $5.6 \%$ & $5.8 \%$ & $5.9 \%$ & $6.1 \%$ \\
\hline Agriculture & $11.7 \%$ & $6.8 \%$ & $6.7 \%$ & $6.8 \%$ & $6.9 \%$ & $7.2 \%$ & $7.4 \%$ \\
\hline Livestock & $3.0 \%$ & $3.4 \%$ & $3.6 \%$ & $4.8 \%$ & $4.8 \%$ & $4.8 \%$ & $4.8 \%$ \\
\hline Forests and fisheries & $2.7 \%$ & $3.5 \%$ & $3.7 \%$ & $4.0 \%$ & $4.2 \%$ & $4.4 \%$ & $4.6 \%$ \\
\hline Other sectors & $2.6 \%$ & $5.1 \%$ & $5.0 \%$ & $5.0 \%$ & $5.3 \%$ & $5.4 \%$ & $5.6 \%$ \\
\hline Extractive industries & $-4.2 \%$ & $3.5 \%$ & $3.5 \%$ & $3.5 \%$ & $5.0 \%$ & $5.0 \%$ & $5.0 \%$ \\
\hline Manufacturing industries & $2.9 \%$ & $4.2 \%$ & $4.2 \%$ & $4.2 \%$ & $5.0 \%$ & $5.0 \%$ & $5.0 \%$ \\
\hline Construction & $3.5 \%$ & $5.2 \%$ & $5.1 \%$ & $5.1 \%$ & $5.3 \%$ & $5.5 \%$ & $5.7 \%$ \\
\hline Trade, hotel industry & $3.5 \%$ & $5.3 \%$ & $5.2 \%$ & $5.2 \%$ & $5.3 \%$ & $5.5 \%$ & $5.6 \%$ \\
\hline Transport and communication & $-1.9 \%$ & $4.9 \%$ & $5.0 \%$ & $5.1 \%$ & $5.4 \%$ & $5.6 \%$ & $5.8 \%$ \\
\hline Other services (real estate and service/business activities) & $3.6 \%$ & $5.4 \%$ & $5.1 \%$ & $5.0 \%$ & $5.3 \%$ & $5.5 \%$ & $5.6 \%$ \\
\hline & & & & & & & \\
\hline & & & & & & & \\
\hline MODERN SECTOR & $7.5 \%$ & $6.4 \%$ & $6.9 \%$ & $7.4 \%$ & $7.1 \%$ & $7.7 \%$ & $8.0 \%$ \\
\hline & & & & & & & \\
\hline Mining & $5.0 \%$ & $6.0 \%$ & $7.0 \%$ & $7.5 \%$ & $8.0 \%$ & $8.5 \%$ & $9.0 \%$ \\
\hline Manufacturing industries & $-1.1 \%$ & $7.2 \%$ & $6.4 \%$ & $6.3 \%$ & $6.4 \%$ & $6.5 \%$ & $6.7 \%$ \\
\hline Water and electricity & $8.4 \%$ & $3.4 \%$ & $3.4 \%$ & $8.0 \%$ & $8.0 \%$ & $8.0 \%$ & $8.0 \%$ \\
\hline Construction and public works & $5.8 \%$ & $9.0 \%$ & $10.3 \%$ & $8.3 \%$ & $6.6 \%$ & $5.6 \%$ & $5.4 \%$ \\
\hline Trade and hotel industry & $4.1 \%$ & $5.8 \%$ & $6.0 \%$ & $6.2 \%$ & $6.4 \%$ & $6.5 \%$ & $6.7 \%$ \\
\hline Transport & $9.0 \%$ & $7.9 \%$ & $8.2 \%$ & $8.5 \%$ & $8.8 \%$ & $9.0 \%$ & $9.2 \%$ \\
\hline Other services & $6.2 \%$ & $6.3 \%$ & $6.4 \%$ & $6.6 \%$ & $6.8 \%$ & $7.0 \%$ & $7.1 \%$ \\
\hline & & & & & & & \\
\hline NON MARKET GDP & $-4.2 \%$ & $2.0 \%$ & $2.0 \%$ & $2.1 \%$ & $3.3 \%$ & $3.3 \%$ & $3.3 \%$ \\
\hline Internal administration & $-0.8 \%$ & $3.0 \%$ & $3.0 \%$ & $3.0 \%$ & $3.0 \%$ & $3.0 \%$ & $3.0 \%$ \\
\hline External administration & $-16.7 \%$ & $2.0 \%$ & $2.0 \%$ & $2.0 \%$ & $4.0 \%$ & $4.0 \%$ & $4.0 \%$ \\
\hline Other non market services & $2.9 \%$ & $0.8 \%$ & $0.9 \%$ & $1.0 \%$ & $3.0 \%$ & $3.0 \%$ & $3.0 \%$ \\
\hline & & & & & & & \\
\hline GDP at factor cost & $4.8 \%$ & $5.1 \%$ & $5.2 \%$ & $5.4 \%$ & $5.7 \%$ & $5.9 \%$ & $6.1 \%$ \\
\hline Import taxes and duties & $4.6 \%$ & $7.0 \%$ & $7.0 \%$ & $7.0 \%$ & $7.0 \%$ & $7.0 \%$ & $7.0 \%$ \\
\hline & & & & & & & \\
\hline GDP at market price & $4.8 \%$ & $5.1 \%$ & $5.3 \%$ & $5.6 \%$ & $5.7 \%$ & $5.9 \%$ & $6.1 \%$ \\
\hline
\end{tabular}

Source: MEF, DGE, PRS review 


\section{2. b. Financial Operations of the Central Government}

(In billions of CFA Francs)

\begin{tabular}{|c|c|c|c|c|c|c|c|}
\hline \multirow{2}{*}{$\begin{array}{ll} & \text { Intermediate scenario } \\
\text { Years } & \end{array}$} & \multicolumn{7}{|c|}{ Projection } \\
\hline & 2006 & 2007 & 2008 & 2009 & 2010 & 2011 & 2012 \\
\hline Total revenue & 247.2 & 236.2 & 288.1 & 343.3 & 405.0 & 475.9 & 549.0 \\
\hline Tax revenue & 203.8 & 224.3 & 268.3 & 316.1 & 369.0 & 423.3 & 492.2 \\
\hline Taxes on external trade & 95.9 & 102.1 & 116.5 & 129.2 & 139.4 & 150.7 & 163.1 \\
\hline Taxes on goods and services & 56.5 & 60.7 & 77.0 & 92.2 & 111.6 & 126.0 & 149.6 \\
\hline Taxes on income and profit & 39.8 & 47.2 & 55.0 & 70.9 & 89.8 & 105.2 & 119.7 \\
\hline Other tax receipts & 11.6 & 14.3 & 19.8 & 23.6 & 28.2 & 41.5 & 59.8 \\
\hline Non tax revenue & 38.5 & 9.3 & 13.2 & 18.9 & 25.7 & 41.5 & 44.9 \\
\hline Annual fiscal revenue + special accounts & 4.9 & 2.6 & 6.6 & 8.3 & 10.3 & 11.1 & 12.0 \\
\hline Offsetting revenue (memorandum item) & 0.0 & 0.0 & 0.0 & 0.0 & 0.0 & 0.0 & 0.0 \\
\hline Total expenditure & 356.8 & 477.9 & 572.4 & 646.8 & 670.0 & 703.0 & 737.2 \\
\hline Overall current expenditure & 174.2 & 230.8 & 278.4 & 321.3 & 335.7 & 354.9 & 371.8 \\
\hline Current budgetary expenditure & 163.8 & 217.1 & 264.3 & 306.8 & 320.8 & 339.6 & 356.1 \\
\hline Wages and salaries & 68.0 & 73.3 & 90.3 & 96.3 & 101.0 & 105.6 & 110.7 \\
\hline Equipment and supplies & 47.4 & 63.0 & 86.4 & 116.5 & 122.5 & 128.2 & 133.6 \\
\hline Subsidies and transfers & 43.5 & 75.3 & 79.7 & 84.2 & 89.1 & 94.1 & 99.5 \\
\hline Interests due & 4.9 & 5.5 & 7.9 & 9.8 & 8.3 & 11.6 & 12.3 \\
\hline External debt & 3.7 & 3.8 & 3.9 & 4.8 & 3.1 & 3.6 & 3.5 \\
\hline Internal debt & 1.2 & 1.7 & 4.0 & 5.0 & 0.6 & 0.5 & 0.4 \\
\hline Annexed budgets/special accounts & 10.4 & 13.7 & 14.1 & 14.4 & 14.9 & 15.3 & 15.7 \\
\hline Capital expenditure and net loans & 182.6 & 247.1 & 281.9 & 304.8 & 322.3 & 337.5 & 353.4 \\
\hline Equipment & 182.6 & 247.1 & 281.9 & 304.8 & 322.3 & 337.5 & 353.4 \\
\hline From budgetary resources & 51.5 & 70.2 & 76.2 & 85.0 & 77.0 & 79.8 & 82.7 \\
\hline From external resources & 131.1 & 176.9 & 205.6 & 219.8 & 245.3 & 257.7 & 270.7 \\
\hline & & & & & & & \\
\hline including: HIPC resources & 15.6 & 18.7 & 0.0 & 0.0 & 0.0 & 0.0 & 0.0 \\
\hline Net loans & 0.0 & 0.0 & 0.0 & 0.0 & 0.0 & 0.0 & 0.0 \\
\hline Adjustment & & & & & & 0.0 & 0.0 \\
\hline Overall balance (commitment base) & -109.6 & -241.7 & -284.3 & -303.5 & -265.1 & -227.1 & -188.2 \\
\hline Basic balance & 21.5 & -64.8 & -78.6 & -83.7 & -19.8 & 30.6 & 82.5 \\
\hline Variation in arrears (reduction -) & -14.0 & -15.8 & -15.0 & -15.0 & -15.0 & -15.0 & -15.0 \\
\hline Internal arrears & -14.0 & -15.8 & -15.0 & -15.0 & -15.0 & -15.0 & -15.0 \\
\hline External arrears & 0.0 & 0.0 & 0.0 & 0.0 & 0.0 & 0.0 & 0.0 \\
\hline Overall balance (cash base) & -123.6 & -257.5 & -299.3 & -318.5 & -280.1 & -242.1 & -203.2 \\
\hline Primary balance (commitment base) & 7.5 & -80.6 & -93.6 & -98.7 & -34.8 & 15.6 & 67.5 \\
\hline Financing & -123.6 & -257.5 & -299.3 & -318.5 & -280.1 & -242.1 & -203.2 \\
\hline External financing & 215.3 & 250.1 & 200.6 & 214.6 & 238.4 & 244.5 & 255.0 \\
\hline Grants & 878.4 & 175.5 & 154.2 & 164.8 & 184.0 & 193.3 & 203.0 \\
\hline Budget support & 18.6 & 65.6 & 0.0 & 0.0 & 0.0 & 0.0 & 0.0 \\
\hline Grants for projects & 75.5 & 109.9 & 154.2 & 164.8 & 184.0 & 193.3 & 203.0 \\
\hline HIPC assistance & 784.3 & 0.0 & 0.0 & 0.0 & 0.0 & 0.0 & 0.0 \\
\hline Loans & 59.8 & 76.0 & 51.4 & 54.9 & 61.3 & 64.4 & 67.7 \\
\hline Budget support & 19.8 & 27.4 & 0.0 & 0.0 & 0.0 & 0.0 & 0.0 \\
\hline
\end{tabular}




\begin{tabular}{|l|r|r|r|r|r|r|r|}
\hline Grants for projects & 40.0 & 48.6 & 51.4 & 54.9 & 61.3 & 64.4 & 67.7 \\
\hline Amortization due & -726.0 & -4.8 & -5.0 & -5.2 & -6.9 & -13.2 & -15.7 \\
\hline Debt alleviation & 0.0 & 0.0 & 0.0 & 0.0 & 0.0 & 0.0 & 0.0 \\
\hline Current debt service & 0.0 & 0.0 & 0.0 & 0.0 & 0.0 & 0.0 & 0.0 \\
\hline Arrears & 0.0 & 0.0 & 0.0 & 0.0 & 0.0 & 0.0 & 0.0 \\
\hline HIPC assistance & 0.0 & 0.0 & 0.0 & 0.0 & 0.0 & 0.0 & 0.0 \\
\hline Debt under discussion & 3.1 & 3.4 & 0.0 & 0.0 & 0.0 & 0.0 & 0.0 \\
\hline Internal financing & -91.2 & 7.4 & -3.5 & -2.3 & 3.1 & 3.1 & 3.1 \\
\hline Banking sector & -82.8 & 7.4 & -3.5 & -2.3 & -3.0 & -3.0 & -3.1 \\
\hline Non bank sector & -8.4 & 0.0 & 0.0 & 0.0 & 0.0 & 0.0 & 0.0 \\
\hline Privatization, net income & 0.0 & 0.0 & 0.0 & 0.0 & 0.0 & 0.0 & 0.0 \\
\hline 2 & & & & & & & \\
\hline Overall balance & 0.5 & 0.0 & -90.0 & -85.5 & -26.5 & 16.2 & 66.9 \\
\hline Exceptional requirements & -0.5 & 88.3 & 90.0 & 85.5 & 26.5 & -16.2 & -66.9 \\
\hline Total foreign borrowings & 59.3 & 136.9 & 141.4 & 140.4 & 87.8 & 48.2 & 0.8 \\
\hline
\end{tabular}

Source: CCE/DGE/ME/F 


\section{2.c. SUMMARY OF KEY INDICATORS}

\begin{tabular}{|c|c|c|c|c|c|c|c|}
\hline \multirow[b]{2}{*}{ Intermediate scenario } & \multicolumn{7}{|c|}{ Projection } \\
\hline & 2006 & 2007 & 2008 & 2009 & 2010 & 2011 & 2012 \\
\hline \multicolumn{8}{|l|}{ Gross domestic product \& prices } \\
\hline Nominal GDP (in billions of CFA) & 1850.0 & 2051.0 & 2199.7 & 2364.9 & 2565.5 & 2768.2 & 2991.3 \\
\hline Per capita GDP (annual growth) & $1.5 \%$ & $1.8 \%$ & $2.0 \%$ & $2.5 \%$ & $2.6 \%$ & $2.8 \%$ & $3.0 \%$ \\
\hline \multicolumn{8}{|l|}{ (Growth rate) } \\
\hline Per capita GDP & $1.5 \%$ & $1.8 \%$ & $2.0 \%$ & $2.5 \%$ & $2.6 \%$ & $2.8 \%$ & $3.0 \%$ \\
\hline Consumption per capita & $2.3 \%$ & $2.6 \%$ & $1.5 \%$ & $2.5 \%$ & $2.8 \%$ & $1.6 \%$ & $1.6 \%$ \\
\hline GDP at constant prices & $4.8 \%$ & $5.1 \%$ & $5.3 \%$ & $5.6 \%$ & $5.7 \%$ & $5.9 \%$ & $6.1 \%$ \\
\hline Informal sector & $5.9 \%$ & $5.3 \%$ & $5.3 \%$ & $5.6 \%$ & $5.8 \%$ & $5.9 \%$ & $6.1 \%$ \\
\hline including Agriculture & $11.7 \%$ & $6.8 \%$ & $6.7 \%$ & $6.8 \%$ & $6.9 \%$ & $7.2 \%$ & $7.4 \%$ \\
\hline Modern sector & $7.5 \%$ & $6.4 \%$ & $6.9 \%$ & $7.4 \%$ & $7.1 \%$ & $7.7 \%$ & $8.0 \%$ \\
\hline \multicolumn{8}{|l|}{ Prices } \\
\hline GDP deflator & $0.6 \%$ & $5.5 \%$ & $1.8 \%$ & $1.8 \%$ & $2.6 \%$ & $1.9 \%$ & $1.9 \%$ \\
\hline Consumer prices & $3.0 \%$ & $3.0 \%$ & $2.0 \%$ & $2.0 \%$ & $2.0 \%$ & $2.0 \%$ & $2.0 \%$ \\
\hline \multicolumn{8}{|l|}{ As percentage of GDP } \\
\hline Consumption & $89.6 \%$ & $98.2 \%$ & $96.5 \%$ & $95.8 \%$ & $95.2 \%$ & $94.5 \%$ & $93.7 \%$ \\
\hline Private & $82.4 \%$ & $82.1 \%$ & $81.9 \%$ & $82.1 \%$ & $81.9 \%$ & $81.5 \%$ & $81.1 \%$ \\
\hline Public & $14.1 \%$ & $13.7 \%$ & $13.3 \%$ & $13.7 \%$ & $13.3 \%$ & $13.0 \%$ & $12.6 \%$ \\
\hline Investment & $21.8 \%$ & $19.5 \%$ & $19.9 \%$ & $20.0 \%$ & $20.0 \%$ & $20.0 \%$ & $20.0 \%$ \\
\hline Gross fixed capital formation & $20.3 \%$ & $19.5 \%$ & $19.9 \%$ & $20.0 \%$ & $20.0 \%$ & $20.0 \%$ & $20.0 \%$ \\
\hline Private & $14.5 \%$ & $13.3 \%$ & $13.6 \%$ & $13.8 \%$ & $13.9 \%$ & $14.2 \%$ & $14.5 \%$ \\
\hline Public & $5.8 \%$ & $6.1 \%$ & $6.3 \%$ & $6.2 \%$ & $6.0 \%$ & $5.8 \%$ & $5.6 \%$ \\
\hline GDP at market price & $100.0 \%$ & $100.0 \%$ & $100.0 \%$ & $100.0 \%$ & $100.0 \%$ & $100.0 \%$ & $100.0 \%$ \\
\hline \multicolumn{8}{|l|}{ Public finance } \\
\hline & & & & & & & \\
\hline Total revenue & $13.4 \%$ & $11.5 \%$ & $13.1 \%$ & $14.5 \%$ & $15.8 \%$ & $17.2 \%$ & $18.4 \%$ \\
\hline Tax revenue & $11.0 \%$ & $10.9 \%$ & $12.2 \%$ & $13.4 \%$ & $14.4 \%$ & $15.3 \%$ & $16.5 \%$ \\
\hline Total expenditure & $19.3 \%$ & $23.3 \%$ & $25.5 \%$ & $26.5 \%$ & $25.6 \%$ & $25.0 \%$ & $24.2 \%$ \\
\hline Current expenditure & $9.4 \%$ & $11.3 \%$ & $12.7 \%$ & $13.6 \%$ & $13.1 \%$ & $12.8 \%$ & $12.4 \%$ \\
\hline Capital expenditure & $9.9 \%$ & $12.0 \%$ & $12.8 \%$ & $12.9 \%$ & $12.6 \%$ & $12.2 \%$ & $11.8 \%$ \\
\hline Overall balance (commitment base) & $-5.9 \%$ & $-11.8 \%$ & $-12.4 \%$ & $-12.0 \%$ & $-9.9 \%$ & $-7.8 \%$ & $-5.9 \%$ \\
\hline Basic overall balance & $1.2 \%$ & $-3.2 \%$ & $-3.0 \%$ & $-2.7 \%$ & $-0.3 \%$ & $1.5 \%$ & $3.2 \%$ \\
\hline Primary balance (commitments) & $-5.7 \%$ & $-11.5 \%$ & $-12.0 \%$ & $-12.6 \%$ & $-10.4 \%$ & $-8.4 \%$ & $-6.4 \%$ \\
\hline Overall balance (cash base) & $-6.7 \%$ & $-12.6 \%$ & $-13.1 \%$ & $-12.6 \%$ & $-10.4 \%$ & $-8.4 \%$ & $-6.4 \%$ \\
\hline \multicolumn{8}{|l|}{ WAEMU convergence criteria } \\
\hline \multicolumn{8}{|l|}{$(\ln \%)$} \\
\hline Basic balance over GDP & $1.2 \%$ & $-3.2 \%$ & $-3.0 \%$ & $-2.7 \%$ & $-0.3 \%$ & $1.5 \%$ & $3.2 \%$ \\
\hline Tax ratio & $11.0 \%$ & $10.9 \%$ & $12.2 \%$ & $13.4 \%$ & $14.4 \%$ & $15.3 \%$ & $16.5 \%$ \\
\hline Wage bill/tax revenue & $33.4 \%$ & $32.7 \%$ & $33.7 \%$ & $33.7 \%$ & $30.5 \%$ & $27.4 \%$ & $25.0 \%$ \\
\hline Capital expenditure on own resources/tax revenue & $25.3 \%$ & $31.3 \%$ & $28.4 \%$ & $28.4 \%$ & $26.9 \%$ & $20.9 \%$ & $18.8 \%$ \\
\hline
\end{tabular}

Source: CCE/DGE/ME/F 


\section{3. a. SECTORAL CONTRIBUTION TO GROWTH: RESOURCES}

(At constant prices, annual growth)

\begin{tabular}{|c|c|c|c|c|c|c|c|}
\hline \multirow{2}{*}{$\begin{array}{l}\text { Reference scenario } \\
\text { Years }\end{array}$} & \multirow[b]{2}{*}{2006} & \multicolumn{6}{|c|}{ Projection } \\
\hline & & 2007 & 2008 & 2009 & 2010 & 2011 & 2012 \\
\hline INFORMAL SECTOR & $5.9 \%$ & $3.7 \%$ & $3.5 \%$ & $3.6 \%$ & $3.8 \%$ & $3.9 \%$ & $4.0 \%$ \\
\hline Agriculture & $11.7 \%$ & $4.0 \%$ & $3.7 \%$ & $3.8 \%$ & $4.1 \%$ & $4.2 \%$ & $4.3 \%$ \\
\hline Livestock & $3.0 \%$ & $3.0 \%$ & $3.3 \%$ & $3.7 \%$ & $3.7 \%$ & $3.7 \%$ & $3.7 \%$ \\
\hline Forests and fisheries & $2.7 \%$ & $3.0 \%$ & $3.2 \%$ & $3.5 \%$ & $3.7 \%$ & $3.8 \%$ & $4.0 \%$ \\
\hline Other sectors & $2.6 \%$ & $3.9 \%$ & $3.4 \%$ & $3.3 \%$ & $3.6 \%$ & $3.7 \%$ & $3.7 \%$ \\
\hline Extractive industries & $-4.2 \%$ & $3.5 \%$ & $3.5 \%$ & $3.5 \%$ & $5.0 \%$ & $5.0 \%$ & $5.0 \%$ \\
\hline Manufacturing industries & $2.9 \%$ & $4.2 \%$ & $4.2 \%$ & $4.2 \%$ & $5.0 \%$ & $5.0 \%$ & $5.0 \%$ \\
\hline Construction & $3.5 \%$ & $3.9 \%$ & $3.3 \%$ & $3.2 \%$ & $3.4 \%$ & $3.5 \%$ & $3.5 \%$ \\
\hline Trade, hotel industry & $3.5 \%$ & $3.7 \%$ & $3.1 \%$ & $3.0 \%$ & $3.2 \%$ & $3.2 \%$ & $3.3 \%$ \\
\hline Transport and communication & $-1.9 \%$ & $3.5 \%$ & $3.1 \%$ & $3.1 \%$ & $3.4 \%$ & $3.5 \%$ & $3.6 \%$ \\
\hline Other services (real estate and service/business activities) & $3.6 \%$ & $4.3 \%$ & $3.6 \%$ & $3.4 \%$ & $3.5 \%$ & $3.6 \%$ & $3.7 \%$ \\
\hline MODERN SECTOR & $7.4 \%$ & $8.2 \%$ & $7.4 \%$ & $6.7 \%$ & $6.7 \%$ & $6.7 \%$ & $6.8 \%$ \\
\hline Mining & $7.6 \%$ & $5.8 \%$ & $6.0 \%$ & $6.2 \%$ & $6.4 \%$ & $6.7 \%$ & $7.0 \%$ \\
\hline Manufacturing industries & $-1.1 \%$ & $6.6 \%$ & $5.0 \%$ & $4.7 \%$ & $4.6 \%$ & $4.6 \%$ & $4.6 \%$ \\
\hline Water and electricity & $8.4 \%$ & $9.0 \%$ & $9.0 \%$ & $9.0 \%$ & $9.0 \%$ & $9.0 \%$ & $9.0 \%$ \\
\hline Construction and public works & $5.8 \%$ & $21.0 \%$ & $14.3 \%$ & $5.0 \%$ & $5.0 \%$ & $5.0 \%$ & $5.0 \%$ \\
\hline Trade and hotel industry & $4.1 \%$ & $5.3 \%$ & $4.6 \%$ & $4.6 \%$ & $4.6 \%$ & $4.6 \%$ & $4.6 \%$ \\
\hline Transport & $9.0 \%$ & $7.3 \%$ & $6.7 \%$ & $6.6 \%$ & $6.5 \%$ & $6.5 \%$ & $6.5 \%$ \\
\hline Other services & $6.2 \%$ & $5.6 \%$ & $4.9 \%$ & $4.9 \%$ & $4.8 \%$ & $4.8 \%$ & $4.9 \%$ \\
\hline NON MARKET GDP & $-4.2 \%$ & $2.6 \%$ & $2.7 \%$ & $2.8 \%$ & $3.3 \%$ & $3.3 \%$ & $3.3 \%$ \\
\hline Internal administration & $-0.8 \%$ & $1.6 \%$ & $1.6 \%$ & $1.8 \%$ & $1.8 \%$ & $1.8 \%$ & $1.8 \%$ \\
\hline External administration & $-16.7 \%$ & $2.0 \%$ & $2.0 \%$ & $2.0 \%$ & $4.0 \%$ & $4.0 \%$ & $4.0 \%$ \\
\hline Other non market services & $2.9 \%$ & $4.3 \%$ & $4.3 \%$ & $4.3 \%$ & $4.3 \%$ & $4.3 \%$ & $4.3 \%$ \\
\hline GDP at factor cost & $4.8 \%$ & $4.2 \%$ & $3.9 \%$ & $3.9 \%$ & $4.2 \%$ & $4.2 \%$ & $4.3 \%$ \\
\hline Import taxes and duties & $4.6 \%$ & $4.0 \%$ & $4.0 \%$ & $6.0 \%$ & $6.0 \%$ & $6.0 \%$ & $6.0 \%$ \\
\hline GDP at market price & $4.8 \%$ & $4.0 \%$ & $4.1 \%$ & $4.1 \%$ & $4.2 \%$ & $4.2 \%$ & $4.3 \%$ \\
\hline
\end{tabular}

Source: MEF, DGE, review of PRS frameworks 


\section{3. b. Financial Operations of the Central Government}

( In billions of CFA Francs)

\begin{tabular}{|c|c|c|c|c|c|c|c|}
\hline \multirow[b]{2}{*}{ Reference scenario } & \multirow[b]{2}{*}{2006} & \multicolumn{6}{|c|}{ Projection } \\
\hline & & 2007 & 2008 & 2009 & 2010 & 2011 & 2012 \\
\hline Total revenue & 247.2 & 236.2 & 263.1 & 299.7 & 332.5 & 363.7 & 403.3 \\
\hline Tax revenue & 203.8 & 224.3 & 255.1 & 283.9 & 311.8 & 341.7 & 380.0 \\
\hline Taxes on external trade & 95.9 & 102.1 & 112.9 & 127.6 & 143.8 & 153.0 & 163.0 \\
\hline Taxes on goods and services & 56.5 & 60.7 & 68.2 & 79.8 & 90.1 & 103.4 & 123.6 \\
\hline Taxes on income and profit & 39.8 & 47.2 & 53.4 & 57.0 & 60.9 & 67.2 & 74.2 \\
\hline Other tax receipts & 11.6 & 14.3 & 11.4 & 16.0 & 17.0 & 18.1 & 19.2 \\
\hline Non tax revenue & 38.5 & 9.3 & 10.3 & 14.4 & 14.6 & 15.5 & 16.5 \\
\hline Annual fiscal revenue + special accounts & 4.9 & 2.6 & 3.9 & 5.3 & 6.1 & 6.5 & 6.9 \\
\hline Offsetting revenue (memorandum item) & 0.0 & 0.0 & 0.0 & 0.0 & 0.0 & 0.0 & 0.0 \\
\hline Total expenditure & 356.8 & 477.9 & 490.4 & 530.0 & 599.9 & 624.0 & 649.1 \\
\hline Overall current expenditure & 174.2 & 230.8 & 247.9 & 266.4 & 270.6 & 280.9 & 291.0 \\
\hline Current budgetary expenditure & 163.8 & 217.1 & 233.9 & 252.1 & 256.0 & 266.0 & 275.8 \\
\hline Wages and salaries & 68.0 & 73.3 & 77.7 & 82.4 & 84.2 & 87.2 & 90.3 \\
\hline Equipment and supplies & 47.4 & 63.0 & 70.5 & 79.3 & 82.8 & 85.8 & 88.9 \\
\hline Subsidies and transfers & 43.5 & 75.3 & 78.6 & 81.9 & 85.3 & 88.9 & 92.6 \\
\hline Interests due & 4.9 & 5.5 & 7.9 & 9.8 & 3.7 & 4.1 & 3.9 \\
\hline External debt & 3.7 & 3.8 & 3.9 & 4.8 & 3.1 & 3.6 & 3.5 \\
\hline Internal debt & 1.2 & 1.7 & 4.0 & 5.0 & 0.6 & 0.5 & 0.4 \\
\hline Annexed budgets/special accounts & 10.4 & 13.7 & 14.0 & 14.3 & 14.6 & 14.9 & 15.2 \\
\hline Capital expenditure and net loans & 182.6 & 247.1 & 255.2 & 276.6 & 333.0 & 347.2 & 362.0 \\
\hline Equipment & 182.6 & 247.1 & 285.9 & 316.4 & 333.0 & 347.2 & 362.0 \\
\hline From budgetary resources & 51.5 & 70.2 & 81.4 & 87.5 & 102.5 & 124.6 & 128.8 \\
\hline From external resources & 131.1 & 176.9 & 173.8 & 189.1 & 230.5 & 222.6 & 233.2 \\
\hline \multicolumn{8}{|l|}{ including: HIPC resources } \\
\hline Net loans & 15.6 & 18.7 & 0.0 & 0.0 & 0.0 & 0.0 & 0.0 \\
\hline Adjustment & 0.0 & 0.0 & 0.0 & 0.0 & 0.0 & 0.0 & 0.0 \\
\hline Overall balance (commitment base) & 109.6 & -241.7 & -227.3 & -230.3 & -267.4 & -260.3 & -245.8 \\
\hline Basic balance & 21.5 & -64.8 & -53.5 & -41.2 & -36.9 & -37.7 & -12.6 \\
\hline Variation in arrears (reduction -) & -14.0 & -15.8 & -15.0 & -15.0 & -15.0 & -15.0 & -15.0 \\
\hline Internal arrears & -14.0 & -15.8 & -15.0 & -15.0 & -15.0 & -15.0 & -15.0 \\
\hline External arrears & 0.0 & 0.0 & 0.0 & 0.0 & 0.0 & 0.0 & 0.0 \\
\hline Overall balance (cash base) & -123.6 & -257.5 & -242.3 & -245.3 & -282.4 & -275.3 & -260.8 \\
\hline Primary balance (commitment base) & -104.7 & -236.2 & -68.5 & -56.2 & -51.9 & -52.7 & -27.6 \\
\hline Financing & 124.1 & 257.5 & 242.3 & 245.3 & 282.4 & 275.3 & 260.8 \\
\hline External financing & 215.3 & 250.1 & 189.8 & 206.6 & 225.5 & 217.6 & 228.2 \\
\hline Grants & 878.4 & 175.5 & 137.4 & 149.3 & 149.8 & 144.7 & 151.6 \\
\hline Budget support & 18.6 & 65.6 & 0.0 & 0.0 & 0.0 & 0.0 & 0.0 \\
\hline Grants for projects & 75.5 & 109.9 & 137.4 & 149.3 & 149.8 & 144.7 & 151.6 \\
\hline HIPC assistance & 784.3 & 0.0 & 0.0 & 0.0 & 0.0 & 0.0 & 0.0 \\
\hline Loans & 59.8 & 76.0 & 57.4 & 62.5 & 80.7 & 77.9 & 81.6 \\
\hline Budget support & 19.8 & 27.4 & 0.0 & 0.0 & 0.0 & 0.0 & 0.0 \\
\hline Grants for projects & 40.0 & 48.6 & 57.4 & 62.5 & 80.7 & 77.9 & 81.6 \\
\hline Amortization due & -726.0 & -4.8 & -5.0 & -5.2 & -6.9 & -13.2 & -15.7 \\
\hline Debt alleviation & 0.0 & 0.0 & 0.0 & 0.0 & 0.0 & 0.0 & 0.0 \\
\hline
\end{tabular}




\begin{tabular}{|l|r|r|r|r|r|r|r|}
\hline Current debt service & 0.0 & 0.0 & 0.0 & 0.0 & 0.0 & 0.0 & 0.0 \\
\hline Arrears & 0.0 & 0.0 & 0.0 & 0.0 & 0.0 & 0.0 & 0.0 \\
\hline HIPC assistance & 0.0 & 0.0 & 0.0 & 0.0 & 0.0 & 0.0 & 0.0 \\
\hline Debt under discussion & 3.1 & 3.4 & 0.0 & 0.0 & 0.0 & 0.0 & 0.0 \\
\hline Domestic financing & -91.2 & 7.4 & -3.5 & -2.3 & -3.0 & -3.0 & -3.1 \\
\hline Banking sector & -82.8 & 7.4 & -3.5 & -2.3 & -3.0 & -3.0 & -3.1 \\
\hline Non banking sector & -8.4 & 0.0 & 0.0 & 0.0 & 0.0 & 0.0 & 0.0 \\
\hline Privatization, net income & 0.0 & 0.0 & 0.0 & 0.0 & 0.0 & 0.0 & 0.0 \\
\hline & & & & & & & \\
\hline Overall balance & 0.5 & 0.0 & -99.4 & -93.7 & -65.2 & -69.7 & -46.8 \\
\hline Exceptional requirements & -0.5 & 0.0 & 99.4 & 93.7 & 65.2 & 69.7 & 46.8 \\
\hline Total foreign borrowings & 59.3 & 76.0 & 156.8 & 156.2 & 145.9 & 147.6 & 128.4 \\
\hline Source: CCE/DGE/MEF & & & & & & & \\
\hline
\end{tabular}




\section{3. c. SUMMARY OF KEY INDICATORS}

\begin{tabular}{|c|c|c|c|c|c|c|c|}
\hline \multirow[t]{2}{*}{ Reference scenario } & \multicolumn{7}{|c|}{ Projection } \\
\hline & 2006 & 2007 & 2008 & 2009 & 2010 & 2011 & 2012 \\
\hline \multicolumn{8}{|l|}{ Gross domestic product \& prices } \\
\hline Nominal GDP (in billions of CFA) & 1850.1 & 2032.4 & 2152.5 & 2279.4 & 2435.2 & 2585.3 & 2746.6 \\
\hline Per capita GDP (annual growth) & $1.5 \%$ & $0.7 \%$ & $0.8 \%$ & $0.8 \%$ & $0.9 \%$ & $0.9 \%$ & $1.0 \%$ \\
\hline \multicolumn{8}{|l|}{ (Growth rate) } \\
\hline Per capita GDP & $1.5 \%$ & $0.7 \%$ & $0.8 \%$ & $0.8 \%$ & $0.9 \%$ & $0.9 \%$ & $1.0 \%$ \\
\hline Consumption per capita & $2.3 \%$ & $7.1 \%$ & $0.3 \%$ & $0.4 \%$ & $0.5 \%$ & $0.6 \%$ & $0.7 \%$ \\
\hline GDP at constant prices & $4.8 \%$ & $4.0 \%$ & $4.1 \%$ & $4.1 \%$ & $4.2 \%$ & $4.2 \%$ & $4.3 \%$ \\
\hline Informal sector & $5.9 \%$ & $3.7 \%$ & $3.5 \%$ & $3.6 \%$ & $3.8 \%$ & $3.9 \%$ & $4.0 \%$ \\
\hline including Agriculture & $11.7 \%$ & $4.0 \%$ & $3.7 \%$ & $3.8 \%$ & $4.1 \%$ & $4.2 \%$ & $4.3 \%$ \\
\hline Modern sector & $7.4 \%$ & $8.2 \%$ & $7.4 \%$ & $6.7 \%$ & $6.7 \%$ & $6.7 \%$ & $6.8 \%$ \\
\hline \multicolumn{8}{|l|}{ Prices } \\
\hline GDP deflator & $0.6 \%$ & $5.6 \%$ & $1.7 \%$ & $1.7 \%$ & $2.6 \%$ & $1.8 \%$ & $1.8 \%$ \\
\hline Consumer prices & $3.0 \%$ & $3.0 \%$ & $2.0 \%$ & $2.0 \%$ & $2.0 \%$ & $2.0 \%$ & $2.0 \%$ \\
\hline \multicolumn{8}{|l|}{ As percentage of GDP } \\
\hline & & & & & & & \\
\hline Consumption & $89.6 \%$ & $91.6 \%$ & $98.0 \%$ & $97.5 \%$ & $97.2 \%$ & $96.8 \%$ & $96.4 \%$ \\
\hline Private & $82.4 \%$ & $81.6 \%$ & $81.1 \%$ & $81.6 \%$ & $81.1 \%$ & $80.4 \%$ & $79.7 \%$ \\
\hline Public & $15.6 \%$ & $15.9 \%$ & $16.1 \%$ & $15.9 \%$ & $16.1 \%$ & $16.4 \%$ & $16.7 \%$ \\
\hline Investment & $21.8 \%$ & $19.5 \%$ & $20.0 \%$ & $20.3 \%$ & $20.3 \%$ & $20.3 \%$ & $20.3 \%$ \\
\hline Gross fixed capital formation & $20.3 \%$ & $19.5 \%$ & $20.0 \%$ & $20.3 \%$ & $20.3 \%$ & $20.3 \%$ & $20.3 \%$ \\
\hline Private & $14.5 \%$ & $13.3 \%$ & $13.5 \%$ & $13.7 \%$ & $13.8 \%$ & $14.0 \%$ & $14.2 \%$ \\
\hline Public & $5.8 \%$ & $6.2 \%$ & $6.5 \%$ & $6.6 \%$ & $6.5 \%$ & $6.3 \%$ & $6.2 \%$ \\
\hline GDP at market price & $100.0 \%$ & $100.0 \%$ & $100.0 \%$ & $100.0 \%$ & $100.0 \%$ & $100.0 \%$ & $100.0 \%$ \\
\hline \multicolumn{8}{|l|}{ Public finance } \\
\hline & & & & & & & \\
\hline Total revenue & $13.4 \%$ & $11.6 \%$ & $12.2 \%$ & $13.1 \%$ & $13.7 \%$ & $14.1 \%$ & $14.7 \%$ \\
\hline Tax revenue & $11.0 \%$ & $11.0 \%$ & $11.4 \%$ & $12.3 \%$ & $12.8 \%$ & $13.2 \%$ & $13.8 \%$ \\
\hline Total expenditure & $19.3 \%$ & $23.5 \%$ & $24.8 \%$ & $25.6 \%$ & $24.8 \%$ & $24.3 \%$ & $23.8 \%$ \\
\hline Current expenditure & $9.4 \%$ & $11.4 \%$ & $11.5 \%$ & $11.7 \%$ & $11.1 \%$ & $10.9 \%$ & $10.6 \%$ \\
\hline Capital expenditure & $9.9 \%$ & $12.2 \%$ & $13.3 \%$ & $13.9 \%$ & $13.7 \%$ & $13.4 \%$ & $13.2 \%$ \\
\hline Overall balance (commitment base) & $-5.9 \%$ & $-11.9 \%$ & $-12.6 \%$ & $-12.4 \%$ & $-11.3 \%$ & $-10.5 \%$ & $-9.5 \%$ \\
\hline Basic overall balance & $1.2 \%$ & $-3.2 \%$ & $-2.8 \%$ & $-2.3 \%$ & $-1.9 \%$ & $-1.9 \%$ & $-1.0 \%$ \\
\hline Primary balance (commitments) & $-5.7 \%$ & $-11.6 \%$ & $-12.2 \%$ & $-13.1 \%$ & $-11.9 \%$ & $-11.1 \%$ & $-10.0 \%$ \\
\hline Overall balance (cash base) & $-6.7 \%$ & $-12.7 \%$ & $-13.3 \%$ & $-13.1 \%$ & $-11.9 \%$ & $-11.1 \%$ & $-10.0 \%$ \\
\hline \multicolumn{8}{|l|}{ WAEMU convergence criteria } \\
\hline \multicolumn{8}{|l|}{$(\ln \%)$} \\
\hline Basic balance over GDP & $1.2 \%$ & $-3.2 \%$ & $-2.8 \%$ & $-2.3 \%$ & $-1.9 \%$ & $-1.9 \%$ & $-1.0 \%$ \\
\hline Tax ratio & $11.0 \%$ & $11.0 \%$ & $11.4 \%$ & $12.3 \%$ & $12.8 \%$ & $13.2 \%$ & $13.8 \%$ \\
\hline Wage bill/tax revenue & $33.4 \%$ & $32.7 \%$ & $31.3 \%$ & $31.3 \%$ & $28.9 \%$ & $27.0 \%$ & $25.5 \%$ \\
\hline $\begin{array}{l}\text { Capital expenditure from own resources/tax } \\
\text { revenue }\end{array}$ & $25.3 \%$ & $31.3 \%$ & $30.3 \%$ & $30.3 \%$ & $30.9 \%$ & $32.9 \%$ & $36.5 \%$ \\
\hline
\end{tabular}

Source: CCE/DGE/ME/F 


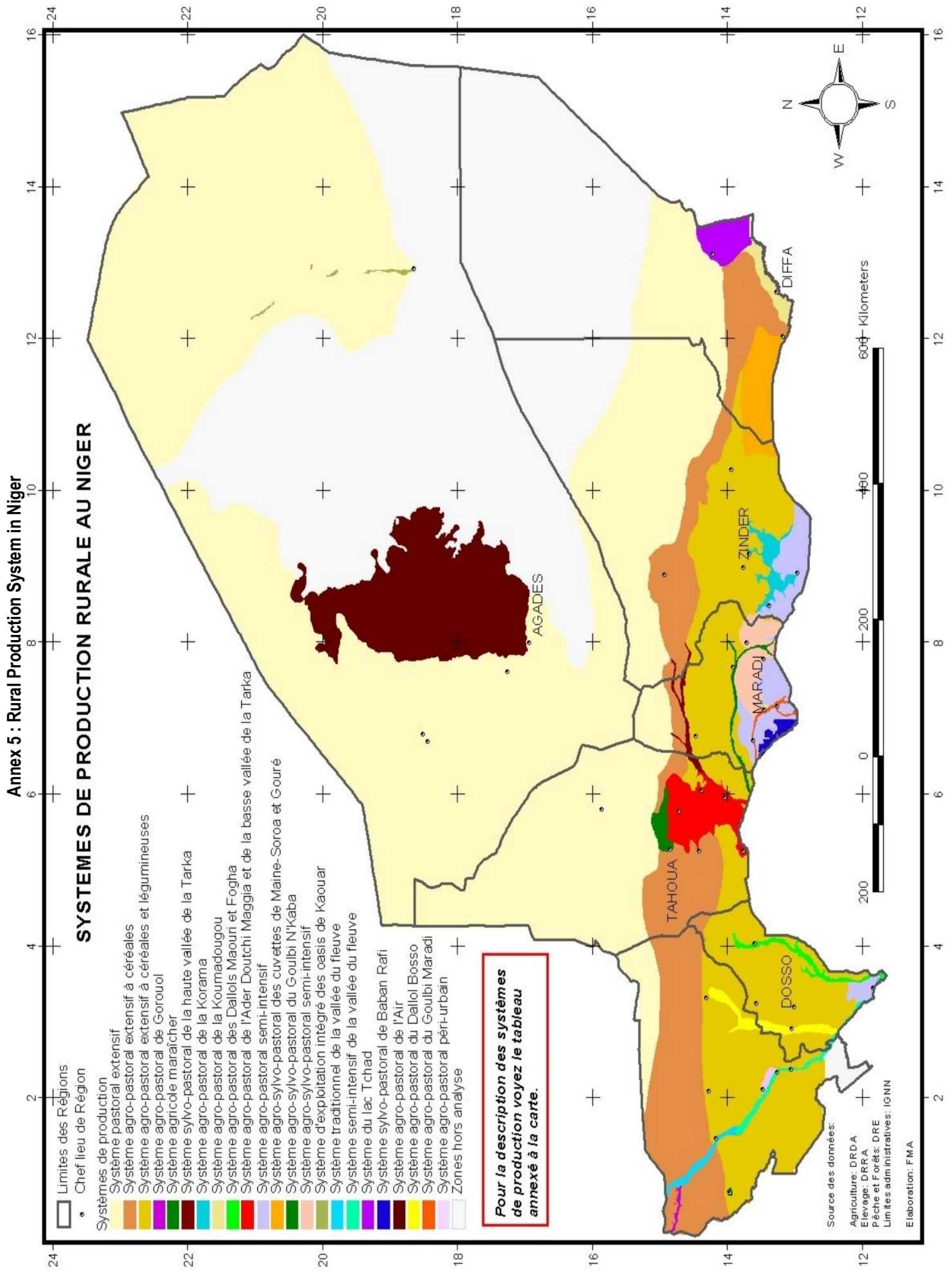




\begin{tabular}{|c|c|c|c|c|c|c|}
\hline 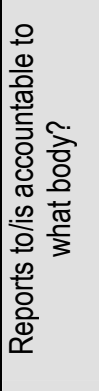 & 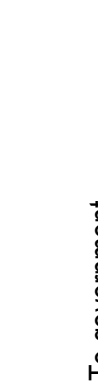 & & 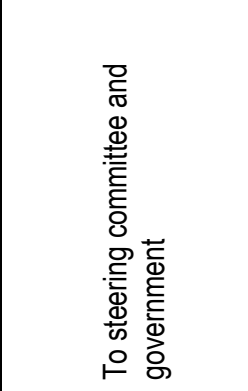 & 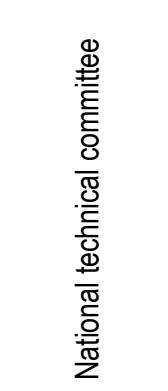 & 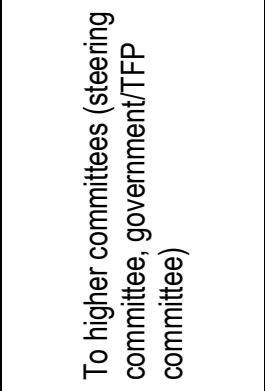 & 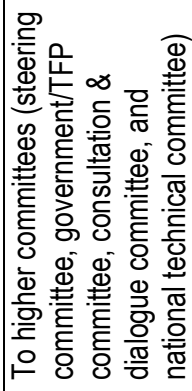 \\
\hline 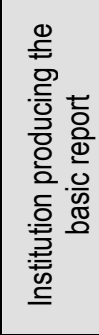 & 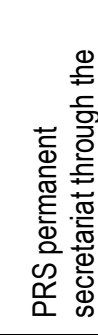 & & 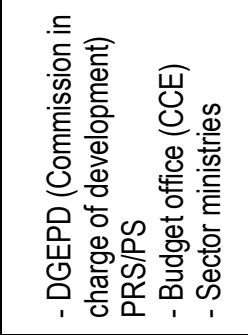 & 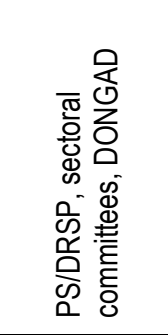 & 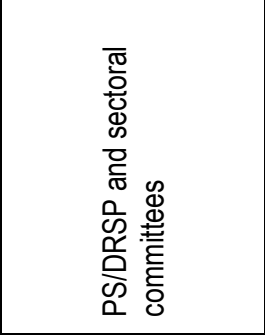 & 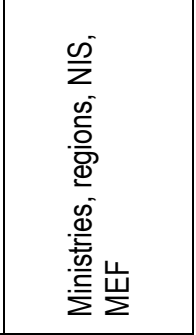 \\
\hline 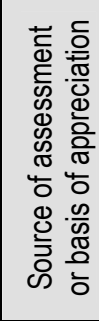 & 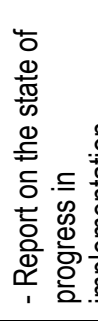 & 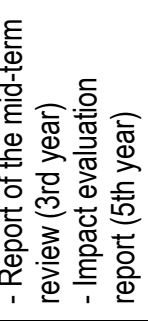 & 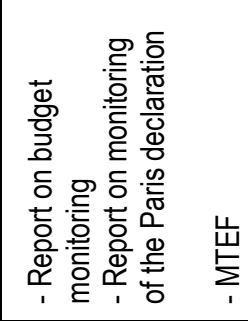 & 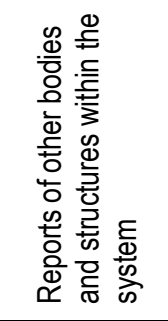 & 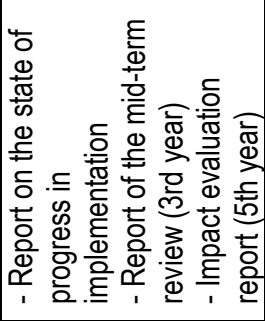 & 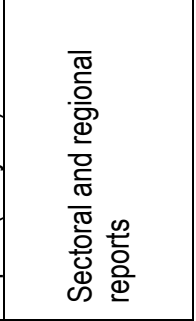 \\
\hline 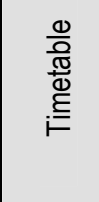 & 引 & & 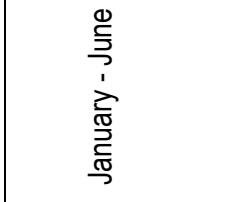 & 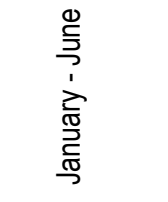 & 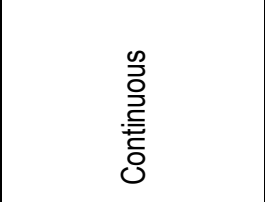 & 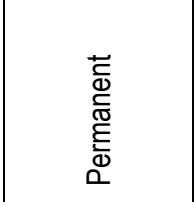 \\
\hline 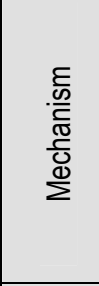 & 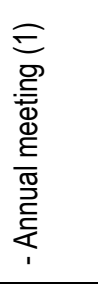 & 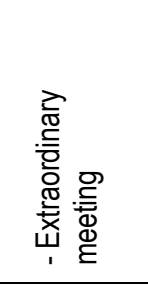 & 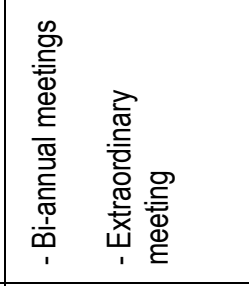 & 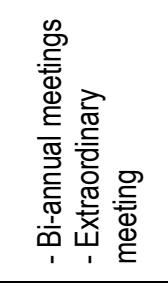 & 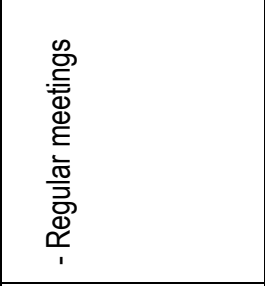 & 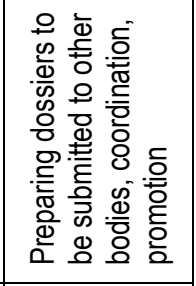 \\
\hline $\begin{array}{l}\text { 음 } \\
\frac{5}{5} \\
\text { ᄂ }\end{array}$ & 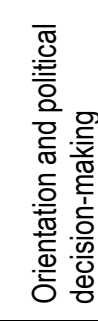 & 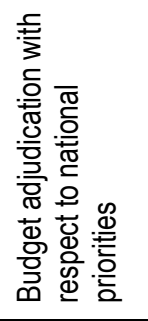 & 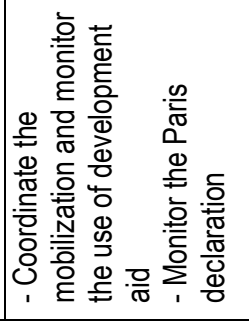 & 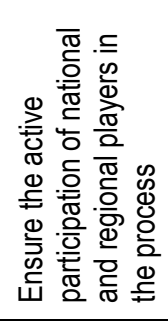 & 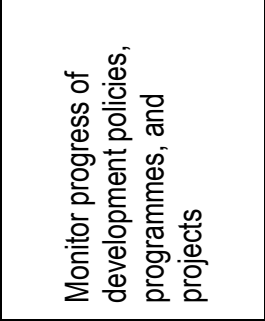 & 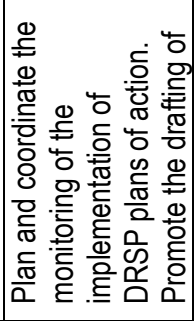 \\
\hline 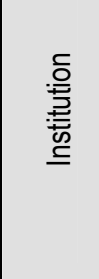 & & 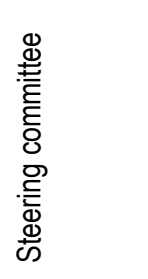 & 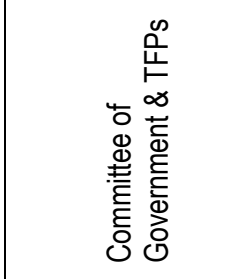 & 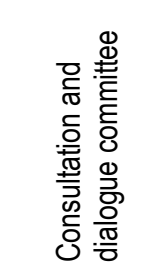 & 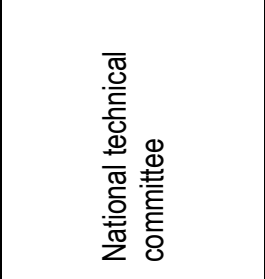 & 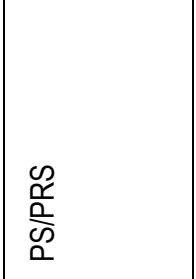 \\
\hline$\stackrel{\circ}{z}$ & & - & $\sim$ & $m$ & $\nabla$ & ما \\
\hline
\end{tabular}




\begin{tabular}{|c|c|c|c|c|c|}
\hline 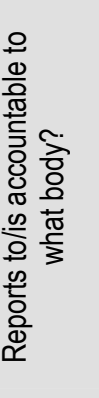 & & 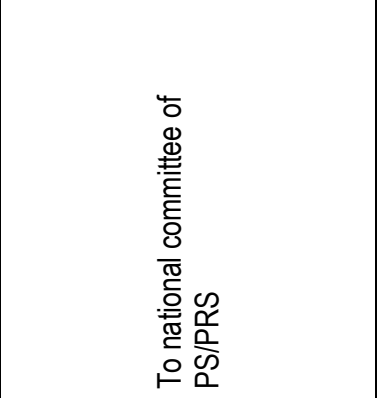 & 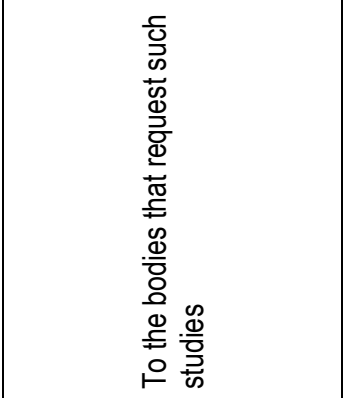 & 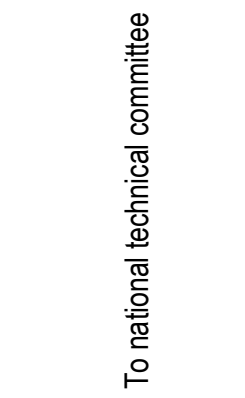 & 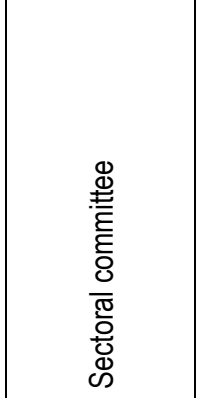 \\
\hline 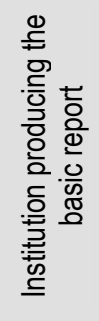 & & 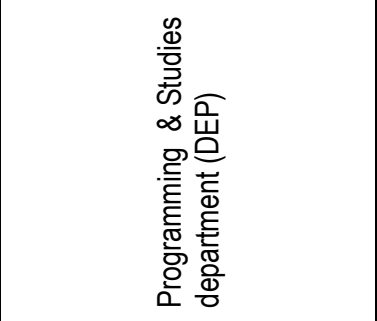 & $\frac{\infty}{Z}$ & 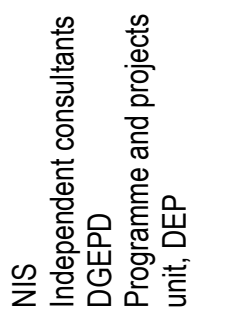 & 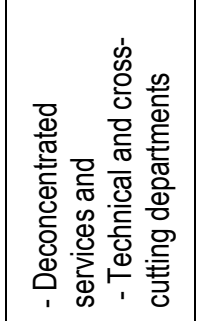 \\
\hline 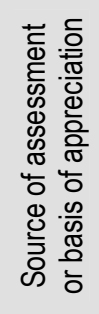 & & 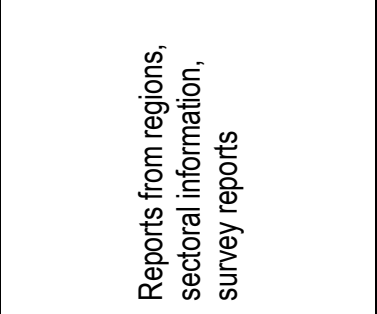 & 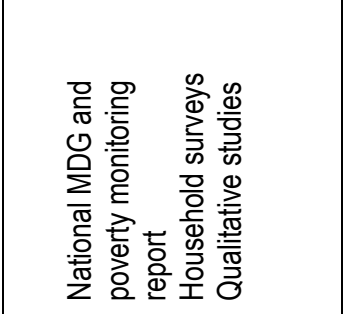 & 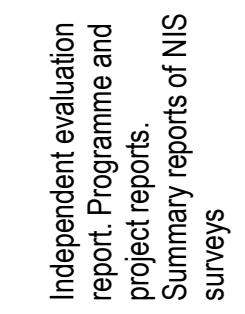 & 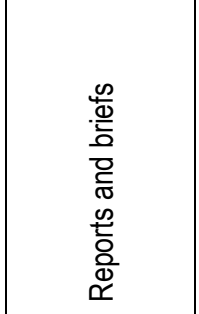 \\
\hline 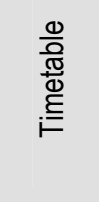 & & 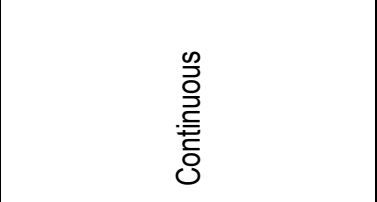 & & & 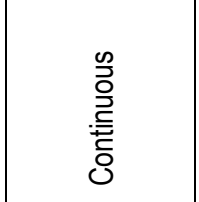 \\
\hline 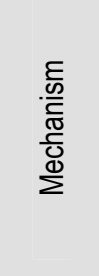 & & 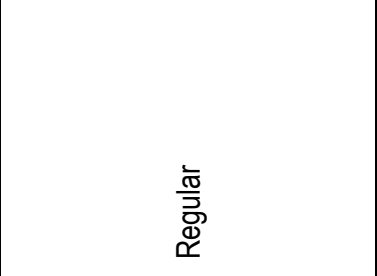 & 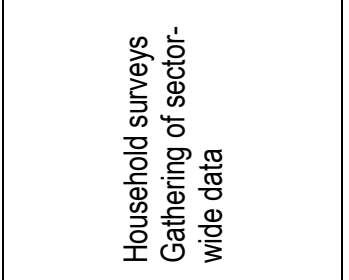 & & 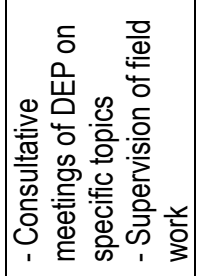 \\
\hline $\begin{array}{l}\text { 듬 } \\
\frac{\bar{J}}{5} \\
\text { L }\end{array}$ & 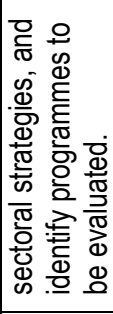 & 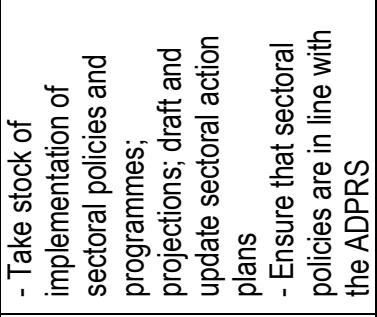 & 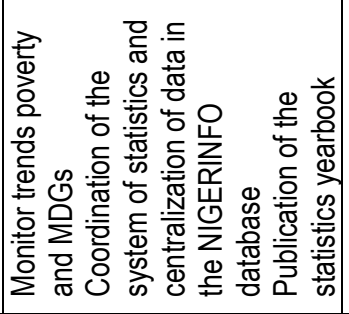 & 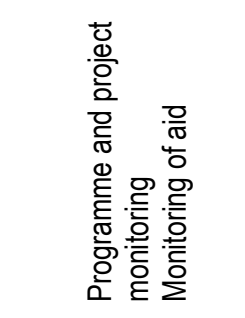 & 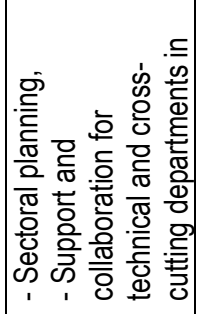 \\
\hline 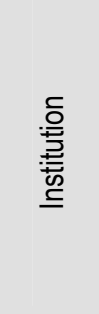 & & 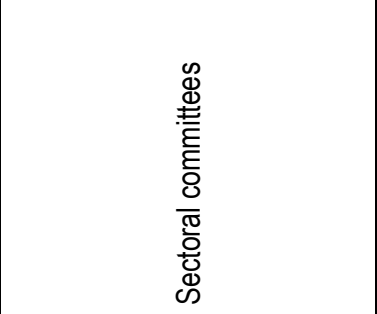 & $\frac{\infty}{Z}$ & 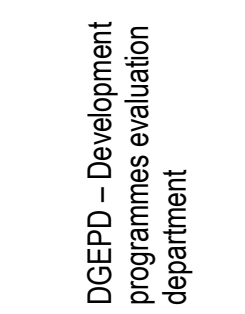 & 㞻 \\
\hline$\stackrel{\circ}{z}$ & & 0 & N & $\infty$ & ( \\
\hline
\end{tabular}

ชู 


\begin{tabular}{|c|c|c|c|c|c|}
\hline 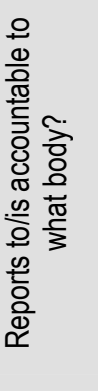 & & 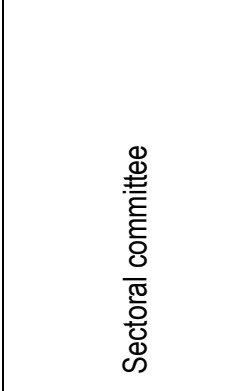 & 1 & & $\frac{\infty}{Z}$ \\
\hline 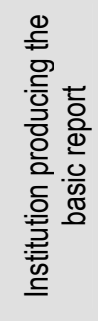 & & 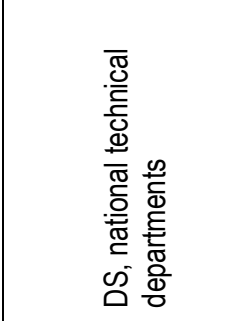 & 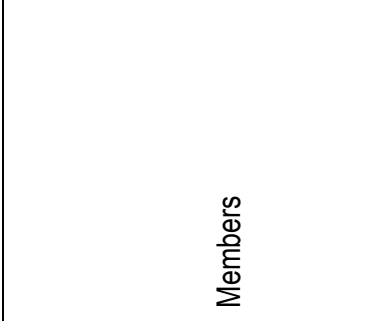 & 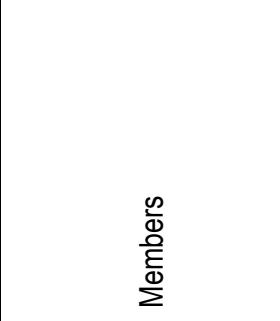 & \\
\hline 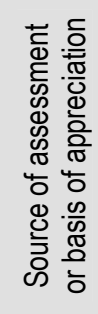 & & 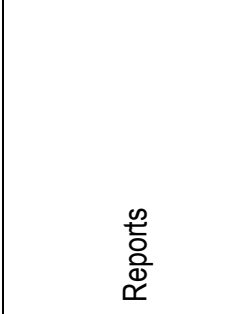 & 竞 & 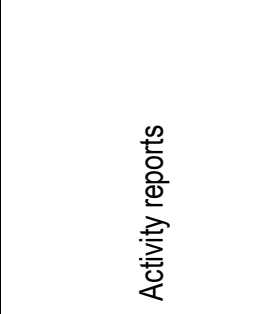 & 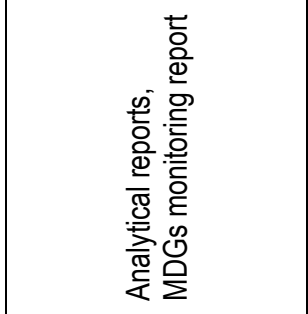 \\
\hline 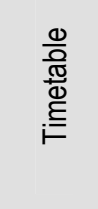 & & ' & 1 & & \\
\hline $\begin{array}{l}\frac{E}{\frac{.0}{E}} \\
\frac{\pi}{0} \\
\frac{\pi}{0} \\
\sum\end{array}$ & 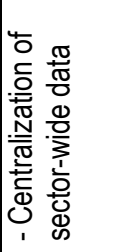 & , & 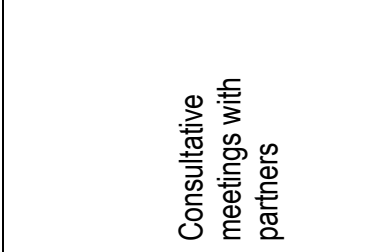 & 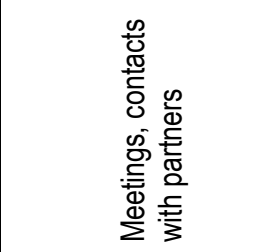 & \\
\hline 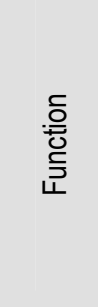 & 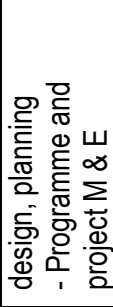 & 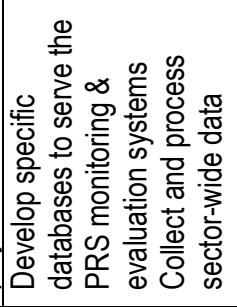 & 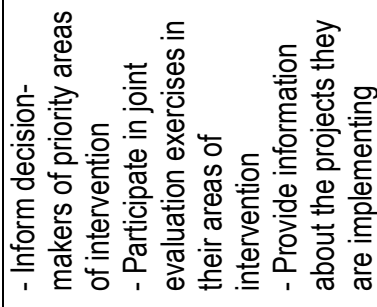 & 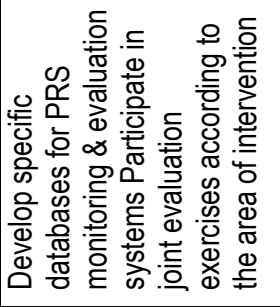 & 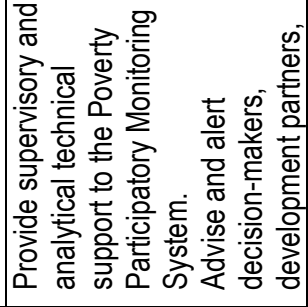 \\
\hline 을 & & 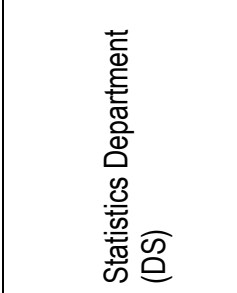 & 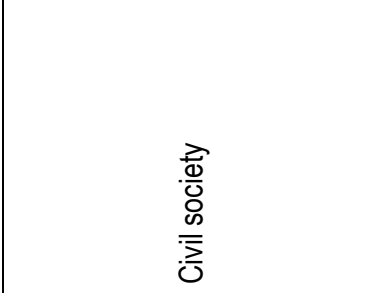 & 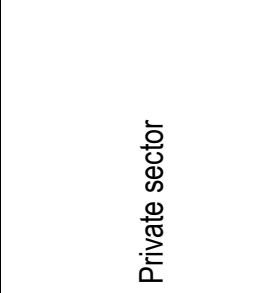 & $\frac{\substack{\frac{1}{2} \\
\frac{1}{2}}}{\frac{1}{z}}$ \\
\hline$\stackrel{\circ}{z}$ & & 으 & $F$ & $\cong$ & $\stackrel{m}{\sim}$ \\
\hline
\end{tabular}

$\underline{6}$ 


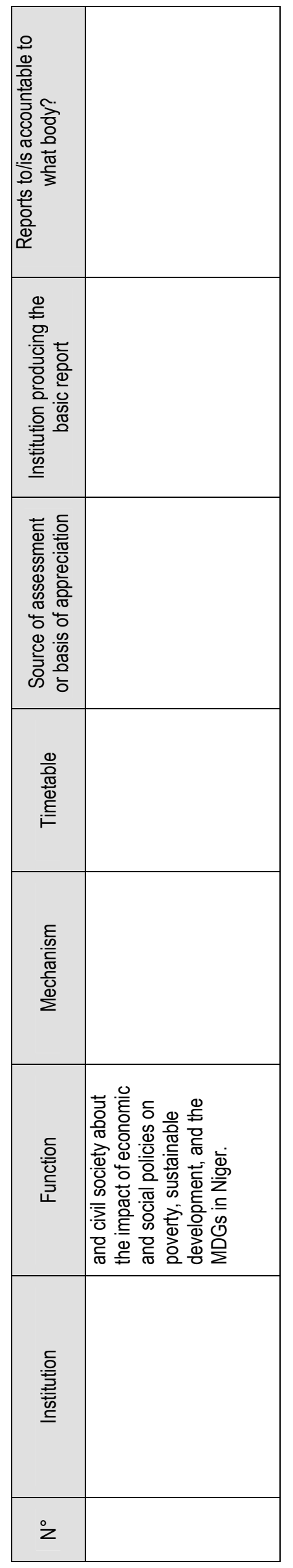

ț 
- Study on the characterization of regional development poles.

- Study on job supply sectors.

- Socio-economic studies in well-targeted areas, in order to obtain an accurate diagnosis and a reference situation (reference indicators and target indicators).

- Studies on the capacity of Niger to mobilize and absorb external resources.

- Design of a simulation model for the rural sector.

- Prospective study.

- Update of the study and commercial exchanges between Niger and Nigeria.

- Study on the fiscal potential of Niger.

- Study on the support and collaboration mechanism for the rural sector.

- More in-depth study on sources of growth.

- Evaluation of the Office of Environmental Assessment and Impact Studies (BEEEI), with a view to strengthening it, given its strategic role.

- Carry out surveys that will allow for obtaining disaggregated data according to gender.

- Conduct studies on the situation of children and women, in relation to health, education, and access to safe drinking water.

- Carry out a study on chronic malnutrition.

- Carry out a study on the phenomenon of migration linked to poverty.

- Study on the politicization of the public administration.

- Study on corruption and governance.

- Study on the issue of decentralization in relation to island-dwelling populations (along the Niger and the Komadougou rivers).

- Carry out a study on the contribution of SCOs to development.

- Carry out gender diagnostic studies in all areas.

- Study on the contribution of civil society to the implementation of the first generation PRS.

- Impact study in relation to gender and human rights.

- Study on productivity in the public sector.

- A study on the capacity of local communities to ensure local development.

- Update of the basic topographic mapping.

- Update of poverty map in light of prospective regionalization of the ADPRS.

- Extend the study on the financial capacity of local communities to all such communities.

- Non-monetary poverty or "standard of living" poverty based on data from the NPHS and MICS surveys.

- In-depth study of the factors that determine poverty and the trends in poverty.

- Study on absorption capacity. 


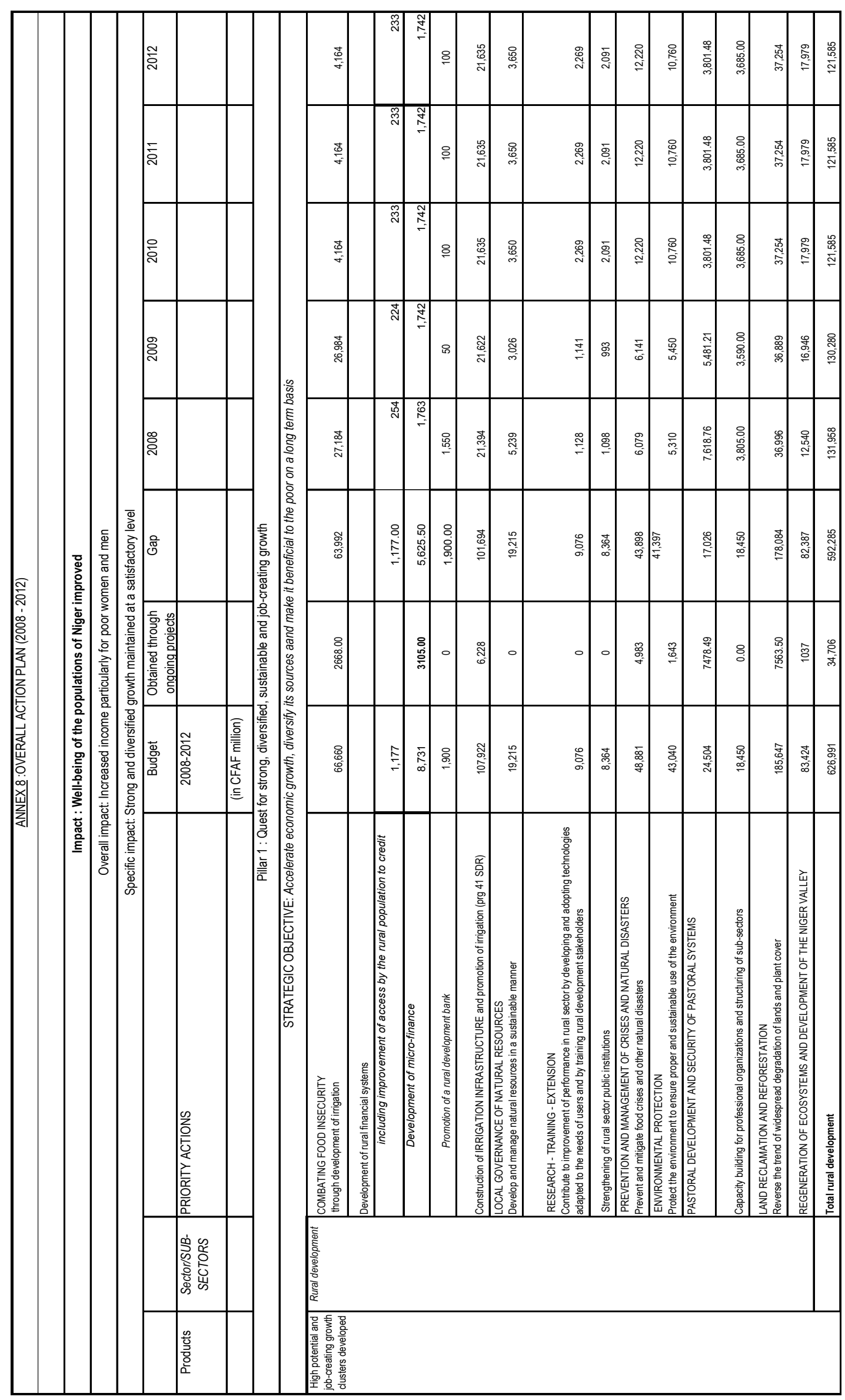

6 


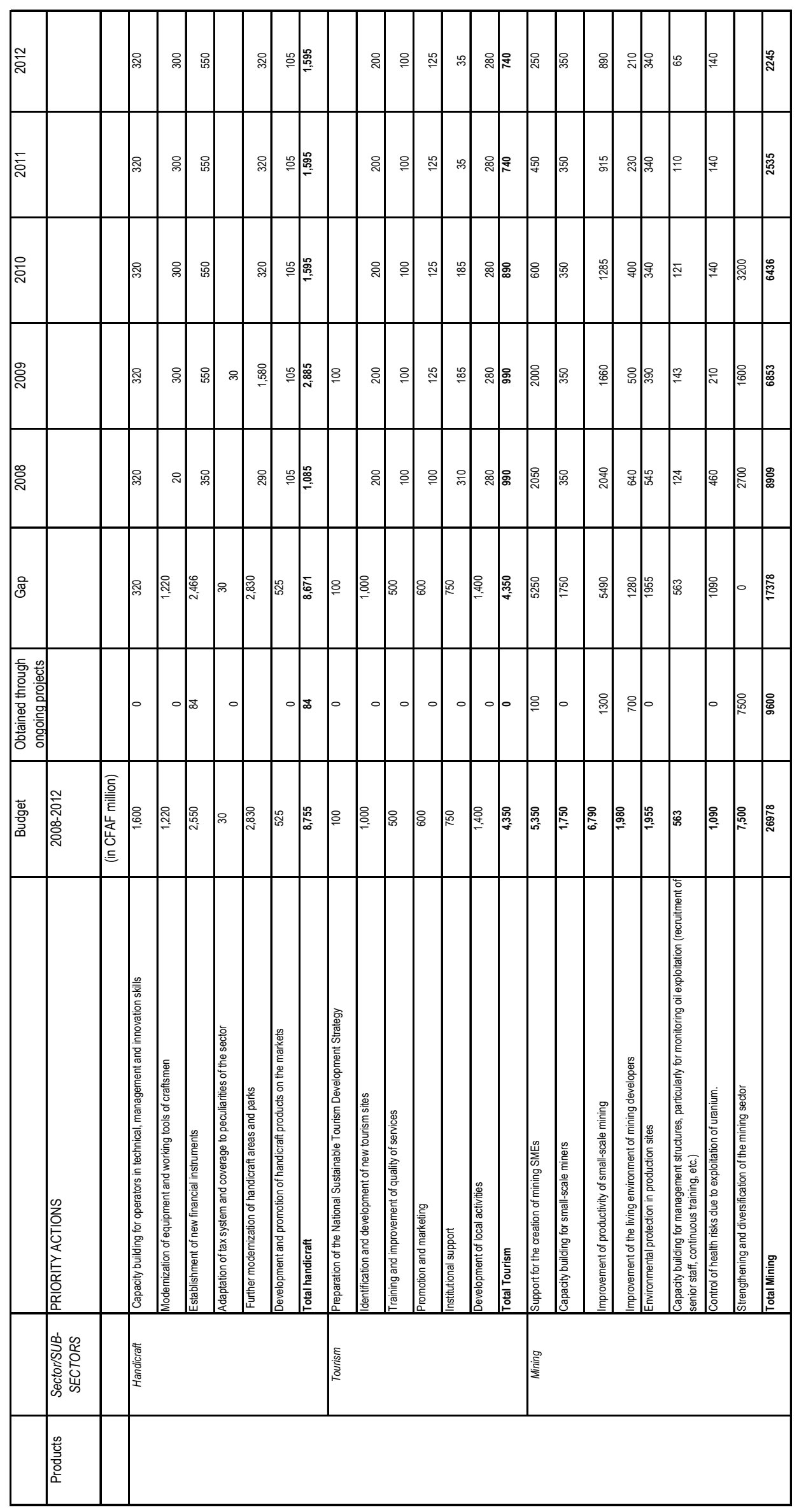

6 


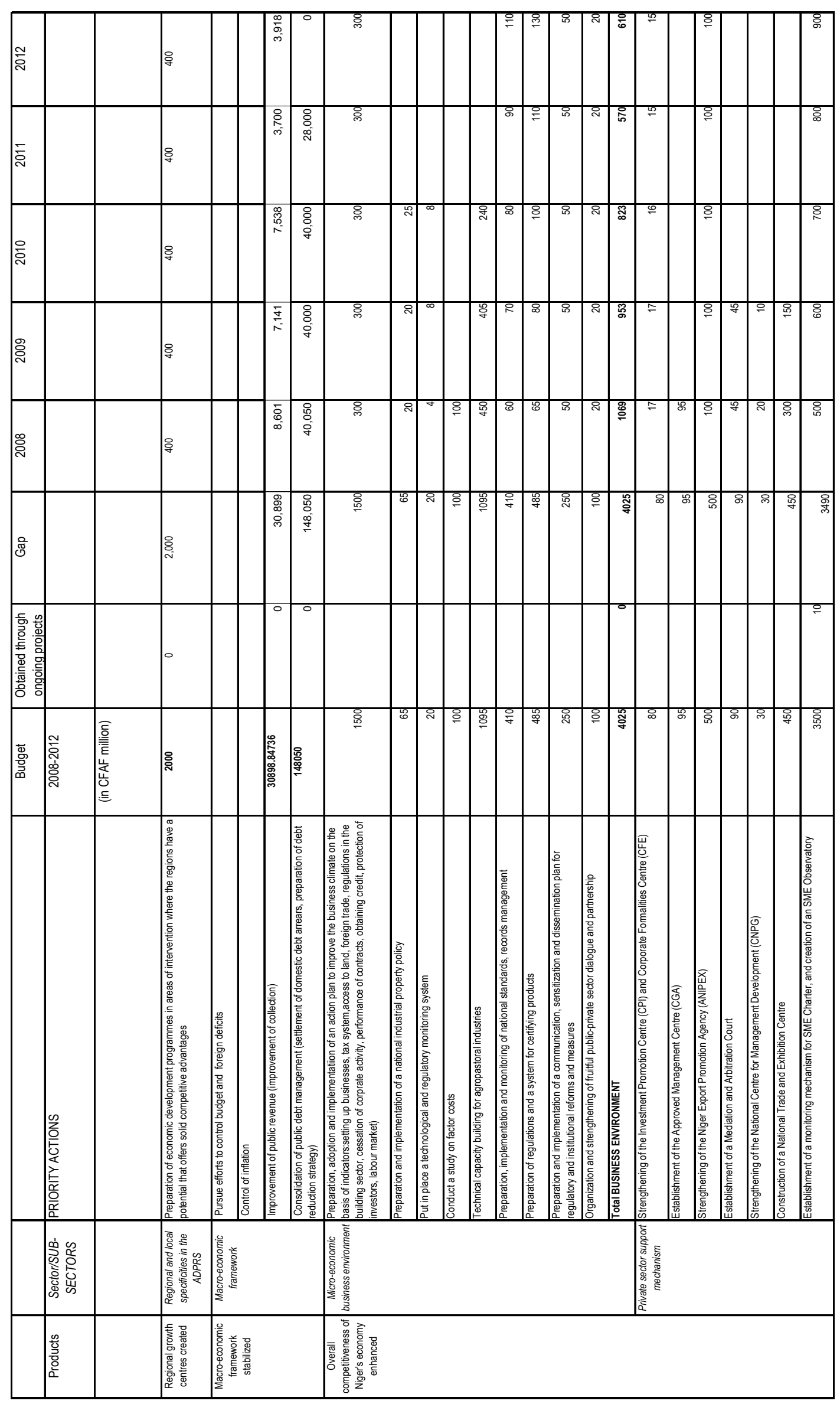

$\underset{b}{0}$ 


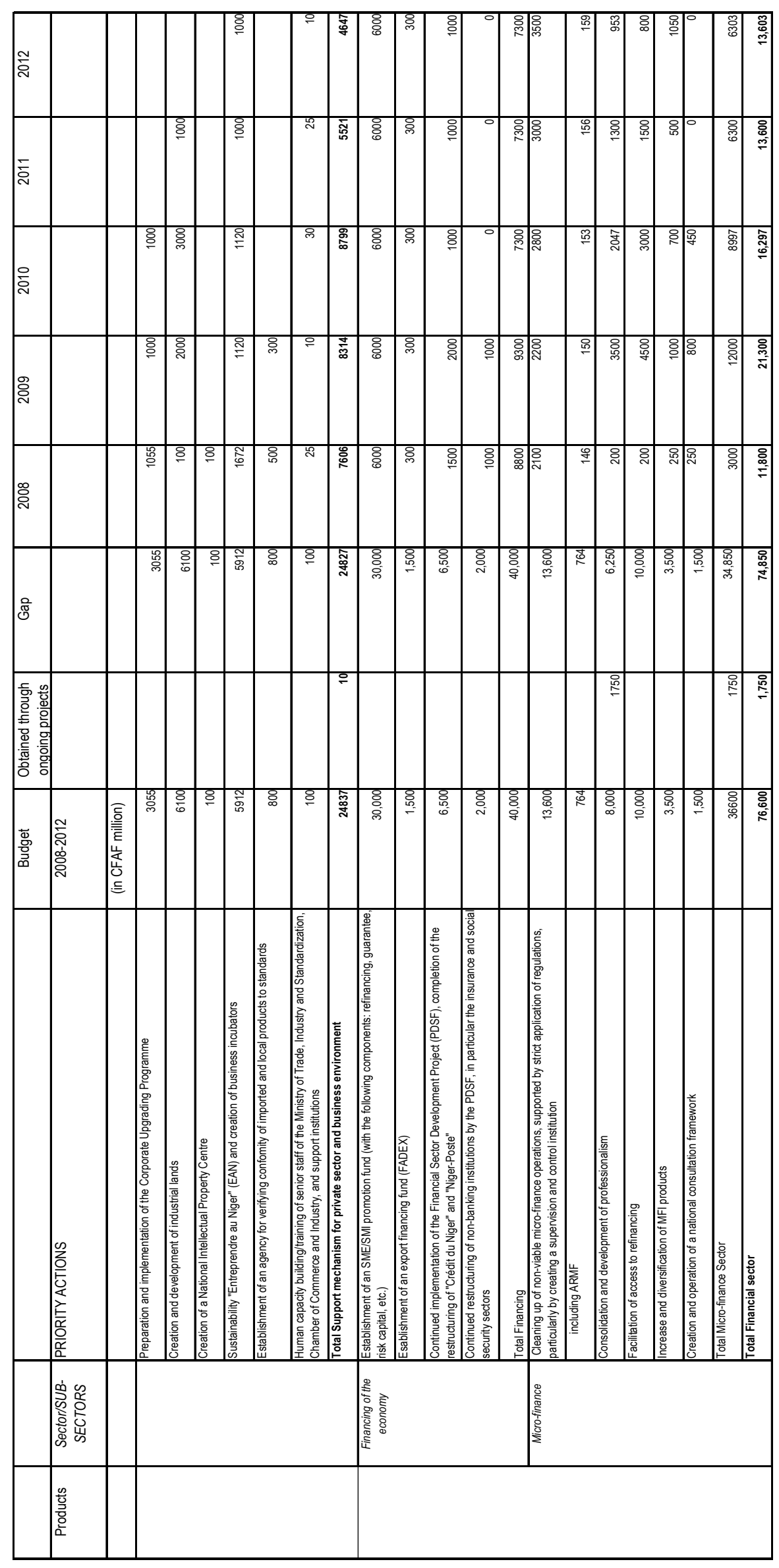

웅 


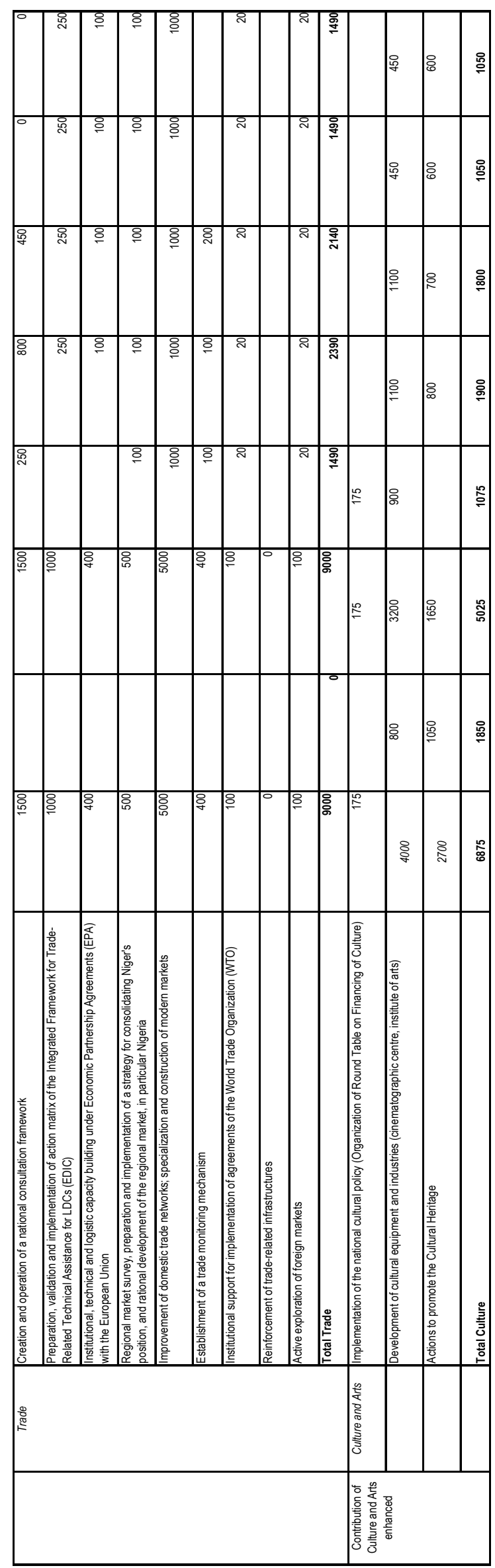

$\Xi$ 


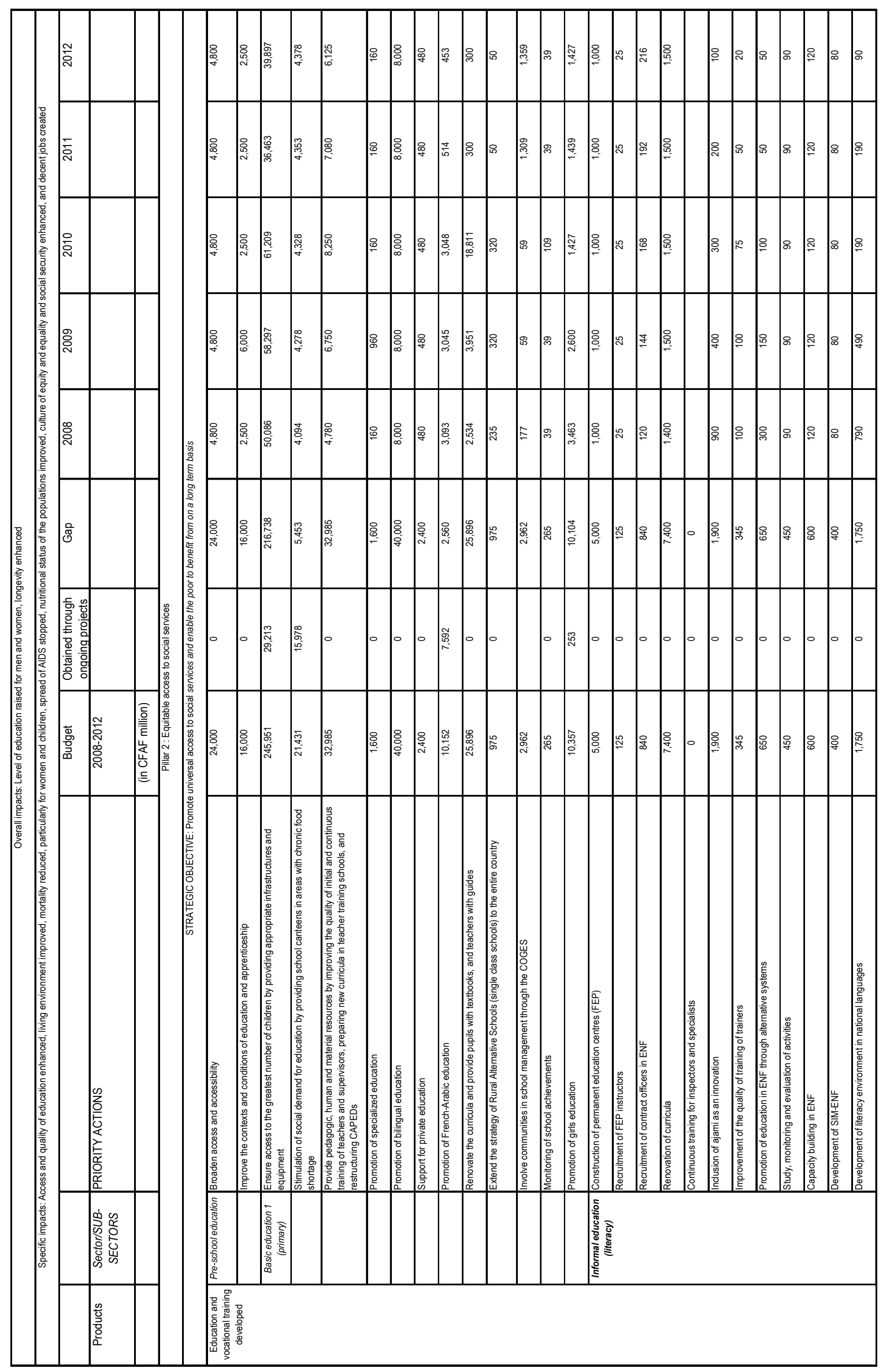

I 


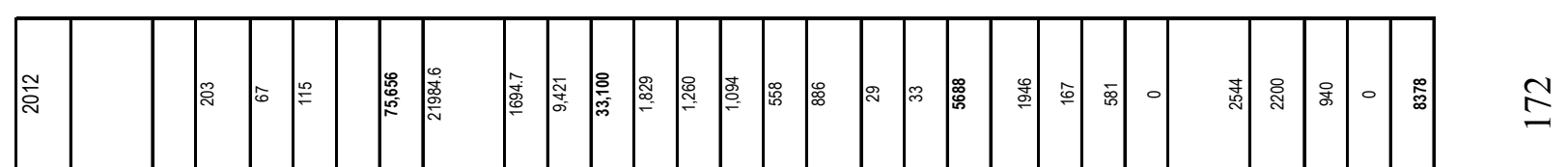

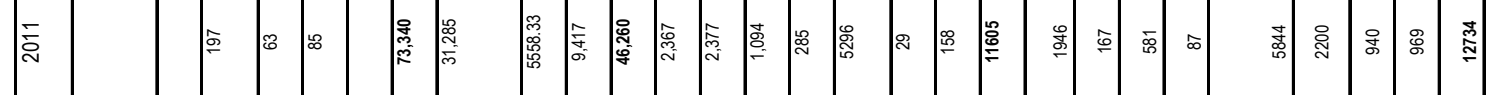

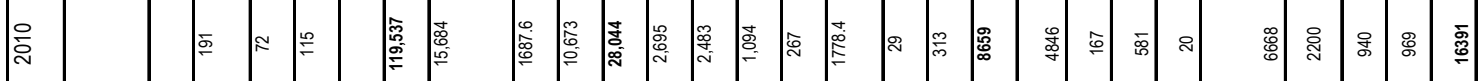

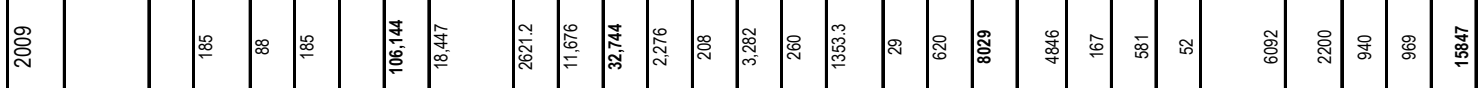

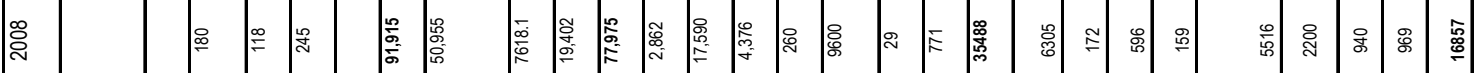

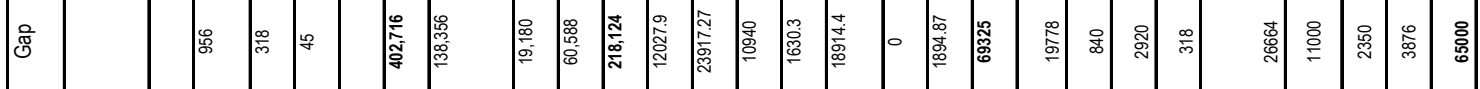

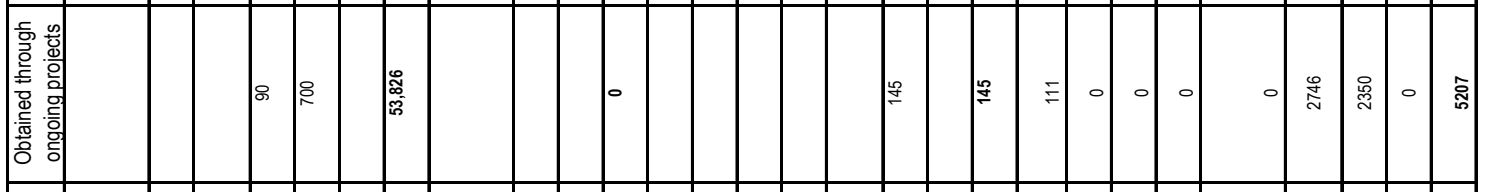

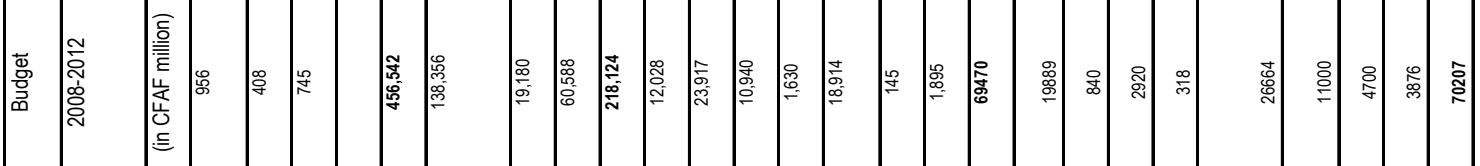

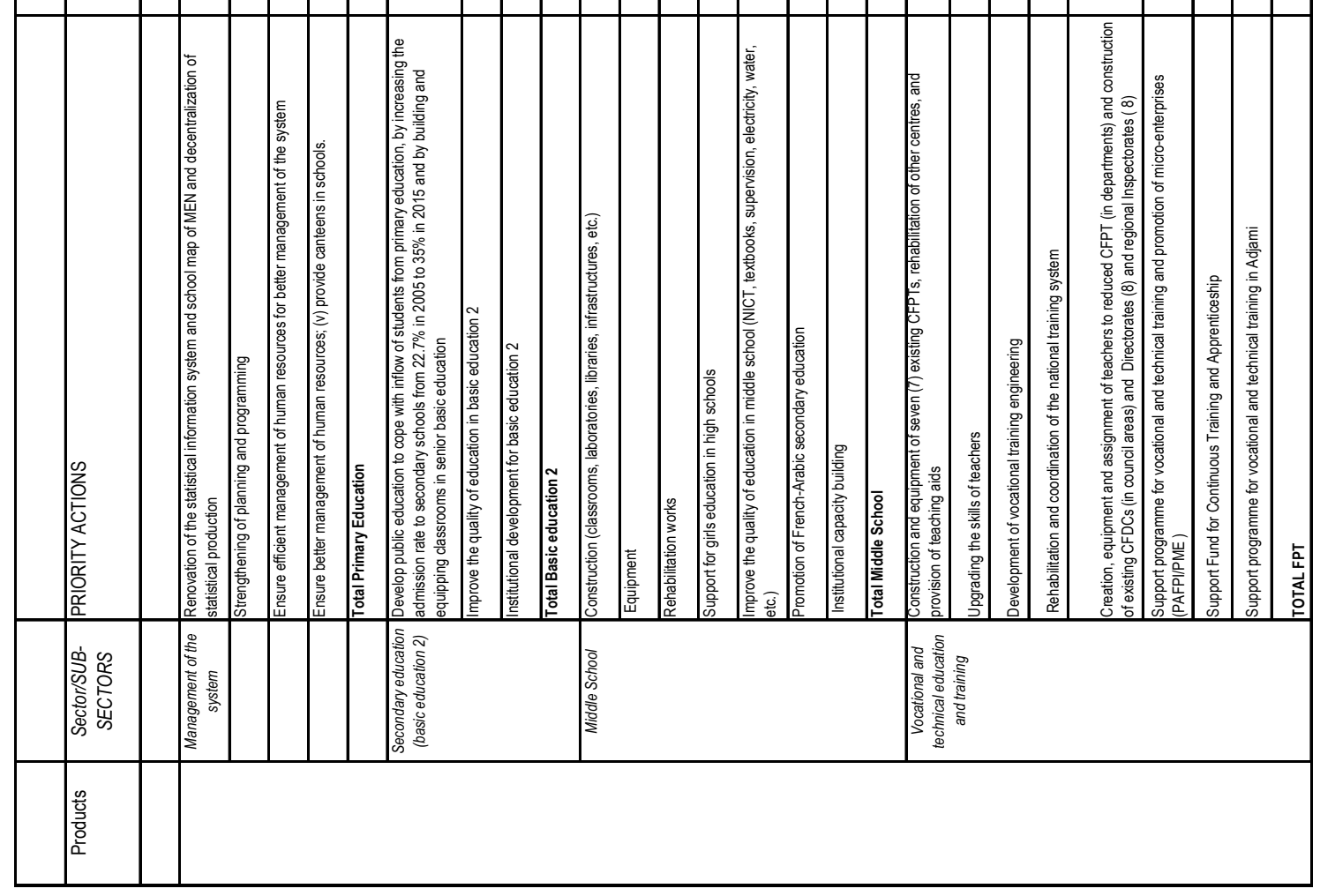




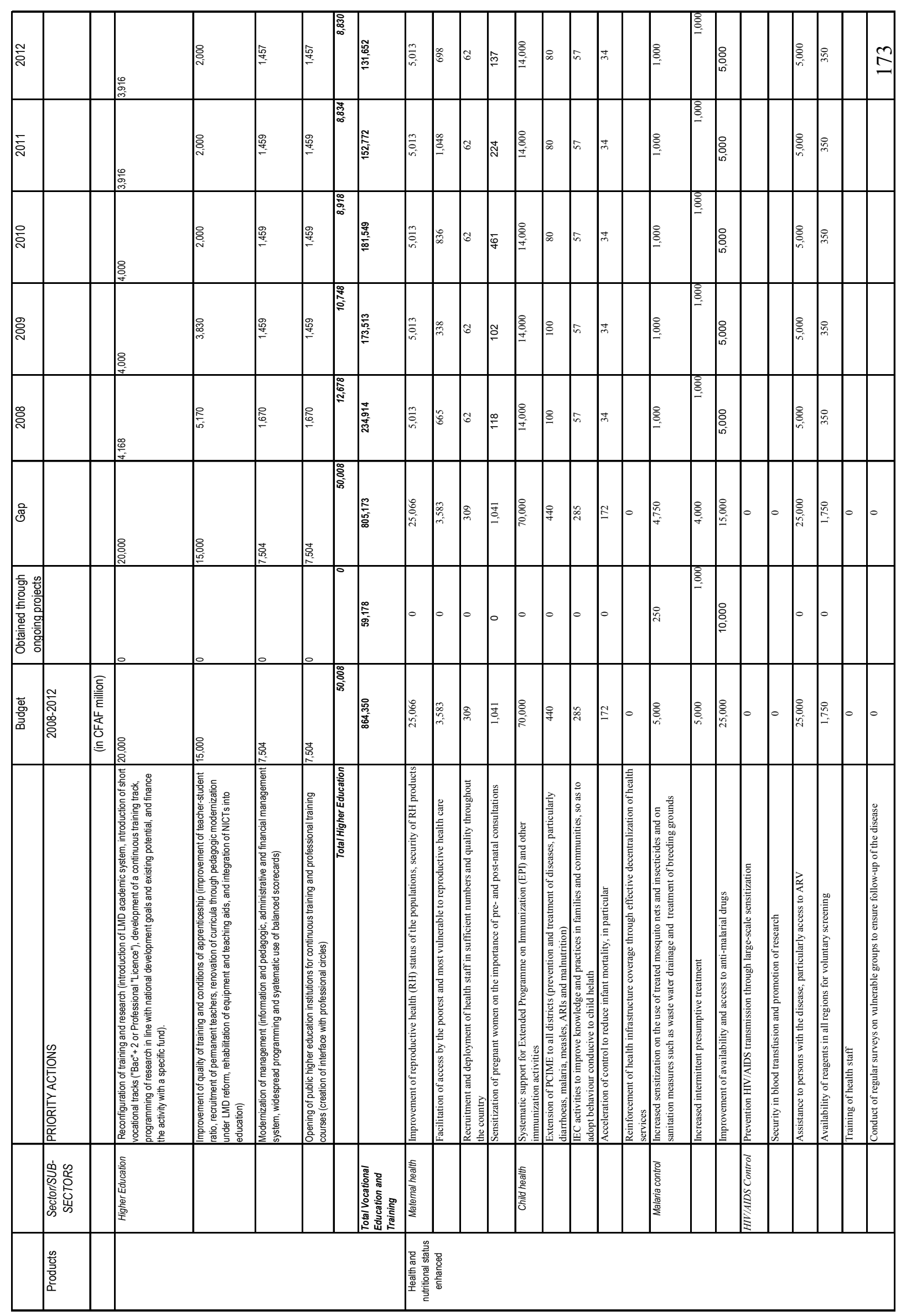




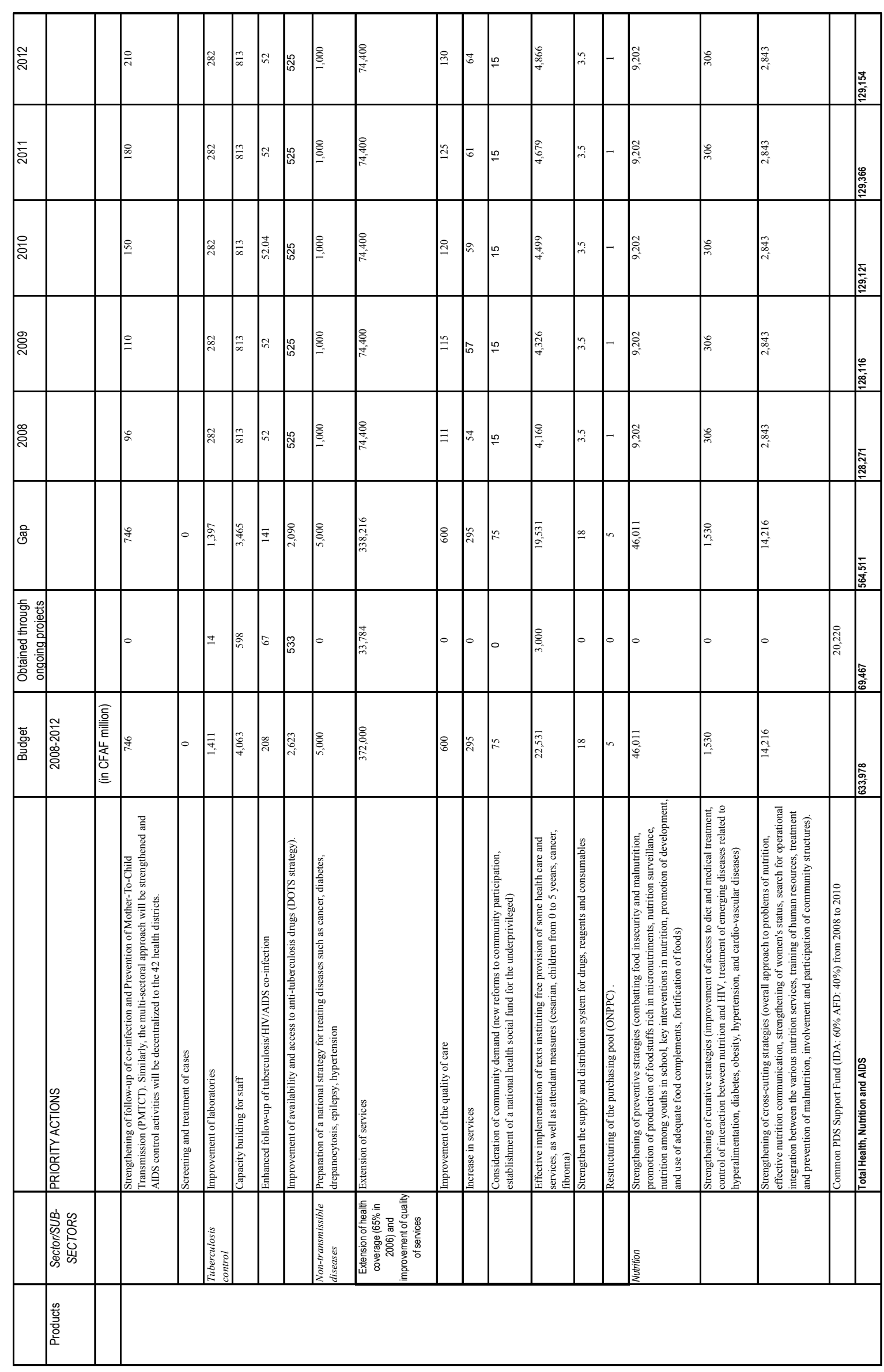




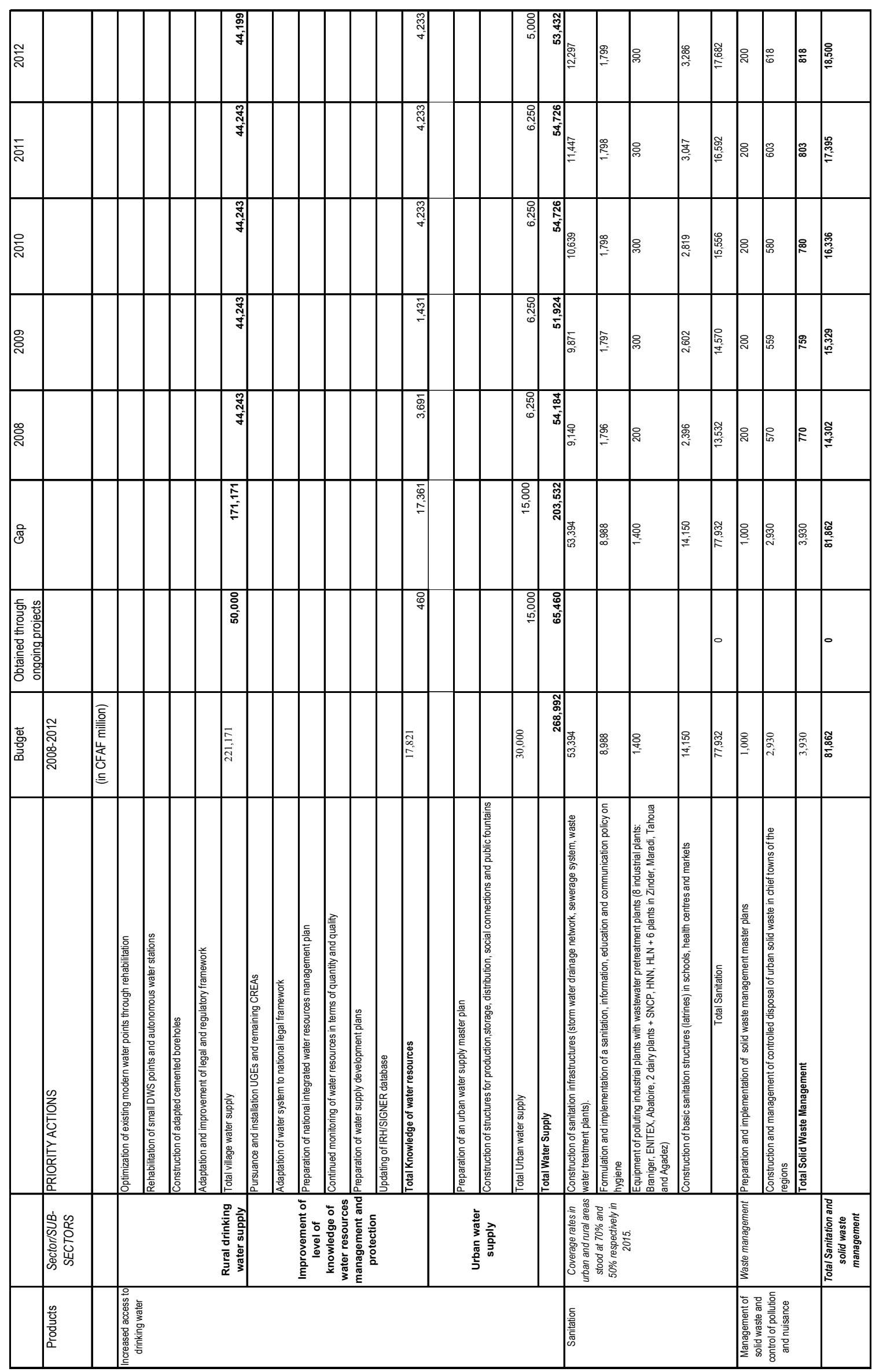




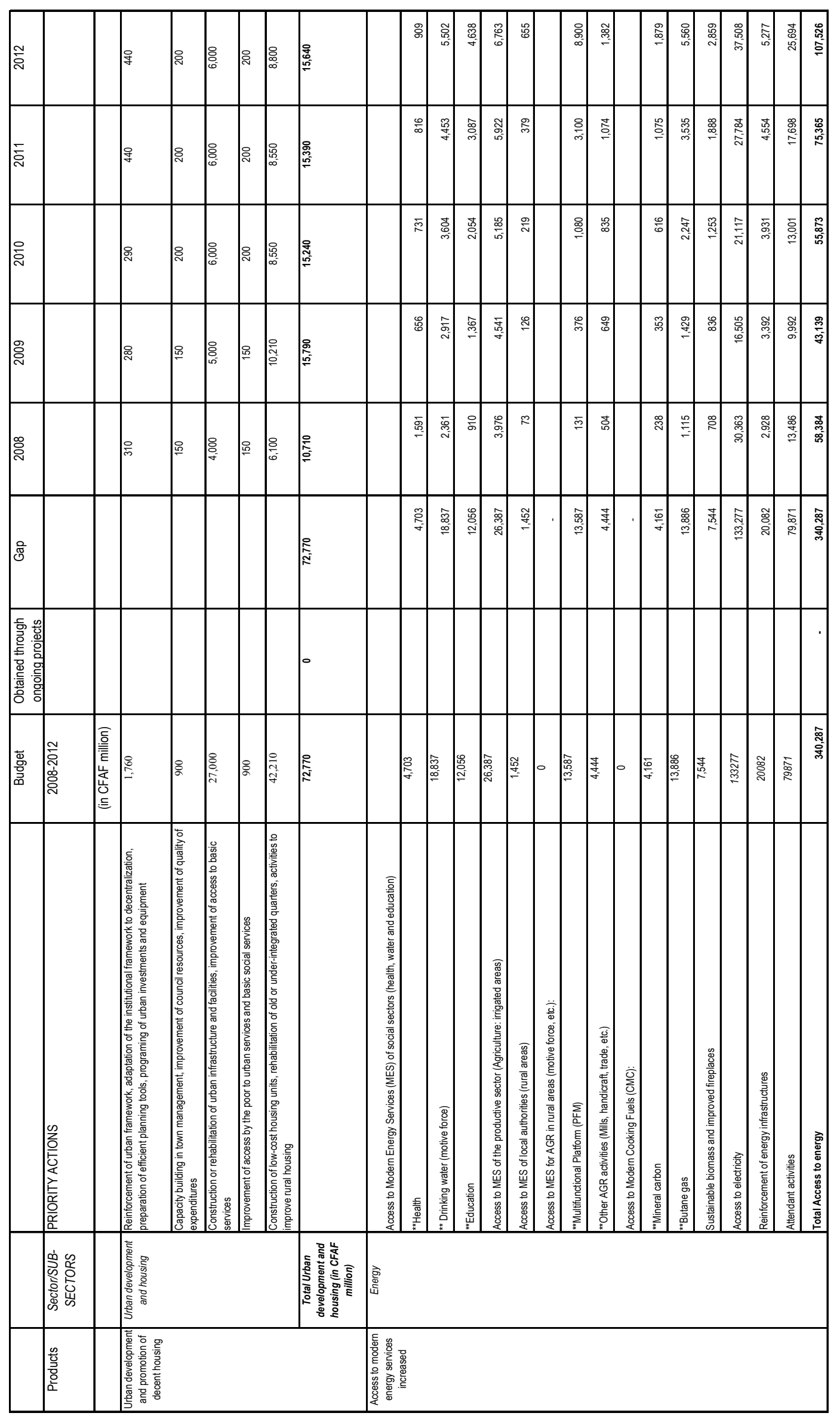




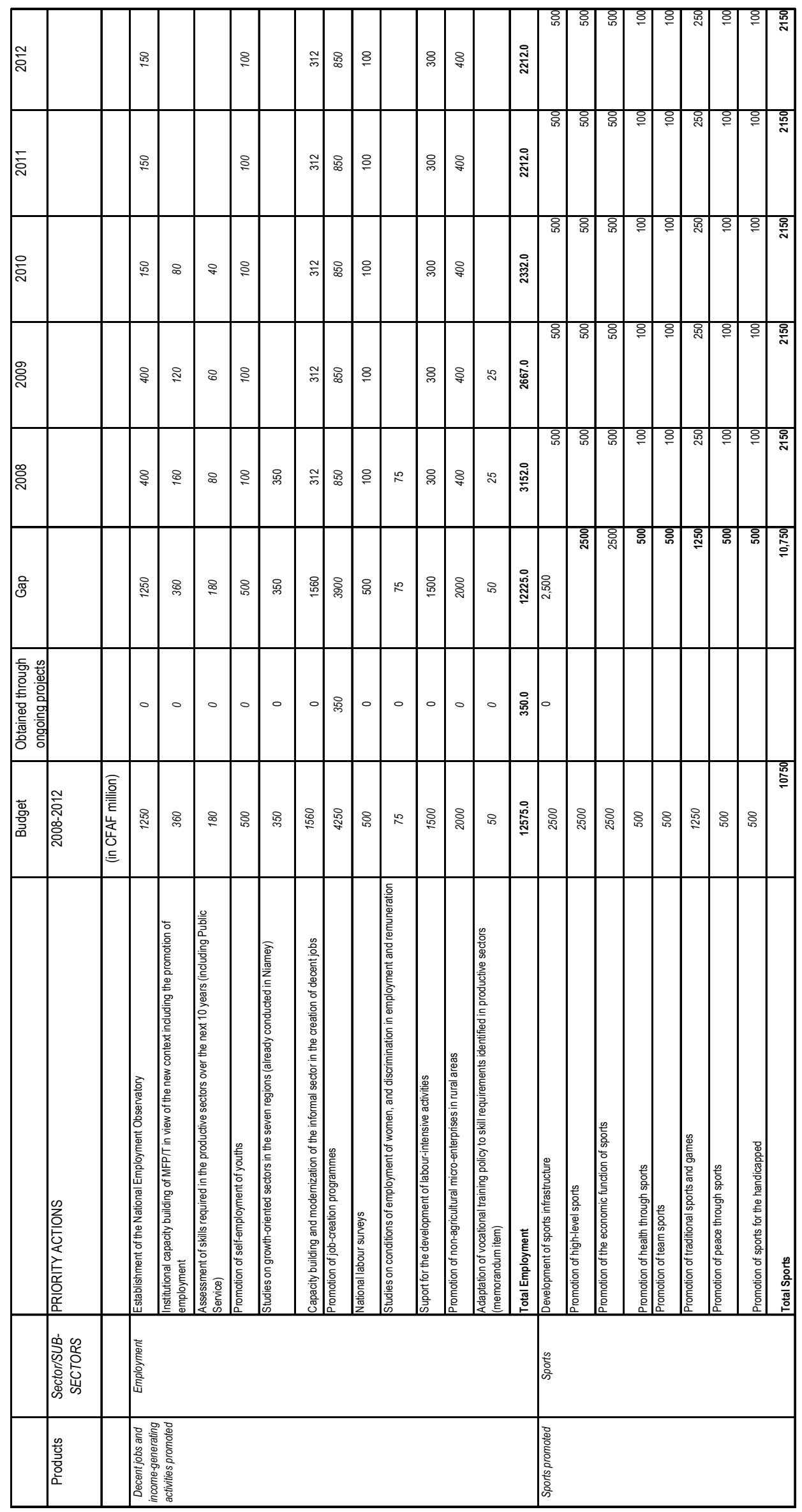




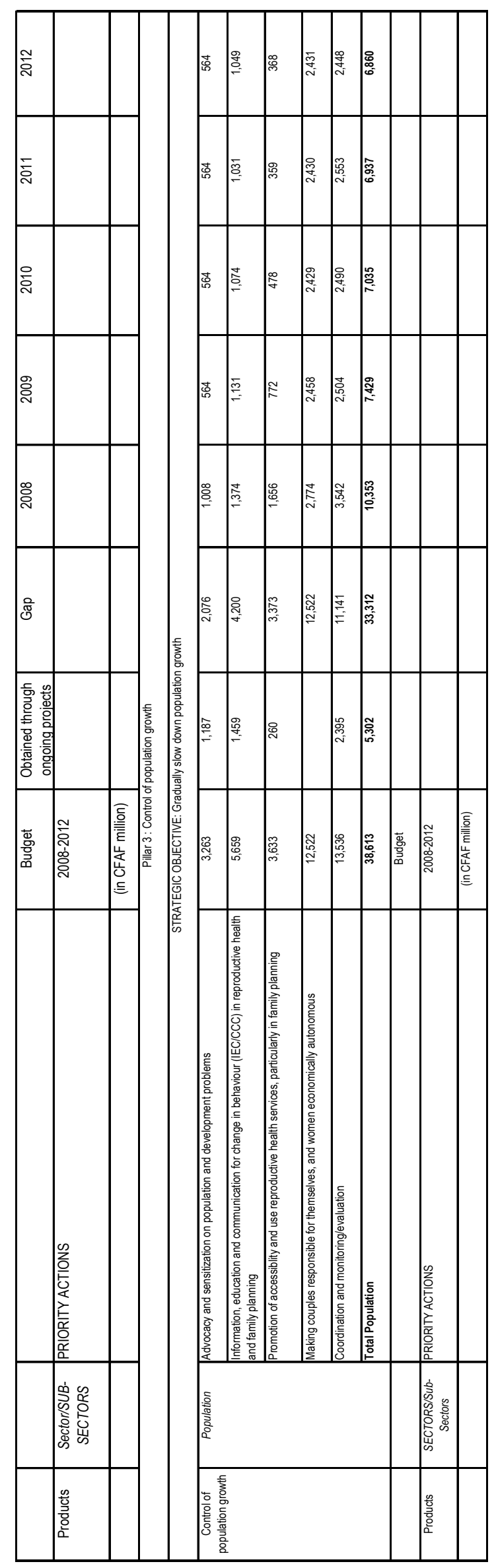

$\stackrel{\infty}{N}$ 


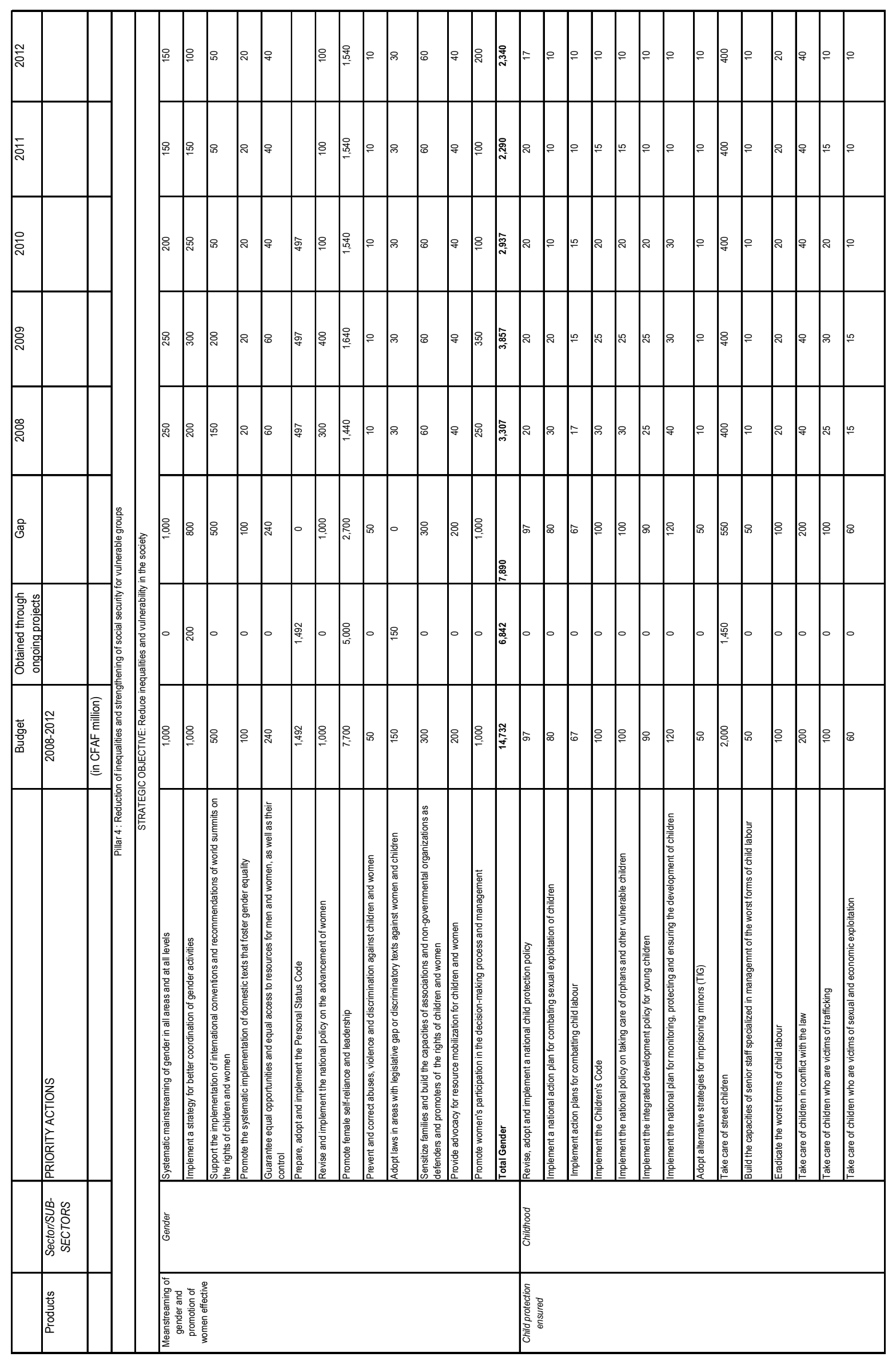




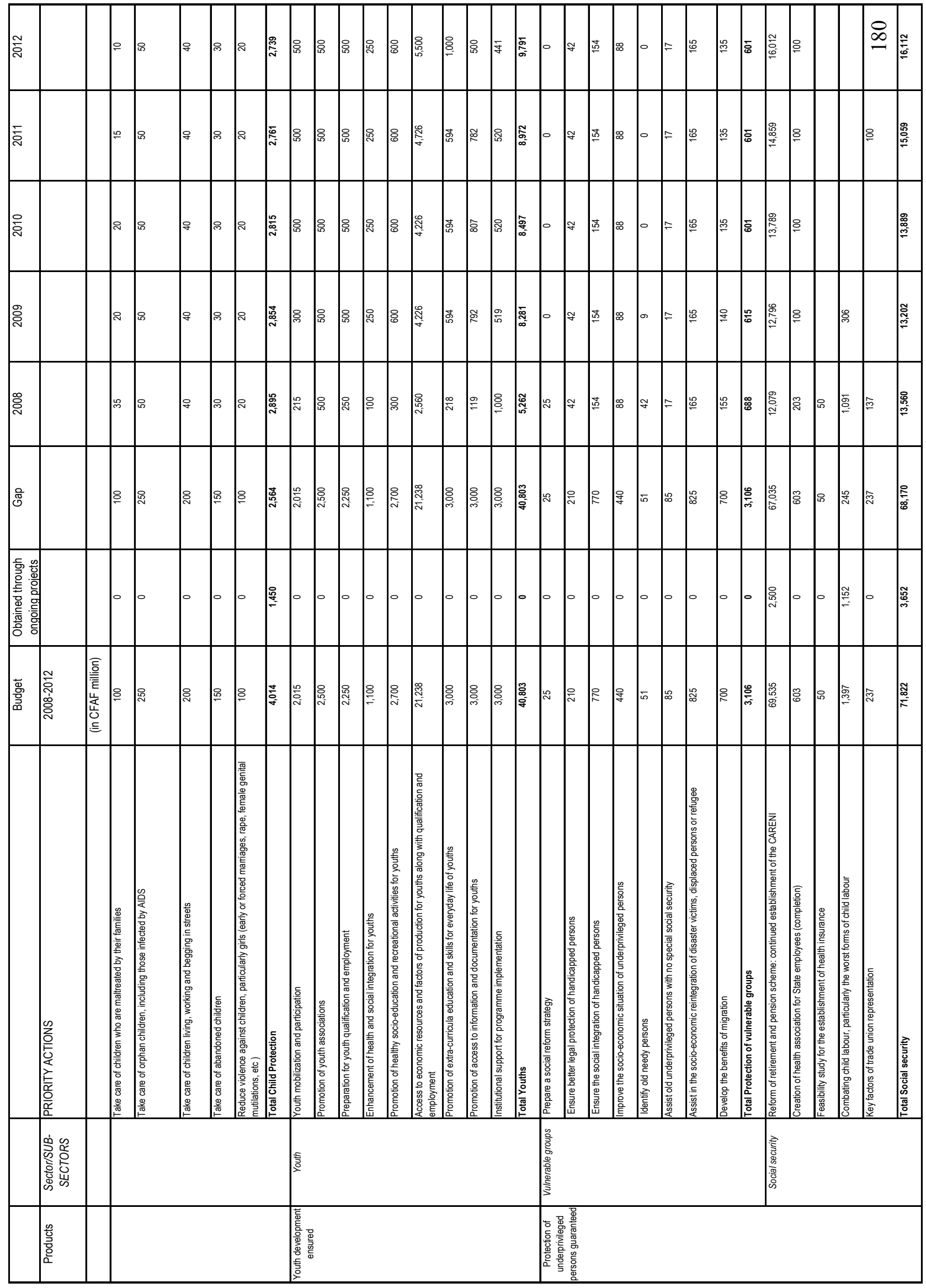




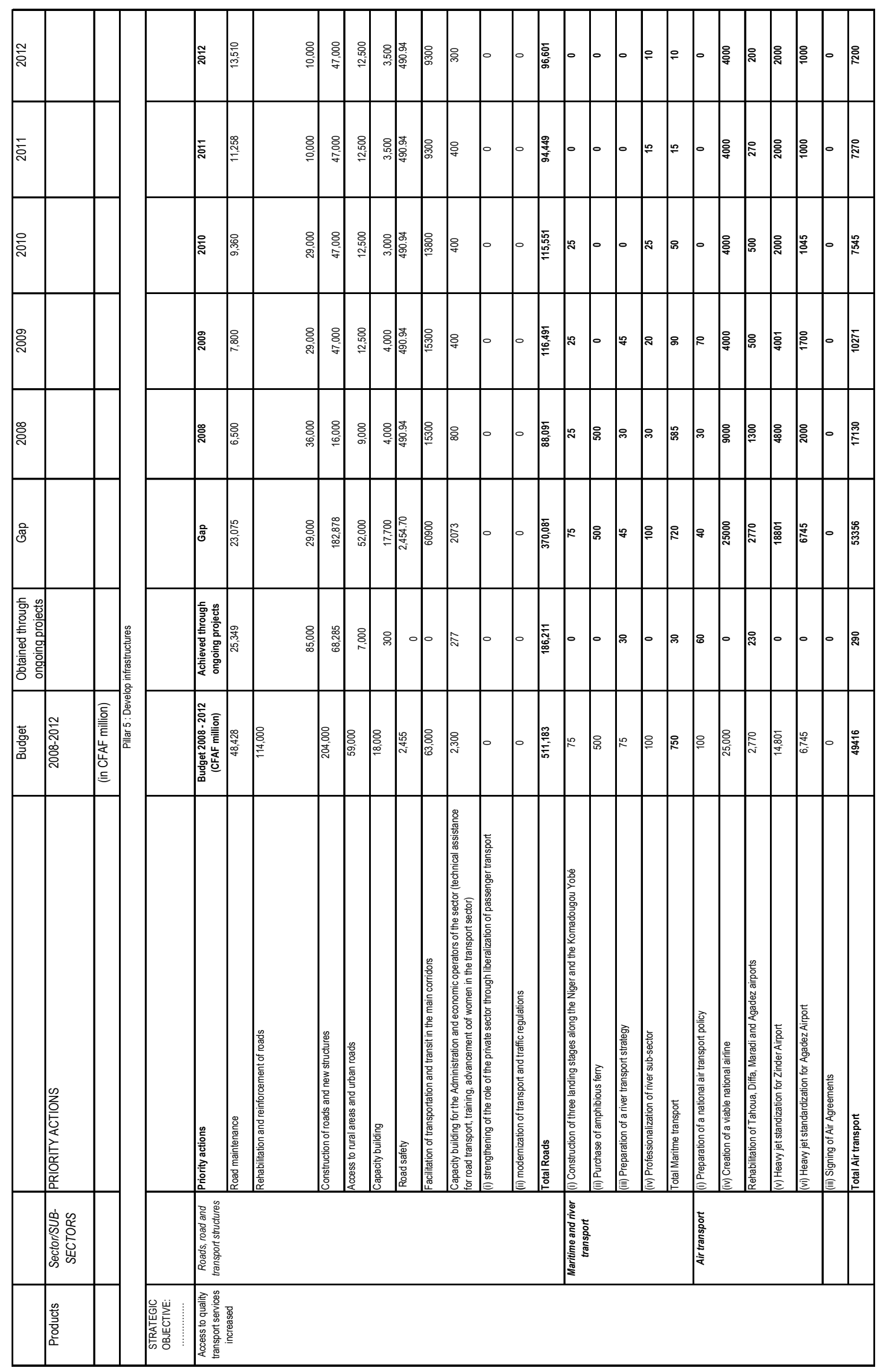




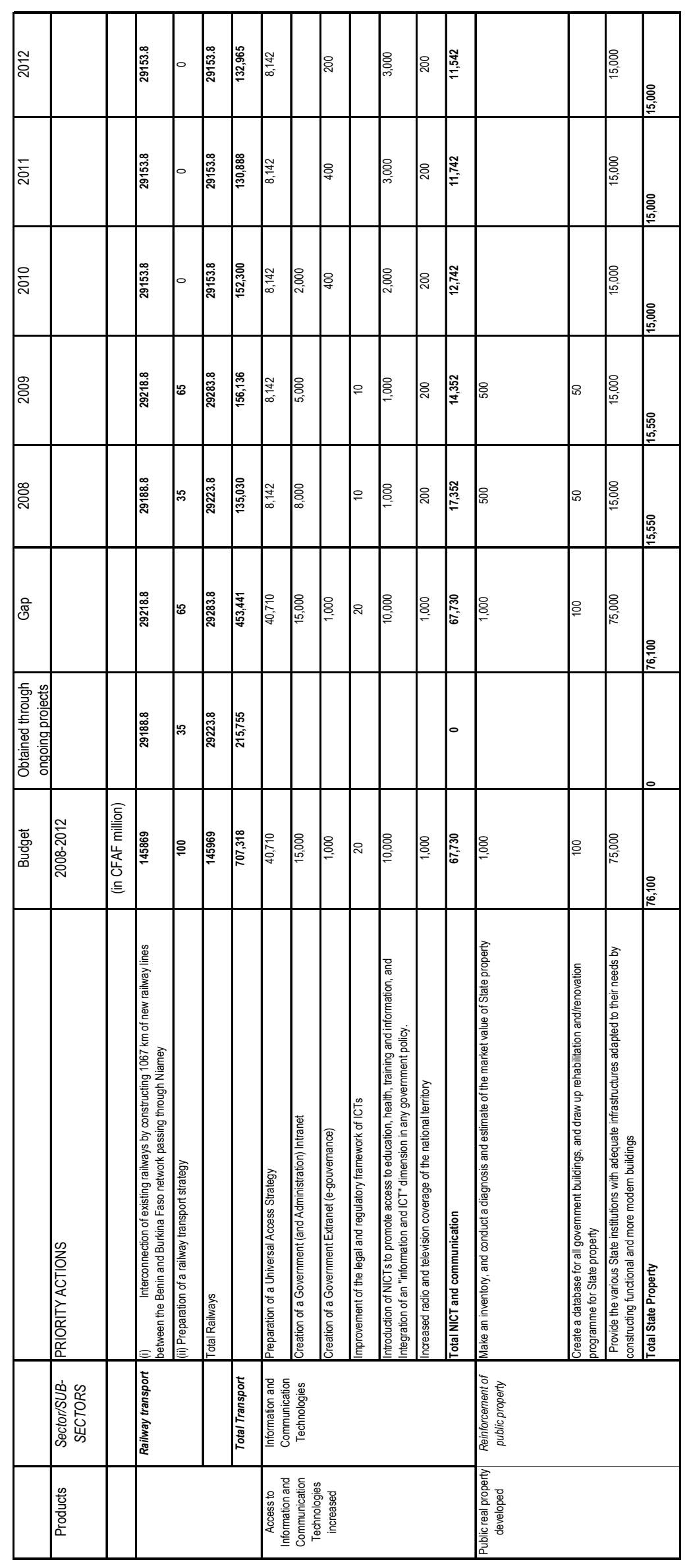

$\infty$ 


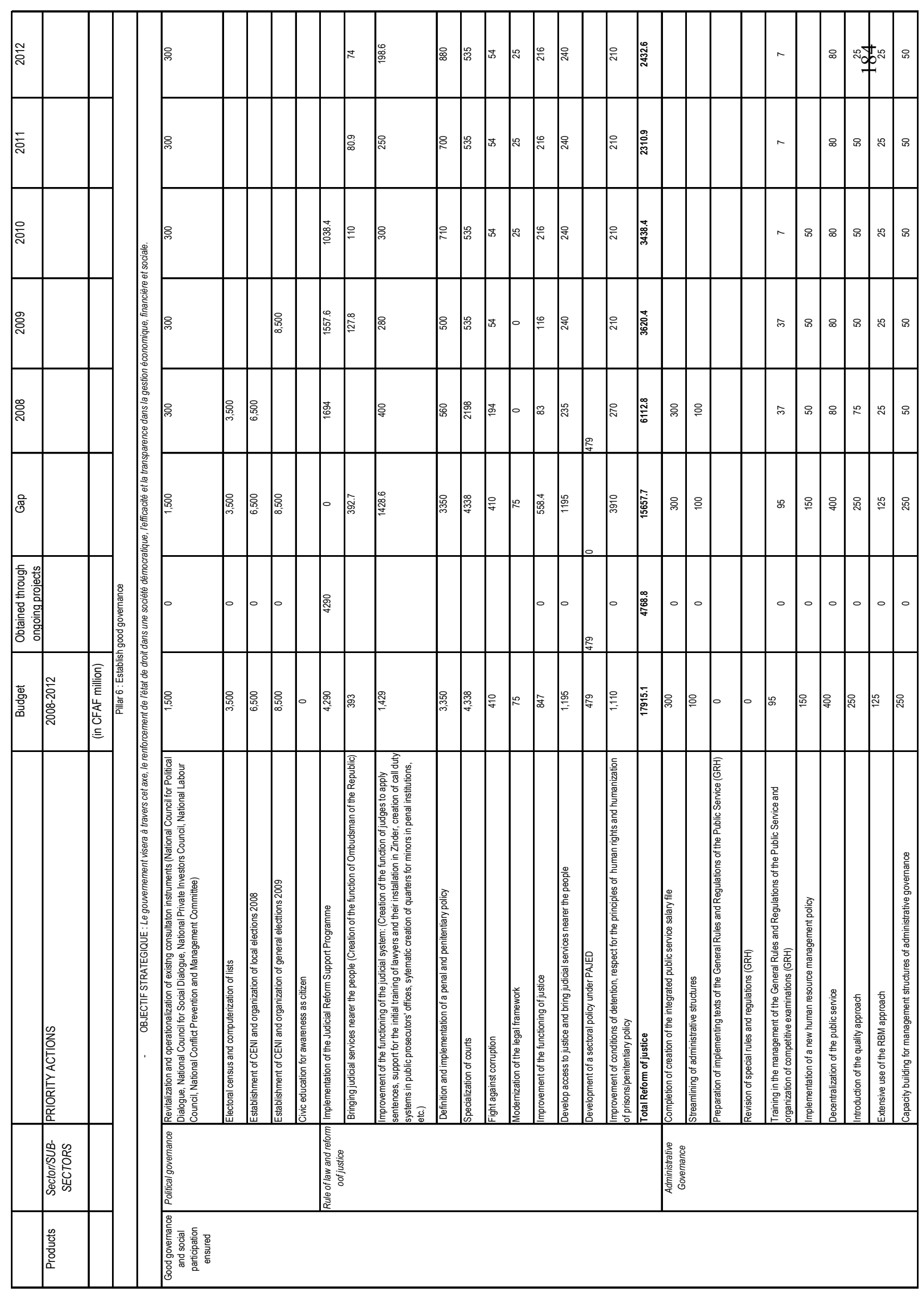




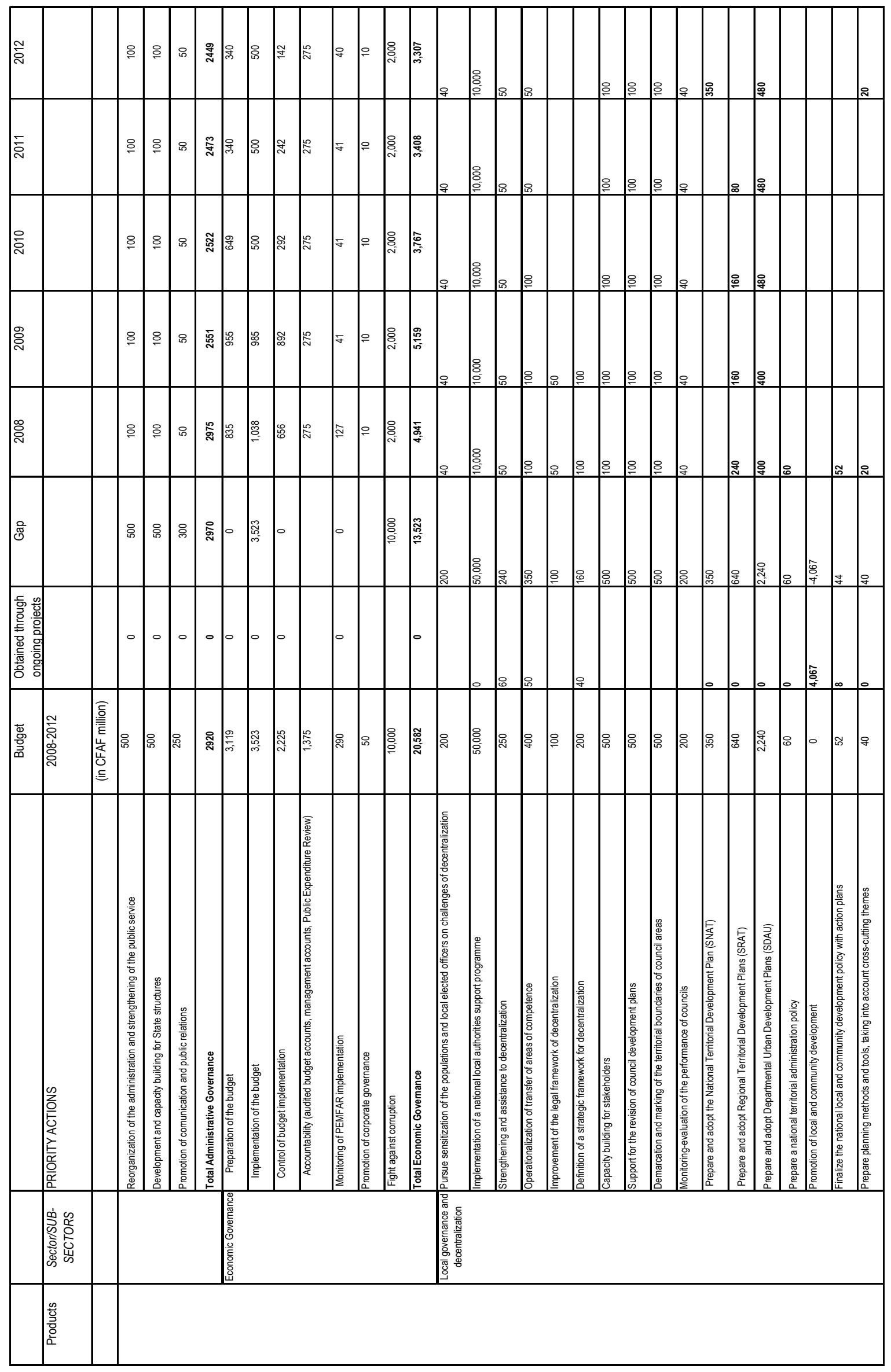




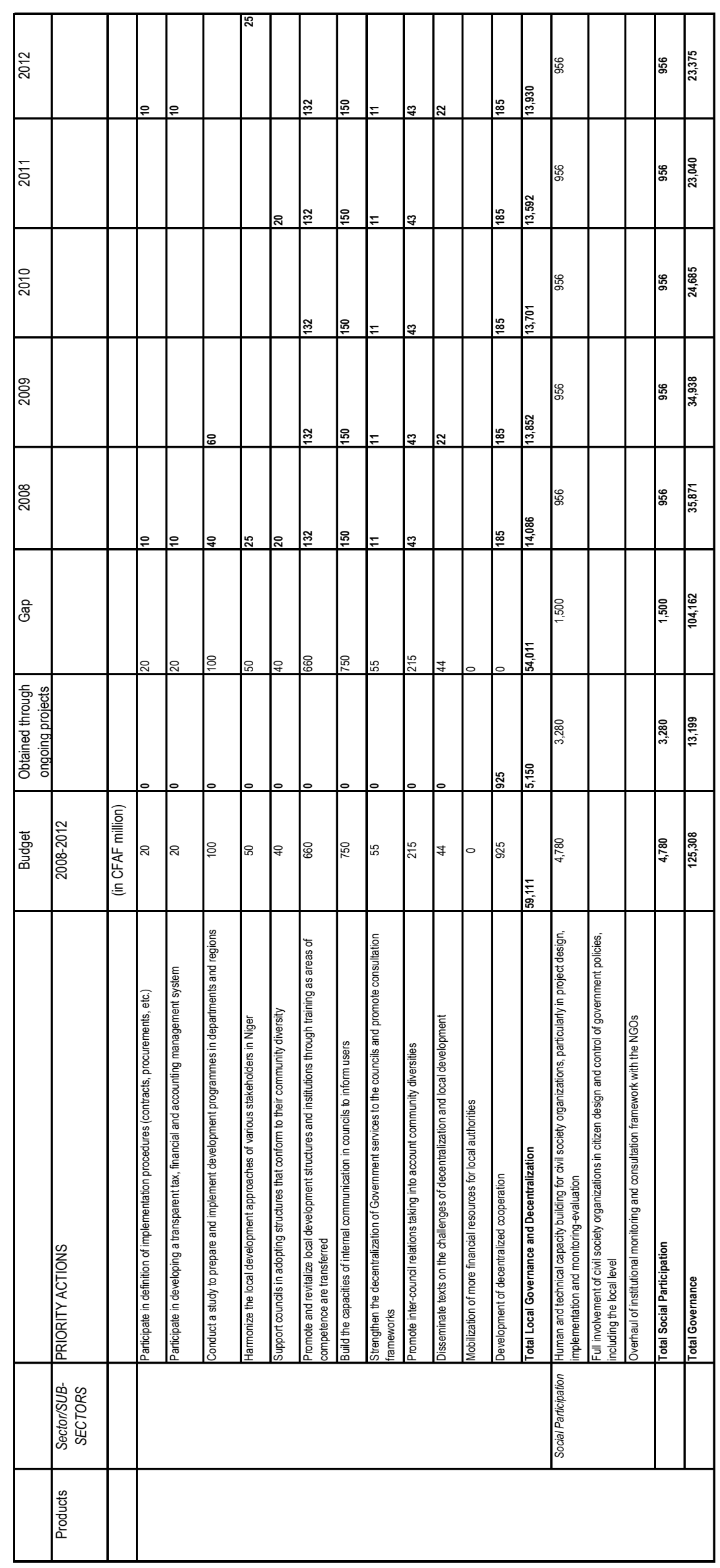

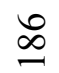




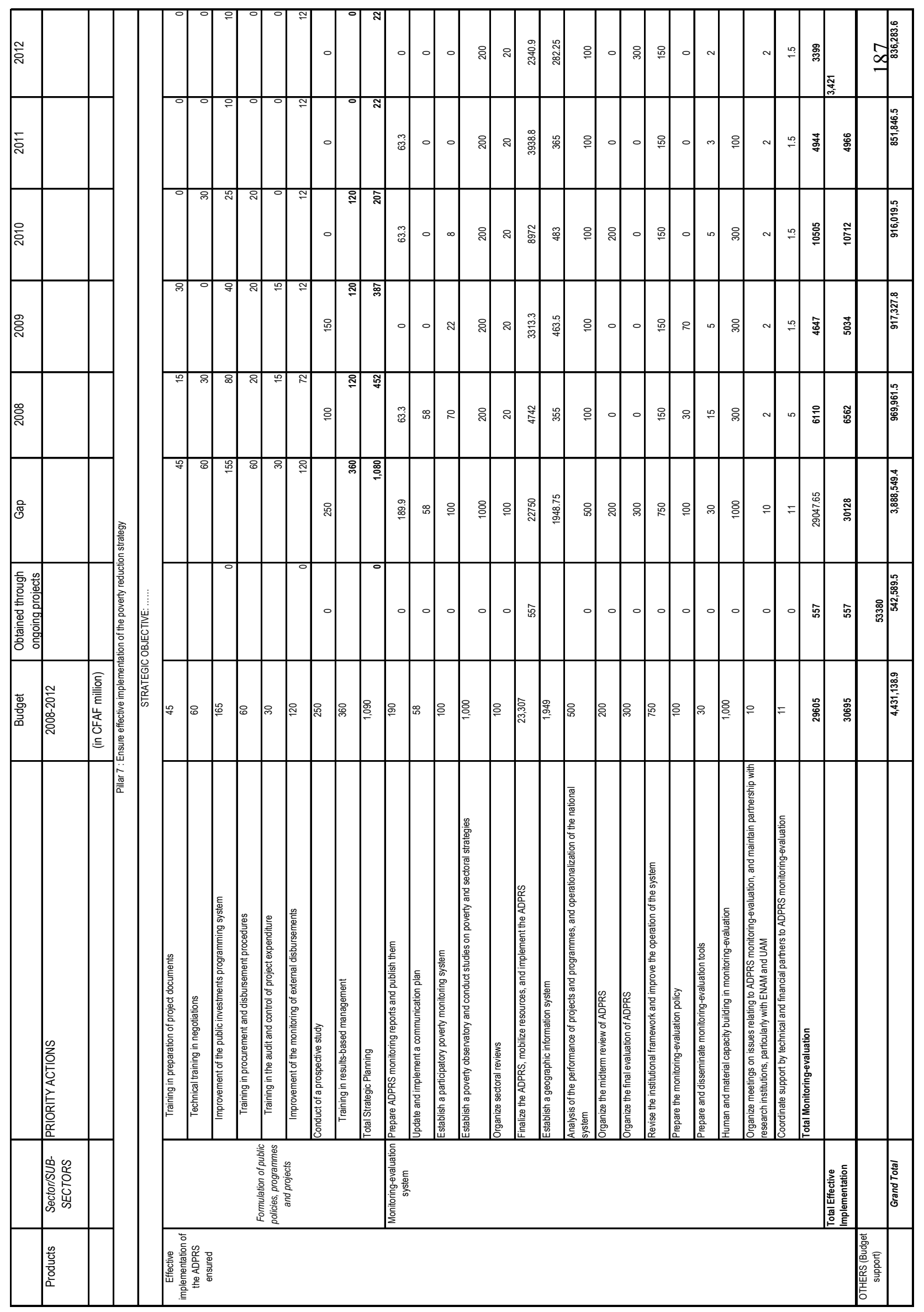

